\title{
Chicken respiratory infections
}

Protective roles of macrophages and cathelicidins

Lianci Peng 
ISBN: 978-94-640-2312-1

(C) 2020, Lianci Peng, Utrecht, The Netherlands

All rights reserved. No part of this thesis may be reproduced or transmitted in any form or by any means without prior permission of the author.

Cover design: $\quad$ Lianci Peng, Roel M. van Harten, www.daosisheji.com

Layout: Lianci Peng

Printing: $\quad$ Gildeprint, Enschede, www.gildeprint.nl

The research described in this thesis was partly financially supported by the Chinese Scholarship Council (CSC).

The research described in this thesis was performed at the Department of Biomolecular Health Sciences, Division of Infectious Diseases \& Immunology, Section of Molecular Host Defence, Faculty of Veterinary Medicine, Utrecht University, Utrecht, The Netherlands.

Printing of this thesis was financially supported by the Department of Biomolecular Health Sciences, Division of Infectious Diseases \& Immunology, Section of Molecular Host Defence, Faculty of Veterinary Medicine, Utrecht University, Utrecht, The Netherlands. 


\title{
Chicken respiratory infections
}

\author{
Protective roles of macrophages and
}

cathelicidins

\section{Respiratoire infecties in de kip}

Beschermende rol van macrofagen en

\section{cathelicidines}

(met een samenvatting in het Nederlands)

\begin{abstract}
Proefschrift
ter verkrijging van de graad van doctor aan de Universiteit Utrecht op gezag van de rector magnificus, prof. dr. H.R.B.M Kummeling, ingevolge het besluit van het college voor promoties in het openbaar te verdedigen op dinsdag 7 juli 2020 des ochtends te 10.30 uur
\end{abstract}

door

\section{Lianci Peng}

geboren op 4 december 1990 te Yubei, Chongqing, China 
Promotor:

Copromotor:
Prof. dr. H. P. Haagsman

Dr. E. J. A. Veldhuizen 


\section{Contents}

$\begin{array}{lll}\text { Chapter } 1 \quad \text { General introduction } & 7\end{array}$

Chapter 2 Avian pathogenic Escherichia coli infection of a chicken lung epithelial cell line

Chapter 3 Avian pathogenic Escherichia coli-induced activation of chicken macrophage HD11 cells

Chapter 4 A method to differentiate chicken monocytes into macrophages with proinflammatory properties

Chapter 5 The immunomodulatory effect of cathelicidin-B1 on chicken macrophages

Chapter 6 Antiviral activity of chicken cathelicidin B1 against 109 influenza A virus

Chapter 7 General discussion

Acknowledgement

Curriculum Vitae

List of publications 
0

-

○ 


\section{Chapter 1}

\section{General introduction}

\section{Lianci Peng}

Department of Biomolecular Health Sciences, Division of Infectious Diseases \& Immunology, Section of Molecular Host Defence, Faculty of Veterinary Medicine, Utrecht University, Utrecht, The Netherlands

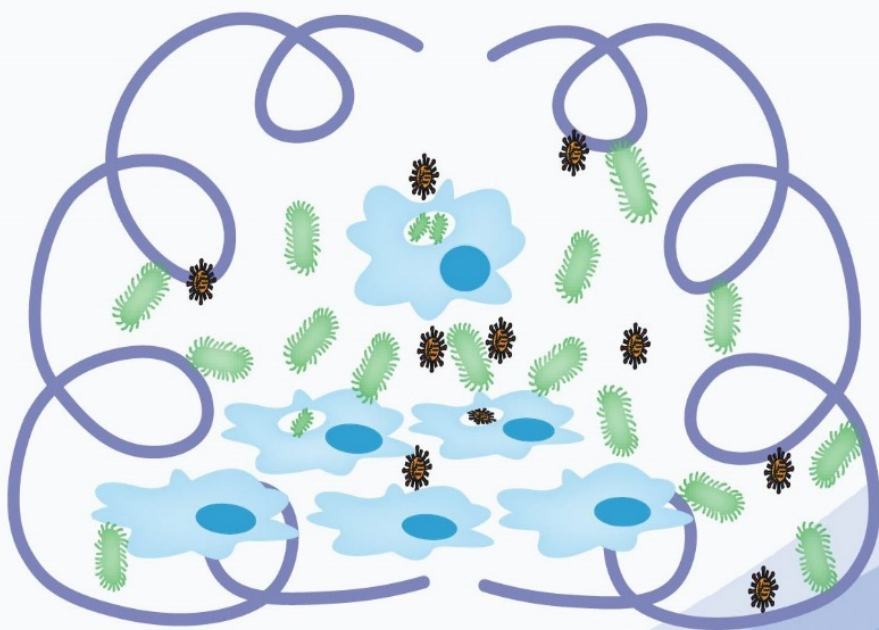




\section{Avian respiratory diseases}

Avian respiratory diseases are a major cause of mortality and morbidity in poultry, leading to a huge economic loss. These diseases are due to Gram-positive or Gram-negative bacteria and viruses (Table 1). Bacterial infections include for instance, Pasteurella multocida (Fowl cholera), Haemophilus paragallinarum (Infectious coryza), Escherichia coli (Colibacillosis), Ornithobacterium rhinotracheale and Bordetella avium (Bordetellosis) (1). Although there is variety of mycoplasmas affecting commercial poultry, the main ones are Mycoplasma gallisepticum, M. synoviae (chicken and turkey), M. iowae (mainly turkey), and $M$. meleagridis (turkey only) (2). Viral infections include infectious bronchitis virus (IBV), newcastle disease virus (NDV), influenza virus, infectious laryngotracheitis virus (ILV), avian leukemia virus (ALV) and pneumonia viruses (3). All of these microorganisms can cause respiratory disease alone, but often co-infections occur by multiple microorganisms, such as simultaneous infections by bacteria and viruses. Currently, the main strategy to prevent infections is vaccination to induce protective immunity against the pathogens. However, there are no (effective) vaccines available for all pathogens and efficacy of vaccines has decreased in some cases especially due to antigenic drift of viruses.

Besides the protection provided by the adaptive immune system by natural antibody production or specific $\mathrm{T}$ cells through vaccination or natural exposure to pathogens, at least an equally important protection mechanism is provided by the innate immune system. Innate immunity consists of specific immune cells and effector molecules that can act quickly against (inhaled) pathogens. When pathogens are inhaled into the airway, phagocytes (Table 2) such as heterophils, dendritic cells and macrophages, quickly act to neutralize these microorganisms. In addition, specific molecules can be quickly released by immune cells upon infection, such as host defense peptides (HDPs). Compared to mammals, the avian innate immune system is understudied. Therefore, avian innate immunity including specific immune cells and HDPs were studied in this thesis. 
Table 1. Brief overview of commonly diagnosed infectious respiratory pathogens in chickens.

\begin{tabular}{ll}
\hline Group & Pathogens \\
\hline Virus & Infectious bronchitis virus (IBV) \\
& Newcastle disease virus (NDV) \\
& Avian influenza virus (AIV) \\
& Infectious laryngotracheitis (ILT) \\
& Avian metapneumovirus (APV) \\
& Fowlpox virus (FPV) \\
\hline Bacteria & Escherichia coli \\
& Mycoplasma gallisepticum \\
& Mycoplasma synoviae \\
& Avibacterium paragallinarum \\
& Pasteurella multocida \\
& Ornithobacterium rhinotracheale \\
\hline Fungi & Aspergillus fumigatus \\
\hline Parasites & Syngamus trachea \\
\hline
\end{tabular}

\section{Avian phagocytic cells}

\section{Heterophils}

Heterophils are granulocytic white blood cells, the counterparts to the mammalian neutrophils which are generated in the bone marrow and circulate in the blood and considered as (one of) the first responder cells against invading pathogens through phagocytosis and by the release of antimicrobial compounds (4). Besides direct antimicrobial effects, neutrophils release cytokines, proteases and other factors that provide a signal of tissue damage and also regulate the adaptive immune response, such as the activation of T cells and B cells $(5,6)$. It is likely that heterophils can fulfil similar roles in chickens.

Similar to neutrophils, avian heterophils are highly phagocytic (7). They are rapidly recruited to the infected site where they phagocytose and kill pathogens (8). Chicken heterophils can effectively phagocytose opsonized or non-opsonized pathogens including avian pathogenic E. coli (APEC) and Salmonella Enteritidis via different receptors, such as toll like receptors (TLR), complement receptors (CR) and Fc receptors (FcR) (9-11). However, it has been shown in vitro that APEC phagocytosis by heterophils was associated with bacterial virulence. The type 1 fimbriae expressed in APEC promoted phagocytosis in heterophils but protected phagocytosed bacteria from subsequent killing, although the mechanism for this is still not 
clear (11). In addition, heterophils had higher phagocytic activity towards both serum- and IgG-opsonized $S$. Enteritidis compared with non-opsonized bacteria (via TLR) and $S$. Enteritidis-induced immune response as measured by cytokine gene expression was also different. Both non-opsonzied (via TLR) and serum-opsonized $S$. Enteritidis (via CR) induced higher gene expression of IL-1 $\beta$ compared to IgG-opsonized $S$. Enteritidis (via FcR), but lower gene expression of TGF- $\beta 4$ compared to IgG-opsonized $S$. Enteritidis, whereas no difference was found for IL-6, IL-8 and IL-18 expression (9). Priming heterophils with recombinant chicken IL-2 increased the gene expression of IL- 8 and IL-18, regardless whether bacteria were opsonized or not (10). These results suggests that different receptors, including TLR, CR and FcR, are involved in the immune response induced by opsonized and non-opsonized bacteria in heterophils.

Once phagocytosed, pathogens are entrappped in the phagosome which triggers the fusion of cytoplasmic granules with the phagosome. The entrapped pathogens are killed by the release of many antimicrobial compounds from the granules in the phagosome. Similar to the granule contents of neutrophils $(12,13)$, these granule substances of heterophils have been reported to contain $\beta$-defensins (Gal-1 and Gal-2), cathepsin, lysozyme, acid phosphatase, $\beta$ glucuronidase, and $\alpha$-glucosidase (14). The most notable contrast to granules in neutrophils is the lack of myeloperoxidase in heterophil granules (15). In addition, the granules of avian heterophils are also lacking alkaline phosphatase and catalase (16). The lack of these enzymes in heterophils leads to a relatively weak oxidative response compared to the activity of mammalian neutrophils.

Host defense peptides, such as defensins and cathelicidins are important granule compounds released by heterophils and play an important role in killing of invading pathogens. Although at least $14 \beta$-defensins have been described in chicken, only AvBD1 (Gal-1) and AvBD2 (Gal-2) were identified to be associacted with heterophils granules (17). A study from our group showed that the chicken antimicrobial peptide chicken cathelicidin-2 (CATH-2), which belongs to the cathelicidin family of HDPs and has potent broad spectrum antibacterial activitity, is released by heterophils upon Salmonella lipopolysaccharides (LPS) stimulation (18). Another study also showed two other chicken cathelicidins (CATH-1 and CATH-3) are produced in heterophils and have antimicrobial activity (19). These cathelicidins exert important functions in the host and are studied in this thesis (introduced further in the cathelicidins section).

Another feature of heterophils is that they can release heterophil extracellular traps (HETs) upon stimulation. HETs contain DNA, histones and likely many other nuclear molecules and are thought to have a similar function as mammalian neutrophil extracellular traps (NETs), namely, trapping and killing pathogens $(15,20)$. In mammals, this process of NETosis is 
believed to be related to the production of an oxidative burst in response to stimulation (21). However, avian heterophils lack myeloperoxidase and therefore produce a weak oxidative burst compared to mammalian neutrophils (22), so formation of HETs might be regulated differently. Despite the weak oxidative response, avian heterophils can still kill pathogens by using antimicrobial proteins $(16,18,23)$. Furthermore, chickens with highly functional heterophils are not susceptible to infections compared with chickens with less active heterophils (24). Excessive heterophils infiltration can create lesions in chickens (25), indicating that the heterophil activity needs to be tightly controlled, although only limited knowledge is present about the exact role of heterophils in inflammation.

Table 2. Characteristics of innate immune cells

\begin{tabular}{|c|c|c|c|c|}
\hline Cell type & Source & Function & $\begin{array}{l}\text { Cell } \\
\text { surface } \\
\text { marker } \\
\text { expression }\end{array}$ & $\begin{array}{l}\text { Specific features } \\
\text { in comparison } \\
\text { with mammalian } \\
\text { cells }\end{array}$ \\
\hline Heterophil & $\begin{array}{l}\text { Bone } \\
\text { marrow/blood }\end{array}$ & $\begin{array}{ll}\text { - } & \text { Phagocytosis } \\
\text { - } & \text { Release of } \\
\text { granular } \\
\text { content } \\
\text { (antimicrobial } \\
\text { peptides) } \\
\text { Activation of } \\
\text { T and B cells }\end{array}$ & & $\begin{array}{l}\text { Release heterophil } \\
\text { extracellular traps } \\
\text { (HETs) but lack } \\
\text { myeloperoxidase }\end{array}$ \\
\hline $\begin{array}{l}\text { Dendritic } \\
\text { cell (DC) }\end{array}$ & Bone marrow & $\begin{array}{ll}\text { - } & \text { Recognition of } \\
\text { pathogens } \\
\text { - } & \text { Antigen } \\
\text { presentation }\end{array}$ & $\begin{array}{l}\text { MHC-II, } \\
\text { CD11c, } \\
\text { CD40, } \\
\text { CD86, } \\
\text { CD83 and } \\
\text { DEC205 } \\
\text { (upon } \\
\text { stimulation) }\end{array}$ & $\begin{array}{l}\text { Chicken DCs exist } \\
\text { in different tissues } \\
\text { and they have } \\
\text { special migration } \\
\text { due to the lack of } \\
\text { lymph nodes }\end{array}$ \\
\hline Macrophage & $\begin{array}{l}\text { Bone } \\
\text { marrow/blood }\end{array}$ & $\begin{array}{ll}\text { - } & \text { Phagocytosis } \\
\text { - } & \text { Production of } \\
& \text { ROS and NOS } \\
\text { - } & \text { Release of } \\
\text { cytokines and } \\
\text { chemokines }\end{array}$ & $\begin{array}{l}\text { MRC1L-B, } \\
\text { MHC-II, } \\
\text { CSF-1 }\end{array}$ & $\begin{array}{l}\text { Polarization not } \\
\text { (yet) described }\end{array}$ \\
\hline
\end{tabular}




\section{Dendritic cells}

Dendritic cells (DCs), members of the mononuclear phagocytic system, are professional antigen-presenting cells (APCs) (26-29). Once DCs recognize a pathogen, they increase the level of major histocompatibility molecules (MHC) and co-stimulatory molecules (CD80/86), migrate to the lymph nodes and present the antigen to the $\mathrm{T}$ cells.

Different subtypes of chicken DCs have been identified in different tissues. Chicken DCs were first described in the bursa of Fabricius and in the cecal tonsil's germinal center, named bursal secretory dendritic cells (BSDC) $(30,31)$. Recently, DCs have also been identified in the chicken thymus (32). In spite of the existence of chicken DCs in different tissues, still little is known about the exact function of chicken DCs. Especially about the migration and APC function of DCs, since chickens actually lack lymph nodes. Most studies on chicken DCs make use of chicken bone marrow-derived DCs (chBM-DCs) in vitro, which can be generated in the presence of granulocyte macrophage colony stimulating factor (GM-CSF) and IL-4 (33). These cultured cells show the typical morphology of DCs containing stretched cells with dendrites. Further characterization of the immature chBM-DCs showed high level expression of MHC class II and CD11c (a DC specific marker), low expression of CD1.1 and the co-stimulatory molecules such as CD40 and CD86, and no expression of CD83 or DEC205 which is expressed in human mature DCs $(34,35)$. Also the immature DCs have the capacity to phagocytose and endocytose bacteria. Upon LPS stimulation chBM-DCs increase expression of CD40, CD1.1, CD86, CD83 and DEC-205, indicating maturation of DCs. However, the capacity of phagocytosis and endocytosis is lost (33).

Cultured cells in vitro have mainly been used to investigate the behaviour of DCs upon infection, but relatively little research is performed on the characterization of DCs in tissues due to limited number of DC-specific antibodies. CD83 monoclonal antibody has been used to identify both DC-like cells and follicular DCs in chicken spleen (36). Although CD83 is highly expressed on DCs, many other immune cells might also express CD83 (36). Indeed, the CD83 antibody actually also recognized a similar protein expressed by the chicken macrophage HD11 cell line (37). Another CD83 specific antibody (clone: IAH F890:GE8) strongly stained DC-like cells in the thymus, but did not stain DCs of bursal follicles and germinal centers (38). The DEC205 antibody recognizes a C-type lectin receptor on the surface of chicken DCs, but also specifically recognizes thymus cortical epithelial cells (32). These examples show the difficulty to specifically identify DCs in chicken tissues, especially with a single antibody. Some progress has been made by double labelling techniques. Recently, the $8 \mathrm{~F} 2 \mathrm{mAb}$ was used to distinguish isolated splenic DC-like cells from KUL01 (a myeloid marker) macrophages (39) and double immunofluorescence staining with vimentin (type III intermediate filament (IF) protein that is expressed in mesenchymal cells) 
and CSF1R provide a valuable tool for identification of chicken DCs (40). However, to further explore morphology and ontogeny of chicken DC subsets in vitro or in vivo, more reagents need to be developed.

\section{Macrophages}

Macrophages belong to the mononuclear phagocytic system and are considered as one of the first responders against pathogenic invasion. Macrophages are actively involved in the phagocytosis and killing of microorganisms. In addition, they are also key regulatory cells of the immune system by the production of an inflammatory or anti-inflammatory response upon stimulation $(41,42)$.

\section{Development of macrophages}

Macrophages originate from bone marrow stem cells (Fig. 1) and can be self sustaining in the tissues. They can also develop from monocytes in the bloodstream under the influence of colony stimulating factor (CSF) (Fig. 1). Macrophages are present in a variety of tissues, where they have specialized functions. Tissue macrophages can, for example, be found in the lung (alveolar macrophages). About $70 \%$ of alveolar macrophages are self-sustaining through division inside the lung, whereas $30 \%$ of alveolar macrophages are monocytederived. In the liver almost all macrophages (called Kupffer cells) are actually derived from blood monocytes. Macrophages are also present in the bone where they are called osteoblasts (43).

In mammals, macrophages have different phenotypes, such as M1, M2, M (Hb), Mox, and M4. However, they should be regarded more as cells with high plasticity that can easily switch from one phenotype to the other (and all intermediate phenotypes) where the designated types are at the extremes of the spectrum (44). The M1 and M2 phenotype have been mainly studied and they have very different immune functions (Fig. 1). M1 macrophages, differentiated using GM-CSF and interferon- $\gamma$, produce mainly proinflammatory cytokines such as IL- 6 and TNF- $\alpha$. On the other hand, M2 macrophages, differentiated using macrophage colony stimulating factor (M-CSF) and IL-4, produce mainly anti-inflammatory cytokines such as IL-10 (45, 46). Functionally, M1 macrophages play a role in killing intracellular pathogens while M2 macrophages are important for wound healing and tissue repair (Fig. 1). M1 macrophages have a "fried egg" appearance and can morphologically be distinguished from M2 macrophages which are more streched. Also the expression of surface markers and chemokine receptor ligands are different (47). For instance, M1 macrophages express CXCL9, CXCL10, and CXCL5 whereas CD163 is highly expressed on M2 macrophages (47-49). 
Unlike that of mammalian macrophages, polarization and phenotypes of chicken macrophages are rarely studied. Monoclonal antibody KUL01 recognizes the chicken mannose receptor and was first used to characterize macrophages in different tissues, including spleen and gut (50). However, unlike humans, chicken has five paralogous genes of this receptor (MRC1L-A to MRC1L-E) of which KUL01 only recognises MRC1L-B (51).

To facilitate studies on chicken macrophages, two chicken macrophage-like cell lines, HD11 and MQ-NCSU, have been developed $(52,53)$ that are used most often in chicken macrophage studies. Cell lines provide convenience and great reproducability for experimental control, but one should be careful with extrapolating results using these cell lines to an in vivo situation. Therefore, several groups also have cultured primary chicken macrophages derived from monocytes in peripheral blood mononuclear cells (PBMCs) and bone marrow (54-57). So far, there is no standard method to culture these macrophages in vitro, but macrophage-like cells are obtained when cells were cultured with chicken GMCSF. In addition, both chicken CSF-1 and IL-34 can promote proliferation of macrophages in vitro (58). These cultured macrophages are morphologically similar to macrophage M1 in mammals (59). In our study, after 3 days culture with GM-CSF, blood monocytes differentiated into M1 like macrophages with proinflammatory properties. A recent study showed that IL-4 induced gene expression associated with M2 markers in HD11 cells and PBMCs, indicating the possible existence of M1/M2 in chicken (60) but better characterizations of M1-like and M2-like macrophages are still needed.

\section{Free avian respiratory macrophages}

In the mammalian lung, respiratory macrophages provide a first line of defense against invading pathogens. These cells reside on the luminal surface of alveoli which enables them to internalize and kill pathogens before they can break the epithelial barrier and cause local and systemic infections (61). In birds, respiratory macrophages are known as free avian respiratory macrophages (FARM) $(62,63)$. FARM in the lung lavage are not only derived from the surface of lung but also from air sacs (64). Interestingly, FARM do not locate on the surface of air capillaries where gas exchange takes place, but are present on the surface of the atria and infundibulae $(64,65)$. Therefore, avian respiratory macrophages seem to locate at strategic places where fresh air is distributed into gas exchange areas, thereby entrapping and removing invading particles. However, the number of respiratory macrophages in chicken lung is almost 20 times lower than found in mammalian lungs (65, 66). One hypothesis is that this contributes to the relatively weak respiratory defense, which might partially explain the high mortality among birds upon invading pathogens. 


\section{Migration of macrophages to the lung in response to infection}

Macrophages are present in all tissues, and can migrate to the site of infection and eliminate invading pathogens or to the site of injury to contribute in tissue repair. Macrophage migration is induced by pathogen-associated molecular patterns (PAMPs) released by invading pathogens or damage-associated molecular patterns (DAMPs) of damaged or dead cells. Macrophages in the inflamed or injured tissue release cytokines and chemokines which attract other immune cells among other macrophages $(67,68)$.

Similar to migration of mammalian macrophages, chicken macrophages can also migrate to sites of infection. This is especially useful in the lung where only low numbers of macrophages are located. For instance, intratracheal administration of live non-pathogenic $P$. multocida vaccine induced a three-fold macrophage increase in the lung and air sacs (69). Similar results were found for IBV and E. coli infection of the respiratory tract (70). Noticeably, macrophage migration to the lung is associated with respiratory inoculation of pathogens, because intravenous inoculation of bacteria only produced a weak induction of respiratory macrophages in the lung (66).

\section{Macrophage function}

Phagocytosis is one of the most classical functions of macrophages during evolution (Fig. 1). Similar to heterophils, phagocytic activity is also mainly mediated via specific receptors including TLRs, mannose receptors (MRs), CRs and FcRs present on the surface of macrophages. These receptors can recognize and bind to specific bacterial targets to induce phagocytosis, which is the key step to kill microbes. For instance, chicken macrophages took up a higher number of $S$. enterica in vitro when bacteria were opsonized with mannosebinding lectin (MBL) (71). Similarly, pre-incubation of Campylobacter jejuni with antiserum enabled chicken peritoneal macrophages to phagocytose more bacteria via FcRs than when bacteria were pre-incubated with PBS (72).

Chicken macrophages act differently in response to different bacterial strains, independent of the opsonization, and some bacteria have developed different protective systems to avoid antibacterial activity of macrophages. For example, the capsulated $P$. multocida adhered in macrophages, but were not internalized by macrophages. The degradation of capsule with hyaluronidase increased bacterial adhesion and subsequent internalization by macrophages (73).

Also in the chicken lung, macrophages have a high phagocytic activity. An in vitro comparative study showed that chicken respiratory macrophages had higher phagocytic capacity than rat alveolar macrophages (74). The chicken macrophage HD11 and MQ-NCSU cell lines have also shown high phagocytic activity and killing capacity against different 
bacterial strains, such as E. coli and Listeria monocytogenes $(75,76)$, but actually failed to kill Salmonella. This is likely due to Salmonella's defense mechanisms against host cells that delay the phagolysosomal maturation and neutralize radical oxygen and nitrogen species (ROS and NOS) (77).

The production of ROS and NOS are important responses of macrophages against intracellular pathogens (Fig. 1). Mouse macrophages were shown to produce high levels of nitric oxide (NO) (78), which has been shown to mediate pathogen killing by macrophages in vivo (79). HD11 cells also produce high NO levels in response to infection or LPS stimulation $(75,80)$. In contrast, chicken monocytes produced a much lower amount of NO, which is more similar to human monocytes-derived macrophages that even failed to produce $\mathrm{NO}$ in response to stimulation $(81,82)$.

Besides NO production, macrophages also produce chemokines and cytokines (Fig. 1). Stimulation with TLR ligands and pathogenic infection in vitro induces pro-inflammatory cytokines such as IL-1 $\beta$, IL-6, IL-8, interferons (IFNs) and IL-10 in both mammalian and chicken macrophages, which play a role in the initial inflammatory response of the host against infection $(75,83)$. Production of IL-1 $\beta$ has been found to promote antimicrobial immunity of macrophages against Mycobacterium tuberculosis by directly killling and upregulates further TNF- $\alpha$ secretion (84). In vivo, IBV infection increased expression of IL$1 \beta$ produced by macrophages in the lung, indicating that IL- $1 \beta$ is an important component of chicken macrophages in response to infection (85). IL-6 can switch the differentiation of human monocytes from dendritic cells to macrophages (86), but it is also important in the modulation of the Th1/Th2 response defending invading pathogens in mice (87). Other cytokines such as IFNs, have been reported to play an important role in the regulation of chicken macrophage inflammatory response to baterial challenge (57). A recent study identified TNF- $\alpha$, which was long considered to be absent in chicken (88) and mRNA expression of TNF- $\alpha$ was induced by LPS in chicken macrophages. The exact role is still not identified but it shares $45 \%$ homology with mammalian TNF- $\alpha$ indicating they may play similar roles in acute and chronic inflammation. So far, many functions as well as the cytokine response overlap between chicken and human macrophages and therefore it is likely that they play similar roles against pathogens. 


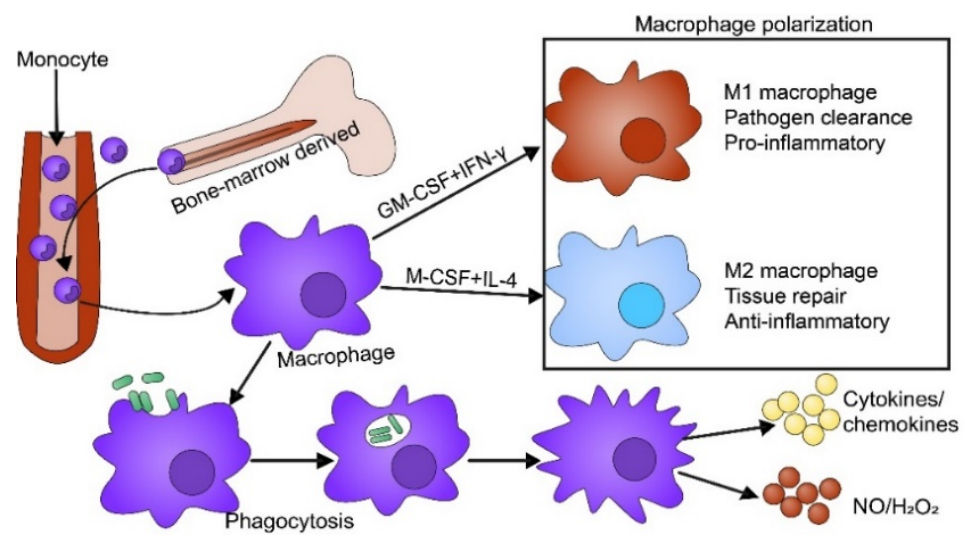

Fig 1. Summary of macrophage functions. Macrophages originate from bone marrow stem cells and also are developed from monocytes in the blood stream. Macrophages have different phenotypes. M1 and M2 phenotypes have been mainly studied and they have very different immune functions. M1 macrophages differentiated using GM-CSF and interferon- $\gamma$ produce mainly pro-inflammatory cytokines and play a role in killing intracellular pathogens. M2 macrophages differentiated using M-CSF and IL-4 produce mainly anti-inflammatory cytokines and are important for wound healing and tissue repair. Macrophages can phagocytose bacteria and kill them; subsequently cytokines and chemokines as well as nitric oxide and peroxide are produced to activate macrophages.

\section{The interaction of macrophages with viruses}

The interaction between avian macrophages and viruses has been well studied. The source of macrophages is important, since peritoneal macrophages act differently from monocyte or bone marrow-derived macrophages (BMDM). Some but not all avian viruses can infect avian macrophages. For example, chicken BMDM have been shown to be resistant to Marek's disease virus (MDV), herpesvirus of turkeys (HVT-FC126), IBV and reticuloendotheliosis virus (REV) infection (89). On the other hand, adenovirus, infectious laryngotracheitis (ILT) virus, reovirus, infectious bursal disease virus (IBDV), myelocytomatosis virus, NDV, avian leukosis virus (ALV) and influenza A virus (IAV) infect and replicate in macrophages (89). In the end, all viral infections result in cell dead. The potential infectivity of avian viruses to macrophages in vitro is not correlated with pathogenity of viruses in chicken in vivo, although the in vitro viral infection provides useful information to investigate the role of chicken macrophages against viruses in vivo.

Macrophages respond differently to different viral strains. Intratracheal IBV infection increased the number of macrophages in the respiratory tract five days post-infection (85) while IBDV infection by eye-drop route led to decreased numbers of splenic macrophages three and five days post-infection (90). Both IBDV and IBV induce pro-inflammatory cytokine production by macrophages, like IL-1 $\beta$, IL-6 and IFN- $\beta(85,90)$. Some viruses cause macrophage dysfunction. For instance, ALV, IBDV or IAV (H6N1) infection decreased macrophage phagocytosis and killing activity (91-93). In contrast, IAV (H5N1) 
enhanced phagocytic activity of chicken macrophages (94). On the other hand, IAV has been shown to induce expression of pro-inflammatory cytokines (IL-6 and IL-1 $\beta$ ) as well as the inflammatory chemokines (CXCLi1 and CXCLi2) in HD11 cells (95).

\section{Chicken cathelicidins}

Cathelicidins are HDPs, short cationic peptides that play an important role in innate immunity against pathogens. They have direct antimicrobial activity as well as immunomodulatory functions (Fig. 2) (96). Cathelicidins have been found in different species including mammals, birds, reptiles, amphibians and some fishes (97). Not all animals have the same number of cathelicidins. For instance, there is only one cathelicidin described in human, mouse and dog (98). So far, four cathelicidins have been characterized in chicken, named CATH-1, -2, -3 and $-\mathrm{B} 1$.

\section{Structure and classification}

All cathelicidins are composed of three parts: a signal peptide, a cathelin domain and the mature peptide. They are encoded by 4 exons. Exon 1 encodes the signal peptide of 29 or 30 amino acids (AA) and the cathelin domain of 99 to 114 AAs is encoded by exon 2 and exon 3. Exon 4 encodes the mature peptide of 12 to 100 AAs (99). The N-terminal signal peptide sequence and the cathelin-domain are highly conserved among species, contrary to the Cterminal domain sequence encoding the mature peptide, which is very diverse (100). This diversity leads to existence of mature cathelicidin peptides with differing length, charge density and structure. However, all the cathelicidins are positively charged due to cationic residues, and amphipathic due to spatial separation of the charged and hydrophobic residues.

The cationic and amphipatic nature enable cathelicidins to interact with negatively charged molecules such as LPS, lipoteichoic acid (LTA) and (phospho)lipids in bacterial membranes (101). Most mature peptides are mainly $\alpha$-helical, such as LL-37 in human (102), SMAP-29 in sheep (103), and BMAP-27/28/34 in cow (104). Chicken CATH-1, -2 and -3 are also mainly $\alpha$-helical segments of which CATH-2 contains 2 helices connected by a proline induced kink in the center. Such a helix-hinge-helix structure is common for more cathelicidins and similar configurations have been described in porcine PMAP-23 and sheep SMAP-29. Chicken cathelicidin (CATH-B1) is less studied compared to the other three chicken cathelicidins. The amino acid sequence of CATH-B1 has been predicted, but its molecular conformation has not been determined. Besides the helical peptides, some cathelicidins have other structural characteristics such as porcine protegrins that contain a $\beta$ hairpin, or peptides that are rich in specific amino acids (proline/arginine) like porcine PR39 (105-107). 


\section{Expression}

Cathelicidins are produced by leukocytes and epithelial cells. They are stored in granules as inactive precursors and then are released as mature peptide upon activation of cells after being cleaved by neutrophil elastase. On a protein level, expression of CATH-2 protein was determined using a specific anti-CATH-2 antibody. This showed that CATH-2 was exclusively expressed in heterophils. The human cathelicidin LL-37, which is produced by neutrophils, has a much broader expression spectrum $(18,108)$. It also indicates that it is well possible that the level of CATH-2 gene expression found in tissues is related to the number of heterophils present in that tissue at time of sampling. CATH-1 and CATH-3 protein were also identified in heterophils by liquid chromatography-mass spectrometry (LC-MS)/MS analysis (19). CATH-B1 is the second chicken cathelicidin for which an antibody is produced enabling the determination of its protein expression. CATH-B1 protein was only found to be expressed in secretory epithelial cells of the bursa surrounding M cells (109) which is a major entry point for pathogens in mucosal lymphoid tissues, but not many other tissues were tested for protein expression.

Gene expression of chicken cathelicidins is broader than actual (determined) protein expression. All four chicken cathelicidins mRNA are actually expressed in most tissues including the skin, the respiratory tract, gastrointestinal tract and lymphoid organs, except for breast muscle (110). CATH-1, -2 and -3 mRNA were highly expressed in bone marrow cells while CATH-B1 mRNA was highly expressed in bursa $(109,110)$. Interestingly, CATH-2 mRNA is highly expressed in the uropygial gland, which secretes preen oil containing antimicrobial factors that transferred to skin and provide protection against infections (111). Furthermore, these gene expression of four cathelicidins already has been detected during embryonic development $(112,113)$. In the early stage of life in chicken, increased gene expression of cathelicidins was observed in different tissues such as lung, bursa and intestine (110). The broader distribution of these cathelicidins in vivo plays an important role against invading pathogens.

\section{Regulation of cathelicidin expression}

Besides developmental regulated expression of cathelicidins, many external factors can also up or downregulate cathelicidin expression. Such factors include inflammatory and microbial stimuli but also vitamin D. Regulation of human cathelicidin expression by these factors and other factors are well studied, but less is known about chicken cathelicidins expression.

Vitamin D was discovered as an inducer of human cathlicidin gene expression in different cell types, such as keratinocytes, monocytes and neutrophils, and human cell lines (114). In chicken a similar effect was observed for vitamin D, gene expression of chicken cathelicidins 
was induced in tissues upon vitamin D supplementation. Chickens fed vitamin D resulted in increased gene expression of CATH-1 and CATH-B1 in the spleen whereas the expression of CATH-3 was downregulated. These changes were tissue specific because the expression of cathelicidins was not affected in PBMCs (115).

Besides vitamin D, other stimuli such as short-chain fatty acids were found to regulate the expression of chicken cathelicidins. Butyrate is a short-chain fatty acid produced by bacterial fermentation of undigested dietary fiber. When HD11 cells and primary monocytes were incubated with butyrate for $24 \mathrm{~h}$, upregulated CATH-B1 gene expression was detected but gene expression of the other three cathelidins was not affected by butyrate (116). Oral administration of butyrate also enhanced CATH-B1 gene expression in chicken jejunal and cecal explants (116). Furthermore, butyrate treatment enhanced antibacterial activity of primary monocytes against $S$. Enteritidis. These compounds may be good feed additives to increase the expression of cathelicidins and thereby potentially increase protection againt infection.

Microbial infection also regulates the expression of chicken cathelicidins, but whether they are up- or down-regulated depends on the bacterial strain. Abundant CATH-2 in heterophils has been observed in the jejunum of $S$. Eenteritidis-challenged broilers post $8 \mathrm{~h}$ infection (18). In contrast to Salmonella infection, Campylobacter jejuni infection in young chicks did not induce CATH-2 protein (heterophil) recruitment to the small intestine and CATH-2 mRNA expression was decreased $48 \mathrm{~h}$ post infection (117). CATH-1 and CATH-3 gene expressions were also downregulated by Campylobacter jejuni, but CATH-B1 gene expression was not affected (118). These differences indicate that possibly some bacteria evade the immune system partially by actively down-regulating cathelicidins.

Besides regulation of gene expression of cathelicidins, the functional regulation of cathelicidins might be on the level of release of the peptides. As mentioned cathelicidins are stored as inactive precursors in secretory granules and only upon secretion and subsequently proteolytic cleavage, active peptide is produced. For CATH-2, it was shown in vitro that LPS induces heterophils to release the mature form of peptide and this proteolytic process of proCATH-2 was mediated by serine proteases (18).

\section{Cathelicidin functions}

\section{Antimicrobial activity}

Cathelicidins have a broad spectrum of antimicrobial activity against Gram-positive and Gram-negative bacteria, fungi, protozoa and viruses (Fig. 2). This antimicrobial activity has been extensively investigated. CATH-1, -2 and -3 showed strong antibacterial activity against both Gram-positive (L. monocytogenes, S. aureus) as well as Gram-negative bacteria (E. coli, 
S. typhimurium, $K$. pneumoniae, $P$. aeruginosa) including antibiotic-resistant strains ( $S$. aureus MRSA) with minimum inhibitory concentrations (MIC) between 0.4-2.0 $\mu \mathrm{M}$ (119, 120). Antibacterial activity of HDPs is often negatively affected by the presence of salts and serum. However, antibacterial activity of CATH-1, -2 and -3 was not affected by the presence of physiological concentrations of salt $(119,120)$. Radial diffusion assays showed that the presence of serum had only a small effect on CATH-2's activity, but did not affect antimicrobial activity of CATH-1 and CATH-3. Whereas many antibiotics induce resistance, CATH-1, -2 and -3 did not induce resistance by multi-resistant bacteria such as $S$. aureus and $K$. pneumoniae (121). Besides their activity against planktonic bacteria, cathelicidins inhibited the formation of bacterial biofilms in vitro. In addition, CATH-2 has been shown to permeabilize the formed biofilm and directly kill the biofilm-associated bacteria $(122,123)$. Besides this antibacterial activity, CATH-2 also has been reported to rapidly kill fungi (Candida albicans) within $5 \mathrm{~min}$ by permeabilizing the fungal cell membrane (124). However, antimicrobial activity of another chicken cathelicidin CATH-B1 is less studied compared to the other three cathelicidins. CATH-B1 has been only tested against a limited number of bacterial strains including E. coli, S. aureus, and $P$. aeruginosa and the MIC value was in the range of $0.63-2.5 \mu \mathrm{M}$, however this was tested against a low amount of bacteria ( $\left.2 \times 10^{3} \mathrm{CFU}\right)(109)$. In another study the MIC value was increased to $12.8 \mu \mathrm{M}$ against $E$. coli and $S$. aureus when higher bacterial concentrations $\left(5 \times 10^{5} \mathrm{CFU}\right)$ were used (125).

The antibacterial mechanism of cathelicidins has been extensively studied. Positively charged and amphipathic peptides can interact with negatively charged outer and/or inner membrane molecules of Gram-negative bacteria. LL-37 kills microorganisms by accumulating on the membrane to induce leakage of the membrane, finally disrupting membrane integrity $(108,126)$. In line with the mechanism of action of LL-37, CATH-2 directly binds to the bacterial membrane and permeabilizes the membranes to kill bacteria in 5 min $(127,128)$. Interestingly, at sub-MIC values, CATH-2 was also detected intracellularly in E.coli where it seemed to affect bacterial DNA and ribosome organization. In addition, CATH-2 also induced (outer) membrane vesicles release (128). These vesicles induced by CATH-2 might be interesting vaccine candidates.

\section{Immunomodulation}

In addition to direct microbial killing, many antimicrobial peptides including chicken cathelicidins have immunomodulatory effects on the host cells (Fig. 2). The immunomodulatory effect of human cathelicidin LL-37 has been extensively studied. LL-37 has many immunomodulatory properties including binding to LPS (108) and blocking LPSinduced production of cytokines and nitric oxide $(129,130)$, mediating migration of leukocytes (131, 132), modulating activation of TLRs (133-135) and regulating cell 
differentiation $(136,137)$. Importantly, LL-37 can directly interact with cell receptors such as formyl-peptide receptor-like 1 (FPRL1) and P2X7 nucleotide receptor to contribute to innate and adaptive immunity against microbial invasion $(131,138)$. Chicken cathelicidins share some properties with LL-37 and some functions of chicken cathelicidins have been investigated.

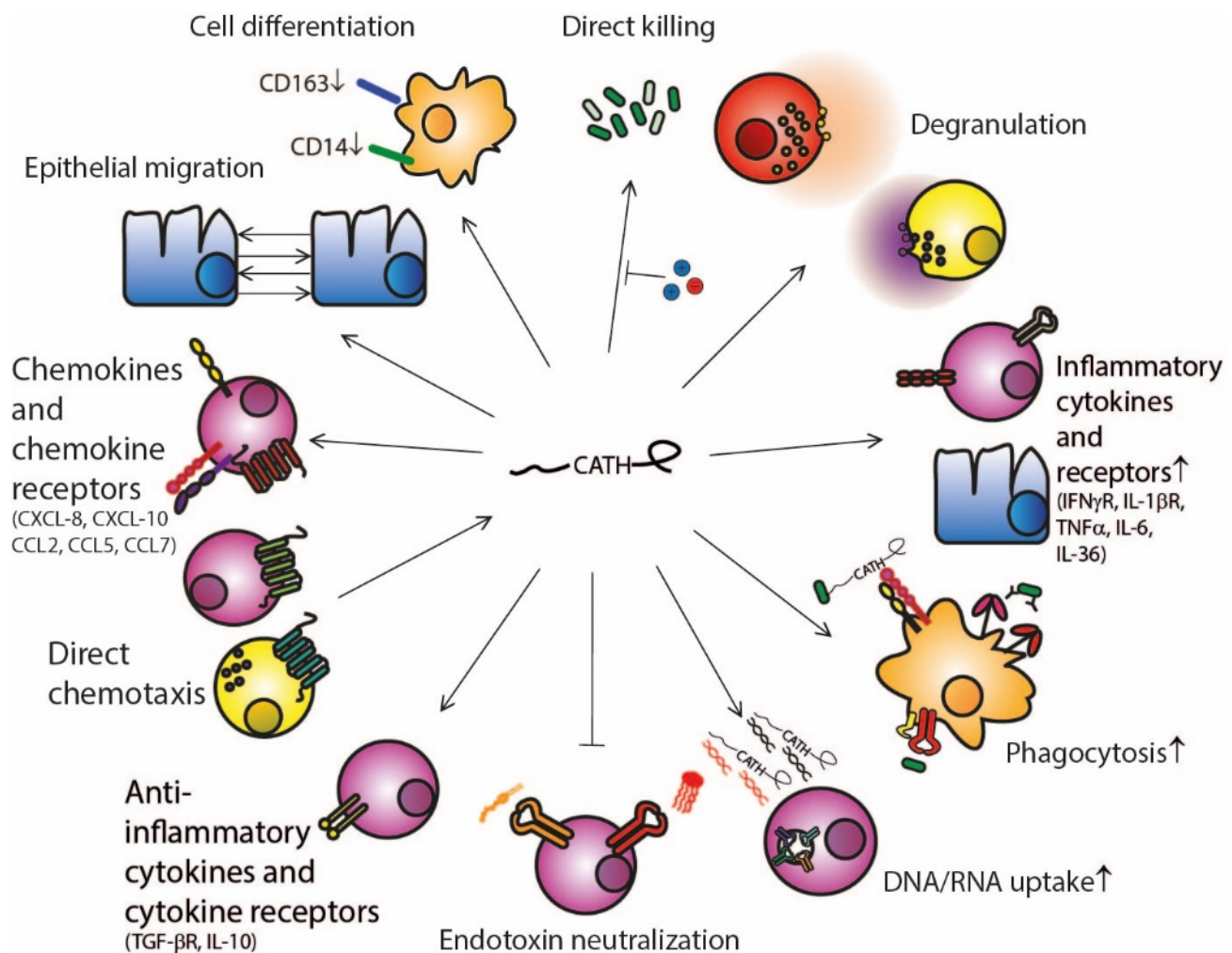

Fig 2. Summary of cathelicidin functions. Cathelicidins have direct killing activity against bacteria, viruses and fungi. They can induce degranulation of neutrophils, enhance phagocytosis, increase DNA/RNA uptake thereby boosting the activation of intracellular TLRs. Furthermore, they neutralize endotoxin via binding to LPS and LTA to inhibit LPS- and LTA-induced inflammatory response, thus directly inducing an anti-inflammatory response. They are directly chemotactic for mast cells and induce production of chemokines including CCL2, CCL5, CCL7, CXCL8 (IL-8) and CXCL10. They also have wound healing function via induction of epithelial migration. Finally, cathelicidins affect cell differentiation by polarizing macrophages to an inflammatory phenotype (M1). Figure was adapted from (96).

Similar to LL-37, chicken cathelicidins (CATH-1, -2, -3) can bind free LPS in vitro and inhibit LPS-induced nitric oxide production and cytokine expression such as monocyte chemotactic protein-1 (MCP-1), TNF- $\alpha$, IL-1 $\beta$, IL-8 and IL-6 (120, 139, 140). CATH-B1 has been shown to bind LPS (125), but it is still unknown whether CATH-B1 modulates LPSinduced immune response of the host cells. A CATH-1 analogue (6-26) directly induced 
activation of macrophages in vitro resulting in cytokine expression and enhanced CD86 and MHC-II expression (141). In addition to blocking LPS-induced stimulation, CATH-2 can directly stimulate cells to produce MCP-1 (139). Unlike LL-37, which induces cytokine expression via the interaction with cell membrane receptors, so far chicken cathelicidins have not been shown to interact with any specific host receptors. However, CATH-2 has been shown to inhibit $E$. coli-induced TLR2 or TLR4 activation by direct killing of bacteria and to enhance DNA-induced TLR9 activation in macrophages $(142,143)$.

In conclusion, chicken cathelicidins have specific antimicrobial and immunomodulatory activities (Fig. 2). However, peptide aggregation, susceptibility to degradation and lack of knock-out chicken lines make it difficult to investigate the specific function of these chicken cathelicidins in vivo. At least, the D-enantiomer of chicken cathelicidin-2 has been shown to reduce chicken mortality and morbidity in an infection model (144). These results indicate that chicken cathelicidins, like other host defense peptides, can be potential therapeutics against microbial infections (145) and that upregulation of expression of chicken cathelicidins by feed additives can boost host immune system to promote chicken health. 


\section{An overview of the thesis}

Avian respiratory diseases caused by pathogens including bacteria and viruses are important diseases leading to huge economic loss in poultry. Avian innate immunity including immune cells and HDPs provide important protection against pathogens, but it is rarely studied. Therefore, in this thesis, we aimed at exploring the role of avian innate immunity to increase our knowledge about the protective mechanisms of the host against pathogens.

In chapter 2, the interactions of chicken lung epithelial cells with APEC is described to understand the role of epithelial cells in APEC infections.

In chapter 3, the interactions of macrophage HD11 cells with APEC is described to understand the role of macrophages in controlling APEC.

In chapter 4, the establishment of a standardized culturing method of monocyte-derived macrophages is described and these cultured macrophages are characterized as proinflammatory macrophages with M1-like properties.

In chapter 5, the immunomodulatory functions of CATH-B1 are described increasing our understanding of the function of this cathelicidin.

In chapter 6, the anti-IAV activity of CATH-B1 is described exploring the possible use of cathelicidins in the development of anti-infective therapies.

In chapter 7, the main findings of this thesis are summarized and discussed. 


\section{References}

1. Glisson JR. Bacterial respiratory diseases of poultry. Poultry Sci. 1998;77:1139-42.

2. Kleven SH. Mycoplasmas in the etiology of multifactorial respiratory disease. Poultry Sci. 1998;77:1146-9.

3. Villegas P. Viral diseases of the respiratory system. Poultry Sci. 1998;77:1143-5.

4. Winkler IG, Barbier V, Wadley R, Zannettino AC, Williams S, Lévesque JP. Positioning of bone marrow hematopoietic and stromal cells relative to blood flow in vivo: serially reconstituting hematopoietic stem cells reside in distinct nonperfused niches. Blood. 2010;116(3):375-85.

5. Kolaczkowska E, Kubes P. Neutrophil recruitment and function in health and inflammation. Nature Reviews Immunology. 2013;13(3):159.

6. de Oliveira S, Rosowski EE, Huttenlocher A. Neutrophil migration in infection and wound repair: going forward in reverse. Nature Reviews Immunology. 2016;16(6):378.

7. Maxwell M, Robertson G. The avian heterophil leucocyte: a review. World's Poultry Science Journal. 1998;54(2):155-78.

8. Stabler J, McCormick T, Powell K, Kogut M. Avian heterophils and monocytes: phagocytic and bactericidal activities against Salmonella enteritidis. Veterinary microbiology. 1994;38(4):293-305.

9. Kogut MH, Rothwell L, Kaiser P. Differential regulation of cytokine gene expression by avian heterophils during receptor-mediated phagocytosis of opsonized and nonopsonized Salmonella enteritidis. Journal of interferon \& cytokine research. 2003;23(6):319-27.

10. Kogut MH, Rothwell L, Kaiser P. Priming by recombinant chicken interleukin-2 induces selective expression of IL-8 and IL-18 mRNA in chicken heterophils during receptor-mediated phagocytosis of opsonized and nonopsonized Salmonella enterica serovar enteritidis. Molecular immunology. 2003;40(9):603-10.

11. Mellata M, Dho-Moulin M, Dozois CM, Curtiss III R, Lehoux B, Fairbrother JM. Role of avian pathogenic Escherichia coli virulence factors in bacterial interaction with chicken heterophils and macrophages. Infection and immunity. 2003;71(1):494-503.

12. Borregaard N. Neutrophils, from marrow to microbes. Immunity. 2010;33(5):657-70.

13. Häger M, Cowland J, Borregaard N. Neutrophil granules in health and disease. Journal of internal medicine. 2010;268(1):25-34.

14. Genovese KJ, He H, Swaggerty CL, Kogut MH. The avian heterophil. Developmental \& Comparative Immunology. 2013;41(3):334-40.

15. Chuammitri P, Ostojić J, Andreasen CB, Redmond SB, Lamont SJ, Palić D. Chicken heterophil extracellular traps (HETs): novel defense mechanism of chicken heterophils. Veterinary immunology and immunopathology. 2009;129(1-2):126-31.

16. Daimon T, Caxton-Martins A. Electron microscopic and enzyme cytochemical studies on granules of mature chicken granular leucocytes. Journal of anatomy. 1977;123(Pt 3):553.

17. Evans EW, Beach GG, Wunderlich J, Harmon BG. Isolation of antimicrobial peptides from avian heterophils. Journal of Leukocyte Biology. 1994;56(5):661-5. 
18. Van Dijk A, Tersteeg-Zijderveld MH, Tjeerdsma-van Bokhoven JL, Jansman AJ, Veldhuizen EJ, Haagsman HP. Chicken heterophils are recruited to the site of Salmonella infection and release antibacterial mature Cathelicidin-2 upon stimulation with LPS. Molecular immunology. 2009;46(7):1517-26.

19. Sekelova Z, Stepanova H, Polansky O, Varmuzova K, Faldynova M, Fedr R, et al. Differential protein expression in chicken macrophages and heterophils in vivo following infection with Salmonella Enteritidis. Veterinary research. 2017;48(1):35.

20. Brinkmann V, Reichard U, Goosmann C, Fauler B, Uhlemann Y, Weiss DS, et al. Neutrophil extracellular traps kill bacteria. Science. 2004;303(5663):1532-5.

21. Ermert D, Urban CF, Laube B, Goosmann C, Zychlinsky A, Brinkmann V. Mouse neutrophil extracellular traps in microbial infections. Journal of innate immunity. 2009;1(3):181-93.

22. Wells LL, Lowry VK, Deloach JR, Kogut MH. Age-dependent phagocytosis and bactericidal activities of the chicken heterophil. Developmental \& Comparative Immunology. 1998;22(1):103-9.

23. Brockus C, Jackwood M, Harmon B. Characterization of $\beta$-defensin prepropeptide mRNA from chicken and turkey bone marrow. Animal genetics. 1998;29(4):283-9.

24. Ferro PJ, Swaggerty CL, Kaiser P, Pevzner IY, Kogut MH. Heterophils isolated from chickens resistant to extra-intestinal Salmonella enteritidis infection express higher levels of pro-inflammatory cytokine mRNA following infection than heterophils from susceptible chickens. Epidemiology \& Infection. 2004;132(6):102937.

25. Harmon BG. Avian heterophils in inflammation and disease resistance. Poultry science. 1998;77(7):972-7.

26. Austyn JM. New insights into the mobilization and phagocytic activity of dendritic cells. The Journal of Experimental Medicine. 1996;183(4):1287-92.

27. Banchereau J, Steinman RM. Dendritic cells and the control of immunity. Nature. 1998;392:245.

28. Steinman RM. The dendritic cell system and its role in immunogenicity. Annual review of immunology. 1991;9:271-96.

29. Steinman RM, Cohn ZA. Identification of a novel cell type in peripheral lymphoid organs of mice: I. Morphology, quantitation, tissue distribution. Journal of Experimental Medicine. 1973;137(5):1142-62.

30. Olah I, Glick B. Secretory cell in the medulla of the bursa of Fabricius. Cellular and Molecular Life Sciences. 1978;34(12):1642-3.

31. OLAH I, GLICK B. Structure of the germinal centers in the chicken caecal tonsil: light and electron microscopic and autoradiographic studies. Poultry science. 1979;58(1):195-210.

32. Bódi I, Minkó K, Molnár D, Nagy N, Oláh I. A novel aspect of the structure of the avian thymic medulla. Cell and tissue research. 2015;359(2):489-501.

33. Wu Z, Rothwell L, Young JR, Kaufman J, Butter C, Kaiser P. Generation and characterization of chicken bone marrow-derived dendritic cells. Immunology. 2010;129(1):133-45.

34. Prechtel AT, Steinkasserer A. CD83: an update on functions and prospects of the maturation marker of dendritic cells. Archives of dermatological research. 2007;299(2):59-69. 
35. Guo M, Gong S, Maric S, Misulovin Z, Pack M, Mahnke K, et al. A monoclonal antibody to the DEC-205 endocytosis receptor on human dendritic cells. Human immunology. 2000;61(8):729-38.

36. Hansell C, Zhu XW, Brooks H, Sheppard M, Withanage S, Maskell D, et al. Unique features and distribution of the chicken CD83+ cell. The Journal of Immunology. 2007;179(8):5117-25.

37. Lee SH, Lillehoj HS, Jang SI, Lee KW, Baldwin C, Tompkins D, et al. Development and characterization of mouse monoclonal antibodies reactive with chicken CD83. Veterinary immunology and immunopathology. 2012;145(1-2):527-33.

38. Staines K, Young JR, Butter C. Expression of chicken DEC205 reflects the unique structure and function of the avian immune system. PLoS One. 2013;8(1):e51799.

39. Quéré P, Pierre J, Hoang M-D, Esnault E, Domenech J, Sibille P, et al. Presence of dendritic cells in chicken spleen cell preparations and their functional interaction with the parasite Toxoplasma gondii. Veterinary immunology and immunopathology. 2013;153(1-2):57-69.

40. Nagy N, Bódi I, Oláh I. Avian dendritic cells: phenotype and ontogeny in lymphoid organs. Developmental \& Comparative Immunology. 2016;58:47-59.

41. Henson PM, Riches DW. Modulation of Macrophage Maturation by Cytokines and Lipid Mediators: A Potential Role in Resolution of Pulmonary Inflammationa. Annals of the New York Academy of Sciences. 1994;725(1):298-308.

42. Dietert RR, Golemboski KA. Avian macrophage metabolism. Poultry science. 1998;77(7):990-7.

43. Qureshi M. Avian macrophage and immune response: an overview. Poultry science. 2003;82(5):691-8.

44. Porcheray F, Viaud S, Rimaniol AC, Leone C, Samah B, Dereuddre-Bosquet N, et al. Macrophage activation switching: an asset for the resolution of inflammation. Clinical \& Experimental Immunology. 2005;142(3):4819.

45. Verreck FA, de Boer T, Langenberg DM, Hoeve MA, Kramer M, Vaisberg E, et al. Human IL-23-producing type 1 macrophages promote but IL-10-producing type 2 macrophages subvert immunity to (myco) bacteria. Proceedings of the National Academy of Sciences. 2004;101(13):4560-5.

46. Fleetwood AJ, Lawrence T, Hamilton JA, Cook AD. Granulocyte-macrophage colony-stimulating factor (CSF) and macrophage CSF-dependent macrophage phenotypes display differences in cytokine profiles and transcription factor activities: implications for CSF blockade in inflammation. The Journal of immunology. 2007;178(8):5245-52.

47. Jinnouchi H, Guo L, Sakamoto A, Torii S, Sato Y, Cornelissen A, et al. Diversity of macrophage phenotypes and responses in atherosclerosis. Cellular and Molecular Life Sciences. 2019:1-14.

48. Mantovani A, Sica A, Sozzani S, Allavena P, Vecchi A, Locati M. The chemokine system in diverse forms of macrophage activation and polarization. Trends in immunology. 2004;25(12):677-86.

49. Nagelkerke SQ, Dekkers G, Kustiawan I, van de Bovenkamp FS, Geissler J, Plomp R, et al. Inhibition of Fc $\gamma$ Rmediated phagocytosis by IVIg is independent of IgG-Fc sialylation and Fc $\gamma$ RIIb in human macrophages. Blood, The Journal of the American Society of Hematology. 2014;124(25):3709-18. 
50. Mast J, Goddeeris B, Peeters K, Vandesande F, Berghman L. Characterisation of chicken monocytes, macrophages and interdigitating cells by the monoclonal antibody KUL01. Veterinary immunology and immunopathology. 1998;61(2-4):343-57.

51. Staines K, Hunt LG, Young JR, Butter C. Evolution of an expanded mannose receptor gene family. PLoS One. 2014;9(11):e110330.

52. Beug H, von Kirchbach A, Döderlein G, Conscience J-F, Graf T. Chicken hematopoietic cells transformed by seven strains of defective avian leukemia viruses display three distinct phenotypes of differentiation. Cell. 1979;18(2):375-90.

53. Qureshi M, Miller L, Lillehoj H, Ficken M. Establishment and characterization of a chicken mononuclear cell line. Veterinary immunology and immunopathology. 1990;26(3):237-50.

54. Feng M, Dai M, Cao W, Tan Y, Li Z, Shi M, et al. ALV-J strain SCAU-HN06 induces innate immune responses in chicken primary monocyte-derived macrophages. Poultry science. 2016;96(1):42-50.

55. Johnston SA, Voelz K, May RC. Cryptococcus neoformans thermotolerance to avian body temperature is sufficient for extracellular growth but not intracellular survival in macrophages. Scientific reports. 2016;6:20977.

56. Kappala D, Sarkhel R, Dixit SK, Mahawar M, Singh M, Ramakrishnan S, et al. Role of different receptors and actin filaments on Salmonella Typhimurium invasion in chicken macrophages. Immunobiology. 2018;223(67):501-7.

57. Garrido D, Alber A, Kut E, Chanteloup NK, Lion A, Trotereau A, et al. The role of type I interferons (IFNs) in the regulation of chicken macrophage inflammatory response to bacterial challenge. Developmental \& Comparative Immunology. 2018;86:156-70.

58. Garceau V, Smith J, Paton IR, Davey M, Fares MA, Sester DP, et al. Pivotal Advance: Avian colonystimulating factor 1 (CSF-1), interleukin-34 (IL-34), and CSF-1 receptor genes and gene products. Journal of leukocyte biology. 2010;87(5):753-64.

59. Gao J, Scheenstra MR, van Dijk A, Veldhuizen EJ, Haagsman HP. A new and efficient culture method for porcine bone marrow-derived M1-and M2-polarized macrophages. Veterinary immunology and immunopathology. 2018;200:7-15.

60. Chaudhari AA, Kim WH, Lillehoj HS. Interleukin-4 (IL-4) may regulate alternative activation of macrophagelike cells in chickens: a sequential study using novel and specific neutralizing monoclonal antibodies against chicken IL-4. Veterinary immunology and immunopathology. 2018;205:72-82.

61. Geiser M, Baumann M, Cruz-Orive LM, Im Hof V, Waber U, Gehr P. The effect of particle inhalation on macrophage number and phagocytic activity in the intrapulmonary conducting airways of hamsters. American journal of respiratory cell and molecular biology. 1994;10(6):594-603.

62. Maina J. Some recent advances on the study and understanding of the functional design of the avian lung: morphological and morphometric perspectives. Biological Reviews. 2002;77(1):97-152.

63. Toth T, Siegel P. Cellular defense of the avian respiratory tract: paucity of free-residing macrophages in the normal chicken. Avian diseases. 1986:67-75. 
64. Nganpiep L, Maina J. Composite cellular defence stratagem in the avian respiratory system: functional morphology of the free (surface) macrophages and specialized pulmonary epithelia. Journal of Anatomy. 2002;200(5):499-516.

65. Maina JN, Cowley HM. Ultrastructural characterization of the pulmonary cellular defences in the lung of a bird, the rock dove, Columba livia. Proceedings of the Royal Society of London Series B: Biological Sciences. 1998;265(1405):1567-72.

66. Toth T, Siegel P, Veit H. Cellular defense of the avian respiratory system. Influx of phagocytes: elicitation versus activation. Avian diseases. 1987:861-7.

67. Martinez FO, Helming L, Gordon S. Alternative activation of macrophages: an immunologic functional perspective. Annual review of immunology. 2009;27:451-83.

68. Nourshargh S, Alon R. Leukocyte migration into inflamed tissues. Immunity. 2014;41(5):694-707.

69. Toth TE, Pyle R, Caceci T, Siegel P, Ochs D. Cellular defense of the avian respiratory system: influx and nonopsonic phagocytosis by respiratory phagocytes activated by Pasteurella multocida. Infection and immunity. 1988;56(5):1171-9.

70. Matthijs MG, Ariaans MP, Dwars RM, van Eck JH, Bouma A, Stegeman A, et al. Course of infection and immune responses in the respiratory tract of IBV infected broilers after superinfection with E. coli. Veterinary immunology and immunopathology. 2009;127(1-2):77-84.

71. Ulrich-Lynge SL, Dalgaard TS, Norup LR, Song X, Sørensen P, Juul-Madsen HR. Chicken mannose-binding lectin function in relation to antibacterial activity towards Salmonella enterica. Immunobiology. 2015;220(5):555-63.

72. Myszewski MA, Stern NJ. Phagocytosis and intracellular killing of Campylobacter jejuni by elicited chicken peritoneal macrophages. Avian diseases. 1991:750-5.

73. Pruimboom IM, Rimler RB, Ackermann MR, Brogden KA. Capsular hyaluronic acid-mediated adhesion of Pasteurella multocida to turkey air sac macrophages. Avian diseases. 1996:887-93.

74. Kiama S, Adekunle J, Maina J. Comparative in vitro study of interactions between particles and respiratory surface macrophages, erythrocytes, and epithelial cells of the chicken and the rat. Journal of Anatomy. 2008;213(4):452-63.

75. Peng L, Matthijs MG, Haagsman HP, Veldhuizen EJ. Avian pathogenic Escherichia coli-induced activation of chicken macrophage HD11 cells. Developmental \& Comparative Immunology. 2018;87:75-83.

76. Jarvis N, Donaldson JR, O'Bryan CA, Ricke SC, Crandall PG. Listeria monocytogenes infection of HD11, chicken macrophage-like cells. Poultry science. 2016;96(4):950-6.

77. Henard CA, Vázquez-Torres A. Nitric oxide and Salmonella pathogenesis. Frontiers in microbiology. $2011 ; 2: 84$.

78. Nathan CF, Hibbs Jr JB. Role of nitric oxide synthesis in macrophage antimicrobial activity. Current opinion in immunology. 1991;3(1):65-70.

79. Liew F, Millott S, Parkinson C, Palmer R, Moncada S. Macrophage killing of Leishmania parasite in vivo is mediated by nitric oxide from L-arginine. The Journal of Immunology. 1990;144(12):4794-7. 
80. van Dijk A, van Eldik M, Veldhuizen EJ, Tjeerdsma-van Bokhoven HL, de Zoete MR, Bikker FJ, et al. Immunomodulatory and anti-inflammatory activities of chicken cathelicidin-2 derived peptides. PLoS One. 2016;11(2):e0147919.

81. Arias M, Zabaleta J, Rodriguez J, Rojas M, Paris S, Garcia L. Failure to induce nitric oxide production by human monocyte-derived macrophages. Manipulation of biochemical pathways. Allergologia et immunopathologia. 1997;25(6):280-8.

82. Crippen TL, Sheffield CL, He H, Lowry VK, Kogut MH. Differential nitric oxide production by chicken immune cells. Developmental \& Comparative Immunology. 2003;27(6-7):603-10.

83. He H, Genovese KJ, Swaggerty CL, MacKinnon KM, Kogut MH. Co-stimulation with TLR3 and TLR21 ligands synergistically up-regulates Th1-cytokine IFN- $\gamma$ and regulatory cytokine IL-10 expression in chicken monocytes. Developmental \& Comparative Immunology. 2012;36(4):756-60.

84. Jayaraman P, Sada-Ovalle I, Nishimura T, Anderson AC, Kuchroo VK, Remold HG, et al. IL-1 $\beta$ promotes antimicrobial immunity in macrophages by regulating TNFR signaling and caspase- 3 activation. The Journal of Immunology. 2013;190(8):4196-204.

85. Amarasinghe A, Abdul-Cader MS, Almatrouk Z, van der Meer F, Cork SC, Gomis S, et al. Induction of innate host responses characterized by production of interleukin (IL)-1 $\beta$ and recruitment of macrophages to the respiratory tract of chickens following infection with infectious bronchitis virus (IBV). Veterinary microbiology. 2018;215:1-10.

86. Chomarat P, Banchereau J, Davoust J, Palucka AK. IL-6 switches the differentiation of monocytes from dendritic cells to macrophages. Nature immunology. 2000;1(6):510.

87. Diehl S, Anguita J, Hoffmeyer A, Zapton T, Ihle JN, Fikrig E, et al. Inhibition of Th1 differentiation by IL-6 is mediated by SOCS1. Immunity. 2000;13(6):805-15.

88. Rohde F, Schusser B, Hron T, Farkašová H, Plachý J, Härtle S, et al. Characterization of chicken tumor necrosis factor- $\alpha$, a long missed cytokine in birds. Frontiers in immunology. 2018;9:605.

89. Bülow Vv, Klasen A. Effects of avian viruses on cultured chicken bone-marrow-derived macrophages. Avian Pathology. 1983;12(2):179-98.

90. Palmquist JM, Khatri M, Cha R, Goddeeris B, Walcheck B, Sharma J. In vivo activation of chicken macrophages by infectious bursal disease virus. Viral immunology. 2006;19(2):305-15.

91. McConnell C, Adair B, McNulty M. Effects of chicken anemia virus on macrophage function in chickens. Avian diseases. 1993:358-65.

92. Lam K. Alteration of chicken heterophil and macrophage functions by the infectious bursal disease virus. Microbial pathogenesis. 1998;25(3):147-55.

93. Kodihalli S, Sivanandan V, Nagaraja KV, Shaw D, Halvorson D. Effect of avian influenza virus infection on the phagocytic function of systemic phagocytes and pulmonary macrophages of turkeys. Avian diseases. 1994:93-102.

94. Laudert E, Sivanandan V, Halvorson D. Effect of an H5N1 avian influenza virus infection on the immune system of mallard ducks. Avian diseases. 1993;37(3):845-53. 
95. Qi X, Liu C, Li R, Zhang H, Xu X, Wang J. Modulation of the innate immune-related genes expression in H9N2 avian influenza virus-infected chicken macrophage-like cells (HD11) in response to Escherichia coli LPS stimulation. Research in veterinary science. 2017;111:36-42.

96. Van Harten RM, Van Woudenbergh E, Van Dijk A, Haagsman HP. Cathelicidins: immunomodulatory antimicrobials. Vaccines. 2018;6(3):63.

97. Hemshekhar M, Anaparti V, Mookherjee N. Functions of cationic host defense peptides in immunity. Pharmaceuticals. 2016;9(3):40.

98. Zanetti M. The role of cathelicidins in the innate host defenses of mammals. Current issues in molecular biology. 2005;7(2):179-96.

99. Kościuczuk EM, Lisowski P, Jarczak J, Strzałkowska N, Jóźwik A, Horbańczuk J, et al. Cathelicidins: family of antimicrobial peptides. A review. Molecular biology reports. 2012;39(12):10957-70.

100. Zanetti M, Gennaro R, Romeo D. Cathelicidins: a novel protein family with a common proregion and a variable C-terminal antimicrobial domain. FEBS letters. 1995;374(1):1-5.

101. Ramanathan B, Davis EG, Ross CR, Blecha F. Cathelicidins: microbicidal activity, mechanisms of action, and roles in innate immunity. Microbes and infection. 2002;4(3):361-72.

102. Agerberth B, Gunne H, Odeberg J, Kogner P, Boman HG, Gudmundsson GH. FALL-39, a putative human peptide antibiotic, is cysteine-free and expressed in bone marrow and testis. Proceedings of the National Academy of Sciences. 1995;92(1):195-9.

103. Mahoney MM, Lee AY, Brezinski-Caliguri DJ, Huttner KM. Molecular analysis of the sheep cathelin family reveals a novel antimicrobial peptide. FEBS letters. 1995;377(3):519-22.

104. Skerlavaj B, Gennaro R, Bagella L, Merluzzi L, Risso A, Zanetti M. Biological characterization of two novel cathelicidin-derived peptides and identification of structural requirements for their antimicrobial and cell lytic activities. Journal of Biological Chemistry. 1996;271(45):28375-81.

105. Zhao C, Ganz T, Lehrer RI. The structure of porcine protegrin genes. FEBS letters. 1995;368(2):197-202.

106. Zhao C, Liu L, Lehrer RI. Identification of a new member of the protegrin family by cDNA cloning. FEBS letters. 1994;346(2-3):285-8.

107. Agerberth B, Lee JY, Bergman T, Carlquist M, Boman HG, Mutt V, et al. Amino acid sequence of PR-39: isolation from pig intestine of a new member of the family of proline-arginine-rich antibacterial peptides. European journal of biochemistry. 1991;202(3):849-54.

108. Turner J, Cho Y, Dinh NN, Waring AJ, Lehrer RI. Activities of LL-37, a cathelin-associated antimicrobial peptide of human neutrophils. Antimicrobial agents and chemotherapy. 1998;42(9):2206-14.

109. Goitsuka R, Chen-lo HC, Benyon L, Asano Y, Kitamura D, Cooper MD. Chicken cathelicidin-B1, an antimicrobial guardian at the mucosal M cell gateway. Proceedings of the National Academy of Sciences. 2007;104(38):15063-8.

110. Achanta M, Sunkara LT, Dai G, Bommineni YR, Jiang W, Zhang G. Tissue expression and developmental regulation of chicken cathelicidin antimicrobial peptides. Journal of animal science and biotechnology. 2012;3(1):15. 
111. Van Dijk A, Veldhuizen EJ, van Asten AJ, Haagsman HP. CMAP27, a novel chicken cathelicidin-like antimicrobial protein. Veterinary immunology and immunopathology. 2005;106(3-4):321-7.

112. Meade KG, Higgs R, Lloyd AT, Giles S, O'Farrelly C. Differential antimicrobial peptide gene expression patterns during early chicken embryological development. Developmental \& Comparative Immunology. 2009;33(4):516-24.

113. Cuperus T, van Dijk A, Dwars RM, Haagsman HP. Localization and developmental expression of two chicken host defense peptides: cathelicidin-2 and avian $\beta$-defensin 9. Developmental \& Comparative Immunology. 2016;61:48-59.

114. Wang T-T, Nestel FP, Bourdeau V, Nagai Y, Wang Q, Liao J, et al. Cutting edge: 1, 25-dihydroxyvitamin D3 is a direct inducer of antimicrobial peptide gene expression. The Journal of Immunology. 2004;173(5):290912.

115. Rodriguez-Lecompte J, Yitbarek A, Cuperus T, Echeverry H, Van Dijk A. The immunomodulatory effect of vitamin $\mathrm{D}$ in chickens is dose-dependent and influenced by calcium and phosphorus levels. Poultry science. 2016;95(11):2547-56.

116. Sunkara LT, Achanta M, Schreiber NB, Bommineni YR, Dai G, Jiang W, et al. Butyrate enhances disease resistance of chickens by inducing antimicrobial host defense peptide gene expression. PLoS one. 2011;6(11):e27225.

117. van Dijk A, Herrebout M, Tersteeg-Zijderveld MH, Tjeerdsma-van Bokhoven JL, Bleumink-Pluym N, Jansman AJ, et al. Campylobacter jejuni is highly susceptible to killing by chicken host defense peptide cathelicidin-2 and suppresses intestinal cathelicidin-2 expression in young broilers. Veterinary microbiology. 2012;160(3-4):347-54.

118. Meade KG, Narciandi F, Cahalane S, Reiman C, Allan B, O’Farrelly C. Comparative in vivo infection models yield insights on early host immune response to Campylobacter in chickens. Immunogenetics. 2009;61(2):10110 .

119. Xiao Y, Cai Y, Bommineni YR, Fernando SC, Prakash O, Gilliland SE, et al. Identification and functional characterization of three chicken cathelicidins with potent antimicrobial activity. Journal of Biological Chemistry. 2006;281(5):2858-67.

120. Bommineni YR, Dai H, Gong YX, Soulages JL, Fernando SC, DeSilva U, et al. Fowlicidin-3 is an $\alpha$-helical cationic host defense peptide with potent antibacterial and lipopolysaccharide-neutralizing activities. The FEBS journal. 2007;274(2):418-28.

121. Veldhuizen EJ, Brouwer EC, Schneider VA, Fluit AC. Chicken cathelicidins display antimicrobial activity against multiresistant bacteria without inducing strong resistance. PloS one. 2013;8(4):e61964.

122. Molhoek EM, van Dijk A, Veldhuizen EJ, Haagsman HP, Bikker FJ. A cathelicidin-2-derived peptide effectively impairs Staphylococcus epidermidis biofilms. International journal of antimicrobial agents. 2011;37(5):476-9.

123. Chen H, Wubbolts RW, Haagsman HP, Veldhuizen EJ. Inhibition and eradication of Pseudomonas aeruginosa biofilms by host defence peptides. Scientific reports. 2018;8(1):10446. 
124. Ordonez SR, Amarullah IH, Wubbolts RW, Veldhuizen EJ, Haagsman HP. Fungicidal mechanisms of cathelicidins LL-37 and CATH-2 revealed by live-cell imaging. Antimicrobial agents and chemotherapy. 2014;58(4):2240-8.

125. Takeda A, Tsubaki T, Sagae N, Onda Y, Inada Y, Mochizuki T, et al. Bacterial toxin-inducible gene expression of cathelicidin-B1 in the chicken bursal lymphoma-derived cell line DT40: functional characterization of cathelicidin-B1. Peptides. 2014;59:94-102.

126. Oren Z, Lerman JC, Gudmundsson GH, Agerberth B, Shai Y. Structure and organization of the human antimicrobial peptide LL-37 in phospholipid membranes: relevance to the molecular basis for its non-cellselective activity. Biochemical Journal. 1999;341(Pt 3):501.

127. Schneider VA, Coorens M, Tjeerdsma-van Bokhoven JL, Posthuma G, van Dijk A, Veldhuizen EJ, et al. Imaging the Antistaphylococcal Activity of CATH-2: Mechanism of Attack and Regulation of Inflammatory Response. mSphere. 2017;2(6):e00370-17.

128. Schneider VA, Coorens M, Ordonez SR, Tjeerdsma-van Bokhoven JL, Posthuma G, Van Dijk A, et al. Imaging the antimicrobial mechanism (s) of cathelicidin-2. Scientific reports. 2016;6:32948.

129. Larrick JW, Hirata M, Zheng H, Zhong J, Bolin D, Cavaillon J-M, et al. A novel granulocyte-derived peptide with lipopolysaccharide-neutralizing activity. The Journal of Immunology. 1994;152(1):231-40.

130. Larrick JW, Hirata M, Balint RF, Lee J, Zhong J, Wright SC. Human CAP18: a novel antimicrobial lipopolysaccharide-binding protein. Infection and immunity. 1995;63(4):1291-7.

131. Yang D, Chen Q, Schmidt AP, Anderson GM, Wang JM, Wooters J, et al. LL-37, the neutrophil granule-and epithelial cell-derived cathelicidin, utilizes formyl peptide receptor-like 1 (FPRL1) as a receptor to chemoattract human peripheral blood neutrophils, monocytes, and T cells. Journal of Experimental Medicine. 2000;192(7):1069-74.

132. Zhang Z, Cherryholmes G, Chang F, Rose DM, Schraufstatter I, Shively JE. Evidence that cathelicidin peptide LL-37 may act as a functional ligand for CXCR2 on human neutrophils. European journal of immunology. 2009;39(11):3181-94.

133. Mookherjee N, Brown KL, Bowdish DM, Doria S, Falsafi R, Hokamp K, et al. Modulation of the TLRmediated inflammatory response by the endogenous human host defense peptide LL-37. The Journal of Immunology. 2006;176(4):2455-64.

134. Kandler K, Shaykhiev R, Kleemann P, Klescz F, Lohoff M, Vogelmeier C, et al. The anti-microbial peptide LL-37 inhibits the activation of dendritic cells by TLR ligands. International immunology. 2006;18(12):172936.

135. Morizane S, Yamasaki K, Mühleisen B, Kotol PF, Murakami M, Aoyama Y, et al. Cathelicidin antimicrobial peptide LL-37 in psoriasis enables keratinocyte reactivity against TLR9 ligands. Journal of Investigative Dermatology. 2012;132(1):135-43.

136. Davidson DJ, Currie AJ, Reid GS, Bowdish DM, MacDonald KL, Ma RC, et al. The cationic antimicrobial peptide LL-37 modulates dendritic cell differentiation and dendritic cell-induced $\mathrm{T}$ cell polarization. The Journal of Immunology. 2004;172(2):1146-56. 
137. van der Does AM, Beekhuizen H, Ravensbergen B, Vos T, Ottenhoff TH, van Dissel JT, et al. LL-37 directs macrophage differentiation toward macrophages with a proinflammatory signature. The journal of immunology. 2010;185(3):1442-9.

138. Nagaoka I, Tamura H, Hirata M. An antimicrobial cathelicidin peptide, human CAP18/LL-37, suppresses neutrophil apoptosis via the activation of formyl-peptide receptor-like 1 and P2X7. The Journal of Immunology. 2006;176(5):3044-52.

139. Van Dijk A, Molhoek EM, Veldhuizen EJ, Tjeerdsma-van Bokhoven JL, Wagendorp E, Bikker F, et al. Identification of chicken cathelicidin-2 core elements involved in antibacterial and immunomodulatory activities. Molecular immunology. 2009;46(13):2465-73.

140. Xiao Y, Herrera AI, Bommineni YR, Soulages JL, Prakash O, Zhang G. The central kink region of fowlicidin2 , an $\alpha$-helical host defense peptide, is critically involved in bacterial killing and endotoxin neutralization. Journal of Innate Immunity. 2009;1(3):268-80.

141. Bommineni YR, Pham GH, Sunkara LT, Achanta M, Zhang G. Immune regulatory activities of fowlicidin-1, a cathelicidin host defense peptide. Molecular immunology. 2014;59(1):55-63.

142. Coorens M, Schneider VA, de Groot AM, van Dijk A, Meijerink M, Wells JM, et al. Cathelicidins inhibit escherichia coli-induced tlr2 and tlr4 activation in a viability-dependent manner. The Journal of Immunology. 2017;199(4):1418-28.

143. Coorens M, van Dijk A, Bikker F, Veldhuizen EJ, Haagsman HP. Importance of endosomal cathelicidin degradation to enhance DNA-induced chicken macrophage activation. The journal of immunology. 2015;195(8):3970-7.

144. Cuperus T, van Dijk A, Matthijs MG, Veldhuizen EJ, Haagsman HP. Protective effect of in ovo treatment with the chicken cathelicidin analog D-CATH-2 against avian pathogenic E. coli. Scientific reports. 2016;6:26622.

145. Mookherjee N, Anderson MA, Haagsman HP, Davidson DJ. Antimicrobial host defence peptides: functions and clinical potential. Nature Reviews Drug Discovery. 2020. 



\section{Chapter 2}

\section{Avian pathogenic Escherichia coli infection of a chicken lung epithelial cell line}

Noëlle Mol$^{1 \$}$, Lianci Peng ${ }^{1 \$}$, Evelyne Esnault ${ }^{2}$, Pascale Quéré ${ }^{2}$, Henk P. Haagsman ${ }^{1}$ and Edwin J.A. Veldhuizen ${ }^{1 *}$

${ }^{1}$ Department of Biomolecular Health Sciences, Division of Infectious Diseases \& Immunology, Section of Molecular Host Defence, Faculty of Veterinary Medicine, Utrecht University, Utrecht, The Netherlands.

${ }^{2}$ INRA, Université François Rabelais de Tours, UMR 1282 Infectiologie et Santé Publique, 37380 Nouzilly, France

\$authors contributed equally.

Veterinary Immunology and Immunopathology (2019) 210:55-59

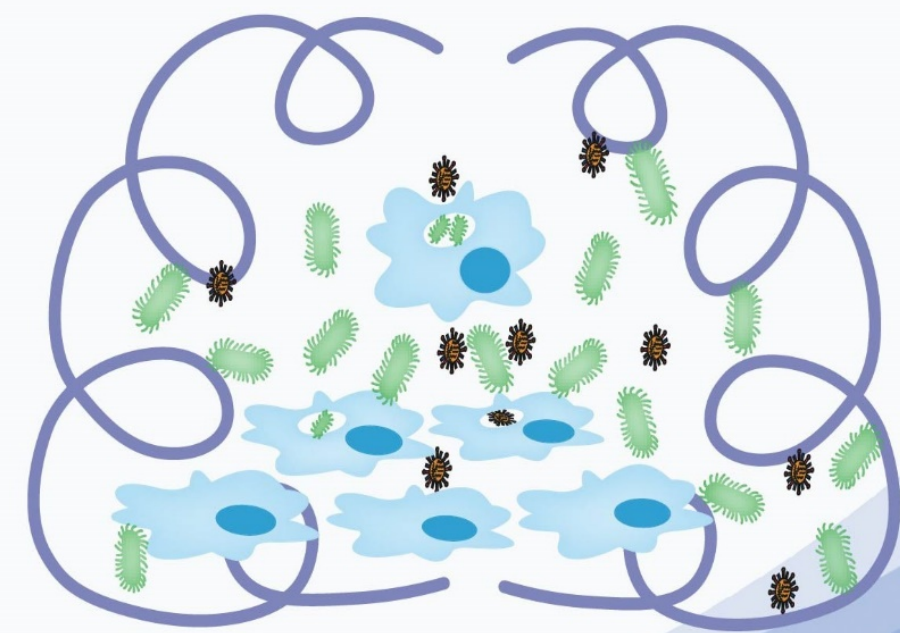




\begin{abstract}
Virulent strains of Escherichia coli (Avian Pathogenic E. coli: APEC) can cause initial infection of the respiratory tract in chickens potentially leading to systemic infection called colibacillosis, which remains a major cause of economic losses in the poultry industry. The role of epithelial lung cells as first targets of APEC and in initiating the innate immune response is unclear and was investigated in this study. APEC was able to adhere and subsequently invade cells from the chicken lung epithelial CLEC213 cell line exhibiting pneumocyte type II-like characteristics. Invasion was confirmed using confocal microscopy after infection with GFP-labelled APEC. Moreover, APEC infection resulted in a significant increase in IL-8 gene expression, a chemo-attractant of macrophages and heterophils. Gene expressions of interferon $\alpha$ and $\beta$ (IFN- $\alpha$ and IFN- $\beta$ ) were not significantly upregulated and chicken surfactant protein A (SP-A), also did not show a significant upregulation on either gene or protein level. The immune response of CLEC213 cells towards APEC was shown to be similar to stimulation with $E$. coli LPS. These results establish CLEC213 cells as a novel model system for studying bacterial infection of the lung epithelium and show that these cells may play a role in the initial innate response towards bacterial pathogens.
\end{abstract}




\section{Introduction}

Escherichia coli (E. coli) is a natural inhabitant of the chicken's intestinal tract and to a lesser extent also of the trachea. However, virulent strains of E. coli (Avian Pathogenic E. coli: APEC) can cause initial infection of the respiratory tract potentially leading to systemic infection and disease in chicken (1). Colibacillosis is currently a major cause of economic losses in the poultry industry, due to decreased hatching rates, egg production, growth and increased mortality (2). There is no highly effective vaccine available to protect against APEC mainly due to the diversity of APEC strains in the field, and therefore often antibioticbased treatment is required.

It is still unclear what makes an E. coli strain virulent in chickens. APEC strains from more than 6 serotypes have been identified often displaying multiple antibiotic resistance genes, but no clear systematic association with the APEC phenotype can be found (3). However the presence of 5 specific genes located on a the large colV virulence plasmid is found in approximately $70 \%$ of APEC strains (4). Nevertheless, a study comparing virulent and nonvirulent $E$. coli could actually not find significant differences in lung histology of infected chickens nor in induction of apoptotic activity in lung cells, indicating again the lack of a thorough understanding of what makes certain $E$. coli strains pathogenic in chicken (5).

APEC pathogenesis has been studied mainly through the use of experimental infection models (6-8). Upon infection, heterophils and macrophages are attracted to the site of infection where they interact with bacteria. Heterophils are the fastest responders to an $E$. coli infection appearing within $6 \mathrm{~h}$ post infection contributing to bacterial clearance by degranulation, and the release of antibacterial compounds (9). Phagocytosis of E. coli by macrophages has been observed in vivo and some studies actually correlates virulence genes of $E$. coli to resistance towards phagocytosis $(9,10)$. In a recent study from our group it was shown that chicken macrophages (HD11 cells) in vitro are capable of providing an immune response towards APEC comparable to non-pathogenic $E$. coli (11). Besides macrophages and heterophils, other leukocytes such as NK cells could also contribute significantly to the innate response towards $E$. coli, but not many studies are present on this subject.

The exact role of lung epithelial cells as first line cellular target initiating innate immune responses towards invading respiratory APEC has not been studied in the chicken. A few studies have described adhesion characteristics of APEC to primary cell cultures of type II pneumocytes derived from 14-day-old chicken embryos $(12,13)$, but more extensive studies on immune responses are hampered by the relative difficulty to isolate epithelial cells from tissues. However, recently a new chicken lung epithelial cell line (CLEC213 cells) was described that showed many characteristics of type II pneumocytes, including the presence of cilia, alkaline phosphatase activity, and importantly the presence of pulmonary surfactant 
protein A (SP-A) mRNA (a protein abundantly expressed by mammalian lung epithelial type II cells) (14). This cell line can be permissive to various chicken pathogens and is capable of developing a pro-inflammatory immune response, as was shown towards Influenza A viral infection and upon LPS stimulation $(14,15)$. In addition, CLEC213 cells were described as a novel chicken epithelial model system to study gametogony of Eimeria Tenella (16). However, except for a single study where the cell line was mainly used as a tool to determine the importance of the Salmonella T3SS secretion system (17), no bacterial infection studies with these cells have been performed. In this study we determined the interaction of APEC with these chicken epithelial cells. Invasion characteristics of APEC were determined, and the innate immune response of epithelial cells was measured and compared to stimulation of these cells by $E$. coli LPS.

\section{Methods and materials}

\section{Bacterial strains}

APEC 506 (O78, K80) isolated from chicken (18) was used in this study. Bacteria were cultured in Tryptic Soy Broth (TSB) and Tryptic Soy Agar (TSA) at $37^{\circ} \mathrm{C}$. For preparation of the green fluorescent protein (GFP)-expression APEC strain, the plasmid pWM1007 was transformed into APEC 506 (O78, K80) by electroporation using an Electro Cell Manipulator according to the manufacturer's instructions. GFP-expression APEC was cultured in the same condition as APEC (11).

\section{Chicken lung epithelial cells}

The chicken lung epithelial cell line CLEC213 (14) was maintained in a humidified $41{ }^{\circ} \mathrm{C}$ incubator with $5 \% \mathrm{CO}_{2}$ and cultured in advanced DMEM supplemented with $4 \%$ Fetal calf serum, glutamax (Thermo Fisher Scientific) and antibiotics (100 U penicillin/mL, $100 \mu \mathrm{g}$ streptomycin $/ \mathrm{mL}$ ). Aliquots of cell suspension were seeded into 12 well plates at $2 \times 10^{5}$ cells/well and cultured overnight to reach $100 \%$ confluence at about $4 \times 10^{5}$ cells/well before being used for assays described below.

\section{Bacterial adhesion and invasion assays}

Before CLEC213 cells were incubated with APEC, culture medium was removed and cells were washed twice with PBS. APEC was grown to log-phase in $3 \mathrm{~h}$. Bacteria were pelleted and resuspended in cell culture medium without antibiotics. Aliquots of $1 \mathrm{~mL}$ of bacterial suspension $\left(10^{6}-10^{8} \mathrm{CFU} / \mathrm{mL}\right)$ were added to each well. For association assays, the CLEC213 cells were incubated for 1, 2 and $3 \mathrm{~h}$ with APEC, washed three times with advanced DMEM medium (without supplements) and lysed in 1\% Triton X-100 in PBS at room temperature (RT) for $5 \mathrm{~min}$ to release the associated bacteria. The suspensions were serially diluted and 
$100 \mu 1$ of each dilution was plated on TSA (Oxoid Limited). From this, total cell-associated viable bacteria (both cell-adherent and intracellular) were calculated. For invasion assays, 1 $\mathrm{mL}$ of colistin at $250 \mu \mathrm{g} / \mathrm{ml}$ per well in advanced DMEM supplemented with Glutamax and 4\% FCS was added to the CLEC213 cultures for $1 \mathrm{~h}$ to kill the remaining extracellular bacteria. Then the cells were washed, treated with Triton X-100 and plated out as described above to enumerate the number of invaded, intracellular bacteria. The number of adhered bacteria was calculated as: number of cell-associated - number of intracellular bacteria. Experiments were performed in at least three independent experiments in duplicate.

\section{Metabolic activity}

Metabolic activity of CLEC 213 cells was determined by the WST-1 assay according to the manufacturer's instructions (Roche, Basel, Switzerland). Absorbance was measured after 30 min at $450 \mathrm{~nm}$ with a FLUOstar Omega microplate reader (BMG Labtech GmbH, Ortenberg, Germany) and was corrected for absorbance at $630 \mathrm{~nm}$. Non-infected control cells were defined as $100 \%$ mitochondrial activity.

\section{Gene expression}

CLEC213 cells were infected with $1 \mathrm{~mL}$ of $1 \times 10^{7} \mathrm{CFU} / \mathrm{mL}$ APEC $(\mathrm{MOI}=25)$ at $41{ }^{\circ} \mathrm{C}$ for $3 \mathrm{~h}$ and subsequently treated with $250 \mu \mathrm{g} / \mathrm{mL}$ colistin as described above, or were stimulated with several doses of LPS ranging from 0.1 to $50 \mathrm{mg} / \mathrm{mL}$ (LPS EB: from E. coli O111:B4, Invivogen, Toulouse, France). After 4 and $24 \mathrm{~h}$ of culture total RNA was extracted by Trizol reagent (Ambion, Carlsbad, CA) according to manufacturer's instructions. RNA (500 ng) was reverse transcribed using the iScript cDNA synthesis kit according to the manufacturer's instructions. Quantitative real time PCR was performed on a CFX Connect qPCR with CFX Manager 3.0 (Bio-Rad). Reactions were performed as follows: 3 min at $95{ }^{\circ} \mathrm{C} ; 40$ cycles: 10 s at $95{ }^{\circ} \mathrm{C}, 30 \mathrm{~s}$ at $60{ }^{\circ} \mathrm{C}$ and $30 \mathrm{~s}$ at $72{ }^{\circ} \mathrm{C}$. Relative gene expression levels were normalized against the expression levels of the house keeping genes GAPDH and 28S. Primer and probe sequences of the genes determined are depicted in Table 1.

\section{Griess assay}

To determine nitric oxide (NO) production, CLEC213 cells were incubated with APEC as described above for qPCR analysis. Subsequently nitrite, a stable metabolite of NO, was measured by the Griess assay in the cell culture supernatant as described before (11). 
Table 1. Primer and probe sequences for $q P C R$.

\begin{tabular}{lll}
\hline Gene & & $\mathbf{5} \rightarrow \mathbf{3}$ 'sequence \\
\hline GAPDH & Forward & GCCGTCCTCTCTGGCAAAG \\
& Reverse & GTAAACCATGTAGTTCAGATCGATGA \\
probe & AGTGGTGGCCATCAATGATCCC \\
IL-8 & Forward & GCCCTCCTCCTGGTTTCA \\
& Reverse & CGCAGCTCATTCCCCATCT \\
& probe & TGCTCTGTCGCAAGGTAGGACGCTG \\
cSP-A & Forward & GGAATGACAGAAGGTGCAATCAG \\
& Reverse & GCAATGTTGAGTTTATTAGCTACAAATG \\
IFN- $\alpha$ & probe & CCGGCTTGTTGTCTGCCAGTTTTAGTGG \\
& Forward & GACAGCCAACGCCAAAGC \\
Reverse & GTCGCTGCTGTCCAAGCATT \\
& probe & CCGGCTTGTTGTCTGCCAGTTTTAGTGG \\
& Rerward & CCTCCAACACCTCTTCAACATG \\
& probe & TGGCGTGTGCGGTCAAT \\
\hline
\end{tabular}

\section{Confocal microscopy}

CLEC 213 cells were seeded on a $12 \mathrm{~mm}$ coverslip in 24-well plate and incubated overnight at $41^{\circ} \mathrm{C}$ to reach confluence. Cells were subsequently infected with GFP-APEC (MOI=25) for $3 \mathrm{~h}$ at $41{ }^{\circ} \mathrm{C}$. After three wash steps with plain advanced DMEM, cells were fixed with $4 \%$ paraformaldehyde (PFA) in PBS for $30 \mathrm{~min}$ at RT. Subsequently, cells were incubated with $50 \mathrm{mM} \mathrm{NH}_{4} \mathrm{Cl}$ in PBS for 10 min at RT and blocked with 5\% normal goat serum in PBS for $1 \mathrm{~h}$ to block non-specific antibody staining. Then, cells were stained with $E$. coli antiserum (1:500) (19) for $1 \mathrm{~h}$. After the wash steps, cells were incubated with Donkey anti-Rabbit Alexa 647 (1:100) (Jackson ImmunoResearch,West Grove, PA, USA) for 1 h. Finally, cells were washed with PBS or water and mounted in FluoroSave. Slides were observed on a Leica SPE-II DMI4000 microscope with LAS-AF software (Leica, Wetzlar, Germany) using a 63× HCX PLAN APO OIL CS objective.

\section{Western blotting}

The presence of cSP-A in the CLEC213 protein fraction was measured by western blot using mouse anti-cSP-A antibodies as described before (20). In short, CLEC213 cells were infected with APEC or stimulated with LPS as described above, after which CLEC213 cell proteins and secreted proteins in the supernatant, were dissolved in denaturing SDS sample buffer and separated on a $10 \%$ SDS-PAGE gel. Subsequently, proteins were blotted on nitrocellulose (Protran BA83, Whatman, Sigma-Aldrich). cSP-A was detected using monoclonal mouse anti-cSP-A antibodies as $1^{\text {st }}$ antibody and horse radish peroxidase labelled Goat anti Mouse antibody (Sigma-Aldrich) as $2^{\text {nd }}$ antibody. 


\section{Statistical analyses}

Results are presented as the mean \pm standard error of the mean (SEM) of at least three independent experiments. Statistical significance was assessed with one-way ANOVA followed by the Tukey Post-Hoc test in Prism software, version 6.02 (Graphpad, La Jolla, CA, USA). Differences were considered statistically significant at $\mathrm{P} \leq 0.05$.

\section{Results and discussion}

\section{Adhesion and invasion characteristics of APEC}

Initial adherence studies were performed for $1 \mathrm{~h}$ with different densities of APEC $\left(1 \mathrm{~mL} 10^{6}\right.$ $-10^{8} \mathrm{CFU} / \mathrm{mL}$; corresponding to an MOI of 2.5, 25 and 250, respectively) as shown in Fig. 1A. Increased inoculum density resulted in an increased APEC adherence. If the adherence was expressed as percentage of the inoculum, the values correspond to approximately $7.5 \%$ for MOI 2.5 and 25, and $2.5 \%$ for the highest bacterial density (MOI 250). Based on this, an inoculum density of $10^{7} \mathrm{CFU} / \mathrm{mL}$ (MOI 25) was chosen for further studies.

The time-dependent adhesion and invasion of APEC to the CLEC213 cells is shown in Fig. $1 \mathrm{~B}$ and 1C. Adherence of APEC at the initial MOI 25 significantly increased over time from $1 \mathrm{~h}$ to $3 \mathrm{~h}$ of incubation, roughly corresponding to 6 bacteria adhering to one CLEC213 cell after $3 \mathrm{~h}\left(2.5 \times 10^{6} \mathrm{CFU} /\right.$ well vs $4 \times 10^{5}$ CLEC213 cells/well) (Fig. 1B). Invasion showed a similar trend towards higher number of invading bacteria with $4.5 \times 10^{4} \mathrm{CFU} /$ well after $3 \mathrm{~h}$ (Fig. 1C). This indicates that after $3 \mathrm{~h}$ less than $2 \%$ of adhered bacteria was able to invade CLEC213 cells. In addition, after removal or killing of extracellular bacteria, the number of invaded bacteria was followed over time. As shown in Fig. 1D, the viability of invaded bacteria actually decreased over time, indicating that invasion does not lead to rapid multiplication of APEC intracellularly. It is unclear if this could be a bacterial strain specific effect or whether CLEC213 cells can potentiate an efficient intracellular immune response against a broader range of (invaded) bacteria.

Studies with isolated cultured chicken type II pneumocytes have shown similar high adherence of APEC, causing cell damage and the loss of microvilli $(12,21)$, but invasion into type II cells was not determined. APEC was also able to adhere to chicken breast and human colorectal adenocarcinoma cells (HCT-8) cells indicating that the adhesion is not specific for pneumocytes (22). With respect to invasion characteristics of APEC, one study tested this on a chicken hepatocyte cell line and found it to be relatively high $(8 \%$ of the total adhered bacteria) but this number was much lower ( $0.2 \%)$ when tested on human type II cells (23). Overall this is the first study quantitively determining the time and density dependency of APEC adhesion and invasion of chicken lung epithelial cells. 

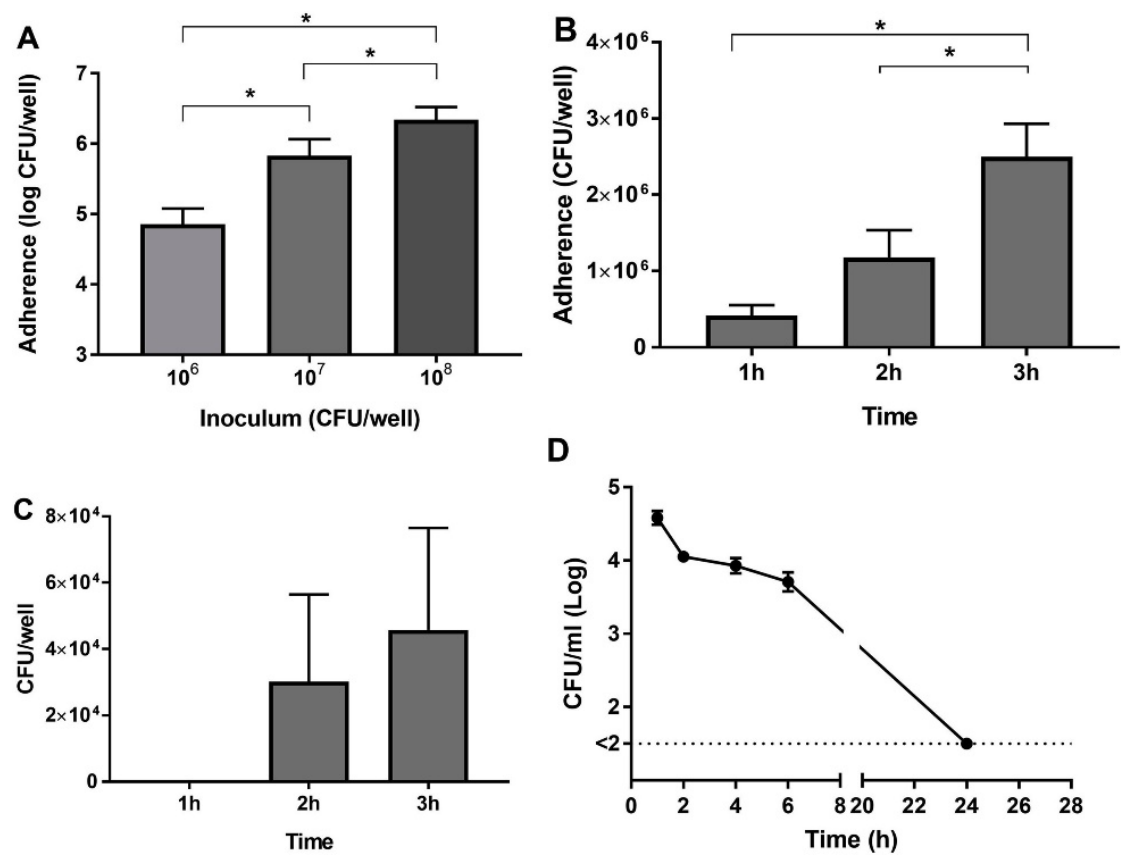

Fig 1. Adherence and invasion characteristics of APEC. (A) CLEC213 cells were incubated for $1 \mathrm{~h}$ with different densities of APEC. After washing of excess bacteria, associated bacteria were plated out and counted. (B) CLEC213 cells were incubated with $10^{7} \mathrm{CFU} / \mathrm{mL}$ for 1-3 h, associated bacteria were determined as in A. (C) CLEC213 cells were incubated with $10^{7} \mathrm{CFU} / \mathrm{mL}$ for 1-3 h, after which extracellular bacteria were killed with colistin. Intracellular bacteria were determined by colony counting. (D) CLEC213 cells were incubated with $10^{7} \mathrm{CFU} / \mathrm{mL}$ for $3 \mathrm{~h}$, after which extracellular bacteria were killed with colistin. Intracellular survival of APEC was followed in time, determined by colony counting. Data are shown as mean \pm SEM of at least 3 independent experiments for each group (in duplicate). * indicates significant difference $(\mathrm{P} \leq 0.05)$.

Next, confocal microscopy was used to confirm the presence of intracellular bacteria after APEC infection in CLEC213 cells. GFP-producing APEC was used to infect CLEC213 cells for $3 \mathrm{~h}$ after which an antiserum against $E$. coli was used to detect the remaining adherent bacteria. Since the CLEC213 cells were not permeabilized, only extracellular APEC was detected by the antibody. As shown in Fig. 2, extracellular and intracellular bacteria can clearly be distinguished. Double labelled (yellow) are available for the anti-E. coli antibody and thus are extracellular, while intracellular APEC are shielded from the antibody and only show the green GFP signal. Control experiments to validate the model without infection or with permeabilized cells showed no staining or only double labelled bacteria, respectively (data not shown). These results confirm that APEC can invade CLEC213 cells and shows that the more indirect results obtained by the adhesion/invasion assay was not caused by, for example, incomplete killing of extracellular bacteria. In addition, a similar experiment was performed with APEC treated with gentamicin. No intracellular localization of these non- 
viable bacteria was observed, showing that invasion is an active process. Our results correspond well to an earlier study where intracellular APEC in cultured chicken type II pneumocytes were detected using transmission electron microscopy (21), although this technique requires several fixation and staining steps, unlike our current confocal imaging set-up.

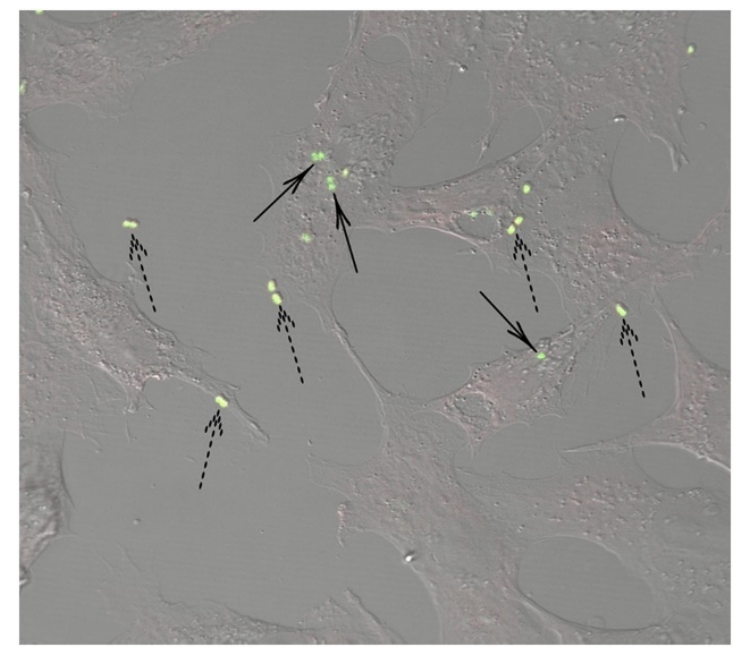

Fig 2. APEC is partially located intracellularly in CLEC213 cells. CLEC213 cells were incubated with GFPAPEC for $3 \mathrm{~h}$. Subsequently, cells were washed and fixed, but not permeabilized. Extracellular APEC were labeled with rabbit anti-E. coli serum and Donkey anti-Rabbit Alexa 647 (red). CLEC213 cells appeared grey under the DIC channel. Intracellular bacteria appear green (solid arrows) while extracellular bacteria appear as red/yellow (dotted arrows).

\section{Immune response upon APEC infection}

CLEC213 cells were infected for $3 \mathrm{~h}$ with APEC after which extracellular bacteria were killed by colistin. At 4 and $24 \mathrm{~h}$ post infection (hpi), gene expression of several immune genes was determined. The largest effect was observed for IL-8 which showed a 6-fold increase in gene expression at 4 hpi. Interestingly, IL-8 is known for its chemotactic activity for macrophages and heterophils in chicken (24), indicating that the observed increase in macrophages in APEC infections in vivo could be partially explained by the initial epithelial response after the first interaction with the respiratory epithelia. SP-A and IFN- $\alpha$ showed a tendency towards upregulation at 4 hpi but this difference did not reach statistical significance (Fig. $3 \mathrm{~A})$. Gene expression was also determined after $24 \mathrm{~h}$, but no significant upregulation could be observed anymore indicating a relatively short immune response for at least the genes studied. Metabolic activity (WST-1 assay) or viability (cell count, Trypan blue exclusion) of CLEC213 cells was not affected by bacterial infection after 4 and $24 \mathrm{~h}$ (data not shown). 


\section{LPS stimulation of CLEC 213 cells}

In the next set of experiments, CLEC213 cells were stimulated with the potent immune stimulant LPS derived from E. coli (Fig. 3B). At the highest concentration of LPS a similar response as seen for APEC infection was observed and comparable to earlier studies using this cell line using LPS (14) or influenza virus infection (15). IL-8 was significantly upregulated, while cSP-A showed a non-significant tendency towards an increased expression. The large variation in cSP-A expression observed in both LPS and APEC stimulation/infection of CLEC213 cells could be partially explained by the low absolute level of cSP-A gene expression. The levels of cSP-A mRNA measured in these experiments were close to or just beyond the detection limit where a linear concentration-response correlation was observed, likely causing lower reproducibility of the data. However, since this protein is highly expressed in type II cells (in mammals) it was still valuable to show. Besides gene expression, the presence of cSP-A was also tested on a protein level by western blot using cSP-A specific antibodies. No cSP-A could be detected in either bacterially infected, LPSstimulated or non-stimulated CLEC213 cells or their supernatants (data not shown). This apparent lack of detectable cSP-A in CLEC213 cells could indicate that they are a different cell type than surfactant producing cells in the chicken lung, or that these cells require a different stimulus in vitro to produce cSP-A. Expression of cSP-A was expected in CLEC213 cells, based on the presence of lamellar bodies which have been detected in long-term cultures (14), however the number remains much lower compared to what can be observed in the chicken lung by electron microscopy (25). In addition, lamellar bodies are not necessarily related to pulmonary surfactant synthesis, since they represent a general storage form of secretory lipids in multiple cell types (26).
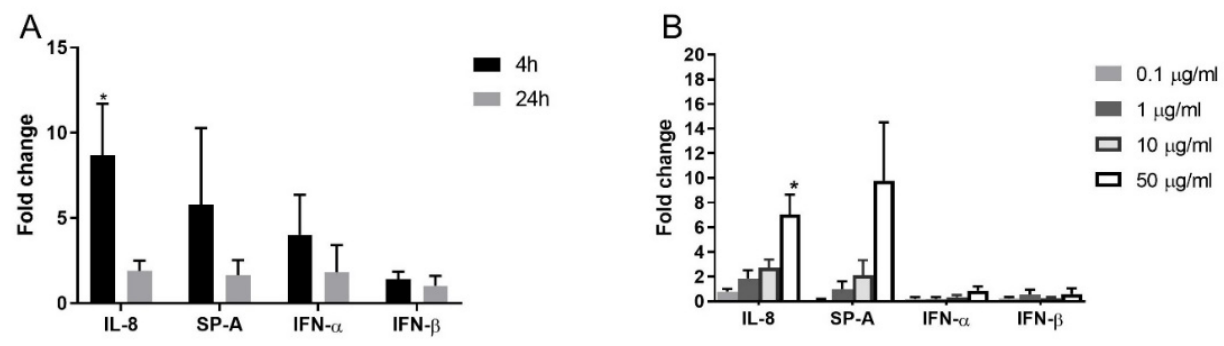

Fig 3. Immune response of CLEC213 cells. (A) CLEC213 cells were incubated with $10^{7} \mathrm{CFU} / \mathrm{mL}$ for $3 \mathrm{~h}$, after which non-associated bacteria were washed away. At 4 and 24 hpi mRNA was isolated and quantitative PCR was used to determine gene expression of selected genes. (B) CLEC213 cells were incubated with E. coli LPS at the indicated concentrations for $4 \mathrm{~h}$. Gene expression was determined using qPCR. Data are shown $\pm \mathrm{SEM}$ of at least three independent experiments for each group (in duplicate). $*$ indicates significant difference $(\mathrm{P} \leq 0.05)$. 
In general, it is worthwhile to realize that in birds, there is not a clear distinction into only two types of alveolar epithelial cells as found in mammals. In the latter, alveoli contain elongated type I cells that are involved in gas exchange, while cuboidal type II cells contain secretory vesicles in which pulmonary surfactant is stored as surfactant-protein rich lamellar bodies. On the contrary, in birds besides granular secretory cells also squamous atrial and squamous respiratory cells (and squamous intermediate cells) are observed. Secretion of surfactant like material is not limited to the granular cells since also the squamous cells secrete a trilaminar substance that covers the epithelium (25, 27). Although immunohistochemistry has shown the presence of cSP-A in specific atrial cells (20), while also another antibody CVI-ChNL 74-3 was described to recognize secretory type II cells (28), it should possibly be concluded that the simple classification in epithelial type I and type II cells is convenient, but oversimplified when used for chicken lungs.

Finally, besides gene expression, also the NO production by CLEC213 cells after LPS stimulation was measured. Although NO production is a common feature for (stimulated) macrophages, the current lack of knowledge on the exact lung epithelial immune defense prompted us to check this. As expected, NO levels were low irrespective of LPS concentration (1-50 mg/mL) or duration of stimulation (4-24 h) (data not shown).

Overall, this study indicates that CLEC213 cells are a valuable tool to determine host pathogen interaction in the chicken lung, and can help in understanding the host response towards bacterial infections.

\section{Acknowledgements}

The authors would like to thank Richard Wubbolts of the Center for Cell Imaging (Faculty of Veterinary Medicine, Utrecht University) for his help with the confocal microscopy experiments. This work was supported by a personal fellowship from the China Scholarship Council (CSC) to Lianci Peng. 


\section{References}

1. Dziva F, Stevens MP. Colibacillosis in poultry: unravelling the molecular basis of virulence of avian pathogenic Escherichia coli in their natural hosts. Avian Pathol. 2008;37(4):355-66.

2. Zhuang QY, Wang SC, Li JP, Liu D, Liu S, Jiang WM, et al. A clinical survey of common avian infectious diseases in China. Avian Dis. 2014;58(2):297-302.

3. Guabiraba R, Schouler C. Avian colibacillosis: still many black holes. FEMS Microbiol Lett. 2015;362(15):fnv118.

4. Schouler C, Schaeffer B, Bree A, Mora A, Dahbi G, Biet F, et al. Diagnostic strategy for identifying avian pathogenic Escherichia coli based on four patterns of virulence genes. J Clin Microbiol. 2012;50(5):1673-8.

5. Horn F, Correa AM, Barbieri NL, Glodde S, Weyrauch KD, Kaspers B, et al. Infections with avian pathogenic and fecal Escherichia coli strains display similar lung histopathology and macrophage apoptosis. PLoS One. 2012;7(7):e41031.

6. Antao EM, Glodde S, Li G, Sharifi R, Homeier T, Laturnus C, et al. The chicken as a natural model for extraintestinal infections caused by avian pathogenic Escherichia coli (APEC). Microb Pathog. 2008;45(56):361-9.

7. Matthijs MG, Ariaans MP, Dwars RM, van Eck JH, Bouma A, Stegeman A, et al. Course of infection and immune responses in the respiratory tract of IBV infected broilers after superinfection with E. coli. Vet Immunol Immunopathol. 2009;127(1-2):77-84.

8. Matthijs MGR, Nieuwenhuis JF, Dwars RM. Signs Indicating Imminent Death in Escherichia coli-Infected Broilers. Avian Dis. 2017;61(3):316-24.

9. Pourbakhsh SA, Boulianne M, Martineau-Doize B, Fairbrother JM. Virulence mechanisms of avian fimbriated Escherichia coli in experimentally inoculated chickens. Vet Microbiol. 1997;58(2-4):195-213.

10. Mellata M, Dho-Moulin M, Dozois CM, Curtiss R, 3rd, Lehoux B, Fairbrother JM. Role of avian pathogenic Escherichia coli virulence factors in bacterial interaction with chicken heterophils and macrophages. Infect Immun. 2003;71(1):494-503.

11. Peng L, Matthijs MGR, Haagsman HP, Veldhuizen EJA. Avian pathogenic Escherichia coli-induced activation of chicken macrophage HD11 cells. Dev Comp Immunol. 2018;87:75-83.

12. Zhang LY, Lv S, Wu SC, Guo X, Xia F, Hu XR, et al. Inhibitory effects of alpha-cyperone on adherence and invasion of avian pathogenic Escherichia coli O78 to chicken type II pneumocytes. Vet Immunol Immunopathol. 2014;159(1-2):50-7.

13. Peng LY, Yuan M, Cui ZQ, Wu ZM, Yu ZJ, Song K, et al. Rutin inhibits quorum sensing, biofilm formation and virulence genes in avian pathogenic Escherichia coli. Microb Pathog. 2018;119:54-9.

14. Esnault E, Bonsergent C, Larcher T, Bed'hom B, Vautherot JF, Delaleu B, et al. A novel chicken lung epithelial cell line: characterization and response to low pathogenicity avian influenza virus. Virus Res. 2011;159(1):3242. 
15. Meyer L, Leymarie O, Chevalier C, Esnault E, Moroldo M, Da Costa B, et al. Transcriptomic profiling of a chicken lung epithelial cell line (CLEC213) reveals a mitochondrial respiratory chain activity boost during influenza virus infection. PLoS One. 2017;12(4):e0176355.

16. Bussiere FI, Niepceron A, Sausset A, Esnault E, Silvestre A, Walker RA, et al. Establishment of an in vitro chicken epithelial cell line model to investigate Eimeria tenella gamete development. Parasit Vectors. 2018;11(1):44.

17. Rossignol A, Roche SM, Virlogeux-Payant I, Wiedemann A, Grepinet O, Fredlund J, et al. Deciphering why Salmonella Gallinarum is less invasive in vitro than Salmonella Enteritidis. Vet Res. 2014;45:81.

18. Cuperus T, van Dijk A, Matthijs MG, Veldhuizen EJ, Haagsman HP. Protective effect of in ovo treatment with the chicken cathelicidin analog D-CATH-2 against avian pathogenic E. coli. Sci Rep. 2016;6:26622.

19. Dwars RM, Matthijs MG, Daemen AJ, van Eck JH, Vervelde L, Landman WJ. Progression of lesions in the respiratory tract of broilers after single infection with Escherichia coli compared to superinfection with E. coli after infection with infectious bronchitis virus. Vet Immunol Immunopathol. 2009;127(1-2):65-76.

20. Zhang W, Cuperus T, van Dijk A, Skjodt K, Hansen S, Haagsman HP, et al. Developmental regulation of chicken surfactant protein A and its localization in lung. Dev Comp Immunol. 2016;61:80-7.

21. Zhang LY, Yi PF, Guo X, Wu SC, Fu YX, Zhang C, et al. Astragaloside IV Inhibits the Inflammatory Injury of Chicken Type II Pneumocytes Induced by Avian Pathogenic Escherichia coli. Inflammation. 2016;39(5):1660-9.

22. LeStrange K, Markland SM, Hoover DG, Sharma M, Kniel KE. An evaluation of the virulence and adherence properties of avian pathogenic Escherichia coli. One Health. 2017;4:22-6.

23. Chanteloup NK, Porcheron G, Delaleu B, Germon P, Schouler C, Moulin-Schouleur M, et al. The extraintestinal avian pathogenic Escherichia coli strain BEN2908 invades avian and human epithelial cells and survives intracellularly. Vet Microbiol. 2011;147(3-4):435-9.

24. Poh TY, Pease J, Young JR, Bumstead N, Kaiser P. Re-evaluation of chicken CXCR1 determines the true gene structure: CXCLi1 (K60) and $\mathrm{CXCLi} 2$ (CAF/interleukin-8) are ligands for this receptor. J Biol Chem. 2008;283(24):16408-15.

25. Bodi I, Kocsis K, Benyeda Z, Fejszak N, Molnar D, Nagy N, et al. Dual secretion locations on type II cells in the avian lung suggest local as well as general roles of surfactant. J Morphol. 2016;277(8):1062-71.

26. Schmitz G, Muller G. Structure and function of lamellar bodies, lipid-protein complexes involved in storage and secretion of cellular lipids. J Lipid Res. 1991;32(10):1539-70.

27. Scheuermann DW, Klika E, De Groodt-Lasseel MH, Bazantova I, Switka A. An electron microscopic study of the parabronchial epithelium in the mature lung of four bird species. Anat Rec. 1997;249(2):213-25.

28. Kocsis K, Benyeda Z, Bodi I, Molnar D, Nagy N, Fejszak N, et al. Chicken dendritic cells and type II pneumocytes express a common intracellular epitope. Br Poult Sci. 2012;53(3):397-400. 



\section{Chapter 3}

\section{Avian pathogenic Escherichia coli-induced activation of chicken macrophage HD11 cells}

Lianci Peng ${ }^{1}$, Mieke G.R. Matthijs ${ }^{2}$, Henk P. Haagsman ${ }^{1}$, Edwin J.A. Veldhuizen ${ }^{1 *}$

${ }^{1}$ Department of Biomolecular Health Sciences, Division of Infectious Diseases \& Immunology, Section of Molecular Host Defence, Faculty of Veterinary Medicine, Utrecht University, Utrecht, The Netherlands.

${ }^{2}$ Department of Farm Animal Health, Faculty of Veterinary Medicine, Utrecht University, Utrecht, The Netherlands.

Developmental \& Comparative Immunology (2018) 87:75-83

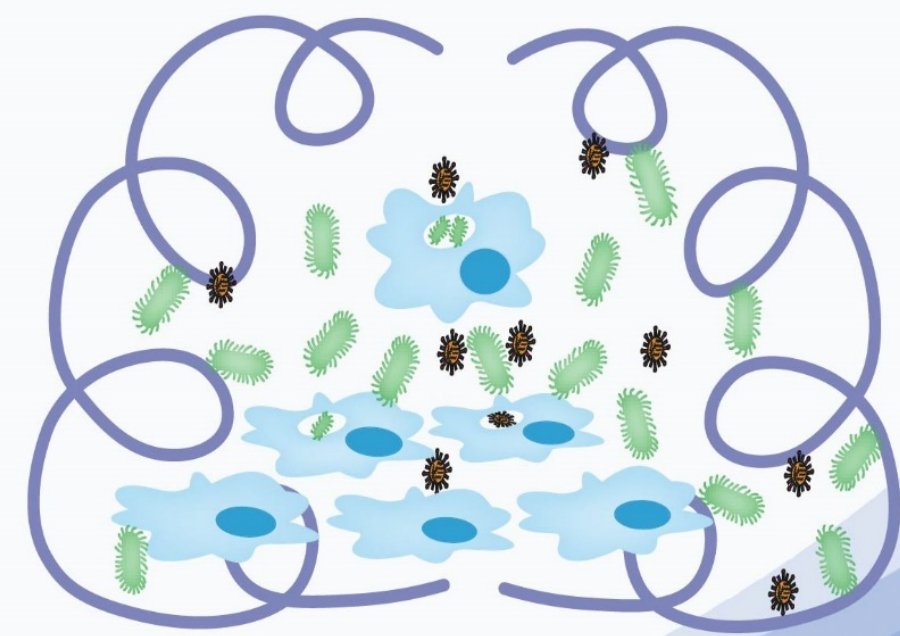




\begin{abstract}
Avian pathogenic Escherichia coli (APEC) can cause severe respiratory diseases in poultry. The initial interaction between APEC and chicken macrophages has not been characterized well and it is unclear how effective chicken macrophages are in neutralizing APEC. Therefore, the effect of APEC on activation of chicken macrophage HD11 cells was studied. Firstly, the effect of temperature $\left(37 \mathrm{vs} 41^{\circ} \mathrm{C}\right)$ on phagocytosis of APEC by HD11 cells was determined. The results showed that APEC was more susceptible to being phagocytosed by HD11 cells at $41{ }^{\circ} \mathrm{C}$ than $37^{\circ} \mathrm{C}$. Subsequently, it was shown that HD11 cells have the capacity to kill APEC. In addition, HD11 cells produced nitric oxide (NO) at $18 \mathrm{~h}$ post infection and a strong increase in the gene expression of IL-8, IL-6, IL-1 $\beta$ and IL-10 was detected, while IFN- $\beta$ gene expression remained unaffected. Finally, it was shown that the response of HD11 was partially dependent on viability of APEC since stimulation of HD11 cells with heat-killed APEC resulted in a reduced gene expression level of these cytokines. In conclusion, APEC induces an effector response in chicken macrophages by enhanced NO production and cytokines gene expression.
\end{abstract}




\section{Introduction}

Avian pathogenic Escherichia coli (APEC) strains can cause severe infections in poultry, such as omphalitis, salpingitis, cellulitis and respiratory tract infections $(1,2)$. In all of these infections, the bacteria can enter the bloodstream and become systemic resulting in colibacillosis $(2,3)$. Nowadays, avian colibacillosis is one of main causes leading to mortality and morbidity in poultry resulting in huge economic losses in the poultry industry (4). So far, there is no highly effective vaccination to protect against APEC strains mainly due to the diversity of APEC strains in the field. Treatment of APEC infection mainly relies on antibiotics, but the increasing emergence of drug resistance makes treatment less successful.

An APEC infection originally starts in the respiratory tract, crosses to the blood stream and can subsequently infect internal organs causing septicemia (5). In the last few years, APEC pathogenesis to the host has been studied through the use of experimental infection models (6-8) and identification of virulence genes (9-12). Furthermore, APEC superinfection with infectious bronchitis virus infection leads to severe pathogenesis in the respiratory tracts as virus damages the respiratory mucosa and facilitates APEC colonization (2). Despite the importance of APEC pathogenesis, the knowledge about APEC invasion and interactions with host cells in chicken is limited and poorly understood.

In order to respond to a microbial infection, host innate immune cells are activated by interaction with (parts of) the pathogen. Activation of these immune cells subsequently leads to activation of intracellular signal pathways resulting in production of cytokines and microbial killing (13). Macrophages are one of the first responder innate cells upon a new infection, as seen in infection models where APEC infection causes a quick increase in the number of macrophages (14). They can phagocytose bacteria and subsequently produce multifunctional compounds including reactive oxygen species (ROS), nitric oxide (NO) and cytokines to kill the infectious microorganisms (15-17) and signal to other immune cells to establish an appropriate response to the infection.

A number of in vitro studies have shown phagocytosis and immune responses of chicken macrophages upon challenge with different bacterial strains, using primary macrophages, or chicken macrophage cell lines (18-21). Although most bacteria tested are phagocytosed by macrophages, some bacteria such as Staphylococcus aureus, can still escape from macrophages through the activation of caspase-3 followed by macrophage cell death (22). However, the role of macrophages in controlling APEC infection and the interaction between APEC and macrophages in chickens is less studied and remains mostly unclear. 
In this study, we investigated the phagocytic capacity of HD11 macrophages towards APEC and the response towards infection as a first step towards understanding role of chicken macrophages in APEC infection.

\section{Materials and methods}

\section{Bacterial strains}

APEC strain (O78, K80) was isolated from chicken (23). Salmonella Enteritidis (strain, 13368) was cultured in Tryptic Soy Broth (TSB) and Tryptic Soy Agar (TSA) at $37^{\circ} \mathrm{C}$. Heatkilled bacteria were prepared by incubating the bacterial suspension at $75^{\circ} \mathrm{C}$ for $15 \mathrm{~min}$; viability was checked by plating out heat treated bacteria on TSA plates. For preparation of the green fluorescent protein (GFP) - expressing APEC strain, the plasmid PWM1007 was transformed into APEC by electroporation using an Electro Cell Manipulator according to the manufacturer's instructions. GFP-expression APEC was cultured in the same condition with APEC.

\section{Chicken macrophages, HD11 cells}

The chicken macrophage-like cell line (24), HD11, was maintained in a humidified $41{ }^{\circ} \mathrm{C}$ incubator with 5\% $\mathrm{CO}_{2}$ and cultured in RPMI 1640-glutamax supplemented with $10 \%$ FCS and antibiotics (100 U penicillin $/ \mathrm{mL}$ and $100 \mu \mathrm{g}$ streptomycin $/ \mathrm{mL}$ ). Aliquots of cell suspension were seeded into each well at $2.5 \times 10^{5}$ cells/well for a 24 -well plate and $5.0 \times 10^{5}$ cells/well for 12-well plates and cultured overnight before being used for assays described below.

\section{Effects of temperature on the growth of APEC}

Log-phase bacteria were diluted to $1 \times 10^{5} \mathrm{CFU} / \mathrm{mL}$ in RPMI 1640-glutamax supplemented with $10 \%$ FCS. Aliquots of this bacterial suspension were added to 2 new tubes and incubated at $37^{\circ} \mathrm{C}$ and $41^{\circ} \mathrm{C}$, respectively. The $\mathrm{OD}_{620 \mathrm{~nm}}$ was measured at $0-6 \mathrm{~h}$ to determine kinetics of bacterial growth.

\section{Effects of temperature on HD11 phagocytic capacity and cell viability}

Before HD11 cells were incubated with APEC, culture medium was removed and cells were washed once with RPMI 1640-glutamax. Aliquots of $1 \mathrm{~mL}$ of bacterial suspension $\left(10^{6}\right.$ $\mathrm{CFU} / \mathrm{mL}$ ) were added to each well with four replicate wells for 24 -well plates, at a multiplicity of infection (MOI) of 2. Cells were incubated for 1, 2, 3 and $4 \mathrm{~h}$ at $37{ }^{\circ} \mathrm{C}$ and $41^{\circ} \mathrm{C}$. After incubation, the bacterial suspension was removed and HD11 cells were washed three times with RPMI 1640-glutamax. Then, RPMI 1640-glutamax containing $500 \mu \mathrm{g} / \mathrm{mL}$ gentamicin was added to each well in order to kill all extracellular, non-phagocytosed 
bacteria and the plates were placed back at $37^{\circ} \mathrm{C}$ and $41^{\circ} \mathrm{C}$ for $1 \mathrm{~h}$. At each appropriate time point (2, 3, 4 and $5 \mathrm{~h}$, after gentamicin treatment), infected cells in three wells were washed three times with RPMI 1640-glutamax and lysed by $1 \mathrm{~mL} 0.5 \%$ Triton X-100. After lysis, dilution series of cells were plated on TSA plates and incubated at $37^{\circ} \mathrm{C}$ for $24 \mathrm{~h}$ to quantify viable bacteria. Cells in the fourth well received $0.1 \mathrm{~mL} 0.01 \%$ trypsin-EDTA and were stained with trypan blue to quantify cell viability.

\section{HD11 killing activity}

Before incubation with APEC, HD11 cells were washed once with RPMI 1640-glutamax. Aliquots of $1 \mathrm{~mL}$ of bacterial suspensions $\left(1 \times 10^{6} \mathrm{CFU} / \mathrm{mL}\right)$ were added to each well, with four replicate wells for 24-well plates at a MOI of 2 and incubated for $3 \mathrm{~h}$ at $41^{\circ} \mathrm{C}$. At $3 \mathrm{~h}$, the bacterial suspension was removed and cells were washed three times with RPMI 1640glutamax and replaced with RPMI 1640-glutamax containing $500 \mu \mathrm{g} / \mathrm{mL}$ gentamicin for $1 \mathrm{~h}$. After this high-gentamicin treatment, medium was replaced by cell medium containing 62.5 $\mu \mathrm{g} / \mathrm{mL}$ gentamicin and cells were incubated back at $41^{\circ} \mathrm{C}$. At each time point $(4,5,6,7$ and $8 \mathrm{~h}$ ), cells in three wells were washed three times with RPMI 1640-glutamax and lysed by 1 $\mathrm{mL} 0.5 \%$ Triton $\mathrm{X}-100$. Then, suspensions were serially diluted, plated on TSA plates and incubated at $37^{\circ} \mathrm{C}$ for $24 \mathrm{~h}$ to quantify viable intracellular bacteria. Cells in the fourth well received $0.1 \mathrm{~mL} 0.01 \%$ trypsin-EDTA and were stained with trypan blue to quantify cell viability.

\section{Nitric oxide (NO) production assay}

Nitrite, a stable metabolite of NO, produced by activated macrophages was measured by the Griess assay (25). HD11 cells were incubated with live or heat-killed bacteria at $41{ }^{\circ} \mathrm{C}$ for 3 $\mathrm{h}$ and treated with $500 \mu \mathrm{g} / \mathrm{mL}$ gentamicin for $15 \mathrm{~h}$. After $18 \mathrm{~h}$ incubation, aliquots of $50 \mu \mathrm{L}$ supernatant were transferred to the wells of a 96-well flat bottom plate. Fifty $\mu \mathrm{L} 1 \%$ sulfanilamide (Merck, Darmstadt, Germany) was added in each well mixed with $50 \mu \mathrm{L} 0.1 \%$ $\mathrm{N}$-(1-naphthyl) ethylenediamine dihydrochloride (VWR) at room temperature for $5 \mathrm{~min}$. The nitrite concentration was determined by measuring optical density at $550 \mathrm{~nm}$. Sodium nitrite (Sigma) was used as a standard to accurately determine the nitrite concentration in the cell supernatant.

\section{Gene expression}

HD11 cells were incubated with APEC at $41^{\circ} \mathrm{C}$ for $3 \mathrm{~h}$ and subsequently treated with 500 $\mu \mathrm{g} / \mathrm{mL}$ gentamicin for $1 \mathrm{~h}$ as described above. After $4 \mathrm{~h}$ incubation, total RNA was extracted by Trizol (Ambion, Carlsbad, CA) reagent according to manufacturer's instructions. RNA (500 ng) was reverse transcribed by the iScript cDNA synthesis kit (Bio-Rad, Veenendaal, the Netherlands) according to the manufacturer's instructions. Primers and probes were 
designed and produced by Eurogentec (Seraing, Belgium) (Table 1). Quantitative real time PCR was performed on a CFX Connect qPCR with CFX Manager 3.0 (Bio-Rad). Reactions were performed as follows: $3 \mathrm{~min}$ at $95{ }^{\circ} \mathrm{C} ; 40$ cycles: $10 \mathrm{~s}$ at $95{ }^{\circ} \mathrm{C}, 30 \mathrm{~s}$ at $60{ }^{\circ} \mathrm{C}$ and $30 \mathrm{~s}$ at $72{ }^{\circ} \mathrm{C}$. Relative gene expression levels were normalized against the expression levels of the house keeping genes GAPDH and $28 \mathrm{~S}$.

Table 1: Primer and probe sequences for $\mathrm{qPCR}$

\begin{tabular}{|c|c|c|}
\hline Gene & & $5 ' \rightarrow 3$ 'sequence \\
\hline \multirow[t]{3}{*}{ GAPDH } & Forward & GTCAACCATGTAGTTCAGATCGATGA \\
\hline & Reverse & GCCGTCCTCTCTGGCAAAG \\
\hline & Probe & AGTGGTGGCCATCAATGATCCC \\
\hline \multirow[t]{3}{*}{$28 S$} & Forward & GACGACCGATTTGCACGTC \\
\hline & Reverse & GGCGAAGCCAGAGGAAA \\
\hline & Probe & AGGACCGCTACGGACCTCCACCA \\
\hline \multirow[t]{3}{*}{ IFN- $\beta$} & Forward & ССТССААСАССТСТТСААСАCG \\
\hline & Reverse & TGGCGTGTGCGGTCAAT \\
\hline & Probe & AGCAGCCCACACACTCCAAAACACT \\
\hline \multirow[t]{3}{*}{ 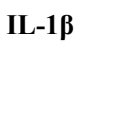 } & Forward & GCTCTACTAGTCGTGTGTGATGAG \\
\hline & Reverse & TGTCGATGTCCCGCATGA \\
\hline & Probe & CCACACTGCAGCTGGAGGAAGCC \\
\hline \multirow[t]{3}{*}{ IL-6 } & Forward & GTCGAGTCTCTGTGCTAC \\
\hline & Reverse & GTCTGGGATGACCACTTC \\
\hline & Probe & ACGATCCGGCAGATGGTGA \\
\hline \multirow[t]{3}{*}{ IL-8 } & Forward & GCCCTCCTCCTGGTTTCA \\
\hline & Reverse & CGCAGCTCATTCCCCATCT \\
\hline & Probe & TGCTCTGTCGCAAGGTAGGACGCTG \\
\hline \multirow[t]{3}{*}{ IL-10 } & Forward & CATGCTGCTGGGCCTGAA \\
\hline & Reverse & CGTCTCCTTGATCTGCTTGATG \\
\hline & Probe & CGACGATGCGGCGCTGTCA \\
\hline
\end{tabular}

\section{Confocal microscopy}

HD1 1 cells were seeded on a $12 \mathrm{~mm}$ coverslip in 24-well plate and incubated overnight. Cells were incubated with GFP-APEC for $3 \mathrm{~h}$ at $41{ }^{\circ} \mathrm{C}$ as described previously. After three wash steps with RPMI 1640-glutamax, cells were fixed with 4\% paraformaldehyde (PFA) in PBS for $30 \mathrm{~min}$ at room temperature (RT). Subsequently, cells were incubated with $50 \mathrm{mM} \mathrm{NH}_{4} \mathrm{Cl}$ in PBS for 10 min at RT and blocked with 5\% normal goat serum in PBS for $1 \mathrm{~h}$. Then, cells were stained with E. coli antiserum (23) (1:500) for $1 \mathrm{~h}$. After the wash steps, cells were incubated with Donkey anti-Rabbit Alexa 647 (Jackson ImmunoResearch, West Grove, PA, USA) (1:100) for $1 \mathrm{~h}$. Finally, cells were washed with PBS or water and mounted in FluoroSave. Slides were observed on a Leica SPE-II DMI4000 microscope with LAS-AF software (Leica, Wetzlar, Germany) using a $63 \times$ HCX PLAN APO OIL CS objective. 


\section{Statistical analysis}

Data are represented as mean \pm SEM of three independent experiments for each group $(n=3)$ and were analyzed by a T-test for two groups or by one-way ANOVA with post-hoc t-test for more than two groups. $\mathrm{p} \leq 0.05$ were considered significant. Bio-Rad CFX Manager 3.0 software was used for qPCR data analysis. All the graphs were made using GraphPad Prism ${ }^{\circledR}$ 5.0 .

\section{Results}

\section{Effect of temperature on the growth of $E$. coli}

It is well known that the optimal culture temperature of some bacterial species is $37^{\circ} \mathrm{C}$. However, enteric bacteria are specifically adapted to their hosts' body temperature. Since a chicken's body temperature is close to $41^{\circ} \mathrm{C}$, we determined whether the temperature can affect the growth of APEC. For this, two E. coli strains (APEC and K88) were simultaneously cultured at $37^{\circ} \mathrm{C}$ and $41^{\circ} \mathrm{C}$. As shown in Fig. 1, both E. coli strains reached the logarithmic phase faster at $41^{\circ} \mathrm{C}$ than $37^{\circ} \mathrm{C}$, resulting in higher OD values at $2 \mathrm{~h}$ and $3 \mathrm{~h}$. Interestingly, at $5 \mathrm{~h}$ and $6 \mathrm{~h}$, the final OD of K88 was significantly lower at $41^{\circ} \mathrm{C}$ compared to $37^{\circ} \mathrm{C}$.
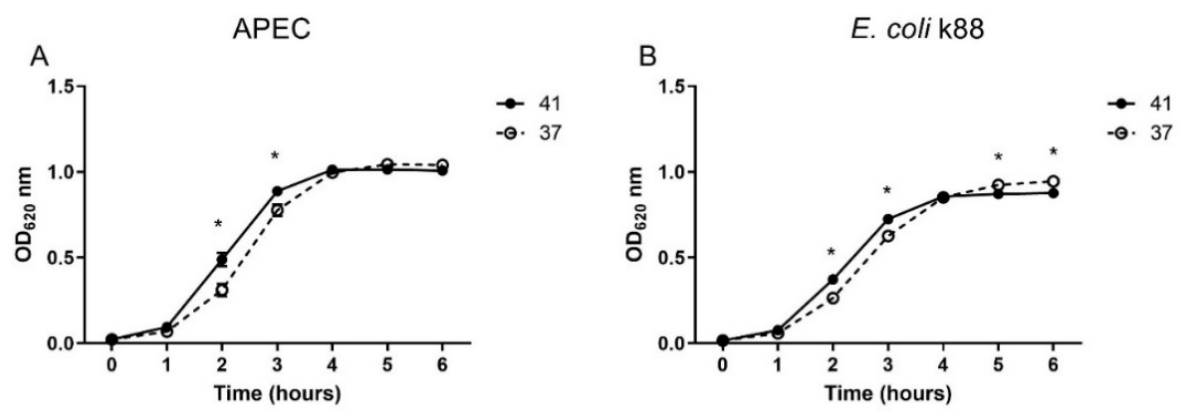

Fig 1. Temperature dependency of growth of $\boldsymbol{E}$. coli strains. (A) APEC. (B) E. coli k88. Data are shown as mean \pm SEM of three independent experiments (in triplicate per experiment) for each group $(\mathrm{n}=3)$. * indicates significant difference $(\mathrm{P} \leq 0.05)$ between $41^{\circ} \mathrm{C}$ and $37^{\circ} \mathrm{C}$ for a single time point using a student's T-test.

\section{Effect of temperature on phagocytic capacity and viability of HD11 cells}

The effect of temperature and incubation time on the phagocytic capacity of HD11 cells was tested. HD11 cells were incubated with APEC at $37{ }^{\circ} \mathrm{C}$ and $41{ }^{\circ} \mathrm{C}$ and the number of intracellular bacteria was determined after 1-5 h. As shown in Fig. 2A, the number of bacteria increased over time, and at all time points more bacteria were phagocytosed at $41^{\circ} \mathrm{C}$. In the same experiment, viability of HD11 cells after the infection was tested with trypan blue. No significant reduction in viability of HD11 was observed (Fig. 2B) at any time point. Based 
on these results, an incubation time of $4 \mathrm{~h}$ at $41^{\circ} \mathrm{C}$ was chosen as the optimal assay condition for subsequent experiments.
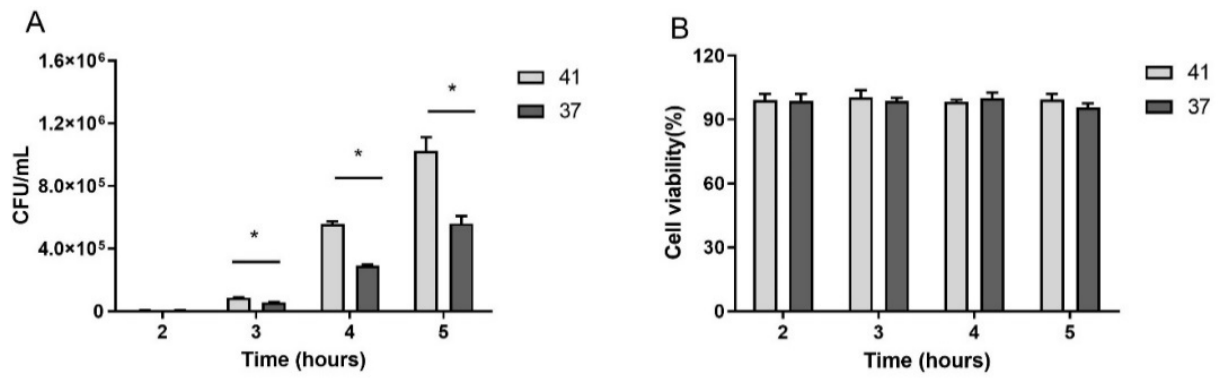

Fig 2. Temperature dependency of phagocytosis of APEC by HD11 cells. (A) Number of phagocytosed APEC in HD1 1 cells at $2-5 \mathrm{~h}$ post-incubation at $37^{\circ} \mathrm{C}$ and $41{ }^{\circ} \mathrm{C}$. (B) Viability of HD11 cells at 2-5 h post incubation. Data are shown as mean \pm SEM of three independent experiments for each group (in triplicate per experiment). * indicates significant difference $(\mathrm{P} \leq 0.05)$ in bacterial number between $37{ }^{\circ} \mathrm{C}$ and $41{ }^{\circ} \mathrm{C}$ using a student's T-test.

\section{Intracellular and extracellular APEC}

In order to confirm the intracellular localization of APEC in our experimental set-up, confocal microscopy was performed. After HD11 incubation with GFP-APEC, the bacteria were stained with an anti-E. coli serum. Because cells were not permeabilized, only extracellular APEC was labelled with this antibody enabling a distinction between phagocytosed intracellular and adhered extracellular APEC. As shown in Fig. 3, intracellular bacteria, only GFP stained bacteria (green) are indeed present in HD11 cells, as well as extracellular bacteria (yellow/red), qualitatively confirming the results shown in Fig. 2.

\section{Killing of APEC by HD11 macrophages}

HD11 cells are capable of phagocytosing S. typhimurium, S. Enteritidis and Listeria monocytogenes $(18,20)$. Once phagocytosed, the number of viable intracellular bacteria decreased over the next $24 \mathrm{~h}$ (19). To determine whether macrophages are also capable of killing intracellular APEC, viability of APEC after phagocytosis was checked at several time points (Fig. 4). At $4 \mathrm{~h}$, a lower number of APEC was present in the macrophage compared to $S$. Enteritidis (Fig. 4A), demonstrating a difference of HD11 uptake capacity towards different strains. At 6,7 and $8 \mathrm{~h}$, a significantly decreased number of APEC was observed (Fig. 4A), indicating that HD11 are able to kill APEC, contrary to $S$. Enteritidis. This observation indicated that $S$. enteritidis is more resistant to HD11 killing. 


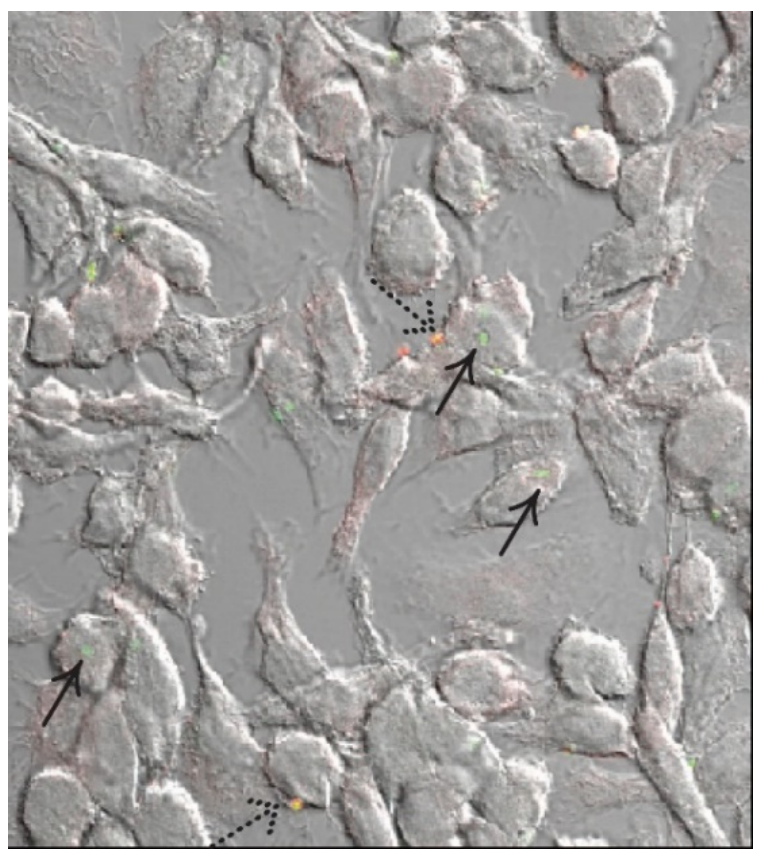

Fig 3. Localization of APEC in HD11 cells. Cells were incubated with GFP-APEC for $3 \mathrm{~h}$. Subsequently, cells were washed and fixed, but not permeabilized. Extracellular APEC were labeled with rabbit anti-E. coli serum and Donkey anti-Rabbit Alexa 647 (red). HD11 cells appeared grey under the DIC channel. Intracellular bacteria appear green (black arrows), while extracellular bacteria appear as red/yellow (dashed arrows).
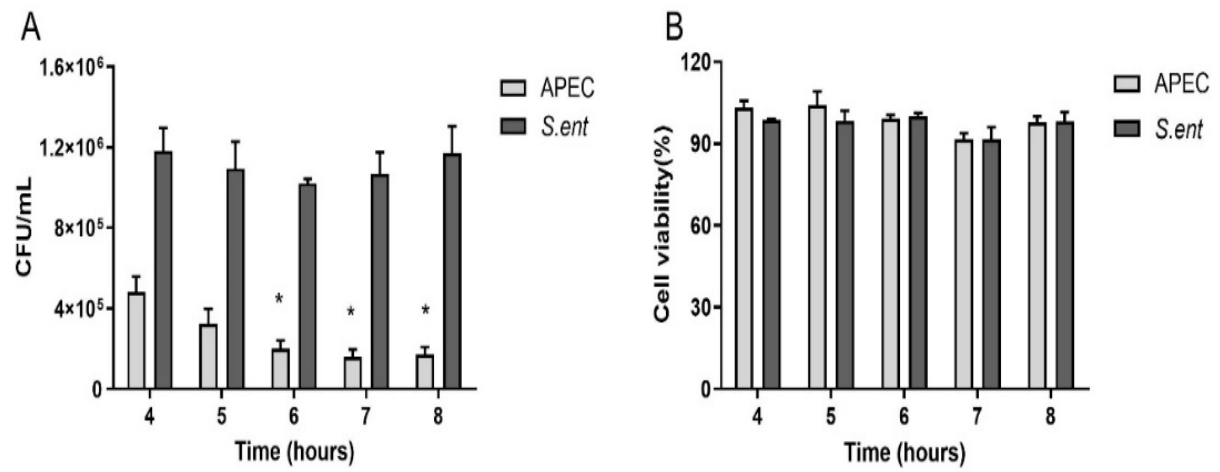

Fig 4. Survival of phagocytosed bacteria in HD11 cells. (A) Viable APEC and S. enteritidis in HD11 cells. (B) Viability of HD11 cells. Data are shown as mean \pm SEM of three independent experiments for each group (in triplicate). * indicates significant difference $(\mathrm{P} \leq 0.05)$ in bacteria compared with $4 \mathrm{~h}$ incubation using one-way ANOVA with post-hoc t-test. 


\section{NO production}

Phagocytosis of APEC and $S$. Enteritidis induced a significant NO production in HD11 cells, with APEC giving higher levels of NO compared to $S$. Enteritidis (Fig. 5). In order to get a first indication whether bacteria had to be viable to activate cells, heat-killed APEC was also used in these experiments. Although the absolute amount of NO was lower for heat-killed APEC, they were still able to induce a significant amount of NO. These results indicate that activation of HD11 cells is partially depending on bacterial strain and viability but that bacterial products are responsible for most activation.

\section{Cytokine expression}

Besides NO production, activation of macrophages can lead to an increased expression of cytokines that further modulate the immune response in response to a bacterial infection. Quantitative real-time PCR (qRT-PCR) was used on selected genes (Table 1) to evaluate the effect of APEC on the immune response in HD11 cells. In addition, to evaluate the effect of viability of APEC on cytokines expression in HD11 cells, heated-killed APEC was also used in these experiments. At $4 \mathrm{~h}$ post-infection, APEC strongly up-regulated the expression of pro-inflammatory cytokines IL-1 $\beta$ and IL-6, inflammatory cytokine IL-8 and antiinflammatory cytokine IL-10 in HD1 1 cells (Fig. 5), whereas IFN- $\beta$ was not affected. Similar results were also found for $S$. Enteritidis stimulation in HD11, indicating that HD11 cells respond similarly towards both bacteria. Interestingly, addition of heat-killed APEC to HD11 cells resulted in a lower expression of IL-1 $\beta$, IL- 6 and IL-8, compared to viable APEC, but expression of IL-10 was not affected. Overall these results show that HD11 cells are capable of a strong cytokine production after phagocytosis of APEC, comparable to $S$. Enteritidis, and that viability of APEC affects most but not all cytokines indicating different signaling pathways could be involved for the production of these mRNAs.

\section{Discussion}

APEC can infect different kinds of birds including chickens, turkeys, and ducks, and causes systemic infections called avian colibacillosis due to immunosuppression and damage of the immune system (6). Despite of the identification of some virulent genes involved in bacterial adhesion and invasion that contribute to APEC pathogenesis (26), the pathogenic mechanism of APEC is still unknown as no specific virulence gene has been identified for the entire APEC pathogenesis in avian host. Most studies have focused on the role of virulence in APEC pathogenesis, but little research is performed on the interaction of APEC with host innate immune cells. Macrophages are quickly increased upon APEC infection response to APEC infection (14). Therefore, we studied the interaction between APEC and macrophages as an important step to determine the initial host response to APEC infection. 

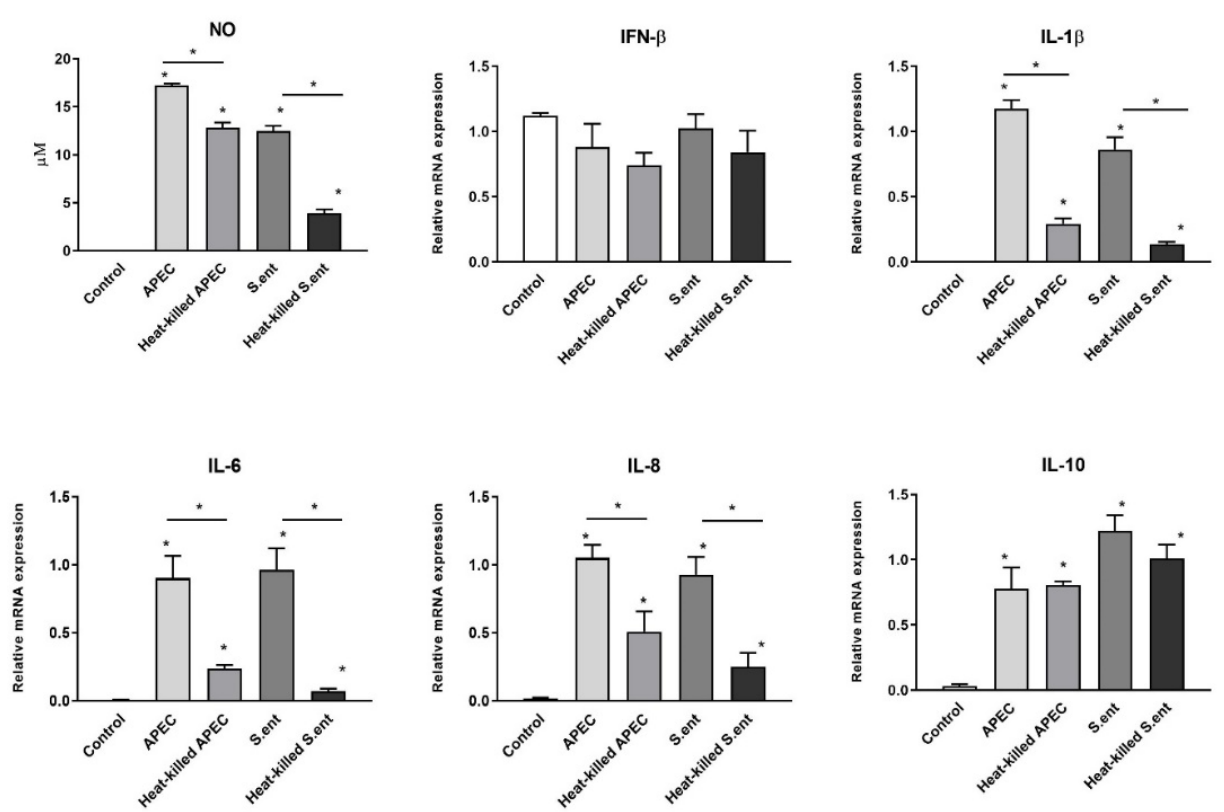

Fig 5. NO production and cytokine expression of HD11 cells after incubation with bacteria. HD11 cells were incubated with live or heat-killed APEC and $S$. Enteritidis for $18 \mathrm{~h}$. Subsequently, nitrite (metabolite of produced NO) content in cell culture media was determined. For cytokines expression, HD11 cells were incubated with APEC and Salmonella for $4 \mathrm{~h}$. Relative mRNA expression of cytokines in HD11 cells was determined using qPCR. Data are shown as mean \pm SEM of three independent experiments (in triplicate) for each group. * indicates a significant difference compared to the control, or (indicated with horizontal bars) between specific treatment groups using oneway ANOVA with post-hoc t-test.

As a first step, the effect of temperature on the phagocytic activity of macrophages was determined. HD1 1 cells are often used at $37^{\circ} \mathrm{C}(20,27,28)$ but the chicken body temperature is closer to $41{ }^{\circ} \mathrm{C}$, which implies that the latter temperature would better resemble the in vivo situation. Indeed, some clear differences were observed at the higher temperature E. coli (APEC and non-APEC) grew faster at $41^{\circ} \mathrm{C}$ (Fig. 1) indicating that the temperature was nonspecific for the growth of APEC. On the other hand, HD11 cells phagocytized more E. coli at $41{ }^{\circ} \mathrm{C}$ (Fig. 2), demonstrating that $\mathrm{HD} 11$ cells have higher phagocytic activity at $41{ }^{\circ} \mathrm{C}$. This is in line with available literature on the effect of temperature on phagocytic activity of immune cells in cold-blooded species. Phagocytic activity has been reported to decline in fish at low $\left(<15^{\circ} \mathrm{C}\right)$ or high $\left(37^{\circ} \mathrm{C}\right)$ temperature (29). Activity of other immune cells and antibody binding activity also reduced at decreased body temperature (30-32). In a mice model experiment, macrophages exposed to an acute cold environment $\left(4{ }^{\circ} \mathrm{C}\right.$ for $\left.24 \mathrm{~h}\right)$ were suppressed in their activity (33). These studies imply that temperature plays an important role in remaining immune response and function of immune cells, which suggests that chicken macrophages should be used at $41{ }^{\circ} \mathrm{C}$ in order to resemble in vivo activity as much as possible. 
The mononuclear phagocytic cells are part of the first line defense against invading pathogens. Activated macrophages can secrete a series of cytokines and chemokines and kill microorganisms by phagocytosis (34-37). For mammalian macrophages, many studies on phagocytic activity have been described, but the available data for chicken macrophages is limited. For chicken macrophage studies, phagocytosis of different bacteria has been investigated, such as S. typhimurium (18), L. monocytogenes (20) and Mycoplasma synoviae (28), but the research about APEC is lacking. Therefore, we studied phagocytosis of APEC in chicken macrophages (HD11). Our data showed that HD11 cells are relatively slow at uptake of APEC with relatively low numbers of APEC at $2 \mathrm{~h}$ post-infection after addition of the bacteria. However, longer incubation times significantly increased the number of phagocytosed APEC, although still much lower than Salmonella (Fig. 2). In initial studies to optimize E. coli uptake by HD11 cells, the effect of addition of chicken serum on phagocytosis of HD11 cells was tested but this had no effect (data not shown). Similarly, low numbers of phagocytosed (non-avian pathogenic) E. coli by HD11 macrophages were also observed by Wisner et al where $E$. coli DH5 $\alpha$ was used as a control group for their Salmonella studies, although these authors suggested that this was due to fast killing of E. coli (18). These differences in phagocytosis indicate that macrophages have different phagocytic capacity to different bacterial strains. After all, phagocytosis is a complex process involving a diverse set of receptors that can stimulate phagocytosis. Different phagocytosed microbes have a different capacity to affect cells. In our study, it is visually shown for the first time that HD11 can indeed phagocytize APEC (Fig. 3) as intracellular APEC was clearly observed under the fluorescent microscopy (Fig. 3), indicating that a lack of uptake is not likely the cause of APEC virulence.

It is well known that macrophages can ingest and kill bacteria. Our results clearly indicated that APEC was killed by HD11 at 6 h post-infection while $S$. Enteritidis survived at all the time points. It has been reported that Salmonella can secrete different virulence factors in host cells to invade, survive and replicate within these host cells $(38,39)$, explaining the observed survival of Salmonella. In addition, Salmonella has been shown to delay the phagolysosomal maturation and neutralize radical oxygen and nitrogen species (ROS and NOS), as defense mechanisms against host cells (40-42). APEC apparently does not have such an evasion strategy although it must be said that after $6 \mathrm{~h}$, the number of APEC did not further change.

NO plays an important role in the host defense against microbial infection (43). It can be produced by activated monocytes or macrophages, and act as effector molecules to kill invading pathogens. Previously, S. Enteritidis-induced NO production was described in chicken macrophages $(16,44)$. Similarly, our results showed that live and, to lesser extent, heat-killed bacteria induced NO production (Fig. 5), demonstrating that NO production might 
partially depend on bacterial viability. Interestingly, even though HD11 cells took up lower numbers of APEC, compared to $S$. Enteritidis, NO production was higher, indicating that APEC is a relatively strong inducer of NO. One study actually showed that (viable) $S$. Enteritidis was able to inhibit production of NO in HD11 cells (19) probably as an evasion mechanism, but the exact mechanism was unknown. The discrepancy with our results could be related to strain dependency since the same study showed that other Salmonella serovars induced a strong NO response in HD11 cells. Overall, chicken macrophages seem to be able to produce a strong response towards APEC, comparable to, or even higher than Salmonella.

Besides intracellular killing of pathogens, professional phagocytes play an important role in modulating the immune response through expression of cytokines and chemokines. Therefore, we explored the initial immune response induced by APEC after $4 \mathrm{~h}$ incubation with chicken macrophages. Our results showed that both APEC and $S$. Enteritidis significantly induced the expression of IL-1 $\beta$, IL-6 and IL-8 (Fig. 5). The induction of IL-6 and IL-1 $\beta$ in this study is consistent with other observations that APEC induced increased expression of IL-6 and IL-1 $\beta$ in chicken monocyte derived macrophages (28). In another study $S$. Enteritidis infection of chickens led to increased expression of IL-8 and IL- $1 \beta$ even through this was measured in the cecum (45). The surfaces of E. coli and $S$. Enteritidis have a variety of microbial associated molecular patterns (MAMPs), like LPS and flagellin, interacting with toll-like receptors (TLR) on the macrophage surface. The observation of induced pro-inflammatory cytokines IL- 8 and IL- $1 \beta$ as well as inflammatory cytokine IL- 6 is likely explained by activation of TLR signaling $(46,47)$. However, we observed that heatkilled APEC induced a lower amount of these three cytokines compared to live APEC, indicating that the level of cytokines expression induced by APEC is partially determined by bacteria and the presence of PAMPs. Interestingly, with respect to anti-inflammatory cytokine IL-10 expression, live APEC and heat-killed APEC induced almost the same level of cytokine expression, but Salmonella induced a higher expression, suggesting that this process might depend on amount and nature of PAMPs and is not necessarily bacteriumspecific. Poly (I:C) and CpG-ODN have been reported to upregulate chicken IL-10 in chicken monocytes, indicating the occurrence of immune regulation to control excessive inflammation (48). Finally, there was not much difference for IFN- $\beta$ expression in this study, which is in agreement with published studies on LPS and bacterial DNA stimulation of HD11 cells which, contrary to viral infection of HD11 cells, did also not have IFN- $\beta$ production (48-50). These results suggest that APEC can induce a strong inflammatory response by the expression of some cytokines, but not for all the cytokines due to different signaling pathways.

In summary, we investigated the interaction of APEC with chicken macrophage HD11 cells. APEC was efficiently phagocytosed by HD11 cells at $41{ }^{\circ} \mathrm{C}$ and subsequently killed. Phagocytosis resulted in a clear pro-inflammatory immune response including production of 
$\mathrm{NO}$ and pro-inflammatory cytokines, indicating that in principle chicken macrophages are capable of an appropriate immune response towards APEC infection. However, although the HD11 cell line is a well-established macrophage cell line, phagocytosis of APEC by chicken primary macrophages needs to be further explored to obtain extra confirmation of our current findings.

\section{Acknowledgements}

The authors would like to thank Richard Wubbolts of the Center for Cell Imaging (Faculty of Veterinary Medicine, Utrecht University) for his help with the confocal microscopy experiments and professor Jos van Putten of Infection Biology (Faculty of Veterinary Medicine, Utrecht University) for providing gfp plasmid. This work was supported by a personal fellowship from the China Scholarship Council (CSC) to Lianci Peng. 


\section{Reference}

1. Dho-Moulin M, Fairbrother J. Avian pathogenic Escherichia coli (APEC). Veterinary Research. 1990;30:299316 .

2. Guabiraba R, Schouler C. Avian colibacillosis: still many black holes. FEMS Microbiol Lett. 2015;362(15):fnv118.

3. Horn F, Correa AM, Barbieri NL, Glodde S, Weyrauch KD, Kaspers B, et al. Infections with avian pathogenic and fecal Escherichia coli strains display similar lung histopathology and macrophage apoptosis. PLoS One. 2012;7(7):e41031.

4. Zhuang QY, Wang SC, Li JP, Liu D, Liu S, Jiang WM, et al. A clinical survey of common avian infectious diseases in China. Avian Dis. 2014;58(2):297-302.

5. Dziva F, Stevens MP. Colibacillosis in poultry: unravelling the molecular basis of virulence of avian pathogenic Escherichia coli in their natural hosts. Avian Pathol. 2008;37(4):355-66.

6. Antao EM, Glodde S, Li G, Sharifi R, Homeier T, Laturnus C, et al. The chicken as a natural model for extraintestinal infections caused by avian pathogenic Escherichia coli (APEC). Microb Pathog. 2008;45(56):361-9.

7. Matthijs MGR, Nieuwenhuis JF, Dwars RM. Signs Indicating Imminent Death in Escherichia coli-Infected Broilers. Avian Dis. 2017;61(3):316-24.

8. Matthijs MG, Ariaans MP, Dwars RM, van Eck JH, Bouma A, Stegeman A, et al. Course of infection and immune responses in the respiratory tract of IBV infected broilers after superinfection with E. coli. Vet Immunol Immunopathol. 2009;127(1-2):77-84.

9. Dozois C, Dho-Moulin M, Bree A, Fairbrother J, Desautels C, Curtiss III R. Relationship between the Tsh autotransporter and pathogenicity of avian Escherichia coli and localization and analysis of the Tsh genetic region. Infection and Immunity. 2000;68(7):4145-54.

10. Lymberopoulos MH, Houle S, Daigle F, Leveille S, Bree A, Moulin-Schouleur M, et al. Characterization of Stg fimbriae from an avian pathogenic Escherichia coli O78:K80 strain and assessment of their contribution to colonization of the chicken respiratory tract. J Bacteriol. 2006;188(18):6449-59.

11. Ma J, Bao Y, Sun M, Dong W, Pan Z, Zhang W, et al. Two Functional Type VI Secretion Systems in Avian Pathogenic Escherichia coli Are Involved in Different Pathogenic Pathways. Infection and Immunity. 2014;82(9):3867-79.

12. Caza M, Lepine F, Dozois CM. Secretion, but not overall synthesis, of catecholate siderophores contributes to virulence of extraintestinal pathogenic Escherichia coli. Mol Microbiol. 2011;80(1):266-82.

13. Kogut MH, Chiang HI, Swaggerty CL, Pevzner IY, Zhou H. Gene Expression Analysis of Toll-Like Receptor Pathways in Heterophils from Genetic Chicken Lines that Differ in Their Susceptibility to Salmonella enteritidis. Front Genet. 2012;3:121.

14. Ariaans MP, Matthijs MG, van Haarlem D, van de Haar P, van Eck JH, Hensen EJ, et al. The role of phagocytic cells in enhanced susceptibility of broilers to colibacillosis after Infectious Bronchitis Virus infection. Vet Immunol Immunopathol. 2008;123(3-4):240-50. 
15. Li D, Xue Y, Geng Z, Chen P. The Suppressive Effects of Bursopentine (BP5) on Oxidative Stress and NF- $\kappa$ B Activation in Lipopolysaccharide-activated Murine Peritoneal Macrophages. Cell Physiol Biochem. 2011(29):09-20.

16. Okamura M, Lillehoj HS, Raybourne RB, Babu US, Heckert RA, Tani H, et al. Differential responses of macrophages to Salmonella enterica serovars Enteritidis and Typhimurium. Vet Immunol Immunopathol. 2005;107(3-4):327-35.

17. Withanage GS, Mastroeni P, Brooks HJ, Maskell DJ, McConnell I. Oxidative and nitrosative responses of the chicken macrophage cell line MQ-NCSU to experimental Salmonella infection. Poult Sci. 2005;46(3):261-7.

18. Wisner AL, Potter AA, Koster W. Effect of the Salmonella pathogenicity island 2 type III secretion system on Salmonella survival in activated chicken macrophage-like HD11 cells. PLoS One. 2011;6(12):e29787.

19. He H, Genovese KJ, Swaggerty CL, Nisbet DJ, Kogut MH. A comparative study on invasion, survival, modulation of oxidative burst, and nitric oxide responses of macrophages (HD11), and systemic infection in chickens by prevalent poultry Salmonella serovars. Foodborne Pathog Dis. 2012;9(12):1104-10.

20. Jarvis NA, Donaldson JR, O'Bryan CA, Ricke SC, Crandall PG. Listeria monocytogenes infection of HD11, chicken macrophage-like cells. Poult Sci. 2017;96(4):950-6.

21. Hashimoto J, Takahashi M, Saito A, Murata M, Kurimura Y, Nishitani C, et al. Surfactant Protein A Inhibits Growth and Adherence of Uropathogenic Escherichia coli To Protect the Bladder from Infection. J Immunol. 2017;198(7):2898-905.

22. Flannagan RS, Heit B, Heinrichs DE. Intracellular replication of Staphylococcus aureus in mature phagolysosomes in macrophages precedes host cell death, and bacterial escape and dissemination. Cell Microbiol. 2016;18(4):514-35.

23. Cuperus T, van Dijk A, Matthijs MG, Veldhuizen EJ, Haagsman HP. Protective effect of in ovo treatment with the chicken cathelicidin analog D-CATH-2 against avian pathogenic E. coli. Sci Rep. 2016;6:26622.

24. Beug H, von Kirchbach A, Doderlein G, Conscience J, Graf T. Chicken hematopoietic cells transformed by seven strains of defective avian leukemia virus display three distinct phenotypes of differetiation. Cell 1979;18:375-90.

25. Green L, Wagner D, Glogowski J, Skipper P, Wishnok J, Tannenbaum S. Analysis of Nitrate, Nitrite, and [15N] Nitrate in Biological Fluids. Anal Biochem. 1982;126:131-8.

26. Kemmett K, Humphrey T, Rushton S, Close A, Wigley P, Williams N. A Longitudinal Study Simultaneously Exploring the carriage of APEC virulence associated genes and the molecular epidemiology of faecal and systemic E.coli in commercial broiler chickens.pdf. PLoS One. 2013;8(6):e67749.

27. Xie H, Raybourne RB, Babu US, Lillehoj HS, Heckert RA. CpG-induced immunomodulation and intracellular bacterial killing in a chicken macrophage cell line. Developmental \& Comparative Immunology. $2003 ; 27(9): 823-34$.

28. Lavric M, Maughan MN, Bliss TW, Dohms JE, Bencina D, Keeler CL, Jr., et al. Gene expression modulation in chicken macrophages exposed to Mycoplasma synoviae or Escherichia coli. Vet Microbiol. 2008;126(13):111-21. 
29. Mondal S, Rai U. In vitro effect of temperature on phagocytic and cytoxic activities of splenic phagocytes of the wall lizard, Hemidactylus flaviviridis. Comparative Biochemistry and Physiology Part A 2001;129:391-8.

30. Collazos M, Barriga C, Ortega E. Seasonal variations in the immune system of the cyprinid Tinca tinca. Phagocytic function. Comp lmmun Microbiol infect Dis. 1995;18(2):105-13.

31. Collazos M, Barriga C, Ortega Rincon E. Seasonal variations in the immune system of the tench, Tinca tinca (Cyprinidae): proliferative response of lymphocytes induced by mitogens. J Comp Physiol B. 1996;165:592-5.

32. Maniero G, Carey C. Changes in selected aspects of immune function in the leopard frog, Rana pipiens, associated with exposure to cold. J Comp Physiol B. 1997;167:256-63.

33. Kizaki T, Oh-ishi S, Ohno H. Acute cold stress induces suppressor macrophages in mice. J Appl Physiol. 1996;81:393-9.

34. Smith CK, Kaiser P, Rothwell L, Humphrey T, Barrow PA, Jones MA. Campylobacter jejuni-induced cytokine responses in avian cells. Infect Immun. 2005;73(4):2094-100.

35. Flannagan RS, Cosio G, Grinstein S. Antimicrobial mechanisms of phagocytes and bacterial evasion strategies. Nat Rev Microbiol. 2009;7(5):355-66.

36. Aderem A, M. Underhill D. Mechanisms of phagocytosis in macrophages. Annu Rev Immunol. 1990;17:593623.

37. Sansonetti P. Phagocytosis of bacterial pathogens: implications in the host response. Semin Immunol. 2001;13(6):381-90.

38. Malik-Kale P, Jolly CE, Lathrop S, Winfree S, Luterbach C, Steele-Mortimer O. Salmonella - at home in the host cell. Front Microbiol. 2011;2:125.

39. Ibarra JA, Steele-Mortimer O. Salmonella--the ultimate insider. Salmonella virulence factors that modulate intracellular survival. Cell Microbiol. 2009;11(11):1579-86.

40. Haraga A, Ohlson MB, Miller SI. Salmonellae interplay with host cells. Nat Rev Microbiol. 2008;6(1):53-66.

41. Aussel L, Zhao W, Hebrard M, Guilhon AA, Viala JP, Henri S, et al. Salmonella detoxifying enzymes are sufficient to cope with the host oxidative burst. Mol Microbiol. 2011;80(3):628-40.

42. Henard CA, Vazquez-Torres A. Nitric oxide and salmonella pathogenesis. Front Microbiol. 2011;2:84.

43. Alam MS, Zaki MH, Sawa T, Islam S, Ahmed KA, Fujii S, et al. Nitric oxide produced in Peyer's patches exhibits antiapoptotic activity contributing to an antimicrobial effect in murine salmonellosis. Microbiol Immunol. 2008;52(4):197-208.

44. Babu US, Gaines DW, Lillehoj H, Raybourne RB. Differential reactive oxygen and nitrogen production and clearance of Salmonella serovars by chicken and mouse macrophages. Dev Comp Immunol. 2006;30(10):94253.

45. Crhanova M, Hradecka H, Faldynova M, Matulova M, Havlickova H, Sisak F, et al. Immune response of chicken gut to natural colonization by gut microflora and to Salmonella enterica serovar enteritidis infection. Infect Immun. 2011;79(7):2755-63. 
46. Iqbal M, Philbin VJ, Smith AL. Expression patterns of chicken Toll-like receptor mRNA in tissues, immune cell subsets and cell lines. Vet Immunol Immunopathol. 2005;104(1-2):117-27.

47. Kogut MH, Iqbal M, He H, Philbin V, Kaiser P, Smith A. Expression and function of Toll-like receptors in chicken heterophils. Dev Comp Immunol. 2005;29(9):791-807.

48. He H, Genovese KJ, Swaggerty CL, MacKinnon KM, Kogut MH. Co-stimulation with TLR3 and TLR21 ligands synergistically up-regulates Th1-cytokine IFN-gamma and regulatory cytokine IL-10 expression in chicken monocytes. Dev Comp Immunol. 2012;36(4):756-60.

49. Gou Z, Jiang S, Zheng C, Tian Z, Lin X. Equol Inhibits LPS-Induced Oxidative Stress and Enhances the Immune Response in Chicken HD11 Macrophages. Cell Physiol Biochem. 2015;36(2):611-21.

50. Lee $\mathrm{CC}, \mathrm{Wu} \mathrm{CC}$, Lin TL. Role of chicken melanoma differentiation-associated gene 5 in induction and activation of innate and adaptive immune responses to infectious bursal disease virus in cultured macrophages. Arch Virol. 2015;160(12):3021-35. 



\section{Chapter 4}

\section{A method to differentiate chicken monocytes into macrophages with proinflammatory properties}

Lianci Peng, Robin H.G.A van den Biggelaar, Christine A. Jansen, Henk P. Haagsman, Edwin J.A. Veldhuizen*

Department of Biomolecular Health Sciences, Division of Infectious Diseases \& Immunology, Faculty of Veterinary Medicine, Utrecht University, Utrecht, The Netherlands.

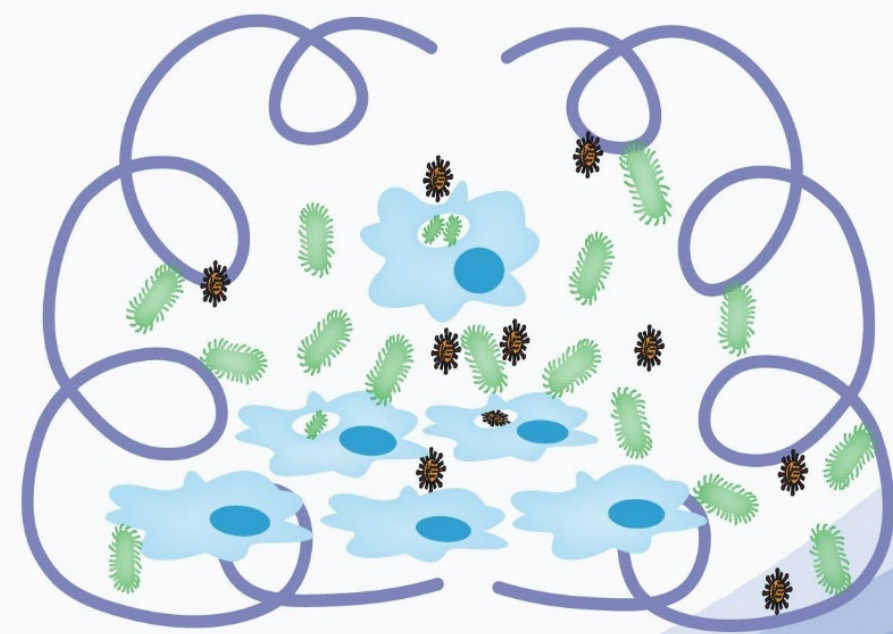




\begin{abstract}
Macrophages are part of the first line of defense against invading pathogens. In mammals, the in vitro culture of macrophages from blood monocytes or bone marrow cells is well established, including culturing conditions to differentiate them towards M1 or M2 macrophages. In chicken, monocyte-derived macrophages have been used in several studies, but there is no uniform protocol or actual characterization of these cells. Therefore, to generate chicken pro-inflammatory M1-like macrophages, in this study blood monocytes were differentiated using chicken GM-CSF for 4 days and characterized based on cell morphology, surface marker expression and cytokine expression response to toll-like receptors (TLRs) agonists stimulation at each (daily) time point. Cell morphology showed that one-day-cultured cells contained a mixture of cell populations, while on day 3 and day 4 the cells were a homogenous population of flat, 'fried-egg' like shaped cells, similar to human M1 macrophages. In addition, cell surface marker staining showed that 3- and 4-day-cultured cells expressed a high level of MRC1L-B (KUL01) and MHC-II. Furthermore, LPS stimulation of the cultured cells induced gene expression of the pro-inflammatory cytokines IL-1 $\beta$, IL-6 and IL-8 after 3 days of culture. Finally, it was shown that 3-day-cultured macrophages were able to phagocytose avian pathogenic E. coli (APEC) and respond by nitric oxide production. Overall, our systematic characterization of the monocyte-derived macrophages from chicken blood showed that a 3-day culture was optimal to obtain proinflammatory M1-like macrophages, increasing our knowledge about chicken macrophage polarization and providing useful information for studies on chicken macrophage phenotypes.
\end{abstract}




\section{Introduction}

Macrophages play an important role in the innate immune system against invading pathogens. They are actively involved in phagocytosis and subsequent killing pathogenic microorganisms. In addition, they are key regulatory cells of the immune system by the production of a pro- or anti-inflammatory response upon stimulation. These immune responses are initiated by specialized pathogen recognition receptors, including the toll-like receptor (TLR) family. TLR4 and TLR7 are important to recognize components of bacteria (LPS) and viruses (RNA), respectively (1). In mammals, macrophages have different phenotypes, such as M1, M2, M (Hb), Mox, and M4. However, all these phenotypes are nowadays considered differentiated 'extreme-states' of a macrophage and depending on environmental factors macrophages can convert and cover the whole spectrum between these different states $(2,3)$.

In recent years, M1 and M2 macrophages have been studied the most and are linked to different macrophage functions. In a simplified view, M1 macrophages are usually considered pro-inflammatory macrophages that play a role in killing intracellular pathogens, while M2 macrophages are 'tolerant' anti-inflammatory macrophages important for wound healing and tissue repair (4). In vitro, M1 and M2 macrophages can be grown by applying different supplements $(5,6)$. Morphologically M1 macrophages differentiate into so-called "fried-egg" shaped cells that express inducible nitric oxide synthase (iNOS) and produce proinflammatory cytokines such as IL-6 and TNF- $\alpha$ in response to stimulation. M2 macrophages are stretched, spindle-like cells that express arginase and produce anti-inflammatory cytokines such as IL-10 in response to stimulation (7-9). Besides morphology, M1 macrophages can also be distinguished from M2 by their different expression of surface markers $(5,6)$. For instance, MHC-II is expressed by both subsets and high MRC1 is a characteristic of M2 macrophages. These different phenotypes of macrophages provide a useful tool for understanding the function and especially potential of macrophages in vivo.

Unlike in vitro-cultured mammalian macrophages that have well described distinct phenotypes under specific conditions, chicken macrophages have been poorly described or standardized. As a common initial step, chicken macrophages are cultured from monocytes purified from peripheral blood or bone marrow by adherence to glass or plastic. After that methodologies diverge and differentiation of monocytes to macrophages occurs without external stimulation, but usually in the presence of chicken serum, or is stimulated through addition of chicken (G)M-CSF (10-12). Interestingly, a recent manuscript used IL-4 to stimulate differentiation into a more M2-like phenotype (13). Besides differences in culturing conditions, there is also no consensus in literature on the duration of culture, which ranges from 1 to 6 days. This lack of culture standardization of monocyte-derived macrophages 
affects reproducibility and comparability of different studies. Although the macrophage cell line (HD11) have been shown to take up and kill avian pathogenic E. coli (APEC) (14), the role of primary macrophages in controlling APEC is less studied due to the lack of standardization of culturing and characterization of macrophages.

In this study, a thorough characterization of chicken blood monocyte-derived macrophages was performed to optimize culture conditions, like culture duration and in the presence of chicken GM-CSF. The morphology, expression of cell surface markers and immune responses upon TLRs agonists stimulation during cell differentiation were determined. Finally, the optimized macrophage culture was functionally assessed for phagocytosis of APEC and nitric oxide (NO) production.

\section{Methods and materials}

\section{Bacterial strains}

APEC strain (O78, K80) was isolated from chicken (clinical isolate, Zoetis, USA) (15), stored as a 25\% glycerol stock and cultured in Tryptic Soy Broth (TSB) (Oxoid) and Tryptic Soy Agar (TSA) (Oxoid) at $37^{\circ} \mathrm{C}$. Green fluorescent protein (GFP) labeling APEC strain was performed as described previously (14).

\section{Cell isolation, culture and cell surface marker staining}

Peripheral blood mononuclear cells (PBMCs) were isolated from 76-week-old healthy chickens blood using Ficoll gradient and cryopreserved in liquid nitrogen until use. PBMCs $\left(1 \times 10^{7}\right.$ cells $)$ were seeded in a 24 -well plate containing $1 \mathrm{~mL}$ RPMI $1640+$ glutamax medium (Gibco, UK) with 10\% FCS (Bodinco, Alkmaar, The Netherlands) and penicillin (100 $\mathrm{U} / \mathrm{mL}$ )/streptomycin $(100 \mu \mathrm{g} / \mathrm{mL})(\mathrm{P} / \mathrm{S})$ (Life Technologies, Carlsbad, CA, USA) and incubated at $41{ }^{\circ} \mathrm{C}$. After overnight incubation, all non-attached cells were removed and attached cells were maintained in RPMI $1640+$ glutamax medium with $10 \%$ FCS and P/S supplemented with chicken GM-CSF for another 3 days at $41{ }^{\circ} \mathrm{C}$. Cell morphology was microscopically examined at each day. In addition, cells were harvested after 1, 2, 3, or 4 days using PBS containing 0.5 mM EDTA to detach the cells (hereafter referred to as day 1day 4 cells). After centrifugation and washing steps, cells were stained for the chicken mannose receptor C-type 1-like-B (MRC1L-B) using the KUL01-FITC antibody (clone KUL01, isotype Southern Biotech, Birmingham, AL, USA) and MHC-II (MHCII-PE, 'clone 2G11'; isotype Southern Biotech) in FACS buffer (0.5\% BSA in PBS) at $4{ }^{\circ} \mathrm{C}$ for $30 \mathrm{~min}$. Afterwards, cells were washed and analyzed using flow cytometry (FACSCanto-II, BD Biosciences, CA, USA) and FlowJo Software v. 10.5 (FlowJo LCC, Ashland, OR, USA). 


\section{LPS and R848 stimulation of monocyte derived macrophages}

Cells were cultured as described above. After 1, 2, 3, or 4 days, ultrapure LPS E. coli O111:B4 (100 ng/mL) (InvivoGen, San Diego, CA, USA) or $10 \mu \mathrm{g} / \mathrm{mL}$ R848 (InvivoGen, San Diego, CA, USA) diluted in RPMI 1640-glutamax medium with $10 \%$ FCS, was added to the cells for $4 \mathrm{~h}$ at $41{ }^{\circ} \mathrm{C}$. Afterwards, cells were washed and lysed in Trizol (Ambion, Carlsbad, CA) stored in $-20{ }^{\circ} \mathrm{C}$ for RNA isolation.

\section{Quantitative real-time PCR (qPCR)}

Total RNA was extracted by Trizol reagent according to the manufacturer's instructions. RNA (500 ng) was reverse transcribed using the iScript cDNA synthesis kit (Bio-Rad, Veenendaal, the Netherlands) according to the manufacturer's instructions. Primers and TaqMan probes were designed and produced by Eurogentec (Seraing, Belgium) (14). Quantitative real time PCR was performed on a CFX Connect qPCR with CFX Manager 3.0 (Bio-Rad). Reactions were performed as follows: 3 min at $95^{\circ} \mathrm{C} ; 40$ cycles: $10 \mathrm{~s}$ at $95{ }^{\circ} \mathrm{C}$, $30 \mathrm{~s}$ at $60^{\circ} \mathrm{C}$ and $30 \mathrm{~s}$ at $72^{\circ} \mathrm{C}$. Relative gene expression levels were normalized against the expression levels of the housekeeping gene GAPDH.

\section{APEC infection in monocyte derived macrophages}

$0.5 \mathrm{~mL} 1 \times 10^{6} \mathrm{CFU} / \mathrm{mL}$ APEC was added to day 3 macrophages with triplicate wells in a 24-well plate and incubated for $3 \mathrm{~h}$ at $41{ }^{\circ} \mathrm{C}$. After $3 \mathrm{~h}$, bacterial suspensions were removed and cells were washed three times with RPMI 1640-glutamax medium with 10\% FCS. Then, RPMI 1640-glutamax containing $500 \mu \mathrm{g} / \mathrm{mL}$ gentamicin (Sigma-Aldrich) was added to cells in order to kill all extracellular, non-phagocytosed bacteria, followed by $1 \mathrm{~h}$ incubation at 41 ${ }^{\circ} \mathrm{C}$. After that, cells were incubated at $41^{\circ} \mathrm{C}$ for 0,2 , or $4 \mathrm{~h}$. At each time point, infected cells were washed three times with RPMI 1640-glutamax and lysed by $0.5 \mathrm{~mL} 0.5 \%$ Triton X-100. After lysis, dilution series of cells were plated on TSA plates and incubated at $37^{\circ} \mathrm{C}$ for $24 \mathrm{~h}$ to quantify viable bacteria.

\section{Confocal microscopy}

Day 3 cells were grown on a $12 \mathrm{~mm}$ glass coverslip in a 24-well plate and infected with GFPAPEC $\left(1 \times 10^{6} \mathrm{CFU} / \mathrm{mL}\right)$ for $3 \mathrm{~h}$ at $41^{\circ} \mathrm{C}$ as described above. After three wash steps with RPMI 1640-glutamax, cells were fixed with $4 \%$ paraformaldehyde (PFA) in PBS for $30 \mathrm{~min}$ at room temperature (RT). Subsequently, cells were incubated with $50 \mathrm{mM} \mathrm{NH}_{4} \mathrm{Cl}$ (Merck) in PBS for 10 min at RT and blocked with 3\% BSA (Sigma-Aldrich) in PBS for 30 min. Then, cells were stained with anti-E. coli rabbit serum (1:500) (15) for $1 \mathrm{~h}$. After the wash steps with PBS, cells were incubated with Donkey anti-Rabbit Alexa 647 (Jackson ImmunoResearch, West Grove, PA, USA) (1:100) for $1 \mathrm{~h}$. Finally, cells were washed with 
PBS and water and mounted in FluoroSave (Merck Millipore, Billerica, MA). Slides were observed on a Leica SPE-II DMI4000 microscope with LAS-AF software (Leica, Wetzlar, Germany) using a $63 \times$ HCX PLAN APO OIL CS objective.

\section{NO production assay}

Nitrite, a stable metabolite of NO, was measured by the Griess assay (16). PBMCs were seeded in a 24-well plate and incubated as described above for 3 days. Then, cells were incubated with bacteria at $41^{\circ} \mathrm{C}$ for $3 \mathrm{~h}$ and treated with $500 \mu \mathrm{g} / \mathrm{mL}$ gentamicin for $15 \mathrm{~h}$. After $18 \mathrm{~h}$ incubation, supernatants were collected and NO was determined as described previously (14).

\section{Statistical analysis}

Data are represented as mean $\pm \mathrm{SEM}$ with three independent experiments for each group $(n=3)$ and were analyzed by a T-test for two groups or by one-way ANOVA with Tukey's multiple comparisons test for more than two groups. Bio-Rad CFX Manager 3.0 software (Bio-Rad) was used for qPCR data analysis. All the graphs were made using GraphPad Prism ${ }^{\circledR} 8.0$.

\section{Results and discussion}

\section{Alteration of cell morphology and surface marker expression during cell differentiation}

Monocytes were isolated from the PBMC fraction of the blood from 76-week-old healthy chickens and cultured for 1, 2, 3, or 4 days in the presence of chicken GM-CSF to differentiate monocytes into macrophages. The cultures were inspected over time for changes in macrophage morphology and purity. The first day of culture, adherent cells were monocytes (Fig. 1A, black arrows). Non-adherent cells were removed. This was a mixed population of other cells including lymphocytes and heterophils and did not contain monocytes (FACS analysis, data not shown). Cells became flat after 2 days of culture (Fig. 1B, dashed arrow). At day 3 and 4, heterophils were lost from the culture and monocytes-derived macrophages remained, as indicated by the 'fried eggs-like' shape of the cells (Fig. 1C and D, dashed arrows), similar to classic mammalian M1 macrophages (9). Next, we used flow cytometry to characterize these cells. Macrophages were determined based on the forward scatter (FSC) (cell size) and side scatter (SSC) (granularity). Increasing amounts of these cells were detected up to 3 days and then leveled between day 3 and 4 (Fig 2A). These quantified macrophages on different days were MRC1L-B and MHC-II positive cells as shown in Fig. 2B. Then, the expression of MRC1L-B and MHC-II were quantified by the geometric mean fluorescence intensity (gMFI). High surface expression of MRC1L-B was detected at day 1 (Fig 2C), reflecting that monocytes in the blood have a high expression of MRC1L-B. 
Subsequent monocyte differentiation and proliferation resulted in higher numbers of cells that were identified as macrophages by our FACS gating strategy, but with a tendency (although not statistically different from day 1) to lower average MRC1L-B expression at day 2. However, MRC1L-B expression increased at day 3 reflecting maturation of the newly differentiated macrophages. The expression of MHC-II increased from day 1 to 3 and then stabilized between day 3 and 4 (Fig 2C), indicating the differentiation and maturation of macrophages. In general, these results indicate that most of the differentiation of monocytes into macrophages was reached at 3 days post-incubation and then remained stable for at least 1 day.
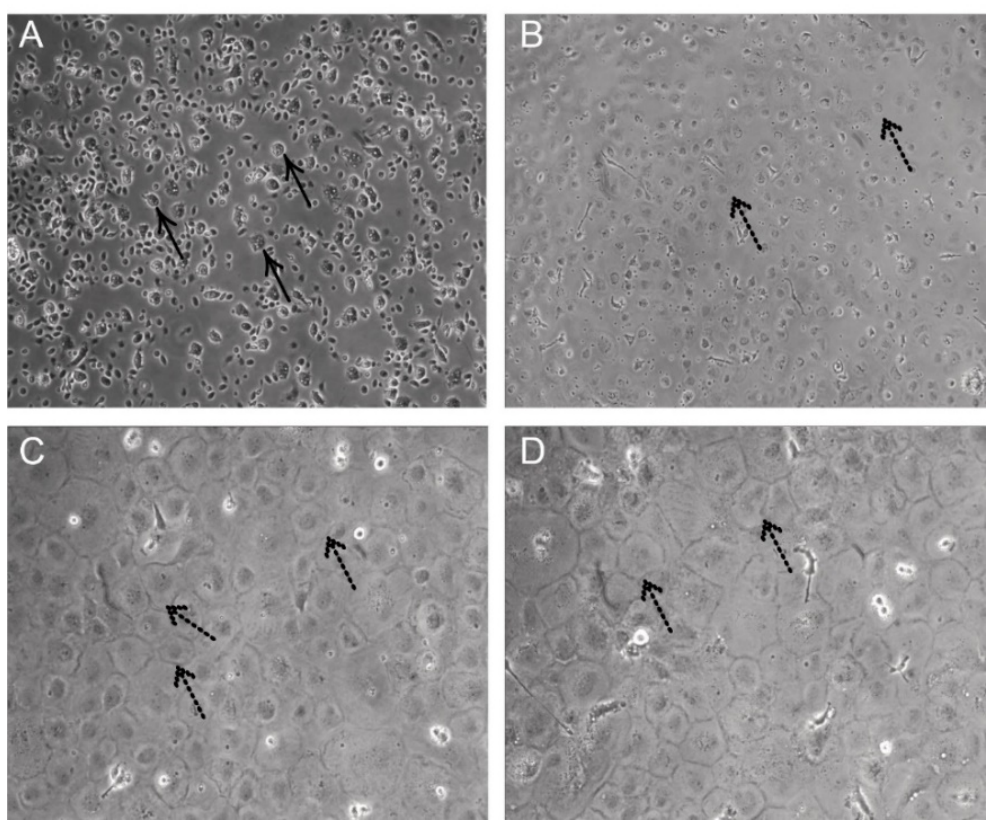

Fig 1. Morphology changes during cell differentiation. Representative microscopic images of monocyte-derived macrophages after (A) one-day-culture, (B) two-day-culture, (C) three-day-culture, and (D) four-day-culture. The black arrows show monocytes and dashed arrows show flat macrophages. All images are at $20 \times$ magnification.

Based on presumed homology of chicken monocyte-derived macrophages with mammalian cells, expression of the cell surface markers (KUL01 and MHC-II) and morphology seem good indicators for chicken monocyte-to-macrophage differentiation. Although the expression of MRC1L-B and MHC-II were used to characterize macrophages, their expression is not limited to macrophages. MHC-II is highly expressed on chicken in vitro bone marrow-derived dendritic cells (DCs) (17) and also by B cells and DCs in vivo (18). Monoclonal antibody KUL01 recognizes a mannose receptor (also known as CD206 in mammals) and was first used to characterize macrophages by Mast et al in different tissues 
including spleen and gut (19). A previous study has described that chicken macrophages actually have five paralogous genes of mannose receptor (MRC1L-A to MRC1L-E), contrary to mammals, and KUL01 only recognizes MRC1L-B (20). KUL01 does not exclusively bind to macrophages, since it also identified Langerhans cells in the chicken skin (19). Interestingly, in mammalian macrophages, MRC1 expression is considered to be connected to M2 macrophages. However, for MRC1L-B which is only one of the orthologs of MRC1 in chicken (20), it is unclear if mammalian data can be extrapolated.
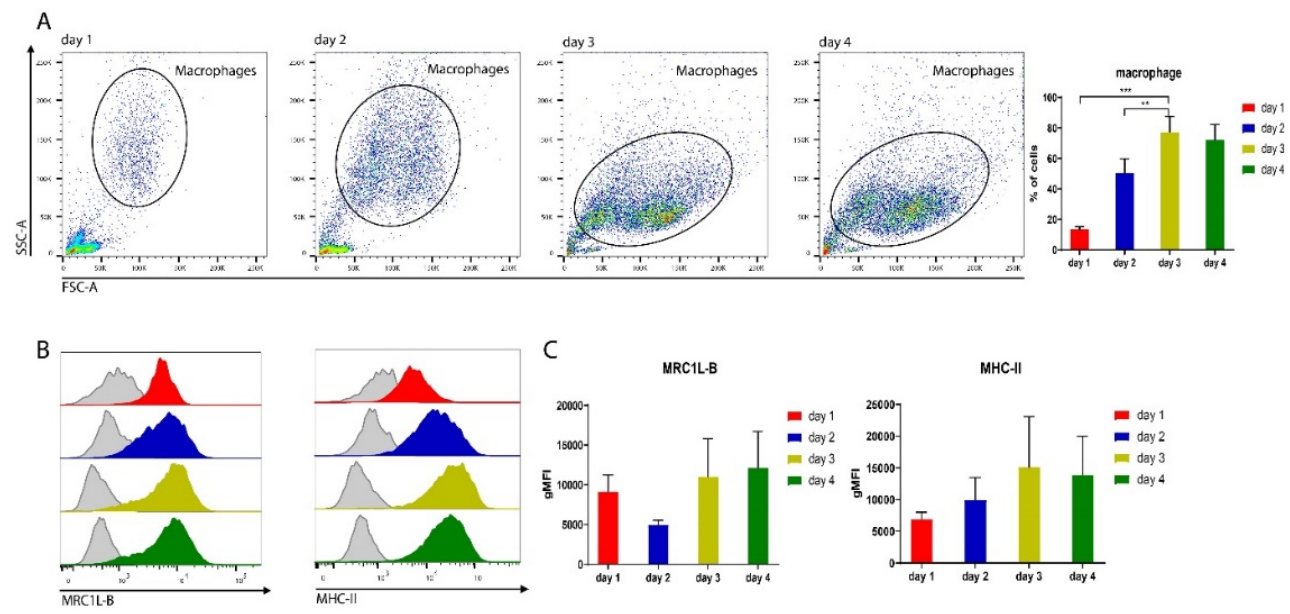

Fig 2. Expression of cell surface marker during cell differentiation. Chicken monocytes were cultured for 1-4 days in the presence of GM-CSF, after which cells were analyzed by flow cytometry. (A) Percentage of macrophages based on FSC (cell size) and SSC (granularity). (B) Representative histograms of MRC1L-B and MHC-II expression, with in grey the unstained controls. (C) The expression of MRC1L-B and MHC-II on the macrophages at different culture times were quantified by the geometric mean fluorescence intensity (gMFI). Data are represented as mean \pm SEM of three independent experiments with three samples per experiment in the bar graphs. For data analysis, one-way ANOVA with Tukey's multiple comparisons test was used. *P $\leq 0.05 ; * * \mathrm{P} \leq 0.01 ;{ }^{* * *} \mathrm{P} \leq 0.005$.

\section{LPS- or R848-induced cytokines during cell differentiation}

The abilities of macrophages to induce an immune response upon stimulation with TLR4 agonist LPS and TLR7 agonist R848 was tested. R848 induced only low expression levels of IFN- $\beta$, IL-1 $\beta$, IL-6, IL-8 and IL-10 (Fig. 3), and no significant effect of different culturing times on cytokine expression was observed. On the other hand, LPS induced a strong expression of these cytokines (Fig. 3). In addition, expression of all pro-inflammatory cytokines increased from day 1 to day 3 cultured cells, while IL-10 did not significantly change. Interestingly the gene expression of cytokines upon LPS stimulation decreased again at day 4 of culture indicating that there is not a lasting linear correlation between culture time and (pro)-inflammatory response. 

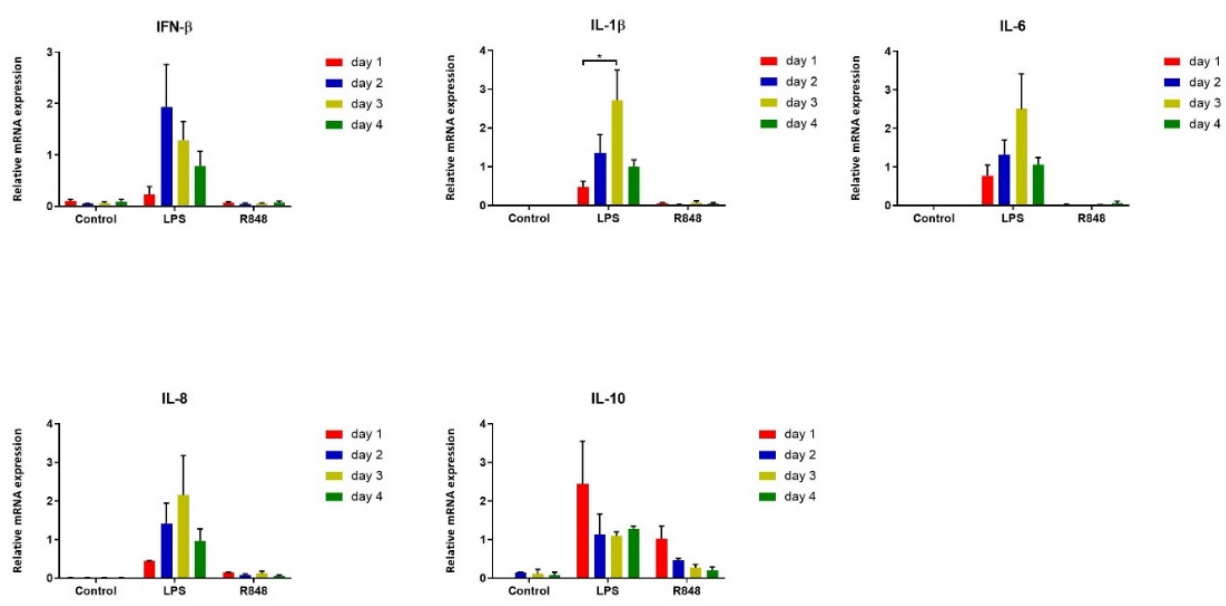

Fig 3. TLR ligands-induced cytokines expression during cell differentiation. Chicken monocytes were cultured for 1-4 days in the presence of GM-CSF, and subsequently stimulated with LPS or R848 for $4 \mathrm{~h}$. Cells were lysed and mRNA was isolated. Finally, qPCR was used to detect gene expression of cytokines. Relative gene expression levels were normalized against the expression levels of the housekeeping gene GAPDH. Data is represented as mean \pm SEM of three independent experiments with triplicate samples per experiment. For data analysis, one-way ANOVA with Tukey's multiple comparisons test was used. $* \mathrm{P} \leq 0.05$;

The macrophage response upon TLR stimulation is related to their differentiation state. For example, in mammals, M1 macrophages produce pro-inflammatory cytokines, whereas M2 macrophages produce anti-inflammatory cytokines in response to TLR stimulation $(8,9)$. The production of these pro-inflammatory cytokines plays an important role in macrophages. IL-1 $\beta$ is an important pro-inflammatory cytokine for host defense against infection (21) and has been used as an immunoadjuvant to improve vaccination efficacy (22). IL-6 has multiple functions including the stimulating differentiation of monocytes to macrophages (23) and IL8 is chemotactic for heterophils. This study showed that day 3 macrophages have a M1 proinflammatory differentiation state based on high expression of IL-1 $\beta$, IL-6 and IL-8. Therefore, high expression of these cytokines upon stimulation indicate that macrophages were most responsive to LPS stimulation at day 3.

Unlike LPS stimulation, R848 did not induce any differences of the immune response in these macrophages. R848 has been reported to induce cytokines expression including TNF- $\alpha$, IL6 and IL-12 in mouse macrophages $(24,25)$. It also induced gene expression of IL-1 $\beta$ and IL-6 in chicken macrophage-like HD11 cell line containing TLR7 (26) although only low expression was detected. This is similar to our observation that low gene expression of IL$1 \beta$, IL-6 and IL-8 was induced upon R848 stimulation. A recent study also showed that low gene expression of IFN- $\beta$ and IL-1 $\beta$ was induced upon R848 $4 \mathrm{~h}$ stimulation in chicken 
PBMCs (27). These results indicate that chicken macrophages might not be sensitively responsive to TLR7 agonist compared with mammalian macrophages.

\section{APEC-induced activation of macrophages}

To assess the function of day 3 macrophages, cells were incubated with APEC, one of the major bacterial pathogens for chicken. After $4 \mathrm{~h}$, intracellular bacteria were detected (Fig. $4 \mathrm{~A}$ ) and after $6 \mathrm{~h}$ and $8 \mathrm{~h}$, the number of bacteria in the cells was significantly decreased compared to $4 \mathrm{~h}$ initially intracellular bacteria (Fig. 4A), indicating that these macrophages are capable of phagocytosing and subsequent killing of APEC. To confirm that bacteria were taken up by macrophages, confocal microscopy was used to distinguish intracellular from extracellular bacteria. Macrophages were infected with GFP-APEC, after which bacteria were stained with anti-E. coli rabbit serum. Since the macrophages were not permeabilized in the procedure, only extracellular GFP-APEC were labeled with antibody and thus doublelabelled (Fig. 4B, yellow bacteria), while intracellular bacteria were only positive for GFP fluorescence (Fig. 4B, green bacteria). A decreased number of bacteria over time and distinction between intra- and extra- cellular bacteria in macrophages are similar to observations that APEC were taken up by HD11 cells (14).

Phagocytosis is an important function of macrophages and in the current study it was shown that cultured primary macrophages phagocytosed and killed APEC. A number of in vitro studies have shown phagocytosis by chicken macrophage cell lines challenged with different bacterial strains (28-31). In vivo, increased numbers of macrophages have been detected in the lung and air sacs after chicken infection with APEC (32), indicating that macrophages play an important role in controlling APEC infection.

Finally, APEC-induced NO was determined. NO is an important mediator for host defense against microorganisms (33) and is mainly produced by activated pro-inflammatory M1 macrophages. APEC induced NO production in day 3 macrophages (Fig. 4C), although to a lower extent than previously observed for HD11 cells, which are actually known for producing high amounts of NO (14). Similarly, LPS has been shown to induce NO in other macrophage cell lines, such as chicken MQ-NCSU cells, and chicken monocytes (34-36). This shows that NO production is a substantial contribution to the TLR4 induced immune response. 

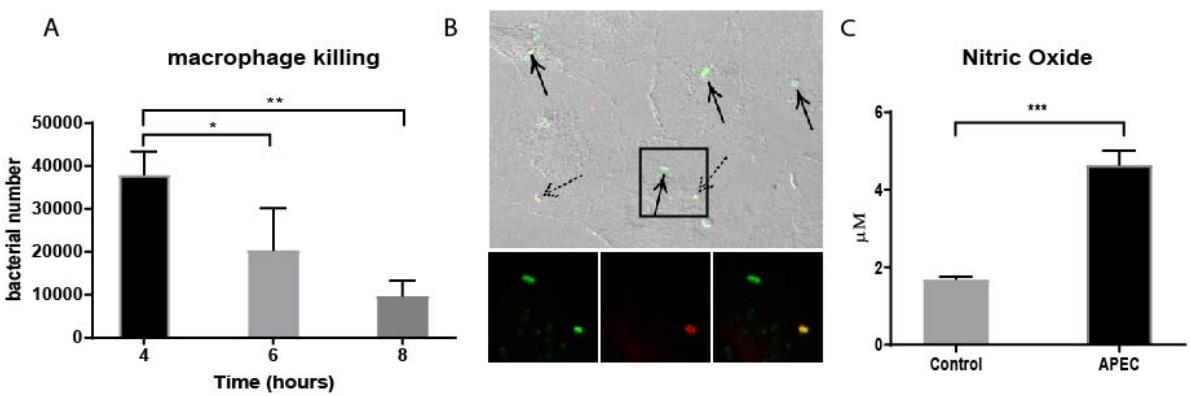

Fig 4. APEC-induced activation of macrophages. (A) Day 3 macrophages were infected with APEC for 3 h, then non-adherent bacteria were removed. Gentamicin was added to kill extracellular bacteria. Intracellular bacteria were quantified at each time point by plating out dilution series of cells on TSA plates. (B) Day 3 macrophages were infected with GFP-APEC for $3 \mathrm{~h}$, after which they were fixed but not permeabilized. Extracellular APEC were stained with rabbit anti-E. coli rabbit serum and Donkey anti-Rabbit Alexa 647 (red). Macrophages were visualized with differential interference contrast (DIC) microscopy. Extracellular bacteria were yellow (double labelled green + red, dashed arrows) and intracellular bacterial were only labelled green (solid arrows). (C) Day 3 macrophages were infected with APEC for $3 \mathrm{~h}$, then bacteria were removed. Extracellular bacteria were killed with gentamicin for $1 \mathrm{~h}$ and subsequently culturing of macrophages was continued $14 \mathrm{~h}$. Nitric oxide was measured in the supernatant by the Griess assay. Data are represented as mean \pm SEM of three independent experiments with triplicates per experiment. For data analysis, a T-test was used in two groups in figure $\mathrm{C}$ and one-way ANOVA with Tukey's multiple comparisons test was used in more than two groups in figure $\mathrm{A}$. ${ }^{*} \mathrm{P} \leq 0.05 ; * * \mathrm{P} \leq 0.01 ; * * * \mathrm{P} \leq 0.005$.

\section{Conclusion}

This study describes an in vitro chicken monocyte-derived macrophage culture in the presence of chicken GM-CSF over time. Our systematic characterization showed that a 3day culture was optimal to obtain pro-inflammatory M1-like macrophages. This provides a tool for further studies on host-pathogens interactions on macrophages, in which plasticity and diversity of macrophage subsets are taken into account, in line with current studies on mammalian macrophages. 


\section{References}

1. Akira S. Mammalian Toll-like receptors. Current opinion in immunology. 2003;15(1):5-11.

2. Porcheray F, Viaud S, Rimaniol AC, Leone C, Samah B, Dereuddre-Bosquet N, et al. Macrophage activation switching: an asset for the resolution of inflammation. Clinical \& Experimental Immunology. 2005;142(3):4819.

3. Lee S, Huen S, Nishio H, Nishio S, Lee HK, Choi B-S, et al. Distinct macrophage phenotypes contribute to kidney injury and repair. Journal of the American Society of Nephrology. 2011;22(2):317-26.

4. Italiani P, Boraschi D. From monocytes to M1/M2 macrophages: phenotypical vs. functional differentiation. Frontiers in immunology. 2014;5:514.

5. Mantovani A, Sica A, Sozzani S, Allavena P, Vecchi A, Locati M. The chemokine system in diverse forms of macrophage activation and polarization. Trends in immunology. 2004;25(12):677-86.

6. Martinez FO, Gordon S. The M1 and M2 paradigm of macrophage activation: time for reassessment. F1000prime reports. 2014;6.

7. Verreck FA, de Boer T, Langenberg DM, Hoeve MA, Kramer M, Vaisberg E, et al. Human IL-23-producing type 1 macrophages promote but IL-10-producing type 2 macrophages subvert immunity to (myco) bacteria. Proceedings of the National Academy of Sciences. 2004;101(13):4560-5.

8. Fleetwood AJ, Lawrence T, Hamilton JA, Cook AD. Granulocyte-macrophage colony-stimulating factor (CSF) and macrophage CSF-dependent macrophage phenotypes display differences in cytokine profiles and transcription factor activities: implications for CSF blockade in inflammation. The Journal of immunology. 2007;178(8):5245-52.

9. Gao J, Scheenstra MR, van Dijk A, Veldhuizen EJ, Haagsman HP. A new and efficient culture method for porcine bone marrow-derived M1-and M2-polarized macrophages. Veterinary immunology and immunopathology. 2018;200:7-15.

10. Feng M, Dai M, Cao W, Tan Y, Li Z, Shi M, et al. ALV-J strain SCAU-HN06 induces innate immune responses in chicken primary monocyte-derived macrophages. Poultry science. 2016;96(1):42-50.

11. Johnston SA, Voelz K, May RC. Cryptococcus neoformans thermotolerance to avian body temperature is sufficient for extracellular growth but not intracellular survival in macrophages. Scientific reports. 2016;6:20977.

12. Kappala D, Sarkhel R, Dixit SK, Mahawar M, Singh M, Ramakrishnan S, et al. Role of different receptors and actin filaments on Salmonella Typhimurium invasion in chicken macrophages. Immunobiology. 2018;223(67):501-7.

13. Chaudhari AA, Kim WH, Lillehoj HS. Interleukin-4 (IL-4) may regulate alternative activation of macrophagelike cells in chickens: A sequential study using novel and specific neutralizing monoclonal antibodies against chicken IL-4. Veterinary immunology and immunopathology. 2018;205:72-82.

14. Peng L, Matthijs MG, Haagsman HP, Veldhuizen EJ. Avian pathogenic Escherichia coli-induced activation of chicken macrophage HD11 cells. Developmental \& Comparative Immunology. 2018;87:75-83. 
15. Cuperus T, van Dijk A, Matthijs MG, Veldhuizen EJ, Haagsman HP. Protective effect of in ovo treatment with the chicken cathelicidin analog D-CATH-2 against avian pathogenic E. coli. Scientific reports. 2016;6:26622.

16. Green LC, Wagner DA, Glogowski J, Skipper PL, Wishnok JS, Tannenbaum SR. Analysis of nitrate, nitrite, and $[15 \mathrm{~N}]$ nitrate in biological fluids. Analytical biochemistry. 1982;126(1):131-8.

17. Wu Z, Rothwell L, Young JR, Kaufman J, Butter C, Kaiser P. Generation and characterization of chicken bone marrow-derived dendritic cells. Immunology. 2010;129(1):133-45.

18. Manh T-PV, Marty H, Sibille P, Le Vern Y, Kaspers B, Dalod M, et al. Existence of conventional dendritic cells in Gallus gallus revealed by comparative gene expression profiling. The Journal of Immunology. 2014;192(10):4510-7.

19. Mast J, Goddeeris B, Peeters K, Vandesande F, Berghman L. Characterisation of chicken monocytes, macrophages and interdigitating cells by the monoclonal antibody KUL01. Veterinary immunology and immunopathology. 1998;61(2-4):343-57.

20. Staines K, Hunt LG, Young JR, Butter C. Evolution of an expanded mannose receptor gene family. PLoS One. 2014;9(11):e110330.

21. Jayaraman P, Sada-Ovalle I, Nishimura T, Anderson AC, Kuchroo VK, Remold HG, et al. IL-1 $\beta$ promotes antimicrobial immunity in macrophages by regulating TNFR signaling and caspase- 3 activation. The Journal of Immunology. 2013;190(8):4196-204.

22. Deryabin P, Ponomaryova T, Karalnik B, Tugambayev T, Denisova T, Atshabar B, et al. Influence of human recombinant interleukin-1beta on protective and immunogenic efficacy of live plague vaccine. Medical and Health Science Journal. 2014;14:27-34.

23. Chomarat P, Banchereau J, Davoust J, Palucka AK. IL-6 switches the differentiation of monocytes from dendritic cells to macrophages. Nature immunology. 2000;1(6):510.

24. Lee J, Chuang T-H, Redecke V, She L, Pitha PM, Carson DA, et al. Molecular basis for the immunostimulatory activity of guanine nucleoside analogs: activation of Toll-like receptor 7. Proceedings of the National Academy of Sciences. 2003;100(11):6646-51.

25. Hemmi H, Kaisho T, Takeuchi O, Sato S, Sanjo H, Hoshino K, et al. Small anti-viral compounds activate immune cells via the TLR7 MyD88-dependent signaling pathway. Nature immunology. 2002;3(2):196-200.

26. Philbin VJ, Iqbal M, Boyd Y, Goodchild MJ, Beal RK, Bumstead N, et al. Identification and characterization of a functional, alternatively spliced Toll-like receptor 7 (TLR7) and genomic disruption of TLR8 in chickens. Immunology. 2005;114(4):507-21.

27. Ramakrishnan S, Annamalai A, Sachan S, Kumar A, Sharma BK, Govindaraj E, et al. Synergy of lipopolysaccharide and resiquimod on type I interferon, pro-inflammatory cytokine, Th1 and Th2 response in chicken peripheral blood mononuclear cells. Molecular immunology. 2015;64(1):177-82.

28. Wisner AL, Potter AA, Köster W. Effect of the Salmonella pathogenicity island 2 type III secretion system on Salmonella survival in activated chicken macrophage-like HD11 cells. PLoS One. 2011;6(12):e29787.

29. He H, Genovese KJ, Swaggerty CL, Nisbet DJ, Kogut MH. A comparative study on invasion, survival, modulation of oxidative burst, and nitric oxide responses of macrophages (HD11), and systemic infection in chickens by prevalent poultry Salmonella serovars. Foodborne pathogens and disease. 2012;9(12):1104-10. 
30. Jarvis N, Donaldson JR, O'Bryan CA, Ricke SC, Crandall PG. Listeria monocytogenes infection of HD11, chicken macrophage-like cells. Poultry science. 2016;96(4):950-6.

31. Lavrič M, Maughan MN, Bliss TW, Dohms JE, Benčina D, Keeler Jr CL, et al. Gene expression modulation in chicken macrophages exposed to Mycoplasma synoviae or Escherichia coli. Veterinary microbiology. 2008;126(1-3):111-21.

32. Matthijs MG, Ariaans MP, Dwars RM, van Eck JH, Bouma A, Stegeman A, et al. Course of infection and immune responses in the respiratory tract of IBV infected broilers after superinfection with E. coli. Veterinary immunology and immunopathology. 2009;127(1-2):77-84.

33. Eisenstein TK. Implications of Salmonella-induced nitric oxide (NO) for host defense and vaccines: NO, an antimicrobial, antitumor, immunosuppressive and immunoregulatory molecule. Microbes and infection. 2001;3(14-15):1223-31.

34. He H, Genovese KJ, Nisbet DJ, Kogut MH. Profile of Toll-like receptor expressions and induction of nitric oxide synthesis by Toll-like receptor agonists in chicken monocytes. Molecular immunology. 2006;43(7):7839 .

35. Alkie TN, Taha-Abdelaziz K, Barjesteh N, Bavananthasivam J, Hodgins DC, Sharif S. Characterization of innate responses induced by PLGA encapsulated-and soluble TLR ligands in vitro and in vivo in chickens. PLoS One. 2017;12(1).

36. Dil N, Qureshi M. Involvement of lipopolysaccharide related receptors and nuclear factor $\kappa \mathrm{B}$ in differential expression of inducible nitric oxide synthase in chicken macrophages from different genetic backgrounds. Veterinary immunology and immunopathology. 2002;88(3-4):149-61. 



\section{Chapter 5}

\section{The immunomodulatory effect of cathelicidin- B1 on chicken macrophages}

Lianci Peng, Maaike R. Scheenstra, Roel M. van Harten, Henk P. Haagsman, Edwin J.A. Veldhuizen*

Department of Biomolecular Health Sciences, Division of Infectious Diseases \& Immunology, Section of Molecular Host Defence, Faculty of Veterinary Medicine, Utrecht University, Utrecht, The Netherlands.

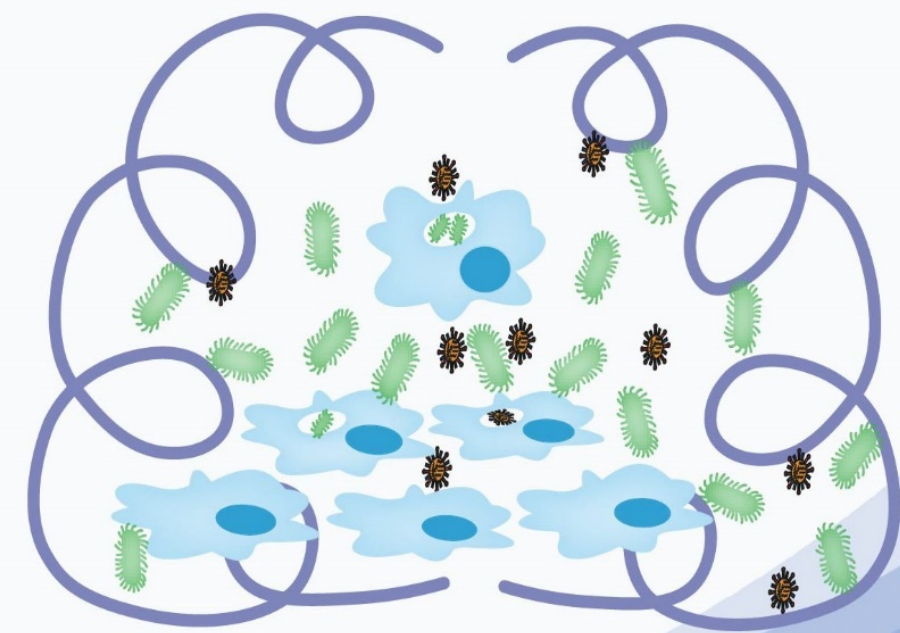




\begin{abstract}
Cathelicidins (CATHs) play an important role in the innate defense against microbial infections. Among the four chicken cathelicidins, CATH-B1 is studied the least. In this study, the effect of CATH-B1 on the macrophage response towards avian pathogenic E. coli (APEC) and bacterial ligands was investigated. Our results show that APEC induced CATH-B1 gene expression in both a chicken macrophage cell line (HD11 cells) and primary macrophages, while expression of the other three CATHs was virtually unaffected. While the antimicrobial activity of CATH-B1 is very low under cell culture conditions, it enhanced bacterial phagocytosis by macrophages. Interestingly, CATH-B1 downregulated APEC-induced gene expression of pro-inflammatory cytokines (IFN- $\beta$, IL-1 $\beta$, IL-6 and IL-8) in primary macrophages. In addition, CATH-B1 pre-incubated macrophages showed a significantly higher gene expression of IL-10 after APEC challenge, indicating an overall antiinflammatory profile for CATH-B1. Using isothermal titration calorimetry (ITC), CATH-B1 was shown to bind LPS. This suggests that CATH-B1 reduces toll like receptor (TLR) 4 dependent activation by APEC which may partly explain the decreased production of proinflammatory cytokines by macrophages. On the contrary, direct binding of CATH-B1 to ODN-2006 enhanced the TLR21 dependent activation of macrophages as measured by nitric oxide production. In conclusion, our results show for the first time that CATH-B1 has several immunomodulatory activities and thereby could be an important factor in the chicken immune response.
\end{abstract}




\section{Introduction}

Cathelicidins are host defense peptides (HDPs) with antimicrobial activity and immunomodulatory functions. They are produced as inactive precursors (prepropeptides), stored in granules, and upon cell activation released as mature peptides by proteolytic cleavage (1). Cathelicidins have been found in many different species, including mammals, reptiles, amphibians, fishes and birds $(2,3)$. Interestingly, the number of functional genes encoding cathelicidins in different species is highly variable (4). For example, only a single cathelicidin (LL-37) is present in human, while chicken has four cathelicidins with varying length and structure (CATH-1, -2, -3 and -B1) (5-8).

Of the four chicken cathelicidins, CATH-2 has been studied extensively. CATH-2 has broad antimicrobial activity and strong immunomodulatory effects, such as lipopolysaccharide (LPS) binding, neutralization of the immune response and enhanced DNA-induced activation of toll like receptor (TLR) 21 (9-12). In addition, in ovo administration of the all D-amino acid enantiomer of CATH-2 (D-CATH-2) at embryonic day 18 resulted in a protective effect against avian pathogenic E. coli (APEC) infection up to 7 days after hatch (13). However, less is known about the activities of CATH-B1, which means that it is challenging to properly compare functionalities and activities (14). When comparing expression patterns, one clear difference between CATH-1, -2, -3 and CATH-B1 is apparent: using immunostaining and mass spectrometry CATH-1, $-2,-3$ were detected in heterophils (15), while CATH-B1 was shown to be produced by epithelial cells in the bursa of Fabricius, although an extended description of CATH-B1 protein expression among cells/tissues was not described (6).

APEC is an important pathogen that causes severe respiratory diseases in chicken, leading to huge economic losses in poultry farming. APEC infection starts in the trachea and damages the respiratory mucosa. Subsequently, it crosses the epithelial layer and enters the blood stream spreading to other tissues (16). APEC can be phagocytosed by macrophages both in the lungs and in the blood stream, which leads to (partial) killing of the pathogen, but also induces an immune response that attracts other immune cells such as heterophils to infected sites.

Compared to mammalian lungs, the healthy chicken lung has a relatively low number of macrophages, but a large increase in number of macrophages occurs in the lung and air sacs after APEC infection (17-19). This suggests that macrophages play an important role in the host defence against microbial infection in the lung. Interestingly, inflammatory stimuli (butyrate) derived from bacteria induced the gene expression of CATH-B1 in chicken macrophages including HD11 cells and primary monocytes, whereas gene expression of the other three cathelicidins was very low in macrophages compared to heterophils (20). This 
implies that CATH-B1 might play an important role in macrophages upon interaction with E. coli.

Therefore, in this study, our main aim was to investigate the effect of CATH-B1 on chicken macrophages and their response towards APEC and TLR agonists. We found that gene expression of CATH-B1 was induced by APEC in both HD11 cells and blood monocytederived macrophages. CATH-B1 enhanced phagocytosis of APEC by macrophages. Furthermore, CATH-B1 inhibited APEC- and LPS- induced immune response but enhanced DNA-induced nitric oxide (NO) in macrophages. Our study provides additional insights in the functions of CATH-B1, that are clearly different from those of the other chicken cathelicidins.

\section{Methods and materials}

\section{Peptides}

All peptides were synthesized by China Peptides (Shanghai, China) using Fmoc-chemistry and purified by reverse phase high-performance liquid chromatography to a purity of $>95 \%$.

\section{Bacterial strains}

The APEC strain $(\mathrm{O} 78, \mathrm{~K} 80)$ is a clinical isolate from chicken (13). Heat-killed bacteria were prepared by heating the bacterial suspension at $75^{\circ} \mathrm{C}$ for $15 \mathrm{~min}$. Viability was checked by plating out on Tryptic Soy Agar (TSA) (Oxoid) plates.

\section{Antimicrobial activity assay}

APEC was cultured in Tryptic Soy Broth (TSB) (Oxoid) at $37{ }^{\circ} \mathrm{C}$ and grown to midlogarithmic growth phase before testing. Bacterial suspensions were pelleted by centrifugation, resuspended in TSB or cell culture medium (RPMI 1640- or DMEMglutamax (Gibco, UK) with $10 \%$ FCS (Corning)) and diluted to $2.0 \times 10^{6} \mathrm{CFU} / \mathrm{mL}$. Twentyfive $\mu \mathrm{L}$ of peptides $(0-80 \mu \mathrm{M})$ were mixed with an equal volume of bacterial suspension and incubated for $3 \mathrm{~h}$ at $37^{\circ} \mathrm{C}$. After incubation, dilution series of bacteria were plated out on TSA plates and incubated at $37^{\circ} \mathrm{C}$ for $24 \mathrm{~h}$ to quantify viable bacteria.

\section{Cell culture}

Peripheral blood mononuclear cells (PBMCs) were isolated from blood of 76-week-old healthy chickens using Ficoll density gradient centrifugation and were frozen in liquid nitrogen until use. PBMCs $\left(1 \times 10^{7}\right.$ cells $)$ were seeded in a $24-w e l l$ plate and incubated at $41{ }^{\circ} \mathrm{C}$. After overnight culture, all non-attached cells were removed and attached cells (monocytes) were maintained in RPMI 1640-glutamax medium with $10 \%$ FCS and $1 \% \mathrm{P} / \mathrm{S}$ (100 U penicillin/mL; $100 \mu \mathrm{g}$ streptomycin/mL (Gibco, UK) supplemented with chicken 
GM-CSF for another 2 days at $41{ }^{\circ} \mathrm{C}$. These monocyte-derived macrophages were used for further analysis.

The chicken macrophage cell line HD11 was maintained in RPMI 1640-glutamax supplemented with $10 \% \mathrm{FCS}$ and $1 \% \mathrm{P} / \mathrm{S}$ at $41{ }^{\circ} \mathrm{C}$. HD1 1 cells were seeded in a 24 -well plate $\left(2.5 \times 10^{5}\right.$ cells/well $)$ or 96 -well plate $\left(0.5 \times 10^{5}\right.$ cells/well $)$ and cultured overnight to adhere before further analysis.

Mouse macrophages (RAW 264.7 cells) were maintained in DMEM-glutamax supplemented with $10 \%$ FCS at $37^{\circ} \mathrm{C}$. RAW cells were seeded in a 96 -well plate $\left(0.5 \times 10^{5}\right.$ cells/well $)$ and cultured overnight to adhere before further analysis.

\section{Cell viability}

Cell viability was determined using the WST-1 assay following the manufacturer's protocol. Briefly, primary macrophages were incubated with peptides for $3 \mathrm{~h}$ at $41{ }^{\circ} \mathrm{C}$. Subsequently, peptides were washed and cells were further incubated for $3 \mathrm{~h}$ at $41^{\circ} \mathrm{C}$. Cell culture medium was removed and replaced with fresh culture medium containing 10\% WST-1 reagent (Roche, Germany). After $20 \mathrm{~min}$ incubation, absorbance was measured at $450 \mathrm{~nm}$ with a FLUOstar Omega microplate reader and was corrected for absorbance at $630 \mathrm{~nm}$.

\section{APEC infection in chicken macrophages}

Primary macrophages and HD11 cells were cultured as described above. Aliquots of $0.5 \mathrm{~mL}$ of bacterial suspensions $\left(1 \times 10^{6} \mathrm{CFU} / \mathrm{mL}\right)$ were added to each well in the presence or absence of $5 \mu \mathrm{M}$ CATH-B1 or CATH-2, with three replicate wells for a 24-well plate and incubated for $3 \mathrm{~h}$ at $41{ }^{\circ} \mathrm{C}$. In phagocytosis studies, bacteria were removed at $3 \mathrm{~h}$ post infection and cells were washed three times with RPMI 1640-glutamax medium with 10\% FCS. Then, RPMI 1640-glutamax containing $500 \mu \mathrm{g} / \mathrm{mL}$ gentamicin (Sigma-Aldrich) was added to cells in order to kill all extracellular, non-phagocytosed bacteria and plates were put back at $41{ }^{\circ} \mathrm{C}$ for $1 \mathrm{~h}$. Infected cells were washed three times with RPMI 1640-glutamax and lysed by $0.5 \mathrm{~mL} 0.5 \%$ Triton X-100. After lysis, dilution series of cells were plated on TSA plates and incubated at $37^{\circ} \mathrm{C}$ for $24 \mathrm{~h}$ to quantify viable bacteria.

In pre-incubation studies, CATH-B1 was added to primary macrophages for $3 \mathrm{~h}$, washed away with cell culture medium after which APEC were added for $3 \mathrm{~h}$. In post-incubation studies, APEC were added to primary macrophages for $3 \mathrm{~h}$, washed away and infected cells were treated with CATH-B1 and gentamicin for $3 \mathrm{~h}$. After that, cells were treated with TriZol (Ambion, Carlsbad, CA) for RNA isolation. 


\section{LPS and ODN-2006 stimulation}

Primary macrophages and RAW cells were cultured as described above. Ultrapure LPS $E$. coli O111:B4 (100 ng/mL) (InvivoGen, San Diego, CA, USA), was diluted in RPMI 1640glutamax medium with $10 \% \mathrm{FCS}$, and added to cells in the presence or absence of $5 \mu \mathrm{M}$ CATH-B1 or CATH-2 for $4 \mathrm{~h}$. Afterwards, primary macrophages were washed and treated with TriZol for RNA isolation.

HD11 cells were prepared in a 96-well plate as described above. ODN-2006 (5 nM) (InvivoGen, France) was added to HD11 cells in the presence or absence of different concentrations $(0-10 \mu \mathrm{M})$ of CATH-B1 and CATH-2 for $20 \mathrm{~h}$. After this incubation, cell supernatants were collected to measure nitric oxide production (see below).

\section{Quantitative real-time PCR (qPCR)}

Primary macrophages were treated with APEC and LPS as described above. After incubation, total RNA was extracted by TriZol (Ambion, Carlsbad, CA) reagent according to the manufacturer's instructions. RNA (500 ng) was reverse transcribed by the iScript cDNA synthesis kit (Bio-Rad, Veenendaal, the Netherlands) according to the manufacturer's instructions. Primers and probes were designed and produced by Eurogentec (Seraing, Belgium) (Table 1). qPCR was performed on a CFX Connect qPCR with CFX Manager 3.0 (Bio-Rad). Reactions were performed as follows: 3 min at $95^{\circ} \mathrm{C} ; 40$ cycles: $10 \mathrm{~s}$ at $95^{\circ} \mathrm{C}$, $30 \mathrm{~s}$ at $60^{\circ} \mathrm{C}$ and $30 \mathrm{~s}$ at $72^{\circ} \mathrm{C}$. Relative gene expression levels were normalized against the expression levels of the house keeping gene GAPDH.

\section{Griess assay}

HD11 cells were stimulated with ODN-2006 as described above. Supernatant was collected to measure NO production. Briefly, $30 \mu \mathrm{L}$ of sample were added to the well in a 96-well flat bottom plate. An equal volume of 1\% sulfanilamide (Merck, Darmstadt, Germany) was added in each well, followed by $30 \mu \mathrm{L} \quad 0.1 \% \quad \mathrm{~N}$-(1-naphthyl) ethylenediamine dihydrochloride (VWR) at room temperature for $5 \mathrm{~min}$. The nitrite concentration was determined by measuring optical density at $550 \mathrm{~nm}$. Sodium nitrite (Sigma-Aldrich) was used as a standard to accurately determine the nitrite concentration in the cell supernatant. 
Table 1: Primer and probe sequences for $q P C R$

\begin{tabular}{lll}
\hline Gene & & $\mathbf{5} \boldsymbol{\rightarrow} \mathbf{3}$ 'sequence \\
\hline GAPDH & Forward & GTCAACCATGTAGTTCAGATCGATGA \\
& Reverse & GCCGTCCTCTCTGGCAAAG \\
& Probe & AGTGGTGGCCATCAATGATCCC \\
& Forward & CCTCCAACACCTCTTCAACACG \\
& Reverse & TGGCGTGTGCGGTCAAT \\
IL-1; & Probe & AGCAGCCCACACACTCCAAAACACT \\
& Forward & GCTCTACTAGTCGTGTGTGATGAG \\
& Reverse & TGTCGATGTCCCGCATGA \\
IL-6 & Probe & CCACACTGCAGCTGGAGGAAGCC \\
& Forward & GTCGAGTCTCTGTGCTAC \\
& Reverse & GTCTGGGATGACCACTTC \\
& Probe & ACGATCCGGCAGATGGTGA \\
& Forward & GCCCTCCTCCTGGTTCA \\
& Reverse & CGCAGCTCATTCCCCATCT \\
& Probe & TGCTCTGTCGCAAGGTAGGACGCTG \\
& Forward & CATGCTGCTGGGCCTGAA \\
& Reverse & CGTCTCCTTGATCTGCTTGATG \\
& Probe & CGACGATGCGGCGCTGTCA
\end{tabular}

\section{Isothermal titration calorimetry}

Interaction between CATH-B1 and E. coli LPS O111:B4 or ODN-2006 was tested using isothermal titration calorimetry (ITC). All ITC experiments were performed on a Low Volume NANO ITC (TA instruments - Waters LLC, New Castle, USA). LPS was diluted in PBS to $0.5 \mathrm{mg} / \mathrm{mL}$ rigorously vortexed for $5 \mathrm{~min}$ and added to the cell chamber $(167 \mu \mathrm{L})$. ODN-2006 was diluted to $25 \mathrm{nM}$ in $75 \%$ PBS. The syringe was filled with a $50 \mu \mathrm{L}$ solution of $200 \mu \mathrm{M}$ CATH-B1 in $75 \%$ PBS. Titrations were incremental with $2 \mu \mathrm{L}$ injections (for LPS) or $1 \mu \mathrm{L}$ injections (for ODN-2006) at 300 seconds intervals. Experiments were performed at $37^{\circ} \mathrm{C}$ and data were analyzed with the Nano Analyze software (TA instruments - Waters LLC).

\section{ELISA}

RAW 264.7 cells were prepared in a 96-well plate as described above. RAW cells were stimulated with $E$. coli LPS $(100 \mathrm{ng} / \mathrm{mL})$ in the presence or absence of $5 \mu \mathrm{M}$ CATH-B1 or CATH-2 for $24 \mathrm{~h}$. Cell supernatants were collected to measure cytokine expression. The mouse IL-6 ELISA kit (Minneapolis, MN) was used to determine the IL-6 concentration of samples. This assay was performed following the manufacturer's protocol. 


\section{Statistical analysis}

Data are represented as mean \pm SEM of three independent experiments for each group $(n=3)$ and were analyzed by a T-test for two groups or by one-way ANOVA with Tukey's multiple comparisons test for more than two groups. Bio-Rad CFX Manager 3.0 software was used for qPCR data analysis. All the graphs were made using GraphPad Prism ${ }^{\circledR}$ 8.0.

\section{Results}

\section{APEC induced CATH-B1 gene expression in macrophages}

CATH-B1 protein has so far only been detected in the bursa of Fabricius, but CATH-B1 mRNA is found in different tissues including the respiratory tract, gastrointestinal tract and lymphoid organs (21), indicating that a broader expression of CATH-B1 is likely. In our study, APEC significantly induced gene expression of CATH-B1 in both HD11 cells (Fig. 1A) and chicken primary macrophages (Fig. 1B). At $6 \mathrm{~h}$ post-infection, up to a 30-fold increase in CATH-B1 gene expression was detected in primary macrophages compared to non-infected cells (Fig. 1B). Gene expression of CATH-1, -2, -3 was not or only mildly induced by APEC in both cell types (Fig. 1A and 1B).

\section{The effect of CATH-B1 on phagocytosis in macrophages}

To determine the effect of CATH-B1 on the function of macrophages, peptide was added to primary macrophages or HD11 cells together with APEC. Bacterial phagocytosis by macrophages was significantly enhanced in HD11 cells (Fig. 2A) when CATH-B1 was present, and slightly enhanced in primary macrophages (Fig. 2B).

\section{Antibacterial activity of chicken cathelicidins against APEC}

The antimicrobial activity against APEC in various culture media was tested for the four chicken cathelicidins (CATH-1, -2, -3 and -B1) in order to determine the minimal bactericidal concentration (MBC). This showed that CATH-1, $-2,-3$ had similar antibacterial activity with MBC values between 5-10 $\mu \mathrm{M}$. In contrast with the other three peptides, CATH-B1 showed a weaker anti-APEC activity at $5 \mu \mathrm{M}$ but killed all bacteria at $10 \mu \mathrm{M}$ (Fig. 3). In cell culture conditions (DMEM-glutamax with 10\% FCS), CATH-2 still showed strong antibacterial activity, whereas the antibacterial activity of CATH-1 and CATH-3 was strongly reduced. CATH-B1 completely lost its antibacterial activity, showing no growth inhibition of APEC at the highest concentration tested $(40 \mu \mathrm{M})$ (Supplementary Fig. 1A and 1B). 
A

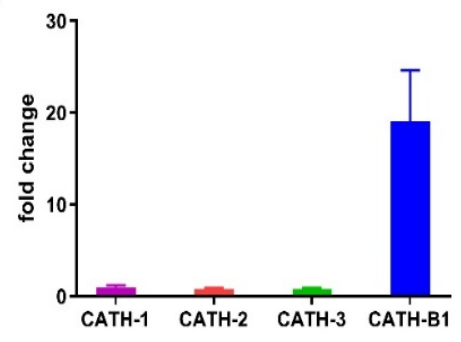

B
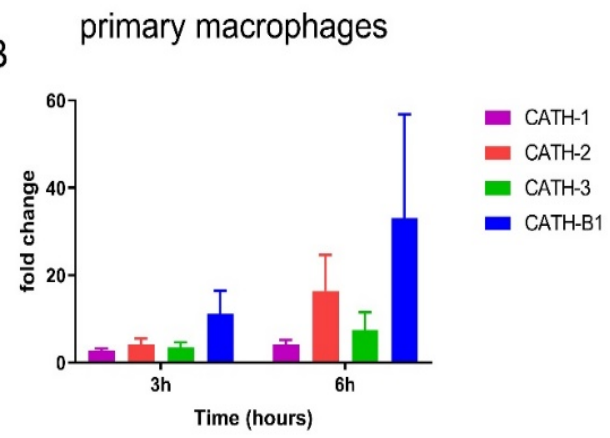

Fig 1. APEC-induced gene expression of chicken cathelicidins (CATHs). Cells were infected with APEC for 3 $\mathrm{h}$ and $6 \mathrm{~h}$. After that, RNA was isolated to determine gene expression of CATHs by qPCR analysis in (A) HD11 cells and (B) primary macrophages. Relative gene expression levels were normalized against the expression levels of the house keeping gene GAPDH; fold change is presented compared to non-infected cells. Data are represented as mean \pm SEM of three independent experiments of triplicate samples per experiment.
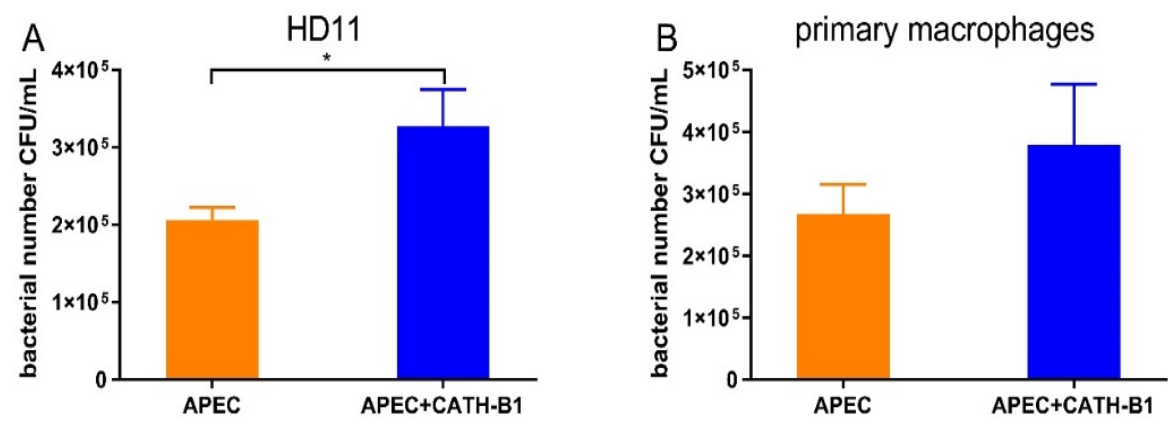

Fig 2. The effect of CATH-B1 on bacterial phagocytosis in chicken macrophages. Cells were infected with APEC for $3 \mathrm{~h}$ in the presence of $5 \mu \mathrm{M}$ CATH-B1, then gentamicin was added to kill extracellular bacteria for $1 \mathrm{~h}$. Finally, cells were lysed to quantify intracellular bacteria in (A) HD11 cells and (B) in primary macrophages. Data are represented as mean $\pm \mathrm{SEM}$ of three independent experiments of triplicate samples per experiment. ${ }^{*} \mathrm{P} \leqslant 0.05$.

\section{Cytotoxicity of CATH-B1}

To determine the toxic effect of CATH-B1 on host cells, the WST-1 assay was used to measure metabolic activity of primary macrophages. CATH-2 was used as a control in this study, which induced cell damage at $5 \mu \mathrm{M}$, at which a $40 \%$ reduction in metabolic activity was detected. CATH-B1 was less toxic than CATH-2 but reduced metabolic activity at concentrations of $10 \mu \mathrm{M}$ or higher (Fig. 4). 


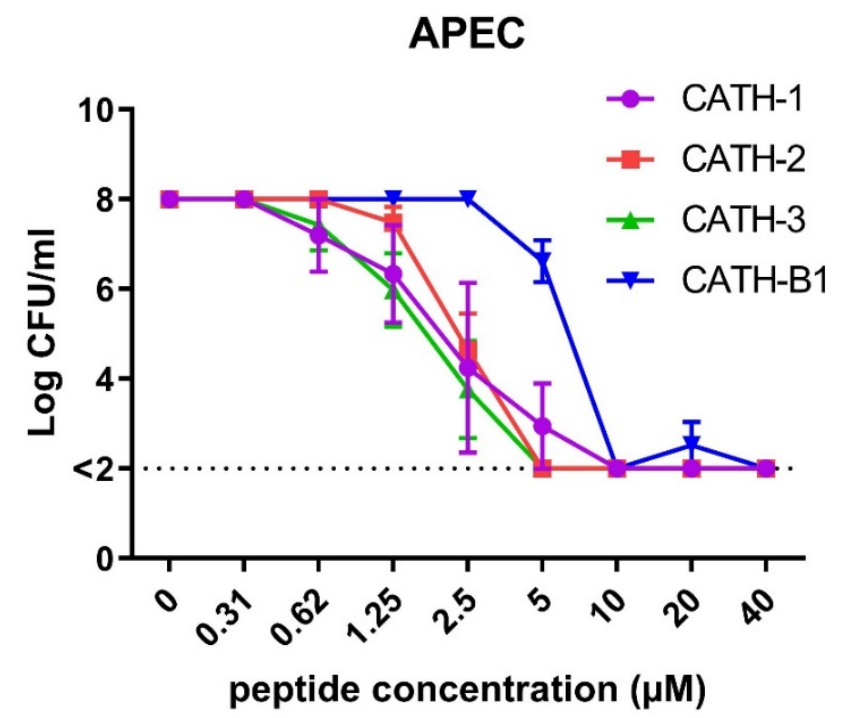

Fig 3. Antibacterial activity of chicken cathelicidins against APEC. Bacteria were incubated with different concentrations of cathelicidins for $3 \mathrm{~h}$, serially diluted and spread plated on TSA plates to quantify viable bacteria. Data are represented as mean \pm SEM of three independent experiments of triplicate samples per experiment.

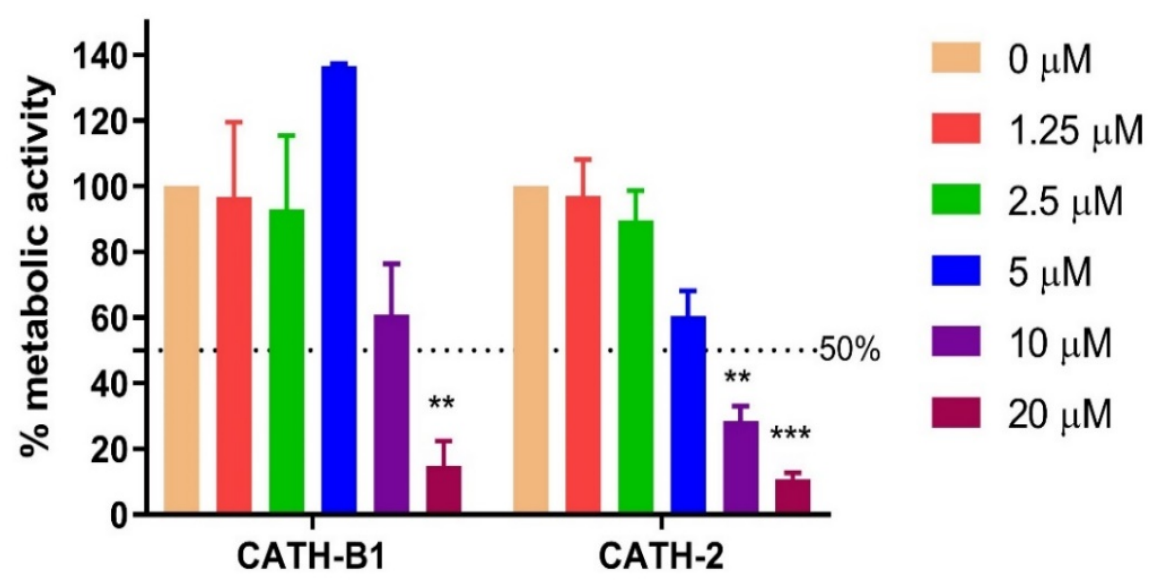

Fig 4. Cytotoxicity of chicken CATH-B1 and CATH-2. Primary macrophages were incubated with different concentrations $(0-20 \mu \mathrm{M})$ of CATH-B1 and CATH-2 for $3 \mathrm{~h}$. Peptides were removed and cells were maintained in new medium for another $3 \mathrm{~h}$. Metabolic activity was tested using WST-1 reagent. Data are represented as mean \pm SEM of three independent experiments of triplicate samples per experiment. $* \mathrm{P} \leqslant 0.05 ; * * \mathrm{P} \leqslant 0.01 ; * * * \mathrm{P} \leqslant$ $0.005 ; * * * * \mathrm{P} \leqslant 0.001$. 


\section{The effect of CATH-B1 on APEC-induced cytokine expression in macrophages}

Activation of macrophages resulting in the release of cytokines is a key immune response against pathogens. However, overexpression of inflammatory cytokines can cause apoptosis of cells leading to tissue damage. Therefore, it is important to have a balanced response of the immune system with respect to release of these cytokines. To investigate whether CATH$\mathrm{B} 1$ regulates APEC-induced activation of macrophages, APEC-induced cytokine expression in the presence or absence of CATH-B1 (and CATH-2 as control) was determined using qPCR. To separate immunomodulatory effects from antibacterial activity of CATH-B1, heatkilled APEC was also used in this experiment. At $3 \mathrm{~h}$ post infection, both viable and heatkilled APEC strongly up-regulated gene expression of pro-inflammatory cytokines IL-1 $\beta$ and IL-6, chemokine IL-8 and the anti-inflammatory cytokine IL-10 (Fig. 5). Both CATH-B1 and CATH-2 downregulated gene expression of these cytokines. Gene expression of IFN- $\beta$ was also upregulated by APEC and both CATH-B1 and CATH-2 significantly inhibited IFN$\beta$ expression (Fig. 5). Interestingly, APEC-induced gene expression of IL-10 was increased by CATH-B1 and CATH-2 (Fig. 5) but the increase was not significant.

To investigate how CATH-B1 inhibited APEC-induced activation, primary macrophages were pre-incubated with peptides prior to or post APEC infection. APEC-induced gene expression after 3 and $6 \mathrm{~h}$ (depending on the setup of the experiment) was similar for IFN- $\beta$, IL-1 $\beta$, IL-8 and IL-10, except for IL-6 gene expression, which was significantly higher after $6 \mathrm{~h}$ (Fig. 6). The inhibitory effect of CATH-B1 on cytokine gene expression, observed in coincubation conditions, was lost in pre- and post-incubation conditions. Noticeably, there was one exception, macrophages pre-incubated with CATH-B1 expressed significantly more IL10 compared to macrophages without CATH-B1. Overall, this indicates an antiinflammatory effect of CATH-B1 on APEC-infected macrophages.

\section{The effect of CATH-B1 on LPS-induced cytokines expression in macrophages}

To further investigate the functional properties of CATH-B1, E. coli LPS-induced cytokine gene expression in the presence or absence of peptides was determined. Again, in these experiments CATH-2 was used as a positive control since CATH-2 has been described to neutralize LPS and that CATH-2-LPS binding was essential for this (12). LPS-induced gene expression of IFN- $\beta$, IL-1 $\beta$, IL-6, IL-8 and IL-10 was significantly downregulated by both CATH-B1 and CATH-2 (Fig. 7A). To investigate whether the inhibitory effect of CATH-B1 is host cell specific, we also tested IL-6 protein production in LPS-stimulated mouse macrophages using ELISA. Also, in mouse macrophages, the cytokine production was inhibited by CATH-B1 (Supplementary Fig. 2), suggesting that the inhibition is due to the interaction of CATH-B1 and LPS. Finally, ITC analysis was used to determine the direct interaction of CATH-B1 and LPS (Fig. 7B). Peptide binding to LPS was detected with an 
observed dissociation constant of $\mathrm{Kd}=1.0 \mu \mathrm{M}$ in a reaction driven by both enthalpy $(\Delta \mathrm{H}=$ $-19.6 \mathrm{~kJ} \cdot \mathrm{mol}^{-1}$ ) and entropy $\Delta \mathrm{S}=51.3 \mathrm{~J} \cdot \mathrm{mol}^{-1}$ ). This indicates that CATH-B1 inhibits LPSinduced cytokine expression in macrophages by binding to LPS and thereby neutralizing LPS, similar as has been described for CATH-2.
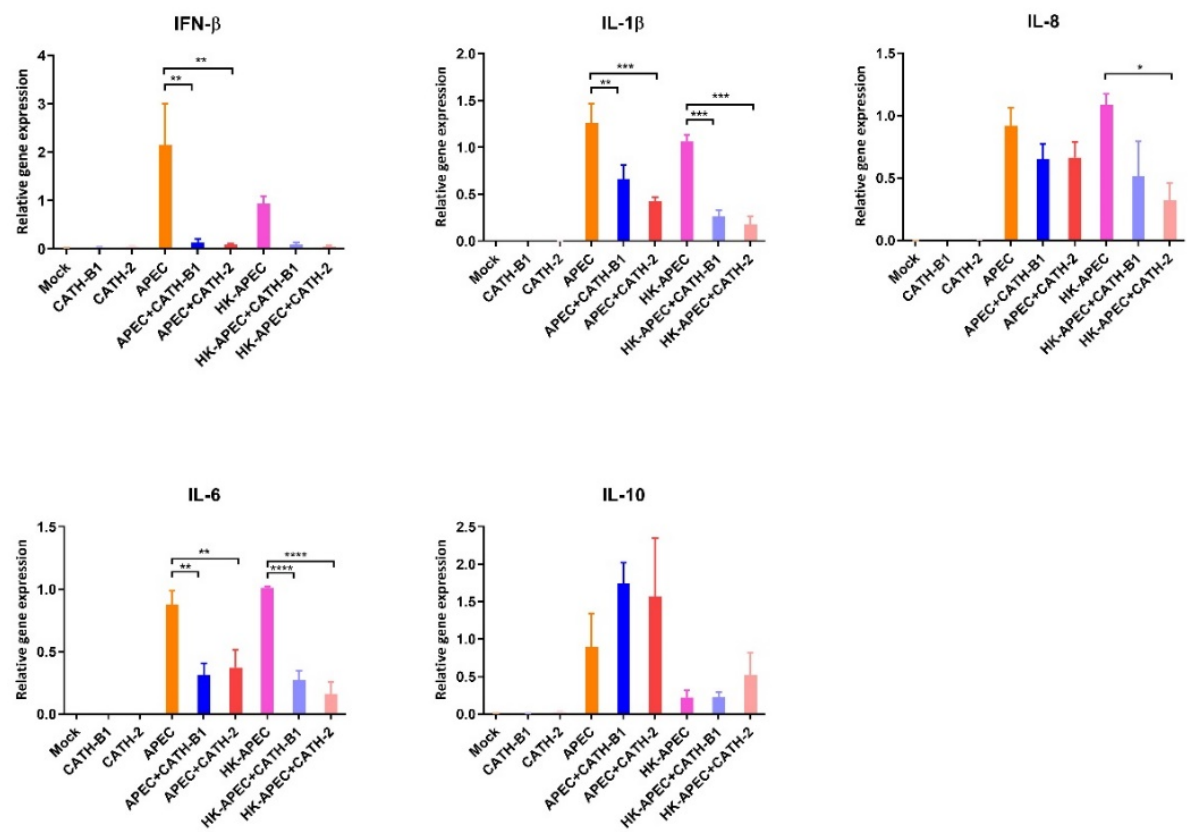

Fig 5. The effect of CATH-B1 on APEC-induced cytokine expression in primary macrophages. Gene expression of cytokines in primary macrophages were determined by qPCR at $3 \mathrm{~h}$ post infection in the presence or absence of $5 \mu \mathrm{M}$ CATH-2 and CATH-B1. Relative gene expression levels were normalized against the expression level of the house keeping gene GAPDH. Data are represented as mean $\pm \mathrm{SEM}$ of three independent experiments of triplicate samples per experiment. $* \mathrm{P} \leq 0.05 ; * * \mathrm{P} \leq 0.01 ; * * * \mathrm{P} \leq 0.005 ; * * * * \mathrm{P} \leq 0.001$. 

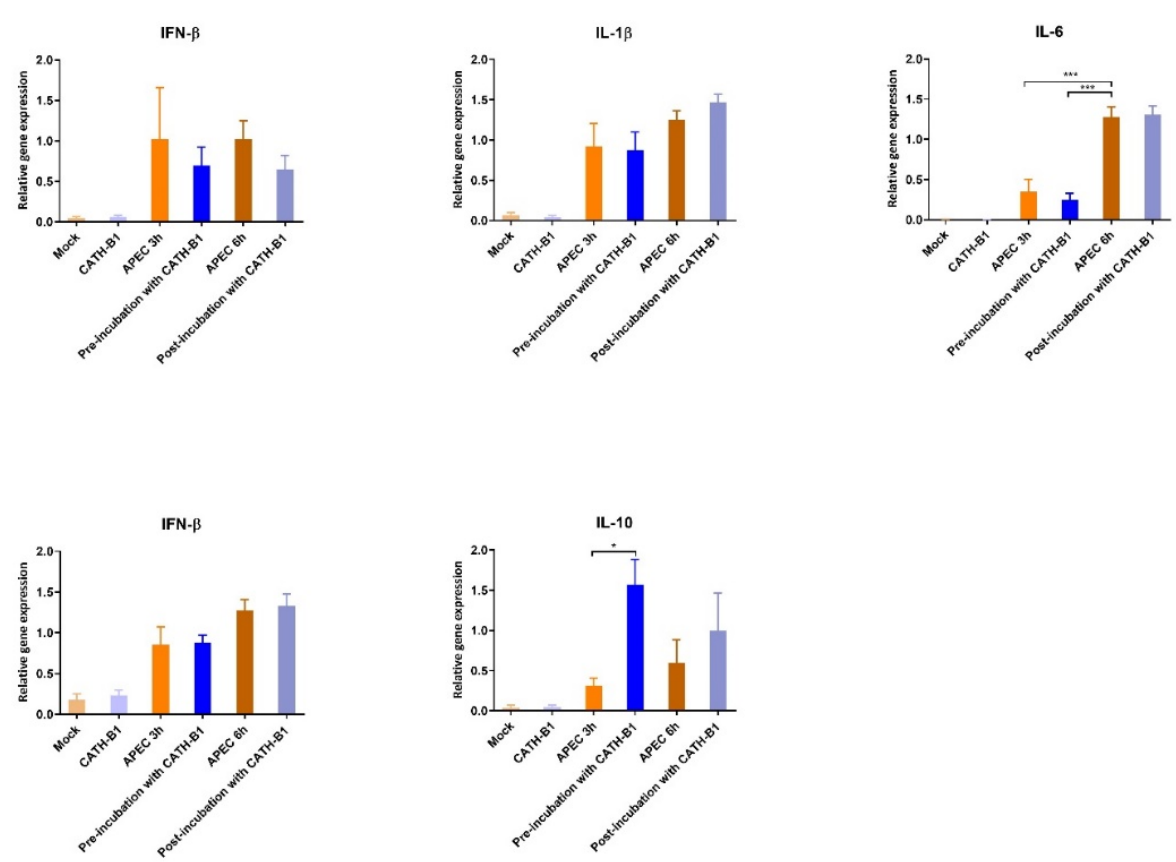

Fig 6. APEC-induced cytokine expression in primary macrophages upon pre- and post-incubation of CATHB1. Primary macrophages were pre-incubated with $5 \mu \mathrm{M}$ CATH-B1 for $3 \mathrm{~h}$ before APEC infection, or postincubated with $5 \mu \mathrm{M}$ CATH-B1 after APEC infection. Then, gene expression of cytokines was determined by qPCR. Gene expression levels were normalized against the expression levels of the house keeping gene GAPDH. Data are represented as mean $\pm \mathrm{SEM}$ of three independent experiments of triplicate samples per experiment. ${ }^{*} \mathrm{P} \leq 0.05$; $* * \mathrm{P} \leq 0.01 ; * * * \mathrm{P} \leq 0.005 ; * * * * \mathrm{P} \leq 0.001$.

\section{The effect of CATH-B1 on DNA-induced NO production in HD11 cells}

Extracellular microbial DNA is an important signaling molecule in infection and inflammation. Bacterial DNA can be released from phagolysosomes after phagocytosis and bacterial degradation by macrophages, leading to activation of bystander macrophages (22). CATH-2 has been shown to increase uptake of extracellular DNA and boost subsequent TLR9 or TLR21 activation (11). To investigate whether CATH-B1 enhances DNA-induced macrophage activation, as shown before for CATH-2, HD11 cells were incubated with ODN2006 in the presence or absence of CATH-B1 and CATH-2 as control. ODN-2006-induced NO production was determined by the Griess assay. HD11 cells did not produce NO without stimulation nor did peptides alone induce NO, whereas high concentration of ODN-2006 (40 $\mathrm{nM}$ ) strongly increased the NO production (data not shown). The ODN-2006-induced NO production was clearly enhanced by the presence of CATH-2 and CATH-B1, although a higher concentration of $5 \mu \mathrm{M}$ CATH-B1 was needed to enhance NO production compared to 
CATH-2 (Fig. 8A). This shows that although the overall effect of CATH-B1 on stimulation of macrophages by APEC is inhibitory, the potential to increase stimulation by enhancing uptake of bacterial DNA is also present. For CATH-2, it was shown that the increased response of macrophages towards ODN-2006 was depended on direct binding of CATH-2 to ODN-2006. Using ITC, it was shown that CATH-B1 indeed also strongly binds ODN-2006 (Fig. 8B) with a Kd-value of $64 \mathrm{nM}$. This binding between CATH-B1 and DNA was enthalpy-driven $\left(\Delta \mathrm{H}=-65.5 \mathrm{~kJ} \cdot \mathrm{mol}^{-1}\right)$ with a negative entropy value $(\Delta \mathrm{S}=-73.5 \mathrm{~J} . \mathrm{mol}-1)$.
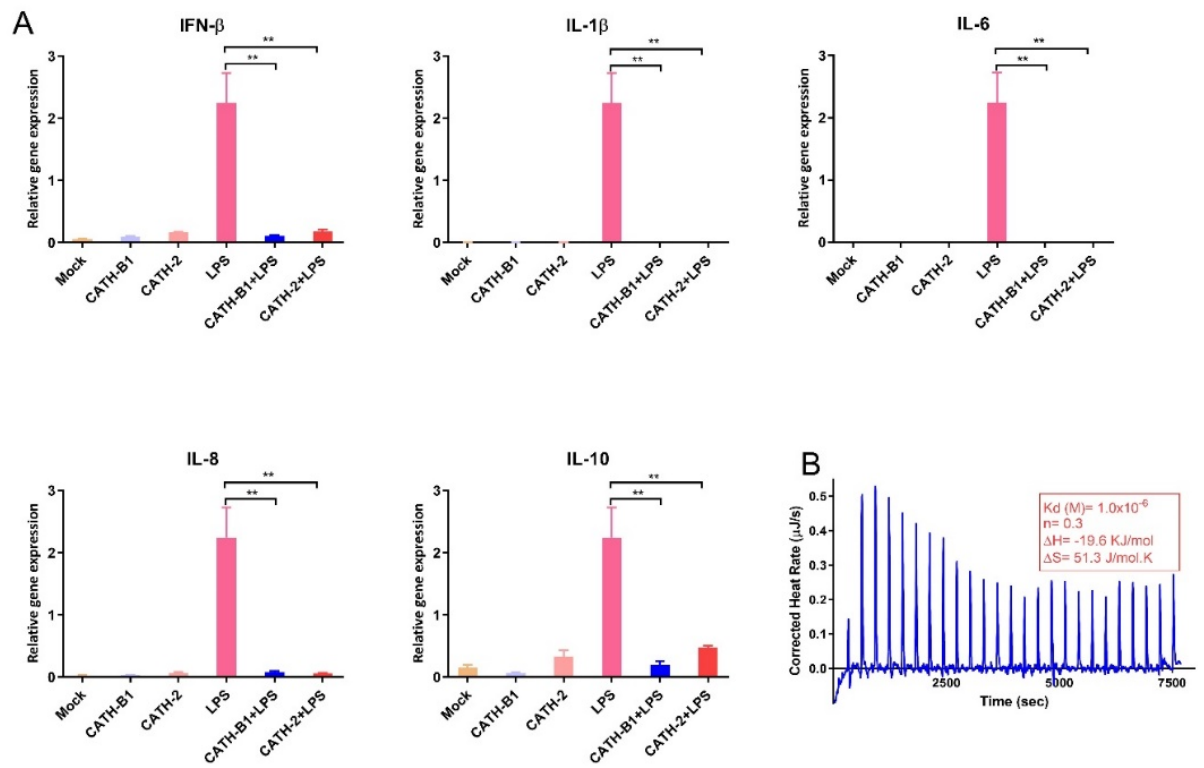

Fig 7. The effect of CATH-B1 on LPS-induced cytokine expression in primary macrophages. Primary macrophages were stimulated with LPS $(100 \mathrm{ng} / \mathrm{mL})$ for $4 \mathrm{~h}$ in the presence or absence of $5 \mu \mathrm{M} \mathrm{CATH}-2$ and CATH-B1. (A) gene expression of cytokines. Relative gene expression levels were normalized against the expression levels of the house keeping gene GAPDH. Data are represented as mean \pm SEM of three independent experiments of triplicate samples per experiment. ${ }^{*} \mathrm{P} \leq 0.05 ; * * \mathrm{P} \leq 0.01 ; * * * \mathrm{P} \leq 0.005 ; * * * * \mathrm{P} \leq 0.001$. (B) ITC thermogram of CATH-B1 binding to LPS E. coli O111:B4. ITC analysis data were calculated as $\mathrm{K}_{\mathrm{d}}=1.0 \times 10^{-6} \mathrm{M}$, $\Delta \mathrm{H}=-19.6 \mathrm{~kJ} \mathrm{~mol}^{-1}$ and $\Delta \mathrm{S}=51.3 \mathrm{~J}_{\mathrm{mol}}{ }^{-1}$.

\section{Discussion}

So far, four cathelicidins have been characterized in chicken, CATH-1, -2, -3, and -B1. In this study, we showed that APEC upregulates gene expression of CATH-B1 in macrophages but not of CATH-1, -2, -3. Recently, it was found by our group that CATH-B1 has strong antiviral activity against influenza A viruses in vitro (14). In this study, the 
immunomodulatory effect of CATH-B1 on APEC-, LPS- or ODN-2006-activated chicken macrophages was explored.

A

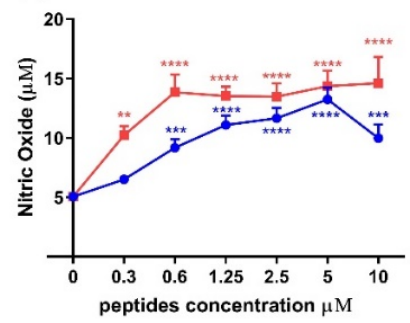

B

$\rightarrow$ CATH-B1

$\rightarrow$ CATH-2

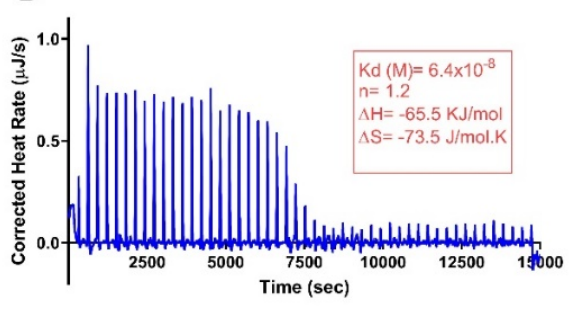

Fig 8. The effect of CATH-B1 on DNA-induced nitric oxide production in HD11 cells. HD11 cells were stimulated with $5 \mathrm{nM}$ ODN-2006 for $20 \mathrm{~h}$ in the presence or absence of different concentrations of peptides. (A) The amount of NO in the cell supernatant were measured by Griess assay. Data are represented as mean $\pm \operatorname{SEM}$ of three independent experiments of triplicate samples per experiment. $* \mathrm{P} \leqslant 0.05 ; * * \mathrm{P} \leqslant 0.01 ; * * * \mathrm{P} \leqslant 0.005 ; * * * * \mathrm{P} \leqslant$ 0.001. (B) ITC thermogram of CATH-B1 binding ODN-2006. ITC analysis data were calculated as $\mathrm{Kd}=6.4 \times 10^{-8}$ $\mathrm{M}, \Delta \mathrm{H}=-65.5 \mathrm{~kJ}^{\mathrm{mol}}{ }^{-1}$ and $\Delta \mathrm{S}=-73.5 \mathrm{~J} \mathrm{~mol}^{-1}$.

The expression of cathelicidins is regulated by many factors including inflammatory and microbial stimuli. In our study, APEC infection enhanced gene expression of CATH-B1 but no or limited upregulation of the other three cathelicidins genes was detected in chicken macrophages. CATH-1, $-2,-3$, in contrast to CATH-B1, are mainly expressed in heterophils, indicating that CATH-B1 gene expression is regulated separately from CATH-1, $-2,-3$ and might play a non-redundant role in macrophages. Similarly, butyrate which has known immunostimulatory activity was previously shown to enhance gene expression of CATH-B1 (but not CATH-1, -2, -3) in chicken primary monocytes. Butyrate also enhanced antibacterial activity of primary monocytes against $S$. enteritidis (20). In contrast to APEC infection, CATH-B1 gene expression was actually downregulated in peripheral blood leukocytes from a Salmonella typhimurium-infected chicken (23), but its expression was not affected by Campylobacter jejuni infection, suggesting that regulation of CATH-B1 expression is dependent on the infecting bacterial species, and likely also on the cell type studied. However, since gene expression and protein production do not always correlate, it is still needed to determine the localization and amount of CATH-B1 in different tissues and cells in normal and stimulated conditions.

Antimicrobial activity is an important function of cathelicidins. CATH-1, -2, -3 showed good anti-APEC activity, which is consistent with the described broad antimicrobial activity of CATH-1, -2, -3 against a set of both Gram-positive and Gram-negative bacteria (24). Compared to the other three cathelicidins, the antimicrobial activity of CATH-B1 is less studied. CATH-B1 has only been tested against a limited number of bacterial strains 
including E. coli, S. aureus, and P. aeruginosa with MIC values in the range of $0.63-2.5 \mu \mathrm{M}$ when tested against a low number of bacteria $\left(2 \times 10^{3} \mathrm{CFU}\right)(6)$. However, in another study the MIC value of CATH-B1 was as high as $12.8 \mu \mathrm{M}$ against $E$. coli and $S$. aureus using a higher number of bacteria (25), more closely resembling the results of this study. In addition, CATH-B1 had very weak anti-APEC activity in cell culture conditions, suggesting that direct killing of bacteria might not be the main activity of this cathelicidin.

Many studies have tried to correlate structure, charge and hydrophobicity to the antimicrobial activity of peptides. Chicken CATH-1, -2, -3 are largely unstructured in aqueous solution but can form an $\alpha$-helical amphipathic conformation in membrane-mimicking environment (5, $26,27)$. Proline residues often induce a kink in the helical structure of cathelicidins and this kink between the two helices is involved in antibacterial activity $(26,28)$. The structure of $\mathrm{CATH}-\mathrm{B} 1$ has been predicted, but its conformation has not been determined. However, there are some clear differences between CATH-1, -2, -3 and CATH-B1. CATH-B1 is longer and contains a lower number of positively charged residues. These differences could at least partially explain the observed difference in antimicrobial activity of CATH-B1, but future structure-activity studies should be performed to determine which characteristics of CATHB1 play a role in its antimicrobial activity.

In addition to direct microbial killing, cathelicidins can exert immunomodulatory effects on host cells. In previous studies, it has been shown that CATH-2 can strongly reduce activation of macrophages by neutralization of bacteria or bacterial products. In fact, it was hypothesized that CATH-2 has a dual role in first killing a pathogen and subsequently reducing an unwanted inflammatory reaction towards the dead bacterium (or its products) (12). Our results showed that CATH-B1 inhibited both viable- and heat-killed APEC-induced inflammatory responses in macrophages, although CATH-B1 did not actually kill bacteria. Subsequent studies on LPS binding and neutralization of LPS-induced immune responses suggest that CATH-B1 exerted similar anti-inflammatory properties to CATH-2 and several other host defense peptides $(29,30)$. Unlike the immunomodulatory functions of LL-37 that are described to be mediated by several receptors, such as FPR2/ALX (31), P2X7 (32) and EGFR (33), it is still unknow whether chicken cathelicidins regulate immune responses via interaction with specific cell receptors, or only act on bacterial ligands like LPS and DNA. Interestingly, when primary macrophages were preincubated with CATH-B1, upregulation of IL-10 expression was observed in response to APEC infection, suggesting that CATH-B1 might modulate inflammation via interaction with host factors.

Besides anti-inflammatory activity, host defense peptides also exert pro-inflammatory effects on host cells (34). In our previous study, CATH-2 has been shown to bind to DNA and enhance the DNA-induced TLR9/21 activation of macrophages (11). Similar to CATH-2, our 
results showed that CATH-B1 also enhances DNA-induced NO production in macrophages, likely using a similar mechanism in which peptide binds to DNA and is taken up as a complex. ITC showed indeed that CATH-B1 strongly bound DNA, with similar entropy-driven binding characteristics as CATH-2. This enhanced response was also induced by other host defense peptides, such as human/porcine cathelicidins and defensins (35-37). The combination of anti-inflammatory and pro-inflammatory properties of cathelicidins provide insight for development of therapeutic immunomodulators to maintain a balanced immune system in the host against microbial infection (38).

In this study, we found that CATH-B1 has no antibacterial activity in cell culture medium. This corresponds with previous studies that many cathelicidins lose their antimicrobial activity in the presence of serum or physiological salt concentrations $(39,40)$. This means that in vivo other antimicrobial mechanisms are needed to kill bacteria. One such way could be that cathelicidins use their immunomodulatory properties to regulate the immune system. On the other hand, it has been shown that cathelicidins can have synergistic effects with other host-derived antimicrobial agents against invading pathogens, such as lysozyme and lactoferrin (41). Therefore, participating in bacterial killing in in vivo conditions might still be an important feature of cathelicidins.

In conclusion, these studies show the overall anti-inflammatory effect of CATH-B1 on APEC-infected or LPS-stimulated macrophages. This functional exploration of CATH-B1 provides a useful first set of information that justifies further investigations into the role of this less studied chicken cathelicidin in vivo.

\section{Acknowledgement}

This work was supported by a personal fellowship from the China Scholarship Council (CSC) to Lianci Peng. 

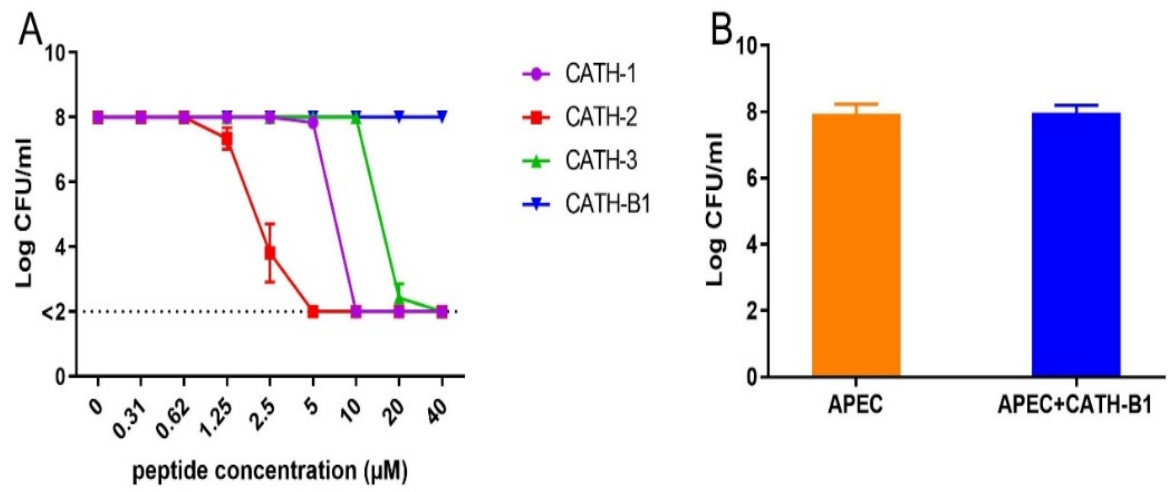

Supplementary fig 1. Antibacterial activity of chicken cathelicidins against APEC in cell culture medium. Bacteria were incubated with different concentrations of cathelicidins in DMEM or RPMI 1640-glutamax containing FCS for $3 \mathrm{~h}$, serially diluted and spread plated on agar media to quantify viable bacteria. (A) Antibacterial activity of cathelicidins in DMEM-glutamax medium containing FCS. (B) Antibacterial activity of $5 \mu$ M CATH-B1 in RPMI 1640-glutamax medium containing $10 \%$ FCS. Data are represented as mean \pm SEM of three independent experiments of triplicate samples per experiment.

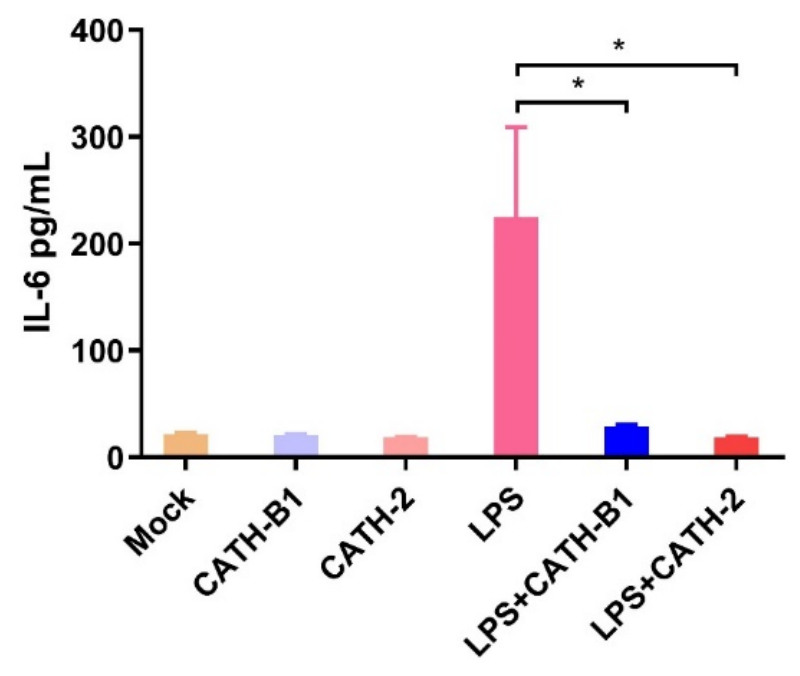

Supplementary fig 2. The effect of CATH-B1 on LPS-induced IL-6 protein production in mouse macrophages. RAW cells were incubated with LPS $(100 \mathrm{ng} / \mathrm{mL})$ in the presence or absence of $5 \mu \mathrm{M} \mathrm{CATH}-2$ and CATH-B1. Concentrations of IL- 6 in the cell supernatant were determined by ELISA. Data are represented as mean \pm SEM of three independent experiments of triplicate samples per experiment. $* \mathrm{P} \leqslant 0.05$. 


\section{References}

1. Kościuczuk EM, Lisowski P, Jarczak J, Strzałkowska N, Jóźwik A, Horbańczuk J, et al. Cathelicidins: family of antimicrobial peptides. A review. Molecular biology reports. 2012;39(12):10957-70.

2. Hemshekhar M, Anaparti V, Mookherjee N. Functions of cationic host defense peptides in immunity. Pharmaceuticals. 2016;9(3):40.

3. van Harten R, van Woudenbergh E, van Dijk A, Haagsman HP. Cathelicidins: immunomodulatory antimicrobials. Vaccines. 2018;6(3):63.

4. Zanetti M. The role of cathelicidins in the innate host defenses of mammals. Current issues in molecular biology. 2005;7(2):179-96.

5. Xiao Y, Cai Y, Bommineni YR, Fernando SC, Prakash O, Gilliland SE, et al. Identification and functional characterization of three chicken cathelicidins with potent antimicrobial activity. Journal of Biological Chemistry. 2006;281(5):2858-67.

6. Goitsuka R, Chen-lo HC, Benyon L, Asano Y, Kitamura D, Cooper MD. Chicken cathelicidin-B1, an antimicrobial guardian at the mucosal M cell gateway. Proceedings of the National Academy of Sciences. 2007;104(38):15063-8.

7. Van Dijk A, Veldhuizen EJ, van Asten AJ, Haagsman HP. CMAP27, a novel chicken cathelicidin-like antimicrobial protein. Immunopathology 2005;106(3-4):321-7.

8. Van Dijk A, Molhoek E, Bikker F, Yu P-L, Veldhuizen E, Haagsman HP. Avian cathelicidins: paradigms for the development of anti-infectives. Veterinary Microbiology 2011;153(1-2):27-36.

9. Van Dijk A, Tersteeg-Zijderveld MH, Tjeerdsma-van Bokhoven JL, Jansman AJ, Veldhuizen EJ, Haagsman HP. Chicken heterophils are recruited to the site of Salmonella infection and release antibacterial mature Cathelicidin-2 upon stimulation with LPS. Molecular immunology. 2009;46(7):1517-26.

10. van Dijk A, van Eldik M, Veldhuizen EJ, Tjeerdsma-van Bokhoven HL, de Zoete MR, Bikker FJ, et al. Immunomodulatory and anti-inflammatory activities of chicken cathelicidin-2 derived peptides. PloS one. 2016;11(2).

11. Coorens M, van Dijk A, Bikker F, Veldhuizen EJ, Haagsman HP. Importance of endosomal cathelicidin degradation to enhance DNA-induced chicken macrophage activation. The journal of immunology. 2015;195(8):3970-7.

12. Coorens M, Schneider VA, de Groot AM, van Dijk A, Meijerink M, Wells JM, et al. Cathelicidins inhibit escherichia coli-induced tlr2 and tlr4 activation in a viability-dependent manner. The Journal of Immunology. 2017;199(4):1418-28.

13. Cuperus T, van Dijk A, Matthijs MG, Veldhuizen EJ, Haagsman HP. Protective effect of in ovo treatment with the chicken cathelicidin analog D-CATH-2 against avian pathogenic E. coli. Scientific reports. 2016;6:26622.

14. Peng L, Du W, Balhuizen MD, Haagsman HP, de Haan CAM, Veldhuizen EJA. Antiviral Activity of Chicken Cathelicidin B1 Against Influenza A Virus. Frontiers in microbiology. 2020;11(426). 
15. Sekelova Z, Stepanova H, Polansky O, Varmuzova K, Faldynova M, Fedr R, et al. Differential protein expression in chicken macrophages and heterophils in vivo following infection with Salmonella Enteritidis. Veterinary research. 2017;48(1):35.

16. Guabiraba R, Schouler C. Avian colibacillosis: still many black holes. FEMS microbiology letters. 2015;362(15):fnv118.

17. Toth T, Siegel P, Veit H. Cellular defense of the avian respiratory system. Influx of phagocytes: elicitation versus activation. Avian diseases. 1987:861-7.

18. Ariaans MP, Matthijs MG, van Haarlem D, van de Haar P, van Eck JH, Hensen EJ, et al. The role of phagocytic cells in enhanced susceptibility of broilers to colibacillosis after infectious bronchitis virus infection. Veterinary immunology and immunopathology. 2008;123(3-4):240-50.

19. Matthijs MG, Ariaans MP, Dwars RM, van Eck JH, Bouma A, Stegeman A, et al. Course of infection and immune responses in the respiratory tract of IBV infected broilers after superinfection with E. coli. Veterinary immunology and immunopathology. 2009;127(1-2):77-84.

20. Sunkara LT, Achanta M, Schreiber NB, Bommineni YR, Dai G, Jiang W, et al. Butyrate enhances disease resistance of chickens by inducing antimicrobial host defense peptide gene expression. PLoS one. 2011;6(11):e27225.

21. Achanta M, Sunkara LT, Dai G, Bommineni YR, Jiang W, Zhang G. Tissue expression and developmental regulation of chicken cathelicidin antimicrobial peptides. Journal of animal science and biotechnology. 2012;3(1):15.

22. Charrel-Dennis M, Latz E, Halmen KA, Trieu-Cuot P, Fitzgerald KA, Kasper DL, et al. TLR-independent type I interferon induction in response to an extracellular bacterial pathogen via intracellular recognition of its DNA. Cell host \& microbe. 2008;4(6):543-54.

23. Meade KG, Narciandi F, Cahalane S, Reiman C, Allan B, O'Farrelly C. Comparative in vivo infection models yield insights on early host immune response to Campylobacter in chickens. Immunogenetics. 2009;61(2):10110 .

24. Veldhuizen EJ, Brouwer EC, Schneider VA, Fluit AC. Chicken cathelicidins display antimicrobial activity against multiresistant bacteria without inducing strong resistance. PloS one. 2013;8(4):e61964.

25. Takeda A, Tsubaki T, Sagae N, Onda Y, Inada Y, Mochizuki T, et al. Bacterial toxin-inducible gene expression of cathelicidin-B1 in the chicken bursal lymphoma-derived cell line DT40: functional characterization of cathelicidin-B1. Peptides. 2014;59:94-102.

26. Xiao Y, Herrera AI, Bommineni YR, Soulages JL, Prakash O, Zhang G. The central kink region of fowlicidin2 , an $\alpha$-helical host defense peptide, is critically involved in bacterial killing and endotoxin neutralization. Journal of Innate Immunity. 2009;1(3):268-80.

27. Bommineni YR, Dai H, Gong YX, Soulages JL, Fernando SC, DeSilva U, et al. Fowlicidin-3 is an $\alpha$-helical cationic host defense peptide with potent antibacterial and lipopolysaccharide-neutralizing activities. The FEBS journal. 2007;274(2):418-28.

28. Van Dijk A, Molhoek EM, Veldhuizen EJ, Tjeerdsma-van Bokhoven JL, Wagendorp E, Bikker F, et al. Identification of chicken cathelicidin-2 core elements involved in antibacterial and immunomodulatory activities. Molecular immunology. 2009;46(13):2465-73. 
29. Hu Z, Murakami T, Suzuki K, Tamura H, Kuwahara-Arai K, Iba T, et al. Antimicrobial cathelicidin peptide LL-37 inhibits the LPS/ATP-induced pyroptosis of macrophages by dual mechanism. PloS one. 2014;9(1):e85765.

30. Scheenstra MR, van den Belt M, Tjeerdsma-van Bokhoven JL, Schneider VA, Ordonez SR, van Dijk A, et al. Cathelicidins PMAP-36, LL-37 and CATH-2 are similar peptides with different modes of action. Scientific reports. 2019;9(1):4780.

31. Yang D, Chen Q, Schmidt AP, Anderson GM, Wang JM, Wooters J, et al. LL-37, the neutrophil granule-and epithelial cell-derived cathelicidin, utilizes formyl peptide receptor-like 1 (FPRL1) as a receptor to chemoattract human peripheral blood neutrophils, monocytes, and T cells. Journal of Experimental Medicine. 2000;192(7):1069-74.

32. Elssner A, Duncan M, Gavrilin M, Wewers MD. A novel P2X7 receptor activator, the human cathelicidinderived peptide LL37, induces IL-1 $\beta$ processing and release. The Journal of Immunology. 2004;172(8):498794.

33. Tokumaru S, Sayama K, Shirakata Y, Komatsuzawa H, Ouhara K, Hanakawa Y, et al. Induction of keratinocyte migration via transactivation of the epidermal growth factor receptor by the antimicrobial peptide LL-37. The journal of immunology. 2005;175(7):4662-8.

34. Easton DM, Nijnik A, Mayer ML, Hancock RE. Potential of immunomodulatory host defense peptides as novel anti-infectives. Trends in biotechnology. 2009;27(10):582-90.

35. Lande R, Gregorio J, Facchinetti V, Chatterjee B, Wang Y-H, Homey B, et al. Plasmacytoid dendritic cells sense self-DNA coupled with antimicrobial peptide. Nature. 2007;449(7162):564.

36. Baumann A, Démoulins T, Python S, Summerfield A. Porcine cathelicidins efficiently complex and deliver nucleic acids to plasmacytoid dendritic cells and can thereby mediate bacteria-induced IFN- $\alpha$ responses. The Journal of Immunology. 2014;193(1):364-71.

37. Tewary P, de la Rosa G, Sharma N, Rodriguez LG, Tarasov SG, Howard OZ, et al. $\beta$-Defensin 2 and 3 promote the uptake of self or CpG DNA, enhance IFN- $\alpha$ production by human plasmacytoid dendritic cells, and promote inflammation. The Journal of Immunology. 2013;191(2):865-74.

38. Mookherjee N, Anderson MA, Haagsman HP, Davidson DJ. Antimicrobial host defence peptides: functions and clinical potential. Nature Reviews Drug Discovery 2020:1-22.

39. Johansson J, Gudmundsson GH, Rottenberg MnE, Berndt KD, Agerberth B. Conformation-dependent antibacterial activity of the naturally occurring human peptide LL-37. Journal of Biological Chemistry. 1998;273(6):3718-24.

40. Coorens M, Scheenstra MR, Veldhuizen EJ, Haagsman HP. Interspecies cathelicidin comparison reveals divergence in antimicrobial activity, TLR modulation, chemokine induction and regulation of phagocytosis. Scientific reports. 2017;7(1):1-11.

41. van der Linden DS, Short D, Dittmann A, Yu P-L. Synergistic effects of ovine-derived cathelicidins and other antimicrobials against Escherichia coli O157: H7 and Staphylococcus aureus 1056 MRSA. Biotechnology letters. 2009;31(8):1265-7. 



\section{Chapter 6}

\section{Antiviral activity of chicken cathelicidin B1 against influenza $A$ virus}

Lianci Peng, Wenjuan Du, Melanie D. Balhuizen, Henk P. Haagsman, Cornelis A.M. de Haan, Edwin J.A. Veldhuizen*

Department of Biomolecular Health Sciences, Division of Infectious Diseases \& Immunology, Section of Molecular Host Defence, Faculty of Veterinary Medicine, Utrecht University, Utrecht, The Netherlands.

Frontiers in Microbiology (2020) 11: 426

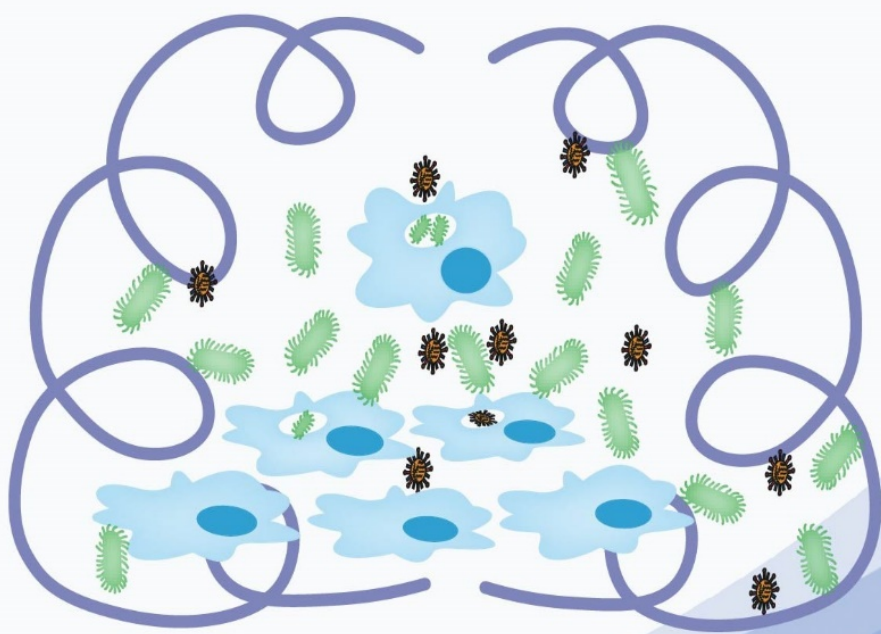




\begin{abstract}
Cathelicidins (CATHs) are host defense peptides (HDPs) that play an important role in the innate immune response against infections. Although multiple functions of cathelicidins have been described including direct antimicrobial activity and several immunomodulatory effects on the host, relatively little is known about their antiviral activity. Therefore, in vitro antiviral activity of chicken cathelicidins and the underlying mechanism was investigated in this study against different influenza A virus (IAVs) strains. Our results show that chicken CATH-B1 has broad anti-IAV activity compared to other cathelicidins (CATH-1, -2, -3, LL-37, PMAP23 and $\mathrm{K} 9 \mathrm{CATH}$ ) with an inhibition of viral infection up to $80 \%$ against three tested IAV strains (H1N1, H3N1 and H5N1). In agreement herewith, CATH-B1 affected virus-induced inflammatory cytokines expression (IFN- $\beta$, IL-1 $\beta$, IL-6 and IL-8). Incubation of cells with CATH-B1 prior to or after their inoculation with virus did not reduce viral infection indicating that direct interaction of virus with the peptide was required for CATH-B1's antiviral activity. Experiments using combined size exclusion and affinity-based separation of virus and peptide also indicated that CATH-B1 bound to viral particles. In addition, using electron microscopy, no morphological change of virus itself was seen upon incubation with CATH-B1 but large aggregates of CATH-B1 and viral particles were observed, indicating that aggregation might be the mechanism of action reducing IAV infectivity. Neuraminidase (NA) activity assays using monovalent or multivalent substrates, indicated that CATH-B1 did not affect NA activity per se, but negatively affected the ability of virus particles to interact with multivalent receptors, presumably by interfering with hemagglutinin activity. In conclusion, our results show CATH-B1 has good antiviral activity against IAV by binding to the viral particle and thereby blocking viral entry.
\end{abstract}




\section{Introduction}

Cathelicidins are short cationic peptides with an important role in the innate immune response against infections. They are mainly expressed by leukocytes and epithelial cells at infection sites in the host. Cathelicidins have been found in all vertebrates, including pigs, dogs, human and chicken, but with some diversity in number and structure. For example, only one 37 amino acid long cathelicidin (LL-37) is present in human while chicken has four cathelicidins (CATH-1, -2, -3 and -B1) with varying length. Cathelicidins have direct antimicrobial activity against a broad range of bacteria and also possess many immunomodulatory functions on host cells $(1,2)$. Out of the chicken cathelicidins, CATH-2 has been most studied. Besides having broad antibacterial activity, it can inhibit LPS-induced TLR4 activation and enhance DNA-induced TLR9 or TLR21 activation in macrophages (3, 4). Furthermore, CATH-2 treatment in ovo has been described to reduce mortality induced by avian pathogenic E. coli in chicken (5). Less information is known about the other chicken cathelicidins although some studies already focused on CATH-1 and CATH-3. CATH-1 and CATH-3 seem to share at least the antimicrobial potency and their localization with CATH$2(6,7)$. On the contrary, the function of CATH-B1 is hardly studied, but it is different from CATH-1, $-2,-3$ by its localization in the bursa of Fabricius in chicken (8). In addition, the antiviral activity for all chicken cathelicidins is still unknown.

Influenza A virus (IAV) is an important pathogen of human and animals. Infection with IAV causes acute respiratory diseases leading to serious morbidity and mortality in human and many animal species. In the past 100 years, influenza A viruses, such as H1N1 in 1918 and H3N2 in 1968, have caused severe pandemics in human $(9,10)$. Animal IAVs, such as highly pathogenic IAV H5N1, pose a constant threat of causing a new pandemic. This latter virus has been reported to infect humans with a mortality rate of 52.8\% from 2003-2019 (source: WHO). Moreover, due to rapid genomic variation of IAVs, novel variants are emerging (such as H7N9 in 2013) that pose a new threat to human health (11). Currently, vaccination and anti-IAV drugs are being used to prevent and treat IAV infections. The efficacy of vaccination is, however, limited in part due to antigenic variation, while the use of anti-IAV drugs is limited by the development of resistance. Therefore, novel preventive and therapeutic options against IAV infection are needed.

In this study, we investigated the antiviral activity and mechanism of chicken cathelicidins against IAVs. The outcome of our study provides useful information for the development of therapies against IAV infection. 


\section{Materials and Methods}

\section{Peptides}

All the peptides were synthesized by China Peptides (Shanghai, China) using Fmocchemistry. All peptides were purified by reverse phase high-performance liquid chromatography to a purity $>95 \%$ (Table 1 ).

Table 1: Characteristics of peptides used in this study

\begin{tabular}{llll}
\hline Peptide & Amino acid sequence & length & charge \\
\hline CATH-1 & RVKRVWPLVIRTVIAGYNLYRAIKKK & 26 & +8 \\
CATH-2 & RFGRFLRKIRRFRPKVTITIQGSARF & 26 & +9 \\
CATH-3 & RVKRFWPLVPVAINTVAAGINLYKAIRRK & 29 & +7 \\
CATH-B1 & PIRNWWIRIWEWLNGIRKRLRQRSPFYVRGHLNVTSTPQP & 40 & +7 \\
LL-37 & LLGDFFRKSKEKIGKEFKRIVQRIKDFLRNLVPRTES & 37 & +6 \\
PMAP-23 & RIIDLLWRVRRPKPKFVTVWVR & 23 & +6 \\
K9 & RLKELITTGGQKIGEKIRRIGORIKDFFKNLQPREEKS & 38 & +6 \\
\hline
\end{tabular}

\section{Cell lines and viruses}

HD11 cells (a chicken macrophage cell line) and Madin-Darby Canine kidney (MDCK-II; ATCC) cells were cultured in RPMI 1640-glutamax and DMEM-glutamax (Gibco, UK), respectively, supplemented with $10 \%$ FCS and antibiotics $(100 \mathrm{U} / \mathrm{mL}$ penicillin and $100 \mu \mathrm{g} / \mathrm{mL}$ streptomycin).

Influenza virus A/Puerto Rico/8/34/Mount Sinai (H1N1/PR8) and reassortant viruses were propagated in MDCK-II cells as described previously and stored aliquoted at $-80^{\circ} \mathrm{C}$ until use. Generation of reassortant viruses H3N1 (containing the HA gene from A/Bilthoven/1761/76 (H3N2) in the genetic background of PR8) and H5N1 (containing the HA gene from A/duck/Hunan/795/2002 (H5N1) in the genetic background of PR8) was described previously $(12,13)$. The H3N1 virus was kindly provided by Ron Fouchier (Erasmus Medical Center, the Netherlands). Virus titers were determined for MDCK-II cells by calculating $50 \%$ tissue culture infectious dose per $\mathrm{ml}$ (TCID50/mL) as described before (14).

\section{Viral infection}

MDCK-II and HD11 cells, seeded in 96-well plate and grown to confluency, were infected with virus at a multiplicity of infection (MOI) of 0.1 in the presence or absence of cathelicidins (CATHs) for $1 \mathrm{~h}$ at $37{ }^{\circ} \mathrm{C}$. In pre-incubation studies CATHs were added to the cells for $1 \mathrm{~h}$, washed away with PBS after which IAV was added for $1 \mathrm{~h}$. Post incubation studies were performed similarly but with the order of peptide and virus addition reversed. All the initial infection and cathelicidin incubation steps were performed in the absence of 
serum. After these incubations, unbound virus or unbound peptide were removed by washing the cells twice with PBS (supplemented with $\mathrm{Ca}^{2+}$ and $\mathrm{Mg}^{2+}$ ). MDCK-II and HD11 cells were incubated for another $7 \mathrm{~h}$ with opti-MEM or RPMI 1640-glutamax supplemented with $2 \%$ FCS, respectively, at $37^{\circ} \mathrm{C}$. Subsequently, cells were fixed with cold methanol at $-20^{\circ} \mathrm{C}$ for 5 min, after which cells were stained with primary mouse monoclonal antibody HB65 (1:1000) specific for the viral nucleoprotein and Alexa Fluor 488-labeled Donkey anti-Mouse IgG antibodies (Life technologies, Eugene, USA) (1:1000) as described previously (15). Cells were visualized using the nuclear stain DAPI (Thermo Fischer Scientific) according to the manufacturer's instructions. Three images per well were taken using an EVOS FL microscope (Thermo Fisher Scientific) and the infected cells were counted. The number of infected cells in inoculated, mock-treated wells was set at $100 \%$.

To investigate whether a direct interaction of CATH-B1 with virus was present and possibly required for CATH-B1's activity, Capto Core 700 beads (GE Healthcare) were used to remove CATH-B1 not bound to virus. To this end, viruses were pre-incubated in opti-MEM medium with or without CATH-B1 for $30 \mathrm{~min}$ at $37^{\circ} \mathrm{C}$, after which Capto Core 700 beads were added to the samples and samples were incubated for $20 \mathrm{~min}$ at $4{ }^{\circ} \mathrm{C}$ while rotating. Afterwards, beads were spun down and supernatants were collected. To control for the efficient removal of CATH-B1, samples containing CATH-B1 but no virus were subjected to the same procedure. Cells were inoculated with the supernatants (or combinations thereof) and processed to determine the number of infected cells as described above.

\section{Cell Viability}

Cell viability was determined using the WST-1 assay following the manufacturer's protocol. In short, cells were incubated with peptides for $1 \mathrm{~h}$ at $37^{\circ} \mathrm{C}$, then peptides were washed away and cells were further incubated for either $7 \mathrm{~h}$ or $23 \mathrm{~h}$ at $37{ }^{\circ} \mathrm{C}$ (corresponding to the incubation times used for immunohistochemistry and detection of cytokine gene expression respectively). Cell culture medium was removed and replaced with fresh culture medium containing 10\% WST-1 reagent. After 20 min incubation, absorbance was measured at 450 $\mathrm{nm}$ with a FLUOstar Omega microplate reader and was corrected for absorbance at $630 \mathrm{~nm}$.

\section{Electron microscopy}

IAV (H3N1) was incubated in the presence or absence of CATH-B1 for $1 \mathrm{~h}$ at $37{ }^{\circ} \mathrm{C}$ and 10 $\mu \mathrm{L}$ sample was placed on a carbon-coated copper grid. Grids were washed three times with PBS and fixed with $1 \%$ glutaraldehyde (Sigma-Aldrich) in PBS for 10 minutes. Next, grids were washed two times with PBS and four times with MilliQ. Subsequently, grids were shortly rinsed with methylcellulose/uranyl acetate $(\mathrm{pH} 4)$ and incubated for 5 minutes with 
methylcellulose/uranyl acetate $(\mathrm{pH} 4)$ on ice. Finally, grids were looped out of the solution and air-dried. Samples were imaged on a Tecnai-12 electron microscope (FEI).

\section{MUNANA and ELLA assay}

The activity of NA in the presence of CATH-B1 towards the synthetic monovalent substrate 2'-(4-methylumbelliferyl)-alpha-D-N-acetylneuraminic acid (MUNANA) (Sigma-Aldrich) was determined by using a fluorometric assay similarly to what was described previously (16). In short, IAV was incubated with CATH-B1 $(0-40 \mu \mathrm{M})$ for $1 \mathrm{~h}$ at $37^{\circ} \mathrm{C}$, followed by addition of MUNANA for another $1 \mathrm{~h}$ at $37{ }^{\circ} \mathrm{C}$. Next, the reaction was stopped, and fluorescence intensity was measured using a FLUOstar Omega microplate reader. The activity of NA toward the sialylated glycoprotein fetuin was analyzed in a solid phase cleavage assay using a previously described enzyme linked lectin assay (ELLA) $(16,17)$. Fetuin (2.5 ug/mL) was coated on Maxisorp Nunc 96-well plates (Thermo Fisher Scientific). Plates were incubated with IAV PR8 $\left(1.78 \times 10^{8} \mathrm{PFU} / \mathrm{mL}\right)$ in the presence or absence of 5 $\mu \mathrm{M}$ CATH-B1 (in $50 \mathrm{mM}$ Tris- $\mathrm{HCl}$ with $4 \mathrm{mM} \mathrm{CaCl}_{2}, \mathrm{pH}=6$ ) for $2 \mathrm{~h}$ at $37^{\circ} \mathrm{C}$. Subsequently, the plates were washed three times with PBS/ $0.05 \%$ Tween 20 after which terminal galactose moieties were quantified using biotin-conjugated peanut agglutinin E. Cristagalli (ECA) lectin (Vector laboratories) $(1.5 \mu \mathrm{g} / \mathrm{mL})$ in combination with streptavidin-HRP (Thermo Fisher Scientific) (1:1000). After washing, TMB was added and plates were incubated for 1-4 minutes at room temperature. Sulfide acid (25\%) was used to stop the reaction. Finally, the plate was read at OD450 nm using the FLUOstar Omega microplate reader. Final OD450 $\mathrm{nm}$ values are presented as OD450 $\mathrm{nm}_{\text {sample-OD450 }} \mathrm{nm}_{\text {backgroud. }}$.

\section{Quantitative real-time PCR (qPCR)}

HD1 1 cells were infected with virus for $1 \mathrm{~h}$ at MOI of 1 in the presence or absence of CATHB1 as described above. After 8 or $24 \mathrm{~h}$ incubation, total RNA was extracted by Trizol (Ambion, Carlsbad, CA) reagent according to the manufacturer's instructions. RNA (500 ng) was reverse transcribed by the iScript cDNA synthesis kit (Bio-Rad, Veenendaal, the Netherlands) according to the manufacturer's instructions. Primers and probes were designed and produced by Eurogentec (Seraing, Belgium) (Table 2). Quantitative real time PCR was performed on a CFX Connect qPCR with CFX Manager 3.0 (Bio-Rad). Reactions were performed as follows: $3 \mathrm{~min}$ at $95^{\circ} \mathrm{C} ; 40$ cycles: $10 \mathrm{~s}$ at $95^{\circ} \mathrm{C}, 30 \mathrm{~s}$ at $60{ }^{\circ} \mathrm{C}$ and $30 \mathrm{~s}$ at $72{ }^{\circ} \mathrm{C}$. Relative gene expression levels were normalized against the expression levels of the house keeping gene GAPDH. 
Table 2: Primer and probe sequences for $q P C R$

\begin{tabular}{lll}
\hline Gene & & $\mathbf{5} \boldsymbol{\rightarrow} \mathbf{3}$ 'sequence \\
\hline GAPDH & Forward & GTCAACCATGTAGTTCAGATCGATGA \\
& Reverse & GCCGTCCTCTCTGGCAAAG \\
& Probe & AGTGGTGGCCATCAATGATCCC \\
IFN-a & Forward & GACAGCCAACGCCAAAGC \\
& Reverse & GTCGCTGCTGTCCAAGCATT \\
& Probe & TCCACCGCTACACCCAGCAGCACCTCG \\
IFN- $\boldsymbol{\beta}$ & Forward & CCTCCAACACCTCTTCAACACG \\
& Reverse & TGGCGTGTGCGGTCAAT \\
& Probe & AGCAGCCCACACACTCCAAAACACT \\
IL-1 $\boldsymbol{\beta}$ & Forward & GCTCTACTAGTCGTGTGTGATGAG \\
& Reverse & TGTCGATGTCCCGCATGA \\
& Probe & CCACACTGCAGCTGGAGGAAGCC \\
& Forward & GTCGAGTCTCTGTGCTAC \\
& Reverse & GTCTGGGATGACCACTTC \\
& Probe & ACGATCCGGCAGATGGTGA \\
& Forward & GCCCTCCTCCTGGTTCA \\
& Reverse & CGCAGCTCATTCCCCATCT \\
& Probe & TGCTCTGTCGCAAGGTAGGACGCTG \\
\hline
\end{tabular}

\section{Statistical analysis}

Data are represented as mean \pm SEM of three independent experiments for each group $(n=3)$ and were analyzed by a T-test for two groups or by one-way ANOVA with Tukey's multiple comparisons test for more than two groups. Bio-Rad CFX Manager 3.0 software was used for qPCR data analysis. All graphs were made using GraphPad Prism ${ }^{\circledR}$ 8.0.

\section{Results}

\section{Cytotoxicity and anti-IAVs activity of cathelicidins}

To investigate the anti-IAVs activity of cathelicidins, three IAV strains (H1N1/PR8, H3N1 and H5N1) were used in this study. Both HD11 and MDCK cells were inoculated with IAVs in the presence or absence of $5 \mu \mathrm{M}$ cathelicidins for $1 \mathrm{~h}$. After $1 \mathrm{~h}$, viruses and peptides were removed, and cells were incubated for another $7 \mathrm{~h}$. At 8 hours post infection (hpi), the number of infected cells was quantified by immunofluorescent labeling of the influenza nuclear protein. As shown in Fig. 1, the cathelicidins displayed different antiviral activities, which for some of them depended to some extent on the viral strain and the cell line used. PMAP23 and K9 did not significantly inhibit infection. Interestingly, LL-37 only showed activity against $\mathrm{H} 3 \mathrm{~N} 1$ and to a lower extent $\mathrm{H} 1 \mathrm{~N} 1$ but not against $\mathrm{H} 5 \mathrm{~N} 1$, while the chicken 
cathelicidins were active against all three influenza strains with inhibition of infectivity of 40-70\%. However, regardless of the cell line or viral strain used, CATH-B1 clearly displayed the strongest antiviral activity, inhibiting infection up to $80-90 \%$.
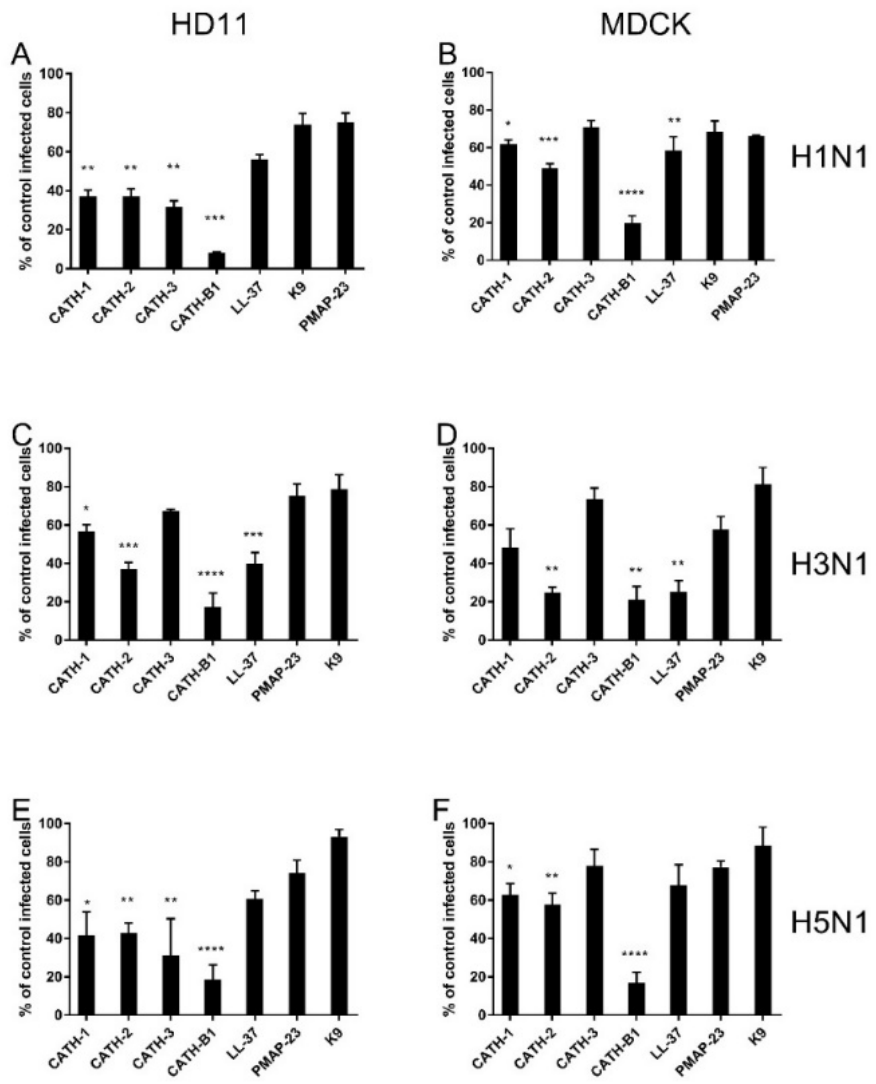

Fig 1. The antiviral effect of cathelicidins against 3 IAV strains (H1N1/PR8, H3N1 and H5N1). Cathelicidins were mixed with virus strains before addition to either HD11 or MDCK cells. H1N1/PR8 infection in the presence of cathelicidins of HD11 (A) and MDCK (B) cells. H3N1 infection in the presence of cathelicidins of HD11 (C) and MDCK (D) cells. H5N1 infection in the presence of cathelicidins of HD11 (E) and MDCK (F) cells. Viral infection was determined by immunofluorescent detection of IAV nuclear protein. Three images per well were taken using an EVOS FL microscope (Thermo Fisher Scientific) and the infected cells were counted. The infection rate in the presence of cathelicidins was normalized against only virus-treated wells. Data are represented as mean \pm SEM of three independent experiments of triplicate samples per experiment. ${ }^{*} \mathrm{p} \leq 0.05 ;{ }^{*} \mathrm{p} \leq 0.01 ;{ }^{* * *} \mathrm{p} \leq 0.005 ;{ }^{* * * *} \mathrm{p} \leq 0.001$.

The inhibitory infectivity of CATH-B1 was dose-dependent (Fig. 2), with an almost complete inhibition of viral infectivity of the $\mathrm{H} 1 \mathrm{~N} 1$ and $\mathrm{H} 3 \mathrm{~N} 1$ strains, while inhibition of H5N1 reached $85 \%$ (Fig. 2). The observed reduction in infected cells was not due to toxicity of cathelicidins towards the mammalian cell lines as shown by the WST assay (Fig. 3). 
Nevertheless, cytotoxicity was observed for CATH-1 and CATH-3 at $10 \mu \mathrm{M}$ to HD11 cells (Fig. 3A).

A

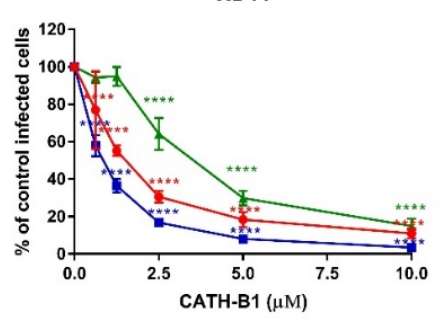

B

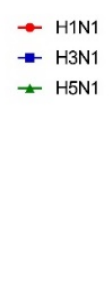

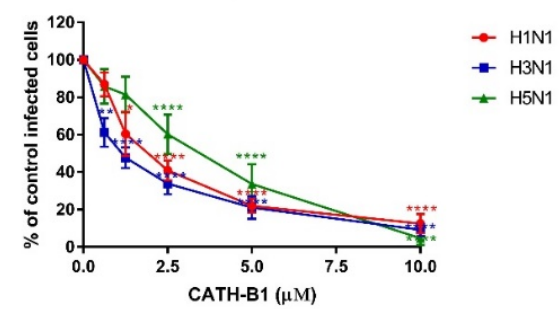

Fig 2. Dose-dependent antiviral activity of CATH-B1 against IAV strains (H1N1/PR8, H3N1 and H5N1). (A) Viral infection with CATH-B1 in HD11 cells. (B) Viral infection with CATH-B1 in MDCK cells. Viral infection was determined by immunofluorescent detection of IAV nuclear protein. Three images per well were taken using an EVOS FL microscope (Thermo Fisher Scientific) and the infected cells were counted. The infection rate in the presence of cathelicidins was normalized against only virus-treated wells. Data are represented as mean \pm SEM of three independent experiments of triplicate samples per experiment. ${ }^{*} \mathrm{p} \leq 0.05 ;{ }^{* *} \mathrm{p} \leq 0.01 ;{ }^{* * *} \mathrm{p} \leq 0.005 ;{ }^{* * * *} \mathrm{p} \leq 0.001$.
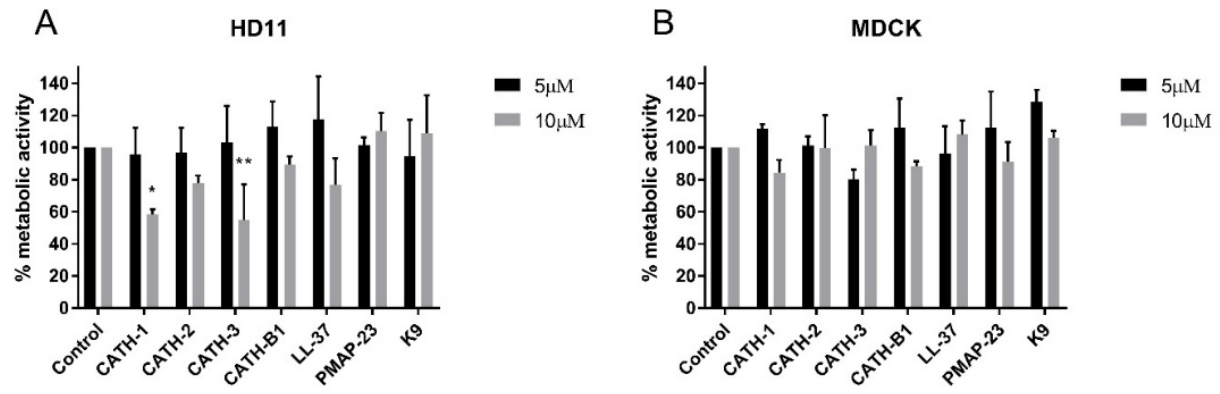

Fig 3. Cytotoxicity of cathelicidins. HD11 and MDCK cells were incubated with cathelicidins, and metabolic activity was tested using WST-reagent. (A) Metabolic activity of HD11 cells incubated for $24 \mathrm{~h}$ with cathelicidins. (B) Metabolic activity of MDCK cells incubated for $8 \mathrm{~h}$ with cathelicidins. Data are represented as mean $\pm \mathrm{SEM}$ of three independent experiments of triplicate samples per experiment. ${ }^{*} \mathrm{p} \leq 0.05 ;{ }^{*} \mathrm{p} \leq 0.01$.

When cathelicidins and virus were sequentially added to cells (either pre- or post-incubation of peptide relative to virus inoculation), the inhibitory effect was mostly lost (Supplementary fig. 1). This indicates that the antiviral effect of the peptides was not achieved through interaction with the HD11 or MDCK cells or by an inhibitory effect on viral replication after the viruses entered the cells, but that CATH-B1 likely blocked viral entry to the cells by direct interaction with the virus. 


\section{The effect of CATH-B1 on IAV-induced gene expression of cytokines in HD11 cells}

Activation of macrophages is important for viral clearance during IAV infection, but an excessive inflammatory response might cause morbidity and mortality (18-20). As several cathelicidins have been reported to affect innate immune responses $(3,4)$, we analyzed to what extent the presence of CATH-B1 affected these responses induced by infection of cells with IAV. To this end, virus-induced gene expression of cytokines in HD11 macrophages was determined by qPCR in the presence or absence of CATH-B1.

Virus infection resulted in induced gene expression of IFN- $\beta$, IL-1 $\beta$, IL-6, and IL-8, but surprisingly not IFN- $\alpha$. However, whether this lack of IFN- $\alpha$ gene expression was IAV strain specific was not further investigated. CATH-B1 downregulated PR8-induced gene expression of IFN- $\beta$, IL-1 $\beta$, IL- 6 , and IL-8, but the relative mRNA level of IFN- $\alpha$ was unaffected (Fig. 4A and supplementary fig. 2). CATH-2 and LL-37 also showed similar effects on gene expression upon virus infection, but the inhibition was not as pronounced as observed for CATH-B1, correlating with the effect of the peptides on virus infection shown in Fig. 1. The effect of CATH-B1 on virus-induced gene expression was diminished when the cells were incubated with CATH-B1 prior to, or immediately after virus infection (Fig. $4 \mathrm{~B})$, indicating that the reduction of the response results from the ability of the peptide to inhibit infection.
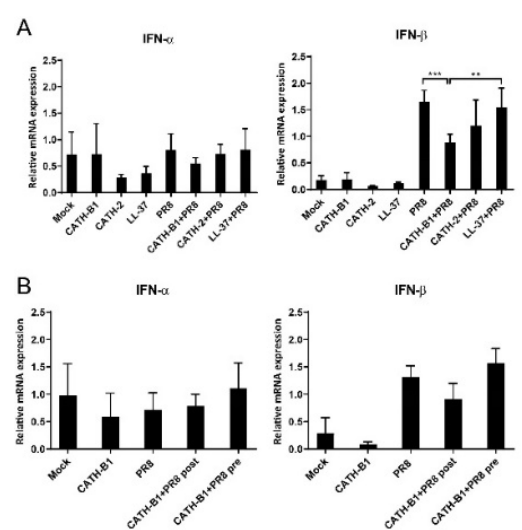

IFN- $\beta$

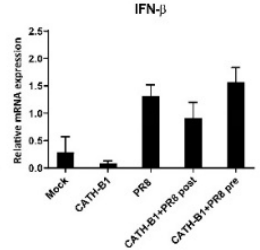

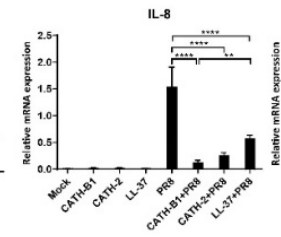

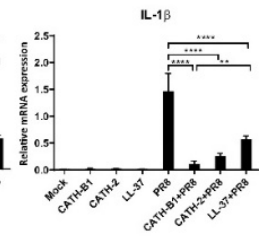

IL-6
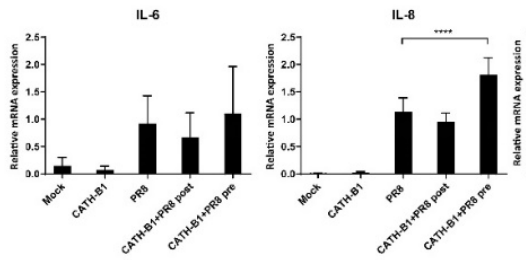

IL-1 $\beta$

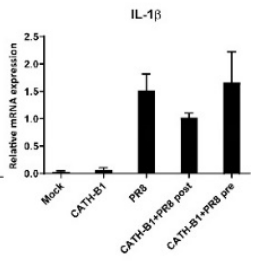

Fig 4. The effect of CATH-B1 on PR8-induced immune response in HD11 cells. (A) Cytokine expression in HD1 1 cells at 24 hpi in the presence or absence of peptides. (B) Cytokine expression in HD11 cells for pre- or postincubation with CATH-B1. Relative gene expression levels were normalized against the expression levels of the house keeping gene GAPDH. Data are represented as mean \pm SEM of two or three independent experiments of triplicate samples per experiment. $* \mathrm{P} \leq 0.05 ; * * \mathrm{P} \leq 0.01 ; * * * \mathrm{P} \leq 0.005 ; * * * * \mathrm{P} \leq 0.001$. 


\section{The interaction of CATH-B1 with IAV}

The inhibitory effect of CATH-B1 on virus infection and induction of cytokine responses is only observed when the peptide is present during inoculation of cells with virus, but not when cells are exposed to the peptides prior to or immediately after virus infection. This suggests that a direct interaction of the peptide with the virus is required for its antiviral effect. To further investigate the antiviral mechanism of CATH-B1, a series of experiments was performed using H1N1. Firstly, a crucial role for a direct interaction of CATH-B1 with virus particles was analyzed by removal of unbound CATH-B1 using Capto Core 700 beads. As controls, incubation of virus itself with the beads did not affect virus infectivity (Fig. 5, red bar), while addition of CATH-B1 solution to virus preparations again resulted in $80 \%$ reduction of virus infectivity on HD11 cells (Fig. 5, dark green bar). Incubation of CATH$\mathrm{B} 1$ with beads prior to virus addition resulted in very little antiviral effect (Fig. 5, orange bar), indicating that CATH-B1 was efficiently removed from solution by the beads. However, when CATH-B1 and virus were mixed prior to their treatment with Capto Core 700 beads, the antiviral activity of CATH-B1 was maintained indicating that CATH-B1 is directly associated with the virus and not captured by the beads (light green bar, Fig. 5). The proposed binding of CATH-B1 to virus is almost instantaneous because in the absence of the $30 \mathrm{~min}$ incubation time upon mixing of virus and $\mathrm{CATH}-\mathrm{B} 1$ prior to addition of the beads, a similar antiviral activity of CATH-B1 was observed (data not shown). Similar results were obtained using MDCK cells (Supplementary fig. 3).

\section{The effect of CATH-B1 on morphology of virus}

Some host defense peptides, such as human neutrophil defensins, have been shown to induce viral aggregation, which might contribute to their antiviral activity $(21,22)$. Other peptides such as LL-37 have been found to directly disrupt the viral membrane (23). To study the effect of CATH-B1 on viral morphology, H3N1 was used in this study as an example. As shown in Fig. 6, there is no clear alteration of the viral structure for CATH-B1, CATH-2 or LL-37 (Fig. 6 A-D). However, large aggregates were observed that contained viral particles and electron dense material at high concentration $(20 \mu \mathrm{M})$ of CATH-B1 (Fig. 6E), while some smaller aggregates were observed at this concentration for CATH-2 and LL-37 (Fig. $6 \mathrm{~F}$ and $6 \mathrm{G}$ ). At $5 \mu \mathrm{M}$ CATH-B1 smaller aggregates were observed (Fig. 6H-J). These results indicate that binding and aggregation of virus particles is likely involved in the antiviral mechanism of CATH-B1. 


\section{HD11}

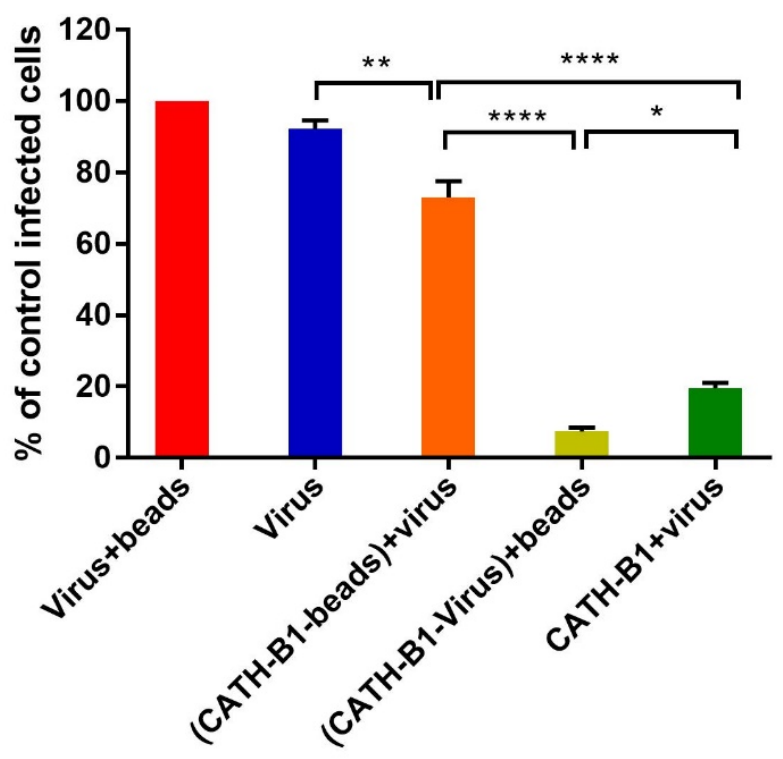

Fig 5. Binding of CATH-B1 to PR8 virus. CATH-B1 was pre-incubated with H1N1 virus after which peptide and virus were separated using Capto beads. (Virus containing) supernatant was then used to infect HD11 cells. Viral infection was determined by immunofluorescent detection of IAV nuclear protein. Three images per well were taken using an EVOS FL microscope (Thermo Fisher Scientific) and the infected cells were counted. The infection rate in the presence of CATH-B1 was normalized against only virus-treated wells. Data are represented as mean \pm SEM of three independent experiments of triplicate samples per experiment. ${ }^{*} \mathrm{p} \leq 0.05 ;{ }^{*} \mathrm{p} \leq 0.01 ; * * * \mathrm{p} \leq 0.005 ; * * * * \mathrm{p} \leq 0.001$.

\section{The effect of CATH-B1 on hemagglutinin and neuraminidase activity}

Hemagglutinin (HA) and neuraminidase (NA) are important functional proteins on the surface of IAVs. During viral infection, the function of HA is binding to sialic acid receptors on host cells and subsequent membrane fusion, while release of newly assembled virus particles requires the sialidase activity of NA. First, we analyzed the ability of CATH-B1 to interfere with the receptor-binding properties of HA by performing a hemagglutination inhibition assay. Unfortunately, CATH-B1 to some extent, induced lysis of erythrocytes, which precluded further analysis of the hemagglutination inhibition assay. Next, we analyzed the ability of CATH-B1 to interfere with NA activity using the substrate MUNANA. Clearly, even at the highest CATH-B1 concentrations, no inhibition of NA activity was observed (Fig. 7A). Next we performed a solid phase cleavage (ELLA) assay using the glycoprotein fetuin. Cleavage of fetuin by NA in this assay depends on the activity of NA, but also on the activity of HA, as receptor-binding by HA contributes significantly to NA cleavage $(24,25)$, at least when multivalent receptors are used. CATH-B1 inhibited cleavage of sialic acids on fetuin 
(Fig. 7B). As CATH-B1 did not affect NA activity per se as demonstrated with the MUNANA assay, we conclude that the inhibitory effect in the ELLA assay results from the ability of CATH-B1 to interfere with virus-receptor binding.
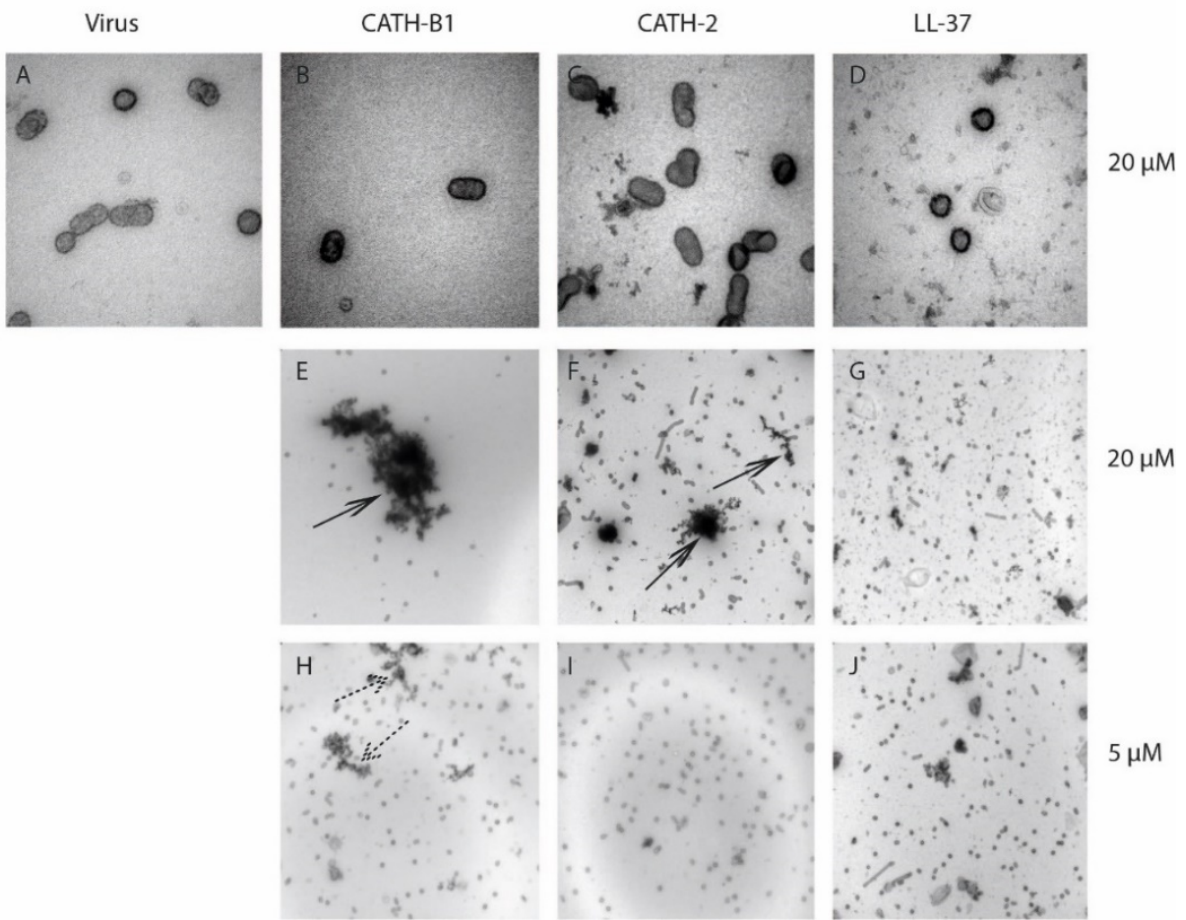

Fig 6. The effect of CATH-B1 on viral morphology. Representative electron microscopic images of H3N1 IAV alone (A) versus IAV pretreated with $20 \mu \mathrm{M}$ (B-G) and $5 \mu \mathrm{M}$ (H-J) of peptides. Large peptides aggregates (black arrows) containing viruses and small aggregates (dashed arrows) were visible at high concentration and low concentration of peptides, respectively. Representative images of $60,000 \times$ magnification (A-D). Representative images of $16,500 \times$ magnification (E-J).

\section{Discussion}

Cathelicidins are important peptides of the innate immune system that protect against invading pathogens. Although cathelicidins have mostly been studied with respect to their antibacterial activity, more recently, studies show potential antiviral activity of these peptides. For example, the human cathelicidin LL-37 has been found to have antiviral activity against IAV, adenovirus, respiratory syncytial virus and HIV (26-28). In addition, defensins including $\alpha$ - and $\beta$-defensins have also been found to exhibit antiviral activity against IAV (22). 

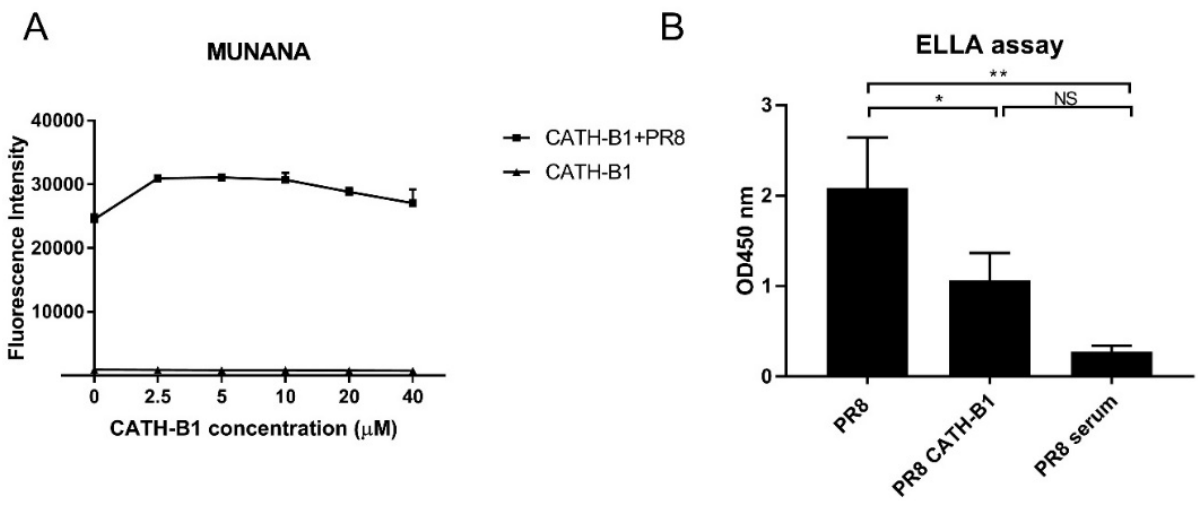

Fig 7. The effect of CATH-B1 on HA and NA activity. (A) NA activity of H1N1/PR8 was directly measured using MUNANA substrate in presence or absence of CATH-B1. (B) Desialylated N-glycans of fetuin were detected using HRP-conjugated ECA lectins, after incubation with H1N1/PR8 in presence or absence of CATH-B1. Data are represented as mean \pm SEM of two independent experiments of triplicate samples per experiment. ${ }^{*} \mathrm{p} \leq 0.05$; $* * \mathrm{p} \leq 0.01$.

Chicken cathelicidins have been studied quite extensively and they have shown to possess many different activities. Besides broad spectrum antibacterial activity, they enhance phagocytosis, neutralize LPS-induced immune responses and enhance DNA-induced TLR21 activation $(3,4,6)$. However, antiviral activity of chicken cathelicidins was never described. Therefore, we investigated the anti-IAV activity and mechanism of inhibition of chicken cathelicidins, since IAV is an important pathogen causing disease in chicken and also in humans.

Four chicken cathelicidins (CATH-1, -2, -3, -B1) were used in this study together with a porcine (PMAP-23), canine (K9CATH) and human cathelicidin (LL-37) for comparison. Our results showed that CATH-B1 has the strongest anti-IAV activity against all three tested virus strains in this study. Comparison of the peptides does not give a clear indication what the main determinant for antiviral activity might be. All peptides have a (predicted) helical structure, are highly cationic and amphipathic. However, the sequence homology itself is quite low between peptides (except for CATH-1 and CATH-3 that also seem to have comparable activity). CATH-B1 is slightly longer than the other cathelicidins tested but it is unclear if that contributes to antiviral activity. Only for LL-37 some structure-antiviral activity studies have been performed which indicated that the central 20 amino acid fragment of LL-37 played a critical role in inhibiting the infection IAV (29). Future mutational studies on CATH-B1 could indicate which domains or residues are important for its observed activity against IAV. 
CATH-B1 is different from the other three chicken cathelicidins in several ways. Besides some structural and sequence differences (Table. 1), it was reported to be exclusively present in the bursa of Fabricius. The peptide is expressed by secretory epithelial cells but is located after secretion surrounding bursal M-cells (8). In contrast, CATH-1, -2, and -3 are mostly expressed in the bone marrow and at least for CATH-2 it was shown that it is present in specific granules in heterophils $(7,30)$ where the peptide is released upon infection (30). In order to determine if CATH-B1 is important in vivo against viral infections, more detailed studies on its expression and localization are needed. If CATH-B1 is indeed only present in the bursa, only a limited antiviral role against for example infectious bursal disease virus can be envisioned, but not really against IAV or other repiratory or intestinal viruses. However, CATH-B1 gene expression seems not restricted to the bursa of Fabricius. Although at much lower levels than found in the bursa, CATH-B1 mRNA was present in several tissues, including spleen and multiple segments of the respiratory and gastrointestinal tract of chicken $(31,32)$. CATH-B1 gene expression was also observed in chicken HD11 macrophages and primary monocytes (33). Finally, some studies have described induced gene expression upon LPS and LTA stimulation in vitro, indicating that higher CATH-B1 levels in multiple tissues upon viral infection could be obtained.

HDPs as antiviral therapeutics are gaining interest with the increasing knowledge on their antiviral potential. However, the antiviral mechanism of action can be quite different from one HDP to another, and is also depended on viruses. Human cathelicidin LL-37 has been found to directly interact with the IAV virion thereby limiting viral replication and virusinduced inflammation in vivo (26). In vitro, LL-37 was described to directly induce disruption of the IAV viral membrane (23), although we did not observe this in our current study, possibly related to differences in the viral strains used. Human neutrophil peptides (HNPs) have been shown to induce viral aggregation and inhibit infectivity mainly through direct interactions with virus without any inhibition of HA activity of IAV (21). Another group of HDPs, defensins, also showed antiviral activity against IAV and HIV-1 but mainly through immunomodulatory effects during viral infection $(34,35)$. The current study showed that CATH-B1 binds to viral particles but this was not accompanied by any obvious disruption of the viral membrane. Instead, peptide-virus aggregates were observed using electron microscopy, indicating that CATH-B1 might exert this mechanism of aggregating pathogens to block infection for viral invasion.

The viral membrane of IAV is characterized by the two key proteins on the surface of the virus, hemagglutinin (HA) and neuraminidase (NA), both of which are important for IAV infection and could potentially be affected by binding of CATH-B1 to the viral surface. HA functions are as a receptor binding and fusion protein, while the NA protein is involed in release of (nascent) virus particles from decoy receptors or the cell surface $(36,37)$. Recently, 
it has been reported that NA activity of IAV is influenced by virus-receptor binding $(17,24$, 25). NA activity is altered based on enhanced or a reduced HA-receptor binding property. Our results suggest that CATH-B1 did not affect NA activity but rather inhibited virusreceptor binding activity, in agreement with CATH-B1 only affecting virus infection when present during virus inoculation. Presumably the inhibiting effect on virus-receptor interaction is related to CATH-B1 induced aggregation of virus. Whether this phenomenom results from a direct interaction of CATH-B1 with HA remains to be established, and other or additional antiviral mechanisms, such as the interaction of CATH-B1 with the viral membrane should be explored further. This antiviral mechanism of CATH-B1 appears to differ from that of LL-37. LL-37 bound to virus but did not inhibit HA-receptor binding and failed to inhibit virus binding to and uptake into cells $(23,29)$. Moreoever, the inhibitory activity of LL-37 depends on the IAV strain used which is consistent with our observation that LL-37 showed much more antiviral activity against H3N1 than against H1N1 and H5N1. Of note, CATH-B1 showed broad antiviral activity against IAVs carrying different HA proteins.

In conclusion, this study showed the potential of CATH-B1 to bind and inhibit the infectivity of IAV, likely by interfering with HA-mediated virus-receptor binding and thereby blocking viral entry. This new activity is important to understand the in vivo role of this cathelicidin, but might also have important implications for the future development of new antivirals based on cathelicidins in general.

\section{Acknowledgements}

This work was supported by a personal fellowship from the China Scholarship Council (CSC) to Lianci Peng. 

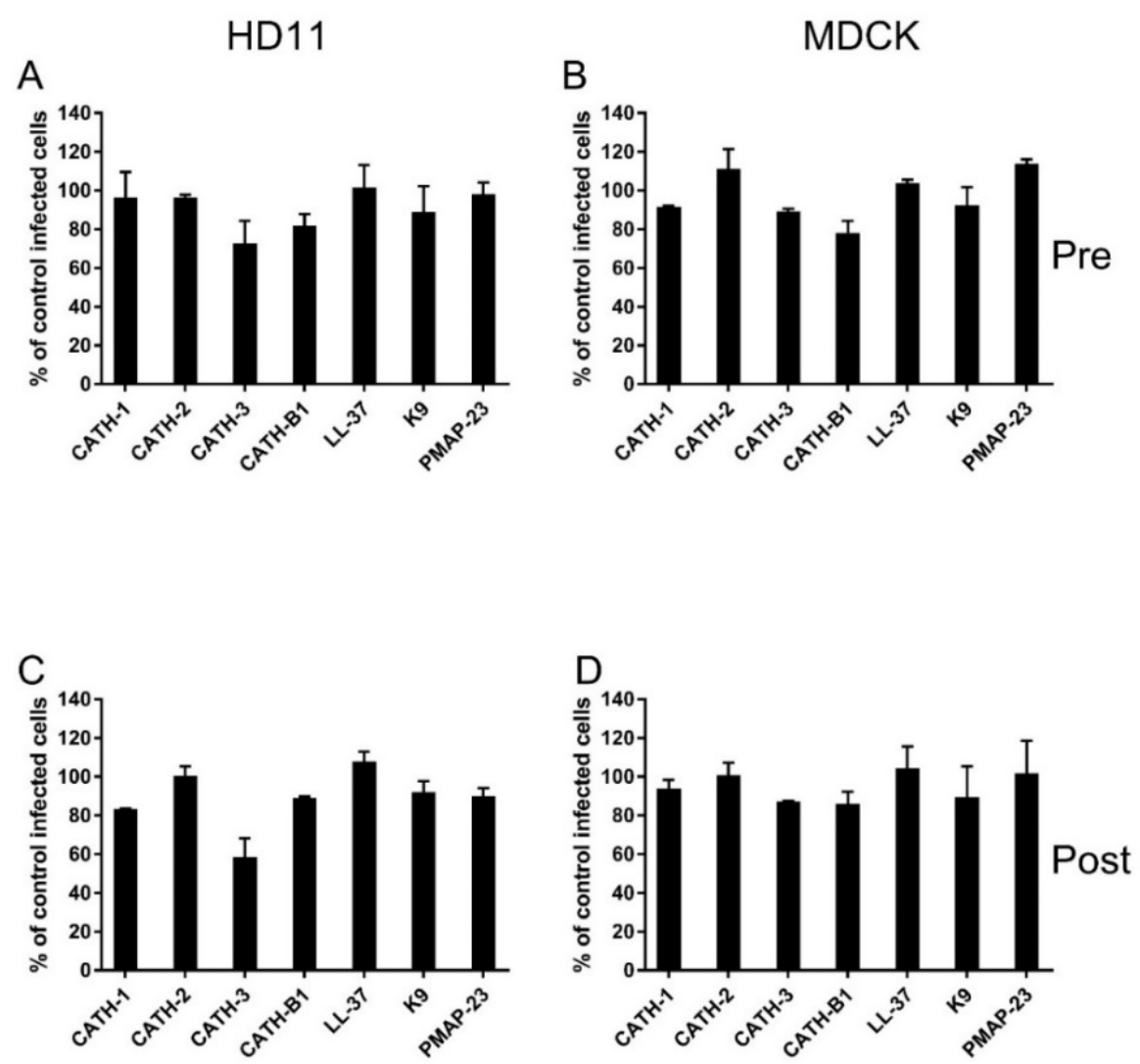

Supplementary fig 1 . The effect of pre-incubation or post-incubation of cathelicidins on viral replication of H1N1/PR8 strain. PR8 infection in HD11 cells (A) or MDCK cells (B) for pre-incubation with cathelicidins. PR8 infection in HD11 cells (C) or MDCK cells (D) for post-incubation with cathelicidins. Viral infection was determined by immunofluorescent detection of IAV nuclear protein. Three images per well were taken using an EVOS FL microscope (Thermo Fisher Scientific) and the infected cells were counted. The infection rate in the presence of cathelicidins was normalized against only virus-treated wells. Data are represented as mean $\pm \mathrm{SEM}$ of two independent experiments of triplicate samples per experiment. 
IFN- $\alpha$

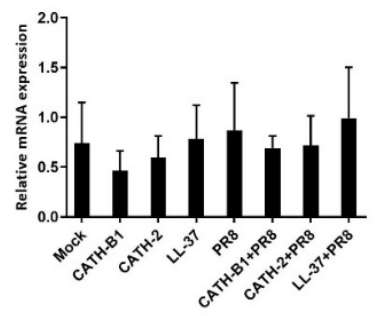

IL-8

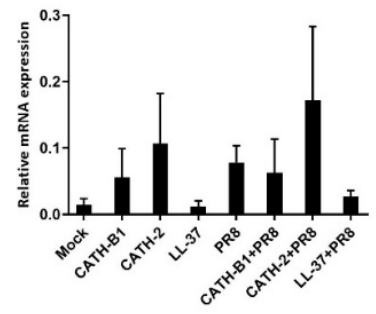

IFN- $\beta$

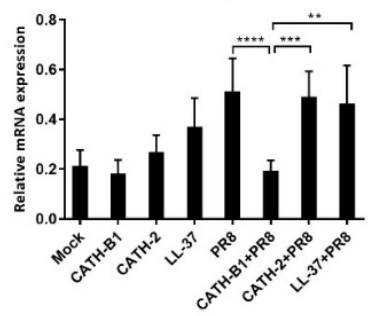

IL-1 $\beta$

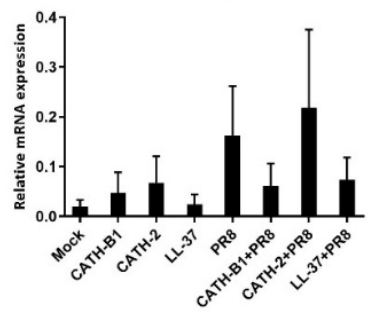

Supplementary fig 2. The effect of CATH-B1 on PR8-induced immune response in HD11 cells. Cytokine expression in HD11 cells at $8 \mathrm{hpi}$ in the presence or absence of peptides. Relative gene expression levels were normalized against the expression levels of the house keeping gene GAPDH. Data are represented as mean $\pm \mathrm{SEM}$ of three independent experiments of triplicate samples per experiment. ${ }^{*} \mathrm{p} \leq 0.05 ;{ }^{* *} \mathrm{p} \leq 0.01 ;{ }^{* * *} \mathrm{p} \leq 0.005$; $* * * * \mathrm{p} \leq 0.001$. 


\section{MDCK}

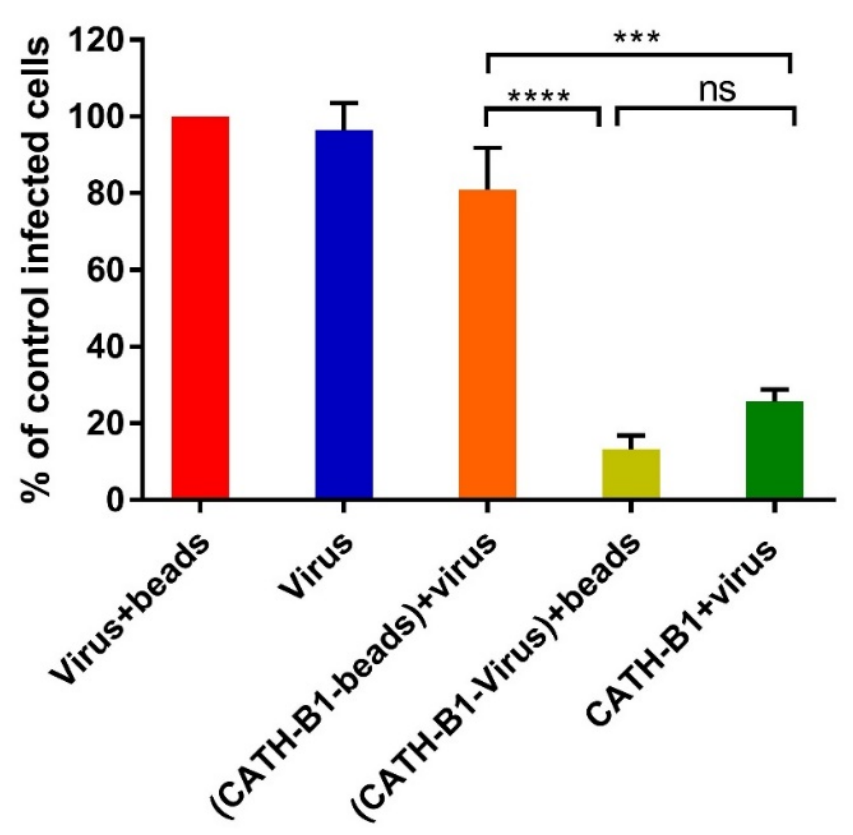

Supplementary fig 3. Binding of CATH-B1 to PR8 virus. CATH-B1 was pre-incubated with H1N1 virus after which peptide and virus were separated using Capto beads. (Virus containing) Supernatant was then used to infect MDCK cells. Viral infection was determined by immunofluorescent detection of IAV nuclear protein. Three images per well were taken using an EVOS FL microscope (Thermo Fisher Scientific) and the infected cells were counted. The infection rate in the presence of cathelicidins was normalized against only virus-treated wells. Data are represented as mean \pm SEM of three independent experiments of triplicate samples per experiment ${ }^{*} \mathrm{p} \leq 0.05$; ${ }^{* *} \mathrm{p} \leq 0.01 ; * * * \mathrm{p} \leq 0.005 ; * * * * \mathrm{p} \leq 0.001$. 


\section{References}

1. Cuperus T, Coorens M, van Dijk A, Haagsman HP. Avian host defense peptides. Developmental \& Comparative Immunology. 2013;41(3):352-69.

2. van Harten R, van Woudenbergh E, van Dijk A, Haagsman HP. Cathelicidins: immunomodulatory antimicrobials. Vaccines. 2018;6(3):63.

3. Coorens M, van Dijk A, Bikker F, Veldhuizen EJ, Haagsman HP. Importance of endosomal cathelicidin degradation to enhance DNA-induced chicken macrophage activation. The journal of immunology. 2015;195(8):3970-7.

4. Coorens M, Schneider VA, de Groot AM, van Dijk A, Meijerink M, Wells JM, et al. Cathelicidins inhibit escherichia coli-induced tlr2 and tlr4 activation in a viability-dependent manner. The Journal of Immunology. 2017;199(4):1418-28.

5. Cuperus T, van Dijk A, Matthijs MG, Veldhuizen EJ, Haagsman HP. Protective effect of in ovo treatment with the chicken cathelicidin analog D-CATH-2 against avian pathogenic E. coli. Sci Rep. 2016;6:26622.

6. Veldhuizen EJ, Brouwer EC, Schneider VA, Fluit AC. Chicken cathelicidins display antimicrobial activity against multiresistant bacteria without inducing strong resistance. PloS one. 2013;8(4):e61964.

7. Sekelova Z, Stepanova H, Polansky O, Varmuzova K, Faldynova M, Fedr R, et al. Differential protein expression in chicken macrophages and heterophils in vivo following infection with Salmonella Enteritidis. Veterinary research. 2017;48(1):35.

8. Goitsuka R, Chen-lo HC, Benyon L, Asano Y, Kitamura D, Cooper MD. Chicken cathelicidin-B1, an antimicrobial guardian at the mucosal M cell gateway. Proceedings of the National Academy of Sciences. 2007;104(38):15063-8.

9. Cox NJ, Subbarao K. Global Epidemiology of Influenza: Past and Present. Annual Review of Medicine. 2000;51(1):407-21.

10. Webby RJ, Webster RG. Are We Ready for Pandemic Influenza? Science. 2003;302(5650):1519-22.

11. Khazeni N, Hutton DW, Collins CI, Garber AM, Owens DK. Health and economic benefits of early vaccination and nonpharmaceutical interventions for a human influenza A (H7N9) pandemic: a modeling study. Annals of internal medicine. 2014;160(10):684-94.

12. Koel BF, Burke DF, Bestebroer TM, van der Vliet S, Zondag GC, Vervaet G, et al. Substitutions near the receptor binding site determine major antigenic change during influenza virus evolution. Science. 2013;342(6161):976-9.

13. Peeters B, Reemers S, Dortmans J, de Vries E, de Jong M, van de Zande S, et al. Genetic versus antigenic differences among highly pathogenic $\mathrm{H} 5 \mathrm{~N} 1$ avian influenza A viruses: consequences for vaccine strain selection. Virology. 2017;503:83-93.

14. Reed LJ, Muench H. A simple method of estimating fifty percent endpoints 12. American Journal of Epidemiology. 1938;27(3):493-7. 
15. De Vries E, Tscherne DM, Wienholts MJ, Cobos-Jiménez V, Scholte F, García-Sastre A, et al. Dissection of the influenza A virus endocytic routes reveals macropinocytosis as an alternative entry pathway. PLoS pathogens. 2011;7(3):e1001329.

16. Dai M, McBride R, Dortmans JC, Peng W, Bakkers MJ, de Groot RJ, et al. Mutation of the second sialic acidbinding site, resulting in reduced neuraminidase activity, preceded the emergence of H7N9 influenza A virus. Journal of virology. 2017;91(9):e00049-17.

17. Du W, Guo H, Nijman VS, Doedt J, van der Vries E, van der Lee J, et al. The 2nd sialic acid-binding site of influenza A virus neuraminidase is an important determinant of the hemagglutinin-neuraminidase-receptor balance. PLoS pathogens. 2019;15(6):e1007860.

18. Kim HM, Lee Y-W, Lee K-J, Kim HS, Cho SW, Van Rooijen N, et al. Alveolar macrophages are indispensable for controlling influenza viruses in lungs of pigs. Journal of virology. 2008;82(9):4265-74.

19. Högner K, Wolff T, Pleschka S, Plog S, Gruber AD, Kalinke U, et al. Macrophage-expressed IFN- $\beta$ contributes to apoptotic alveolar epithelial cell injury in severe influenza virus pneumonia. PLoS pathogens. 2013;9(2):e1003188.

20. Cheung C, Poon L, Lau A, Luk W, Lau Y, Shortridge K, et al. Induction of proinflammatory cytokines in human macrophages by influenza A (H5N1) viruses: a mechanism for the unusual severity of human disease? The Lancet. 2002;360(9348):1831-7.

21. Hartshorn KL, White MR, Tecle T, Holmskov U, Crouch EC. Innate defense against influenza A virus: activity of human neutrophil defensins and interactions of defensins with surfactant protein D. The Journal of Immunology. 2006;176(11):6962-72.

22. Doss M, White MR, Tecle T, Gantz D, Crouch EC, Jung G, et al. Interactions of $\alpha$-, $\beta$-, and $\theta$-defensins with influenza A virus and surfactant protein D. The Journal of Immunology. 2009;182(12):7878-87.

23. Tripathi S, Tecle T, Verma A, Crouch E, White M, Hartshorn KL. The human cathelicidin LL-37 inhibits influenza A viruses through a mechanism distinct from that of surfactant protein D or defensins. The Journal of general virology. 2013;94(Pt 1):40.

24. Guo H, Rabouw H, Slomp A, Dai M, van der Vegt F, van Lent JW, et al. Kinetic analysis of the influenza A virus HA/NA balance reveals contribution of NA to virus-receptor binding and NA-dependent rolling on receptor-containing surfaces. PLoS pathogens. 2018;14(8):e1007233.

25. Lai JCC, Karunarathna HM, Wong HH, Peiris JS, Nicholls JM. Neuraminidase activity and specificity of influenza A virus are influenced by haemagglutinin-receptor binding. Emerging microbes \& infections. 2019;8(1):327-38.

26. Barlow PG, Svoboda P, Mackellar A, Nash AA, York IA, Pohl J, et al. Antiviral activity and increased host defense against influenza infection elicited by the human cathelicidin LL-37. PloS one. 2011;6(10):e25333.

27. Bergman P, Walter-Jallow L, Broliden K, Agerberth B, Soderlund J. The antimicrobial peptide LL-37 inhibits HIV-1 replication. Current HIV research. 2007;5(4):410-5.

28. Currie SM, Findlay EG, McFarlane AJ, Fitch PM, Böttcher B, Colegrave N, et al. Cathelicidins have direct antiviral activity against respiratory syncytial virus in vitro and protective function in vivo in mice and humans. The Journal of Immunology. 2016;196(6):2699-710. 
29. Tripathi S, Wang G, White M, Qi L, Taubenberger J, Hartshorn KL. Antiviral activity of the human cathelicidin, LL-37, and derived peptides on seasonal and pandemic influenza A viruses. PLoS One. 2015;10(4):e0124706.

30. Van Dijk A, Tersteeg-Zijderveld MH, Tjeerdsma-van Bokhoven JL, Jansman AJ, Veldhuizen EJ, Haagsman HP. Chicken heterophils are recruited to the site of Salmonella infection and release antibacterial mature Cathelicidin-2 upon stimulation with LPS. Molecular immunology. 2009;46(7):1517-26.

31. Achanta M, Sunkara LT, Dai G, Bommineni YR, Jiang W, Zhang G. Tissue expression and developmental regulation of chicken cathelicidin antimicrobial peptides. Journal of animal science and biotechnology. 2012;3(1):15.

32. Rodriguez-Lecompte J, Yitbarek A, Cuperus T, Echeverry H, Van Dijk A. The immunomodulatory effect of vitamin $\mathrm{D}$ in chickens is dose-dependent and influenced by calcium and phosphorus levels. Poultry science. 2016;95(11):2547-56.

33. Sunkara LT. Enhancing chicken innate immunity and disease resistance by boosting host defense peptide synthesis: Oklahoma State University; 2011.

34. Ryan LK, Dai J, Yin Z, Megjugorac N, Uhlhorn V, Yim S, et al. Modulation of human $\beta$-defensin-1 (hBD-1) in plasmacytoid dendritic cells (PDC), monocytes, and epithelial cells by influenza virus, Herpes simplex virus, and Sendai virus and its possible role in innate immunity. Journal of leukocyte biology. 2011;90(2):343-56.

35. Wang W, Owen SM, Rudolph DL, Cole AM, Hong T, Waring AJ, et al. Activity of $\alpha$-and $\theta$-defensins against primary isolates of HIV-1. The Journal of Immunology. 2004;173(1):515-20.

36. Gamblin SJ, Skehel JJ. Influenza hemagglutinin and neuraminidase membrane glycoproteins. Journal of Biological Chemistry. 2010;285(37):28403-9.

37. Dou D, Revol R, Östbye H, Wang H, Daniels R. Influenza A virus cell entry, replication, virion assembly and movement. Frontiers in immunology. 2018;9. 



\section{Chapter 7}

\section{General discussion}

\section{Lianci Peng}

Department of Biomolecular Health Sciences, Division of Infectious Diseases \& Immunology, Section of Molecular Host Defence, Faculty of Veterinary Medicine, Utrecht University, Utrecht, The Netherlands

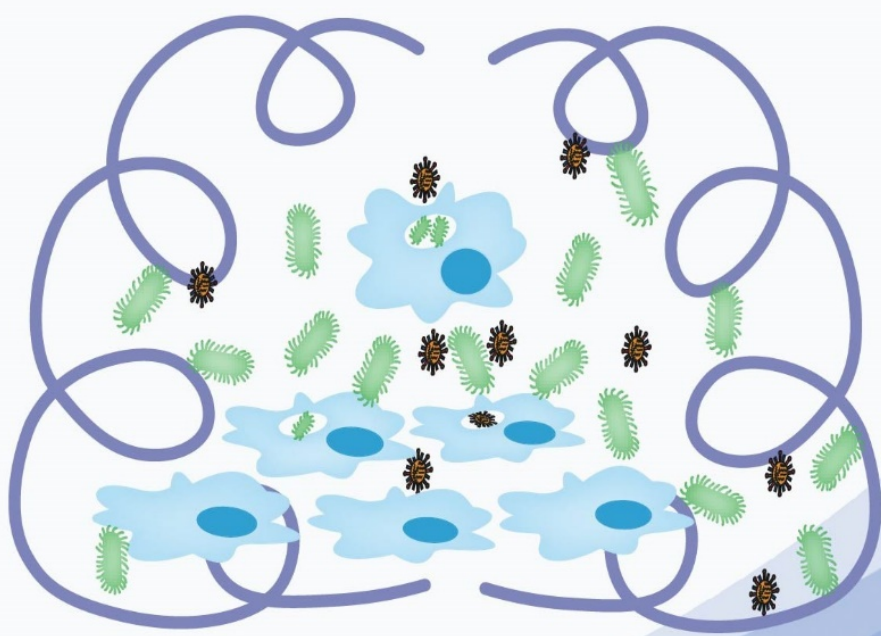


The lung is a major target organ for pathogens causing respiratory diseases in poultry. Avian respiratory diseases (ARD) lead to serious economic losses for most poultry industries (1). ARD are mainly caused by mycoplasmas, bacteria and viruses. For bacterial infection, avian pathogenic E. coli (APEC) is one of most prevalent pathogens causing systemic diseases called avian colibacillosis (2). APEC infection starts in the trachea and results in damaged respiratory mucosa; the bacteria subsequently cross the epithelium and enter the blood stream, finally spreading to other tissues (2). Furthermore, damaged epithelial cells facilitate colonization of other pathogens, such as viruses. During this process of infection, epithelial cells are the first cellular defense line against APEC infection and will produce cytokines and chemokines to initiate the immune response. Similarly, macrophages and heterophils will be quickly recruited to the site of infection to fight against the infection in the respiratory tract. Nevertheless, the exact role of these cells in controlling APEC infection is still unclear and therefore investigated in the studies described in this thesis.

So far, the treatment of an APEC infection in chicken mainly depends on antibiotics, but increasing antibiotic resistance makes this less effective (3). Therefore, new anti-infectives are needed and host defense peptides (HDPs) such as cathelicidins are considered as a promising alternative to antibiotics. They are mainly expressed by leukocytes and epithelial cells at infection sites in the host (4). They have broad antimicrobial activity and immunomodulatory effects on the host cells. These functions are important features for the development of anti-infectives.

In chicken, four cathelicidins (CATH-1, -2, -3 and -B1) have been described of which CATH2 is the best studied. CATH-2 has strong antibacterial and antifungal activities $(5,6)$. In addition, CATH-2 can bind to LPS and inhibits LPS-induced production of inflammatory cytokines (7), inhibits E. coli-induced TLR2 and TLR4 activation (8) and enhances DNAinduced TLR21 activation in chicken macrophages (9). Some of these activities have also been described for CATH-1 and CATH-3 (10, 11), but especially for CATH-B1 knowledge on its role is lacking. Contrary to the localization of CATH-1, $-2,-3$ in heterophils, the CATH-B1 peptide is only described to be produced by epithelial cells in the bursa of Fabricius, while its function is speculated to protect this organ, but this is not backed up with any functional assays (12).

In this thesis, we investigated the interaction of chicken macrophages and epithelial cells with APEC to establish an appropriate APEC infection model in vitro. Then, we investigated the immunomodulatory effect of CATH-B1 on the chicken macrophages. Furthermore, antiviral activity of chicken cathelicidins against influenza A virus was studied. 


\section{The role of chicken lung-associated non-specific cellular defense against microbial infection}

Lung epithelial cells act as a physical barrier, and are the first cells to produce an immune response upon infection (13). Due to the lack of a standard method of primary cultures, the chicken lung epithelial cell line (CLEC213) which exhibits pneumocyte type II-like characteristics is often used to investigate the interaction between lung epithelial cells and invading pathogens (14). As shown in chapter 2, APEC adhered to CLEC213 cells and subsequently invaded cells leading to a significant increase of IL-8 gene expression. Similarly, adherence of APEC was also observed in cultured chicken type II pneumocytes (15). Besides bacterial infection, viruses and parasites have also been shown to be able to infect CLEC213 cells $(14,16)$. These results show that CLEC213 cells can be used as infection model for multiple microorganisms. However, as shown in chapter 2, the immune response of CLEC213 cells was relatively low upon LPS stimulation since only IL-8 gene expression was highly induced, which is not completely in line with a previous study that showed a strong immune response upon LPS stimulation with high gene expression of IFN$\alpha$, IFN- $\beta$ and IL-8 (14) using the same cell line. It is unclear what caused this discrepancy but these results indicate that this cell line might have a different behavior under slightly changed conditions. Therefore, one should be careful to use this cell line as a standardized system to study the chicken lung epithelial immune system. To further investigate the immune defense of lung epithelium against pathogens, a stabilized lung epithelial cell line or the culture of chicken primary epithelial cells need to be developed in the future.

The healthy avian lung has a low number of free respiratory macrophages compared to mammalian lung, but they can be quickly recruited from underneath the respiratory epithelia or from the blood upon infection (17-20), suggesting that macrophages indeed play an important role in the immune response towards microbes. To facilitate chicken macrophage studies, two chicken macrophage-like cell lines including HD11 and MQ-NCSU have been developed that have often been used by several groups $(21,22)$. In chapter 3 , we report studies on the interactions of macrophages with APEC in HD11 cells. Besides phagocytosis of APEC, HD11 cells also showed phagocytic activity towards other bacteria that infect chicken, such as Salmonella typhimurium (23), Listeria monocytogenes (24) and Mycoplasma synoviae (25).

Besides the functional study of HD11 cells, primary macrophages are also a very useful tool for understanding the function of macrophages in vivo, expected to be resembling natural macrophages better than cell lines. However, there is no uniform protocol or characterization of chicken primary macrophages. Therefore, we established a standardized culturing system of monocyte-derived macrophages from chicken blood and characterized these cells by 
morphology, cell surface marker expression and cytokine expression in response to TLR ligands stimulation. As shown in chapter 4, after 3 days of culturing monocytes with chicken GM-CSF, macrophages with a pro-inflammatory property were obtained. These macrophages showed high expression of IL-1 $\beta$, IL-6 and IL-8 upon LPS stimulation, which is similar to classic mammalian M1-like macrophages (26). In addition, these cells had a "fried-egg" like shape and the three-day-cultured macrophages had a high expression of MRC1L-B and MHC-II, indicating the maturation of macrophages. In addition, these macrophages showed phagocytic activity towards APEC. Besides phagocytosis of APEC, monocyte-derived macrophages have been shown to take up fungi such as Cryptococcus neoformans (27). These results suggest that macrophages as non-specific defense cells have phagocytic activity against a broad array of microbial infections.

Macrophages have different killing capacities towards various bacterial strains. Our results in chapter 3 and chapter 4 showed that APEC were killed by HD11 cells and primary macrophages but Salmonella Enteritidis survived in HD11 cells. Salmonella can secrete different virulence factors to invade, survive and replicate within host cells $(28,29)$, explaining the observed survival of Salmonella. Recently, it has been shown that the interaction between Salmonella and macrophages was associated with host specificity (30). Avian host-specific Salmonella had a high survival rate while non-avian strains induced high level of cell death in chicken primary macrophages. Our in vitro infection model showed that APEC did not have such an evasion strategy since the number of viable intracellular APEC reduced with longer incubation time in both HD11 cells and primary macrophages.

When APEC is taken up by macrophages it also induces an immune response through the expression of cytokines and chemokines. As shown in (parts of) chapter 3, 4 and 5 APEC did indeed induce nitric oxide (NO) production by macrophages as well as expression of several cytokines including IL-1 $\beta$, IL-6, IL-8 and IL-10 in both HD11 cells and primary macrophages. Induction of this immune response suggests that activation of macrophages by APEC leads to a strong pro-inflammatory immune response, which is likely similar to the response of macrophages against APEC in vivo.

\section{The host immune response to respiratory infections}

Our results using the macrophage cell line and the monocyte-derived macrophages have clearly contributed to a better understanding of the defense provided by macrophages towards bacterial infections, but there are also some limitations to our studies. In our experiments we used the respiratory pathogen APEC (E. coli 506, O78:K80) as an example in vitro. This O78 serotype APEC strain is in most countries one of the most common pathogens causing avian colibacillosis (31). This APEC strain has been shown to cause purulent necrosis of parabronchi in chicken lung (32). Moreover, in a chicken lung infection model, E. coli 506 
induced increased number of macrophages in the blood and spleen but the role of macrophages during infection is still understudied (19).

However, it needs to be pointed out that our infection studies are limited using only this APEC strain, while APEC is a general name for the large family of pathogenic E. coli with different genetic backgrounds. For example a pathogenic isolate (MT78, O2:K1), has also been reported to induce high numbers of heterophils and macrophages in the lung $(33,34)$. These macrophages have been observed to phagocytose this APEC in vivo and also showed high phagocytic activity towards these bacteria in vitro (34). It would therefore be worthwhile to extend our studies to determine if the results can be extrapolated to other E. coli strains. In addition, besides APEC, respiratory infections, caused by Mycoplasma, Pasteurella multocida and Ornithobacterium rhinotracheale, have also been shown to induce activation of macrophages resulting in increased phagocytosis and release of inflammatory cytokines (35-37). These results suggest that macrophages play a non-specific defense role against respiratory infections and it would be interesting to include these bacteria in our future studies.

\section{The immunomodulatory effect of chicken cathelicidins on host cells}

In addition to direct microbial killing, cathelicidins can exert immunomodulatory effects on the host cells. The immunomodulatory effect of human cathelicidin LL-37 has been extensively studied. LL-37 has many immunomodulatory properties including binding to LPS and blocking LPS-induced production of cytokines by macrophages $(38,39)$, mediating leukocytes migration (40), modulating activation of TLRs (41-43) and regulating cell differentiation $(44,45)$. The chicken cathelicidin CATH-2 shares many of these properties with LL-37, but other peptides such as CATH-B1, had not been investigated.

As shown in chapter 5, both CATH-2 and CATH-B1 bind to LPS and inhibit LPS-induced inflammatory cytokine expression in macrophages. These results are in line with previous studies that showed the binding of CATH-2 and CATH-B1 to E. coli LPS by ITC analysis and a chromogenic limulus amoebocyte lysate (LAL) assay, respectively $(8,46)$.

Besides LPS binding, both CATH-2 and CATH-B1 inhibited the APEC-induced inflammatory response in primary macrophages. CATH-2 has been shown to permeabilize the inner membrane of E. coli and thereby kills the bacterium. Subsequently, activation of TLR2 and TLR4 was inhibited by CATH-2, leading to inhibition of activation of macrophages (8). CATH-B1 did not kill bacteria and slightly enhanced bacterial phagocytosis by chicken macrophages, but interestingly it reduced APEC-induced activation of macrophages, indicating a different mechanism than CATH-2 which only reduces nonviable APEC-induced activation of macrophages. In addition, macrophages pre-incubated with CATH-B1 produced significantly higher expression of IL-10 after challenge with APEC. 
These results suggest that CATH-B1 plays a role in the anti-inflammatory response, but the exact mechanism is still not clear. In earlier studies, CATH-2 was described to induce MCP3 gene expression in macrophages (7), suggesting chicken cathelicidins may be involved in signaling pathways to regulate immune responses, but it is still unknown whether chicken cathelicidins regulate the immune response via interaction with other specific cell receptors or only act on bacterial ligands such as LPS and DNA. To further find out which host factors are affected by chicken cathelicidins, RNA-seq technology could be used to screen differences in host gene expression upon incubation with cathelicidins.

\section{The role of chicken cathelicidins against viral infections}

Viruses are important pathogens causing diseases, leading to morbidity and mortality in chickens. Development of drug resistance is the main problem that makes treatment less effective. Cathelicidins as endogenous proteins in the host can be an option to develop novel antiviral therapeutics. Recently, the human cathelicidin LL-37 was found to have antiviral activity against different viruses, including influenza A virus (IAV), adenovirus, respiratory syncytial virus and HIV (47-49). As shown in chapter 6, we described, for the first time, antiviral activity of chicken cathelicidins against IAV in vitro. The four chicken cathelicidins displayed different antiviral activities and CATH-B1 showed the strongest antiviral activity.

So far, it has been described that possible antiviral mechanisms of cathelicidins are due to a direct interaction with viral particles or to modulation of host cell responses upon viral infection (50). LL-37 was found to directly interact with the IAV virion and to disrupt the viral membrane thereby limiting viral replication and virus-induced inflammation in vivo (47, 51). In our studies, CATH-B1 did not induce an (obvious) disruption of viral particles, but CATH-B1 bound and aggregated viruses thereby blocking viral entry. These results suggest antiviral activity of cathelicidins at the early stage of viral infection. This activity could have important implications for the future development of new antivirals based on cathelicidins in general (52). Furthermore, this functional exploration of antiviral activity of CATH-B1 is an important indication that CATH-B1 might have local functions in the bursa against other pathogens, such as IBDV. It will be interesting to investigate anti-IBDV activity of CATH$\mathrm{B} 1$ on the host cells, such as DT-40 cells, or perform in vivo experiments to further understand the exact role of CATH-B1.

\section{The role of CATH-B1 against microbial infection of host cells}

CATH-B1 is different from the other three chicken cathelicidins in several ways. First, CATH-B1 protein expression was only observed in the secretory epithelial cells of the bursa (12). Second, CATH-B1 antimicrobial activity differs from that of the other cathelicidins. CATH-B1 has limited antibacterial activity compared to the other three chicken cathelicidins, 
but CATH-B1 actually showed the strongest antiviral activity against IAV. Many investigators tried to link the antimicrobial mechanism of cathelicidins to the structure of the peptide. The central kink of CATH-2 produced by a proline residue plays an important role in the antibacterial activity (53) and the central fragment of LL-37 is important to inhibit viral infection $(54,55)$. Our results show that CATH-1 and CATH-3 exerted similar antimicrobial activities against IAV and APEC, which is not surprising since they are $70 \%$ homologous, while CATH-B1 has no apparent homology with the other three chicken cathelicidins. These results indicate that some structural and sequence differences might lead to different antimicrobial activities of cathelicidins. However, with the limited data available for CATH$\mathrm{B} 1$ and the lack of homology with other peptides, it is hard to deduce any structure-function relationships. A separate study using truncated and mutated CATH-B1 variants would be necessary to obtain some more information on this.

CATH-1, -2, and -3 have been reported to be expressed in bone marrow and their proteins were detected in heterophils using immunostaining and mass spectrometry $(56,57)$, but CATH-B1 protein is expressed by epithelial cells in bursa. However, gene expression of CATH-B1, in contrast to protein expression is not limited to the Bursa since CATH-B1 mRNA was also found to be present in several other tissues. Our results in chapter 5 showed that CATH-B1 gene expression was induced by APEC in HD11 cells and in primary macrophages. This seemed like a specific upregulation because gene expression of the other three cathelicidins was stable or only very mildly induced, although it should be pointed out that mRNA levels of these cathelicidins was relatively low. In addition, CATH-B1 showed immunomodulatory activity towards the macrophages (chapter 5). These results could suggest that CATH-B1 may actually be produced upon infection in macrophages and subsequently may play an active role against microbial infections. However, it is essential for this to determine if CATH-B1 translation actually occurs because gene expression does not always correlate with protein expression. This could potentially be done, for example, with a CATH-B1 antibody or with mass spectrometry.

\section{The clinical potential application of HDPs for anti-infective therapies}

HDPs play an important role in the host's response to infection and inflammation. Initial researches focused on antimicrobial activity of HDPs was to develop alternatives to antibiotics against microorganisms. Over the past decades, some studies demonstrated that HDPs not only have antimicrobial activity since many HDPs lose their antimicrobial activity under physiological conditions, whereas their immunomodulatory activities are presented both in tissue cultures and in vivo (58).

As shown in chapter 5, CATH-B1 lost its antibacterial activity but exerted its antiinflammatory activity under cell culture condition. Other synthetic innate defense regulator 
peptides which lacked antimicrobial activity have been shown to protect mice from infection in vivo (59-61). Similarly, the human $\alpha$-defensin HNP-1 also protected mice from infection by leukocyte accumulation, despite of its weak antimicrobial activity (62). These results indicate that anti-infective properties of HDPs are exerted by their immunomodulatory activity. Therefore, HDP-based therapies are developed not only as antimicrobials but also as immunomodulators. Recently, exogenous administration of HDPs have been used in many animal infection models to provide protection against microbial infection. For instance, LL37 application protected animals from infection with Pseudomonas aeruginosa, influenza viruses and respiratory syncytial virus in vivo (52) in a neutrophil-dependent manner. Another study showed that in ovo administration of CATH-2 provided protection in chicken against respiratory E. coli infection (63). However, so far, most studies focused on potential application of HDPs are still limited in the preclinical stage. Only a few studies in humans were successful to use HDPs in clinical trials, such as LL-37 application in venous leg ulcers and protegrin 1 application in pneumonia (clinical trials have been reviewed in 52). Notably, the application of HDPs in the field of veterinary medicine is a promising approach to develop anti-infective therapies. One major problem of this approach is related to costs, since the production of peptides is relatively expensive, making treatment or prevention challenging using exogenous host defense peptides. Another approach would be to stimulate the endogenous production of HDP to increase the immune status of chicken. In several studies, this hypothesis was tested and it was shown that indeed HDP production (in chickens and mammals) can be increased by short chain fatty acids such as butyrate (64), and but also for example by vitamin D. Feed additives based on these compounds could therefore have great beneficial effect at relatively low costs. Our studies on CATH-B1 in this thesis add to the existing activity profile for chicken cathelicidins and contains new valuable information for the potential development of anti-infectives in later clinical studies.

\section{Concluding remarks}

In the work described in this thesis, we aimed to investigate chicken lung-associated cellular defense against microbial infections and the anti-infective role of CATH-B1 in vitro during infection. Studies on the interaction of APEC with epithelial cells and macrophages increase our knowledge about the chicken lung-associated immune system upon infection. The functional exploration on the immunomodulation and antiviral activities provide insight in the possible use of cathelicidins in the development of anti-infective therapies. 


\section{References}

1. Toth TE. Nonspecific cellular defense of the avian respiratory system: a review. Developmental \& Comparative Immunology. 2000;24(2-3):121-39.

2. Guabiraba R, Schouler C. Avian colibacillosis: still many black holes. FEMS microbiology letters. 2015;362(15):fnv118.

3. Gyles CL. Antimicrobial resistance in selected bacteria from poultry. Animal health research reviews. 2008;9(2):149-58.

4. Steinstraesser L, Kraneburg U, Jacobsen F, Al-Benna S. Host defense peptides and their antimicrobialimmunomodulatory duality. Immunobiology. 2011;216(3):322-33.

5. Veldhuizen EJ, Brouwer EC, Schneider VA, Fluit AC. Chicken cathelicidins display antimicrobial activity against multiresistant bacteria without inducing strong resistance. PloS one. 2013;8(4):e61964.

6. Ordonez SR, Amarullah IH, Wubbolts RW, Veldhuizen EJ, Haagsman HP. Fungicidal mechanisms of cathelicidins LL-37 and CATH-2 revealed by live-cell imaging. Antimicrobial agents and chemotherapy. 2014;58(4):2240-8.

7. van Dijk A, van Eldik M, Veldhuizen EJ, Tjeerdsma-van Bokhoven HL, de Zoete MR, Bikker FJ, et al. Immunomodulatory and anti-inflammatory activities of chicken cathelicidin-2 derived peptides. PLoS One. 2016;11(2):e0147919.

8. Coorens M, Schneider VA, de Groot AM, van Dijk A, Meijerink M, Wells JM, et al. Cathelicidins inhibit escherichia coli-induced tlr2 and tlr4 activation in a viability-dependent manner. The Journal of Immunology. 2017;199(4):1418-28.

9. Coorens M, van Dijk A, Bikker F, Veldhuizen EJ, Haagsman HP. Importance of endosomal cathelicidin degradation to enhance DNA-induced chicken macrophage activation. The journal of immunology. 2015;195(8):3970-7.

10. Xiao Y, Dai H, Bommineni YR, Soulages JL, Gong YX, Prakash O, et al. Structure-activity relationships of fowlicidin-1, a cathelicidin antimicrobial peptide in chicken. The FEBS journal. 2006;273(12):2581-93.

11. Bommineni YR, Achanta M, Alexander J, Sunkara LT, Ritchey JW, Zhang G. A fowlicidin-1 analog protects mice from lethal infections induced by methicillin-resistant Staphylococcus aureus. Peptides. 2010;31(7):122530 .

12. Goitsuka R, Chen-lo HC, Benyon L, Asano Y, Kitamura D, Cooper MD. Chicken cathelicidin-B1, an antimicrobial guardian at the mucosal $\mathrm{M}$ cell gateway. Proceedings of the National Academy of Sciences. 2007;104(38):15063-8.

13. Chaudhuri N, Sabroe I. Basic science of the innate immune system and the lung. Paediatric respiratory reviews. 2008;9(4):236-42.

14. Esnault E, Bonsergent C, Larcher T, Bed'hom B, Vautherot J-F, Delaleu B, et al. A novel chicken lung epithelial cell line: characterization and response to low pathogenicity avian influenza virus. Virus research. 2011;159(1):32-42.

15. Zhang L-Y, Lv S, Wu S-C, Guo X, Xia F, Hu X-R, et al. Inhibitory effects of $\alpha$-cyperone on adherence and 
invasion of avian pathogenic Escherichia coli O78 to chicken type II pneumocytes. Veterinary immunology and immunopathology. 2014;159(1-2):50-7.

16. Bussière FI, Niepceron A, Sausset A, Esnault E, Silvestre A, Walker RA, et al. Establishment of an in vitro chicken epithelial cell line model to investigate Eimeria tenella gamete development. Parasites \& vectors. 2018;11(1):44.

17. Toth T, Siegel P, Veit H. Cellular defense of the avian respiratory system. Influx of phagocytes: elicitation versus activation. Avian diseases. 1987:861-7.

18. Matthijs MG, Ariaans MP, Dwars RM, van Eck JH, Bouma A, Stegeman A, et al. Course of infection and immune responses in the respiratory tract of IBV infected broilers after superinfection with E. coli. Veterinary immunology and immunopathology. 2009;127(1-2):77-84.

19. Ariaans MP, Matthijs MG, van Haarlem D, van de Haar P, van Eck JH, Hensen EJ, et al. The role of phagocytic cells in enhanced susceptibility of broilers to colibacillosis after infectious bronchitis virus infection. Veterinary immunology and immunopathology. 2008;123(3-4):240-50.

20. Maina J. Some recent advances on the study and understanding of the functional design of the avian lung: morphological and morphometric perspectives. Biological Reviews. 2002;77(1):97-152.

21. Beug H, von Kirchbach A, Döderlein G, Conscience J-F, Graf T. Chicken hematopoietic cells transformed by seven strains of defective avian leukemia viruses display three distinct phenotypes of differentiation. cell. 1979;18(2):375-90.

22. Qureshi M, Miller L, Lillehoj H, Ficken M. Establishment and characterization of a chicken mononuclear cell line. Veterinary immunology and immunopathology. 1990;26(3):237-50.

23. Wisner AL, Potter AA, Köster W. Effect of the Salmonella pathogenicity island 2 type III secretion system on Salmonella survival in activated chicken macrophage-like HD11 cells. PLoS One. 2011;6(12):e29787.

24. Jarvis N, Donaldson JR, O’Bryan CA, Ricke SC, Crandall PG. Listeria monocytogenes infection of HD11, chicken macrophage-like cells. Poultry science. 2016;96(4):950-6.

25. Lavrič M, Maughan MN, Bliss TW, Dohms JE, Benčina D, Keeler Jr CL, et al. Gene expression modulation in chicken macrophages exposed to Mycoplasma synoviae or Escherichia coli. Veterinary microbiology. 2008;126(1-3):111-21.

26. Gao J, Scheenstra MR, van Dijk A, Veldhuizen EJ, Haagsman HP. A new and efficient culture method for porcine bone marrow-derived M1-and M2-polarized macrophages. Veterinary immunology and immunopathology. 2018;200:7-15.

27. Johnston SA, Voelz K, May RC. Cryptococcus neoformans thermotolerance to avian body temperature is sufficient for extracellular growth but not intracellular survival in macrophages. Scientific reports. 2016;6:20977.

28. Malik Kale P, Jolly CE, Lathrop S, Winfree S, Luterbach C, Steele-Mortimer O. Salmonella-at home in the host cell. Frontiers in microbiology. 2011;2:125.

29. Ibarra JA, Steele-Mortimer O. Salmonella-the ultimate insider. Salmonella virulence factors that modulate intracellular survival. Cellular microbiology. 2009;11(11):1579-86. 
30. Huang K, Herrero-Fresno A, Thøfner I, Skov S, Olsen JE. Interaction-differences of the avian host-specific Salmonella serovar Gallinarum, the host-generalist S. Typhimurium, and the cattle host-adapted S. Dublin with chicken primary macrophage. Infection and Immunity. 2019:IAI. 00552-19.

31. Sojka W, Carnaghan RBA. Escherichia coli infection in poultry. Research in veterinary science. 1961;2(4):34052.

32. Dwars RM, Matthijs MG, Daemen AJ, van Eck JH, Vervelde L, Landman WJ, et al. Progression of lesions in the respiratory tract of broilers after single infection with Escherichia coli compared to superinfection with E. coli after infection with infectious bronchitis virus. Veterinary immunology and immunopathology. 2009;127(1-2):65-76.

33. Pourbakhsh SA, Boulianne M, Martineau-Doizé B, Fairbrother JM. Virulence mechanisms of avian fimbriated Escherichia coli in experimentally inoculated chickens. Veterinary microbiology. 1997;58(2-4):195-213.

34. Horn F, Corrêa AMR, Barbieri NL, Glodde S, Weyrauch KD, Kaspers B, et al. Infections with avian pathogenic and fecal Escherichia coli strains display similar lung histopathology and macrophage apoptosis. PloS one. $2012 ; 7(7)$.

35. Lam K, DaMassa AJ. Mycoplasma gallisepticum-induced release of macrophage inflammatory protein-1 beta from chicken monocytes-macrophages. Journal of comparative pathology. 2000;122(1):35-42.

36. Toth TE, Pyle R, Caceci T, Siegel P, Ochs DJI, immunity. Cellular defense of the avian respiratory system: influx and nonopsonic phagocytosis by respiratory phagocytes activated by Pasteurella multocida. Infection and immunity. 1988;56(5):1171-9.

37. Chansiripornchai N, van Putten JP. Interaction of the Avian Pathogen Ornithobacterium rhinotracheale with Chicken and Murine Macrophages.25.

38. Turner J, Cho Y, Dinh N-N, Waring AJ, Lehrer RI. Activities of LL-37, a cathelin-associated antimicrobial peptide of human neutrophils. Antimicrobial agents and chemotherapy. 1998;42(9):2206-14.

39. Larrick JW, Hirata M, Zheng H, Zhong J, Bolin D, Cavaillon J-M, et al. A novel granulocyte-derived peptide with lipopolysaccharide-neutralizing activity. The Journal of Immunology. 1994;152(1):231-40.

40. Zhang Z, Cherryholmes G, Chang F, Rose DM, Schraufstatter I, Shively JE. Evidence that cathelicidin peptide LL-37 may act as a functional ligand for CXCR2 on human neutrophils. European journal of immunology. 2009;39(11):3181-94.

41. Mookherjee N, Brown KL, Bowdish DM, Doria S, Falsafi R, Hokamp K, et al. Modulation of the TLRmediated inflammatory response by the endogenous human host defense peptide LL-37. The Journal of Immunology. 2006;176(4):2455-64.

42. Kandler K, Shaykhiev R, Kleemann P, Klescz F, Lohoff M, Vogelmeier C, et al. The anti-microbial peptide LL37 inhibits the activation of dendritic cells by TLR ligands. International immunology. 2006;18(12):1729-36.

43. Morizane S, Yamasaki K, Mühleisen B, Kotol PF, Murakami M, Aoyama Y, et al. Cathelicidin antimicrobial peptide LL-37 in psoriasis enables keratinocyte reactivity against TLR9 ligands. Journal of investigative dermatology. 2012;132(1):135-43.

44. Davidson DJ, Currie AJ, Reid GS, Bowdish DM, MacDonald KL, Ma RC, et al. The cationic antimicrobial peptide LL-37 modulates dendritic cell differentiation and dendritic cell-induced $\mathrm{T}$ cell polarization. The 
Journal of Immunology. 2004;172(2):1146-56.

45. van der Does AM, Beekhuizen H, Ravensbergen B, Vos T, Ottenhoff TH, van Dissel JT, et al. LL-37 directs macrophage differentiation toward macrophages with a proinflammatory signature. The journal of immunology. 2010;185(3):1442-9.

46. Takeda A, Tsubaki T, Sagae N, Onda Y, Inada Y, Mochizuki T, et al. Bacterial toxin-inducible gene expression of cathelicidin-B1 in the chicken bursal lymphoma-derived cell line DT40: functional characterization of cathelicidin-B1. Peptides. 2014;59:94-102.

47. Barlow PG, Svoboda P, Mackellar A, Nash AA, York IA, Pohl J, et al. Antiviral activity and increased host defense against influenza infection elicited by the human cathelicidin LL-37. PloS one. 2011;6(10):e25333.

48. Bergman P, Walter-Jallow L, Broliden K, Agerberth B, Soderlund J. The antimicrobial peptide LL-37 inhibits HIV-1 replication. Current HIV research. 2007;5(4):410-5.

49. Currie SM, Findlay EG, McFarlane AJ, Fitch PM, Böttcher B, Colegrave N, et al. Cathelicidins have direct antiviral activity against respiratory syncytial virus in vitro and protective function in vivo in mice and humans. The Journal of Immunology. 2016;196(6):2699-710.

50. Barlow PG, Findlay EG, Currie SM, Davidson DJ. Antiviral potential of cathelicidins. Future microbiology. 2014;9(1):55-73.

51. Tripathi S, Tecle T, Verma A, Crouch E, White M, Hartshorn KL. The human cathelicidin LL-37 inhibits influenza A viruses through a mechanism distinct from that of surfactant protein D or defensins. The Journal of general virology. 2013;94(Pt 1):40.

52. Mookherjee N, Anderson MA, Haagsman HP, Davidson DJ. Antimicrobial host defence peptides: functions and clinical potential. Nature Reviews Drug Discovery. 2020.

53. Van Dijk A, Molhoek EM, Veldhuizen EJ, Tjeerdsma-van Bokhoven JL, Wagendorp E, Bikker F, et al. Identification of chicken cathelicidin-2 core elements involved in antibacterial and immunomodulatory activities. Molecular immunology. 2009;46(13):2465-73.

54. Tripathi S, Wang G, White M, Qi L, Taubenberger J, Hartshorn KL. Antiviral activity of the human cathelicidin, LL-37, and derived peptides on seasonal and pandemic influenza A viruses. PLoS One. 2015;10(4):e0124706.

55. Li X, Li Y, Han H, Miller DW, Wang G. Solution structures of human LL-37 fragments and NMR-based identification of a minimal membrane-targeting antimicrobial and anticancer region. Journal of the American Chemical Society. 2006;128(17):5776-85.

56. Van Dijk A, Tersteeg-Zijderveld MH, Tjeerdsma-van Bokhoven JL, Jansman AJ, Veldhuizen EJ, Haagsman HP. Chicken heterophils are recruited to the site of Salmonella infection and release antibacterial mature Cathelicidin-2 upon stimulation with LPS. Molecular immunology. 2009;46(7):1517-26.

57. Sekelova Z, Stepanova H, Polansky O, Varmuzova K, Faldynova M, Fedr R, et al. Differential protein expression in chicken macrophages and heterophils in vivo following infection with Salmonella Enteritidis. Veterinary research. 2017;48(1):35.

58. Hilchie AL, Wuerth $\mathrm{K}$, Hancock REW. Immune modulation by multifaceted cationic host defense (antimicrobial) peptides. Nature chemical biology. 2013;9(12):761. 
59. Scott MG, Dullaghan E, Mookherjee N, Glavas N, Waldbrook M, Thompson A, et al. An anti-infective peptide that selectively modulates the innate immune response. Nature biotechnology. 2007;25(4):465-72.

60. Nijnik A, Madera L, Ma S, Waldbrook M, Elliott MR, Easton DM, et al. Synthetic cationic peptide IDR-1002 provides protection against bacterial infections through chemokine induction and enhanced leukocyte recruitment. The journal of immunology. 2010;184(5):2539-50.

61. Rivas-Santiago B, Castañeda-Delgado JE, Santiago CER, Waldbrook M, González-Curiel I, León-Contreras JC, et al. Ability of innate defence regulator peptides IDR-1002, IDR-HH2 and IDR-1018 to protect against Mycobacterium tuberculosis infections in animal models. PloS One. 2013;8(3).

62. Welling MM, Hiemstra PS, van den Barselaar MT, Paulusma-Annema A, Nibbering PH, Pauwels E, et al. Antibacterial activity of human neutrophil defensins in experimental infections in mice is accompanied by increased leukocyte accumulation. The Journal of clinical investigation. 1998;102(8):1583-90.

63. Cuperus T, van Dijk A, Matthijs MG, Veldhuizen EJ, Haagsman HP. Protective effect of in ovo treatment with the chicken cathelicidin analog D-CATH-2 against avian pathogenic E. coli. Scientific reports. 2016;6:26622.

64. Sunkara LT, Achanta M, Schreiber NB, Bommineni YR, Dai G, Jiang W, et al. Butyrate enhances disease resistance of chickens by inducing antimicrobial host defense peptide gene expression. PloS one. 2011;6(11). 



\section{Appendices}

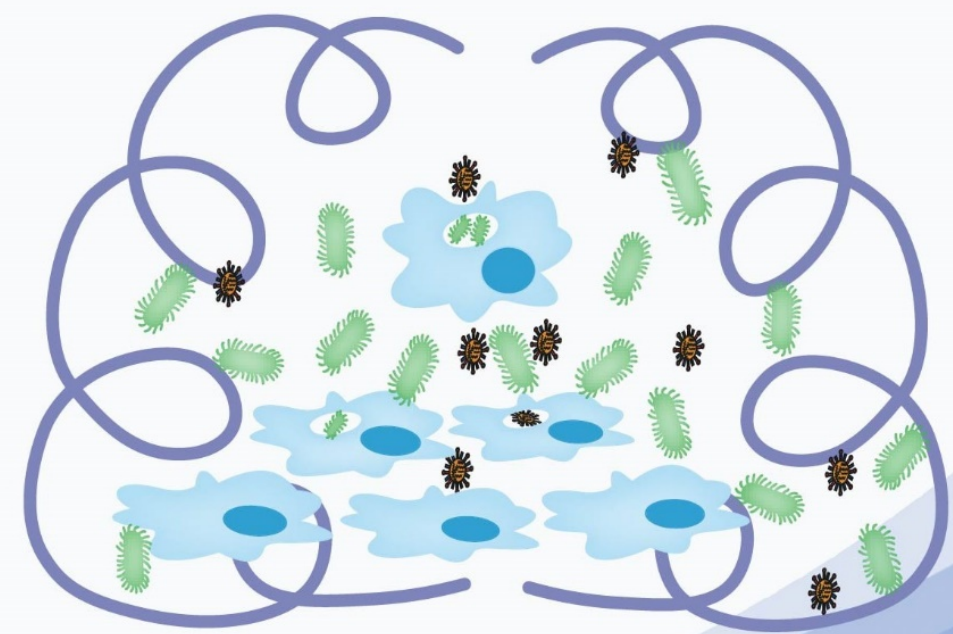




\section{Nederlandse samenvatting}


Infecties van het respiratoire systeem zijn een belangrijk probleem in de pluimveesector. Ze veroorzaken veel uitval van vogels en zorgen daarbij voor een enorme economische schade. Longinfecties kunnen veroorzaakt worden door verschillende micro-organismen zoals virussen en bacteriën (inclusief mycoplasma). 'Avian Pathogenic Escherichia coli' (APEC) is één van de belangrijkste bacteriële ziekteverwekkers in de sector die leidt tot colibacillose, een systemische infectie waarbij meerdere organen geïnfecteerd worden. De initiële APECinfectie start in de trachea waar de slijmvliezen van de luchtwegen beschadigd kunnen worden. Daarna kan de bacterie de longepitheelcellen infecteren en uiteindelijk ook in de bloedbaan komen waardoor het andere organen kan bereiken en infecteren. Daarnaast zorgt de mucosale beschadiging er ook voor dat andere pathogenen, zoals bijvoorbeeld virussen makkelijker de long kunnen infecteren, zogenaamde co-infectie.

Wanneer een infectie optreedt zal de gastheer een immuunreactie initiëren. Epitheelcellen produceren dan onder andere cytokines en chemokines, en cellen van het aangeboren immuunsysteem, zoals heterofielen en macrofagen worden snel naar de infectiebron gerecruteerd om de infectie te bestrijden. Echter, het exacte mechanisme van deze cellulaire en moleculaire afweerreactie bij de kip is nog niet bekend, mede door een gebrek aan goede modelsystemen waarmee dit onderzocht kan worden.

Een APEC-infectie wordt nog steeds behandeld met antibiotica maar de toenemende bacteriële resistentie tegen antibiotica zorgt ervoor dat de behandeling steeds minder effectief wordt. Hierdoor zijn nieuwe antimicrobiële middelen nodig om infecties te bestrijden en zogenaamde 'Host Defence Peptiden' (HDP) worden gezien als een potentieel nieuw antimicrobieel middel. Deze HDP zijn onderdeel van het aangeboren immuunsysteem van de gastheer en worden voornamelijk aangemaakt door witte bloedcellen en epitheelcellen. Vaak wordt de aanmaak ervan ook opgereguleerd op de plaats waar de infectie plaatsvindt. Deze HDPs hebben 2 verschillende functies, ze kunnen micro-organismen doden of neutraliseren, en ze kunnen ook het immuunsysteem sturen (immuunmodulatie). Beide eigenschappen zijn belangrijk voor de eventuele ontwikkeling van een alternatief voor antibiotica gebaseerd op deze HDP.

Binnen de familie van HDP zijn er verschillende subklassen te onderscheiden, waaronder defensines en cathelicidines; deze laatste groep wordt in dit proefschrift bestudeerd. De kip heeft 4 cathelicidines, CATH-1, -2, -3 en CATH-B1, en hiervan is CATH-2 veruit het beste bestudeerd in de literatuur. CATH-2 heeft een sterke antimicrobiële activiteit tegen een breed-spectrum aan bacteriën, maar het is bijvoorbeeld ook actief tegen bepaalde schimmels. Daarnaast is beschreven dat CATH-2: 1) aan Lipopolysaccharide (LPS, onderdeel van Gram negatieve bacteriemembraan) kan binden, waardoor het LPS geïnduceerde productie van cytokines vermindert, 2) E. coli geïnduceerde activatie van Toll- Like Receptor 2 (TLR2) en 
TLR4 kan verminderen, en 3) DNA-geinduceerde activatie van TLR21 kan stimuleren. Sommige van deze aktiviteiten zijn (in mindere mate) ook voor CATH-1 en CATH-3 beschreven maar vooral voor CATH-B1 is weinig bekend over welke antimicrobiële en/of immuunmodulerende eigenschappen het bezit. Een ander verschil is dat CATH-1 t/m -3 in heterofielen worden geproduceerd terwijl gerapporteerd is dat CATH-B1 vooral in epitheelcellen van de Bursa van Fabricius gemaakt zou worden. Een hypothese is dat CATHB1 specifiek dit orgaan moet beschermen maar er zijn nog geen goede functionele tests beschreven die deze hypothese onderbouwen.

In de experimenten beschreven in dit proefschrift werd de interactie van kippenmacrofagen en kippenepitheelcellen met APEC onderzocht, met als doel een in vitro APEC-infectiemodel op te zetten dat gebruikt kan worden voor respiratoire infectiestudies bij kippen. Daarnaast werd het immuunmodulerend effect van CATH-B1 op macrofagen onderzocht en ook werd de antivirale activiteit van CATH-B1 bepaald tegen het influenza A Virus.

\section{Rol van epitheelcellen in de luchtwegen bij $E$. coli infectie.}

Het longepitheel vormt niet alleen een fysieke barrière maar kan ook een specifieke immunologische reactie initiëren als het worden geïnfecteerd. Het onderzoek naar deze immuunreactie in kippen is beperkt omdat er geen goede en makkelijke methode is om primaire epitheelcelculturen te kweken waarmee geëxperimenteerd kan worden. Wat wel beschikbaar is, en dus voor onderzoek gebruikt wordt, is de kippen-epitheel cellijn CLEC213, die volgens de literatuur karakteristieken heeft die lijken op epitheliale type-II-cellen uit de long. In de experimenten beschreven in hoofdstuk 2 werd de interactie van APEC met deze CLEC213 cellen bestudeerd om een goed beeld te krijgen in hoeverre deze cellen als een goed model kunnen dienen voor bacteriële longinfecties in de kip. Uit de experimenten bleek dat APEC goed aan deze epitheelcellen konden aanhechten en dat ze deze vervolgens konden binnendringen, vergelijkbaar met de in vivo situatie. Invasie van CLEC213 cellen leidde o.a. tot een verhoogde IL-8 gen-expressie, hetgeen vergelijkbaar is met observaties in een eerdere studie met geïsoleerde kippen type-II-pneumocyten. Andere beschreven studies hebben aangetoond dat virussen en parasieten de CLEC213 cellen kunnen infecteren wat aangeeft dat deze cellijn ook een goed representatief model kan zijn voor dit soort studies. Echter, uit de studies in hoofdstuk 2 bleek dat op IL-8 inductie na, de inductie van andere cytokinen in CLEC213 cellen, zoals bijvoorbeeld IFN- $\alpha$ en IFN- $\beta$ productie door LPS stimulatie, vrijwel niet detecteerbaar was terwijl dit wel eerder beschreven was. Een verklaring hiervoor zou kunnen zijn dat relatief kleine veranderingen in de opzet van een experiment een groot effect op de immuunreactie van de cel kunnen hebben. Mede hierdoor werd geconcludeerd dat men voorzichtig moet zijn met de interpretatie van de resultaten bij het gebruik van deze cellijn. Voor toekomstige immunologische studies naar infecties van het respiratoire longepitheel is 
er een noodzaak voor een beter modelsysteem. Een gestandaardiseerde cultuur van primaire epitheelcellen, dan wel een meer geschikte cellijn met betere epitheelspecifieke immuunkarakteristieken zou de voorkeur hebben.

\section{De rol van de macrofaag in bacteriële infecties}

In een gezonde kippenlong zijn relatief weinig macrofagen aanwezig in vergelijking met een zoogdierlong zoals bijvoorbeeld in de muis of de mens. Echter, als bij kippen een infectie in de long optreedt kunnen er zeer snel en veel macrofagen gerecruteerd worden vanuit het bloed of het weefsel onder de geïnfecteerde epitheellaag. Dit geeft aan dat macrofagen een belangrijke rol spelen in de bestrijding van infecties. Er zijn momenteel twee kippenmacrofaag cellijnen beschikbaar, HD11 en MQ-NCSU, die veel gebruikt worden voor studies naar de rol van kippenmacrofagen. In hoofdstuk 3 zijn experimenten beschreven waarin HD1 1 cellen gebruikt werden om de interacties van macrofagen met APEC te bepalen. Met behulp van microbiologische technieken als ook met elektronenmicroscopie kon worden bepaald dat HD11 cellen APEC opnemen (fagocytose), zoals al was beschreven voor een select aantal andere bacteriën (Salmonella typhimurium, Listeria monocytogenes and Mycoplasma synoviae). Fagocytose van APEC leidde tot gedeeltelijke doding van de bacterie en een verhoogde productie van stikstofmonoxide en cytokinen, waaronder IL-8. Deze functionele bepalingen geven aan dat HD11 cellen in principe een goed werkend en makkelijk model zijn om de basisfuncties van macrofagen te bestuderen.

Naast het gebruik van een macrofaag cellijn kunnen primaire celculturen van macrofagen ook gebruikt worden om de immuunrespons van deze cellen te bepalen. Deze primaire culturen komen in het algemeen beter overeen met de in vivo situatie van macrofagen in vergelijking met (geïmmortaliseerde) cellijnen zoals HD11. Echter, hoewel meerdere groepen het gebruik van primaire macrofagen, gekweekt uit bloed of beenmerg hadden beschreven was er geen duidelijk uniform protocol beschikbaar voor de kweek van kippenmacrofagen. In hoofdstuk 4 is daarom een standaard methode om primaire macrofagen te kweken uit monocyten beschreven. Deze macrofagen werden gekarakteriseerd aan de hand van belangrijke eigenschappen zoals morfologie, oppervlakte (celmembraan) markers en cytokinerespons bij TLR-stimulatie. Uit deze studies bleek dat om de best reproduceerbare pro-inflammatoire macrofagen te krijgen, bloed-monocyten 3 dagen lang in cultuur gehouden moesten worden in de aanwezigheid van GM-CSF. Na 3 dagen hadden deze macrofagen: 1) een 'gebakken ei' vorm, karakteristiek voor zoogdier pro-inflammatoire macrofagen, 2) een hoge IL-1 $\beta$, IL-6 and IL-8 expressie na LPS-stimulatie en 3) een hoge expressie van de specifieke celoppervlak eiwitten MHC-II en MRC1L-B. Deze macrofagen konden tevens APEC fagocyteren, wat een goede indicatie is dat deze manier van macrofagen 
kweken een goede benadering kan geven van de natuurlijke in vivo functie van kippenmacrofagen.

Uit de resultaten van hoofdstuk 3 en 4 kon ook worden afgeleid dat kippenmacrofagen (zowel HD11 als primaire macrofagen) APEC kunnen doden nadat deze bacteriën gefagocyteerd waren. Dit is echter wel bacterie-afhankelijk want bijvoorbeeld Salmonella Enteritidis kon wel worden gefagocyteerd maar werd niet gedood, omdat deze bacterie specifieke virulentiefactoren kan uitscheiden waardoor deze bacteriestam in macrofagen kan overleven en zich zelfs kan vermenigvuldigen. Dit fenomeen is mogelijk uniek voor Salmonella Enteritidis stammen die specifiek voorkomen bij vogels aangezien Salmonella soorten geïsoleerd uit zoogdieren niet konden overleven in kippenmacrofagen.

\section{De immuunmodulerende werking van CATH-B1 op macrofagen}

Cathelicidines spelen ook een grote rol tijdens een bacteriële infectie. Naast hun directe antimicrobiële rol kunnen ze ook het immuunsysteem moduleren. In hoofdstuk 5 is onderzoek beschreven naar de mechanismen waarop kippencathelicidines de immuunrespons van macrofagen kunnen beïnvloeden. Zowel CATH-2 als CATH-B1 konden de LPSgeïnduceerde cytokineproductie van primaire macrofagen verlagen. Uit zogenoemde 'isothermal titration calorimetry' metingen bleek dat directe binding van de cathelicidines aan LPS hieraan ten grondslag lag. CATH-B1 en CATH-2 verlaagden ook de immuunrespons van macrofagen bij infectie met APEC. Echter, CATH-2 deed dat door de APEC te doden, terwijl CATH-B1 de immuunrespons verlaagde zonder directe antimicrobiële werking tegen de bacterie. Daarnaast stimuleerde CATH-B1 lichtelijk de fagocytose van APEC, hetgeen niet het geval was met CATH-2. Pre-incubatie van macrofagen met CATH-B1 verhoogde ook de productie van het anti-inflammatoire cytokine IL-10. Het anti-inflammatoire werkingsmechanisme van beide cathelicidines is dus duidelijk verschillend, maar er is nog steeds veel onderzoek nodig om de precieze werking van de cathelicidines te ontrafelen.

\section{Antivirale werking van CATH-B-1}

Naast bacteriële infecties zijn ook virale infecties van de luchtwegen een belangrijke oorzaak van uitval bij kippen en economische schade in de sector. De kennis over antivirale activiteit van cathelicidines is erg beperkt maar van de humane cathelicidine LL-37 is beschreven dat het o.a. het Influenza A virus (IAV) kan neutraliseren. In dit hoofdstuk werd voor de eerste keer bepaald of ook kippencathelicidines antivirale activiteit tegen IAV bezitten. Gebruik makend van in vitro infectiemodellen bleek dat van de 4 geteste kippencathelicidines CATHB1 de sterkste neutraliserende activiteit had tegen 3 verschillende IAV stammen. De neutraliserende werking trad alleen op als virus en peptide tegelijk werden toegevoegd na 
een korte incubatieperiode, wat erop duidt dat de werking van het peptide gebaseerd is op interactie met het virus en niet door immuunmodulatie van de gastheercel. Met behulp van elektronenmicroscopie werd gevonden dat CATH-B1 niet het virus zelf kapot maakte maar dat het wel grote aggregraten vormde van virus en peptide. Hieruit werd de hypothese gevormd dat het peptide het virus neutraliseert door het te aggregeren en daarbij de eerste fase van de virusinfectie, namelijk de aanhechting van het virion aan de gastheel cel, kan verstoren. Toekomstige studies zouden kunnen uitwijzen of CATH-B1 dezelfde effectiviteit heeft tegen andere virusinfecties waaronder bijvoorbeeld het 'Infectious Bursal Disease Virus' dat zich vermenigvuldigt in de bursa van Fabricius, het orgaan met een hoge expressie van CATH-B1.

\section{Conclusie}

De studies beschreven in dit proefschrift laten zien dat zowel cellen, met name macrofagen, als moleculen zoals cathelicidines een belangrijke rol kunnen spelen in de bescherming tegen bacteriële en virale infecties van de kippenlong. Tevens dragen de studies bij aan de ontwikkeling van goede modelsystemen om longinfecties te kunnen bestuderen. Toekomstige studies kunnen op deze informatie verder bouwen om nog meer inzicht in het aangeboren immuunsysteem te krijgen en eventuele therapeutische of preventieve toepassingen te ontwikkelen tegen luchtweginfecties bij de kip. 


\section{Acknowledgements}

Finally, I came to write the most read part in this thesis. I imagined many times how I would formulate this most precious part. In the past four years, I know that I have never been alone in the Netherlands. Many people were around me and helped me during my challenging and meaningful journey. I am really lucky to have met so many people that gave me a helping hand and shared every happy and sad moment with me. I really appreciate all my experiences in the Netherlands! I would like to express my gratitude to all the people who accompanied me during the years that I studied and worked in the Netherlands. All of you made my life here so wonderful. I will never forget you!

Edwin, my daily supervisor, there are no exact words to express how I appreciate that I could do my $\mathrm{PhD}$ project under your supervision. You are always kind and positive. You always have a relaxed attitude towards our work so that I have never felt a big pressure during my $\mathrm{PhD}$ life. You provided many useful suggestions when I was stuck in some experiments. You convinced me that there are always alternative ways to go. You did not only guide me in my research, but also inspired me to think how to do research. You really made me enjoy my $\mathrm{PhD}$ life in the lab. Thanks for all the efforts that you made for me. Also, thanks for all the concerns about my life. I still remember you noticed and resolved the problem of my bicycle's tire flat when we were cycling with strong wind in Terschelling. I am sure I will never forget how you understood me and cheered me up when I was emotional.

Henk, my promotor, I will never forget the first time I was in your office to meet you. Your kind smile made me not much nervous for that interview. Thanks for giving me a chance to work in this lab. You made my $\mathrm{PhD}$ story really happened in the Netherlands. You are such a good planner which helped me to finish my $\mathrm{PhD}$ on time. Thanks for telling me the sheep story and encouraging me to move on. I really enjoyed all the stories that you told me about your travel to China. I also enjoyed your explanation about the history of the Netherlands when we went outside. You are such a broad minded person. In every monthly meeting, you always inspired me to think about science in different perspectives. You always think about the combination of science and application. I really admire you a lot.

Albert, it seems like you know every experiment in the lab. Thanks for patiently explaining everything to me and sharing some nice places where I can visit in the Netherlands. You told me so much knowledge about bicycles. Now I already know which height is comfortable for me, haha.

Hanne, you were always interested in my life and I really liked to share my holiday stories with you. Thanks for listening to all my relaxed stuff. 
Maaike, you are like a "housekeeper" in the lab. You really organize the lab stuff well. Thanks for giving me useful suggestions in the work meetings and sharing funny jokes during lunch time.

Melanie, it was nice to be your officemate and share some funny things with you every day. You are a highly organized person and always plan lab work well. You are such a patient person and you make very nice pieces of art. Of course, you are also a very good baker and I really love your cakes. Thanks for your help with the EM experiments. Thanks for the wish cards every year, it is really sweet. I wish that your $\mathrm{PhD}$ project will be successful.

Roel, you are a very good organizer of all social activities. Thank you for all the events that you organized. I really have good memories about all the fun activities. Thanks for your help with the isolation and culture of macrophages. I wish you the best for the rest of your $\mathrm{PhD}$ project.

Hongwei and Jiye, it is such a coincidence that we are from the same city (Chongqing). It was nice to meet you in this lab. Thanks for all your help! Thank you, Hongwei for giving me very useful advice about job searching. Noëlle, thanks for the contribution on the CLEC cells work. Kim, thanks for sharing nice Vietnamese food and telling me your life story. Angelica, we had nice conversations and we shared our opinions. I really enjoyed the time when you did your research in the Netherlands. Hope you are doing well in Italy.

Dear MHD members, I am happy to be a member of this group. I "grew up" and learned how to do research in this group. It was a nice experience. All of you really helped me a lot, no matter in science or in life. I appreciate that tremendously. We had nice trips together and also had tasty hot pot together. I will keep all the memories during my stay in this group. You are always welcome in my hometown (Chongqing) and I will let you taste real hot pot.

Xander, thanks for the guidance in the IAV work. It was nice to collaborate with you. Your many good suggestions made this project going smoothly.

Christine and Robin, thanks for your help with the chicken macrophages. Thank you, Robin for your assistance with the FACS work. I wish that you have a bright scientific future. Ger, thanks for your patient explanation of the FACS. Richard, thank you for your help with the confocal fluorescence microscope.

Infection biology group (Marc, Karin, Marcel, Linda, Nancy, Guus), thanks for all the happy moments we shared. I really enjoyed our joint social activities. Jos, I will never forget your handshake after I finished my interview presentation on the 4th floor. It really warmed my heart. Thanks for providing the gfp plasmid to let me make nice bacteria. 
Avian group, Thank you all for sharing experimental materials, interesting discussions and fruitful collaborations. I am confident that the endeavors of this hard-working group will result in a better chicken world. Thanks Hélène for nice discussion and suggestions about my experiment. It was a nice experience to learn the culture of tracheal in your lab.

Ali, Yasin, Steinbusch, Joao, Fred, Sandra, Gusta, Sarah, Anna, Majed, thanks for giving me so much help in Maastricht. I really had great time with you guys. All the happy moments are still clear in my mind. I wish all of you are doing good in your own field.

刘梦娇, 姚其容, 燕姐, 梦想最初认识的你们。感谢你们陪我度过在荷兰第一年最难謷 的日子, 我们一起分享了太多。Lizzy, 我将永远铭记往返于你我的 50 路公交, 那些 有你陪伴的岁月，有泪有笑的生活，都将伴随我一直成长，我知道我们对彼此的那 颗真诚而采热的内心，从未改变，祝福你能按着自己想要的生活方式生活，心之所 向, 哪里都会有属于你的温暖和美好。Sam, 谢谢你的真诚和信赖, 让我们的友情一 直延续, 祝福你未来的生活。马城的旅途如此短暂但却使人如此难忘, 感谢毛线团的 存在, 让我们可以尽情的分享一切, 那座美好的城, 你们一直是我不愿放下的牵挂。 天宇，我们一起从北京飞到荷兰，开启我们的留学之旅，感恩最初的岁月里，一直 有你相伴，那些我们一起暴走的岁月，都深深的记在了我的心里，我坚信你的执着 你的坚持终将等来你所期待的美好。辛莹，喜欢和你一起聊天的日子，你的贴心你 的理解总能让我在迷雾中豁然开朗, 祝福你和拉芳的生活越来越好。小明, 喜欢你 开心而爽朗的笑容，做任何事都不拖泥带水，说话也能简明扼要的说到重点，你的 努力会让你和你斌哥的生活越来越好。感谢在比利时的张佩华，袁彪，媛媛，和你 们相聚的日子真的很开心，张佩华做的菜真的很好吃，你的细心和耐心，让人觉得 和你相处是一件很舒服的事。袁彪的毒舌总能让人又气又好笑，我们一起同学 6 年， 然后一起出国, 我一直深信, 你对科研的热爱, 一定会让你有所收获。媛媛的阳光 独立总能散发出独特的鬼丰力, 祝福亲爱的小伙伴们生活越来越幸福。钟秀琴, 同寝 6 年的大学时光, 以及一直延续到至今的友情, 让我倍感珍惜我们之间的缘分, 那次 跟你的瑞典之旅, 至今记忆尤新, 感谢你一路相伴, 祝福你在梦想的地方收获你想 要的幸福。

刘磊华，梁俊，和你们同一屋檐下的生活，共同倾诉点滴的生活，将会深深的印在 我的脑海里, 祝问问小朋友健康快乐的成长。钟蔚, 静涵, 有幸成为你们的室友, 与你们同住同吃同玩的日子，真的让我的生活无比轻松，你们的善良，你们内心的 温暖，真的让我感觉无比的幸福，是你们让我看见了平凡的时间里最不平凡的幸福 生活, 希望你们的幸福可以一直延续。常富强, 感谢在我刚到乌特勒支时, 对我所 有的帮助以及对我实验的鼓励, 一直觉得你是一个在科研上很有想法的人，相信你 
的积累一定会让你收获很多, 祝福你的科研和生活一切顺利。杨宇, 与你们一起同 游的经历, 将会是我博士生活里最美好的记忆之一, 希望你的善良你的坚持让你收 获你所期待的美好, 我在重庆等着你们来与我一起吃火锅, 也期待能在国内还能与 你们一起同游, 谈天说地。肖玲, 是什么样的缘分让我们在超市相遇, 感恩与你一 起骑行一起聊天的日子, 让人舒心而殹意, 我眼里那个独立而认真的你一定能在科 研的世界里绽放属于你自己的光芒, 愿你在美国的生活一切都好。欣悦, 外冷内热 的你, 让人禁不住的觉得, 你的内心需要别人慢慢去品读, 不活在别人眼里的你, 注定让你看到与别人不一样的风景, 未来, 继续前行就好。雪峰, 健男, 谢谢你们 平时对我的照顾, 和你们聊天始终会有一种亲切的感觉, 祝福你们的博士生活一切 顺利。文涛师兄, 谢谢你的热心相助, 让我有了流感这个课题的源头, 你对科研如 此执着而热爱, 相信你定会在科研的世界里达到你所企及的高度。文娟, 谢谢你在 流感课题里对我所有的帮助, 谢谢你的耐心倾听, 和你每日一聊的日子真的让我身 心愉悦, 那些有你相伴的日子, 真的让我无比安心, 希望你能顺利找到博后的职位, 也祝福你与王博的生活幸福美满。永涛师兄, 很高兴能在博士最后一年与你相识, 和你聊天, 总能获益良多, 感谢你平时跟我们普及的无数社会知识, 你博学的知识 让人惊叹你身上蕴藏着无尽的精力, 希望你在荷兰的科研生活一切顺利, 满载而归。 春燕, 外表看似柔弱的你, 却有着一颗无比坚定的内心, 感恩最初的相识相知, 希 望你带着你的执着和倔强在属于你的路上越走越精彩。感谢病毒组的其他小伙伴, 谢谢一飞提供的好多关于旅行的建议, 谢谢赵珊, 我们共同拥有的那些分享美食的 日子, 谢谢梦莹和永乐贴心的明信片。

感谢硕士导师殷中琼教授, 对我出国留学的支持, 无论是生活还是学习, 谢谢您给 予我的关心, 您认真的科研态度一直是我学习的榜样。赵兴洪, 陈振振, 李正文, 杨逸, 我们将同门情谊从国内延续到了海外, 很高兴能在欧洲继续与你们相伴。还 有远在美国的胡志强, 你乐观积极的态度总能感染我, 和你的每次聊天都能让我感 觉很放松, 愿你和光熙的生活幸福美满, 也愿你以后的科研之路越来越好。赵兴洪, 我知道你是如此的努力, 兼顾国内国外学位的忙碌生活让你从来没有放弃过, 看着 你一路成长为更好的模样, 真的很为你感到开心, 希望你的答辩一切顺利, 也祝福 你和小万的生活美满幸福。陈振振, 你是一个有目标有追求的人, 不轻易言弃, 和 你一起谈心的短暂时光让我们彼此都感觉到内心的成熟, 希望你的努力和坚持能让 你收获你想要的美好。李正文, 感谢的耐心, 在我没有耐心有脾气的时候默默忍受, 希望你接下来的毕业一切顺利。杨逸, 和你短暂的几次交流, 让我知道原来我们有 如此多相似的想法, 那个有想法的女孩, 未来的路一定会很精彩, 祝福你的博士生 活一切顺利。 
感谢在国内一直在背后支持我的家人和朋友 (一恋, 舒杨, 向发), 近 5 年的时光, 我们虽然没有相伴左右, 但是我知道你们从未远离。谢谢我的父母, 二妹和田田, 给予我最温暖的力量, 你们是我漂泊在外让我感觉最安心的港湾。我亲爱的爸妈, 谢谢你们对我无条件的支持和信任, 你们永远是我前行路上最坚实的后盾。我亲爱 的二妹, 感谢你分享给我的关于国内的一切, 让我们姐妹俩之间的心靠得如此近, 你的那些玩笑, 我对你肆无忌惮的吐槽, 让我感觉自己有你这个妹妹真的无比幸福。 感谢田田对我家人的照顾, 让我不用担心家里的一切, 祝福你和二妹的生活幸福美 满。感谢仲基, 带给我家人无尽的欢乐, 因为你的陪伴, 让我们的家显得格外温暖。 最后, 感谢那个一路顺其自然成长至今的自己, 我知道你害怕过, 你惶恐过, 你甚 至没有放弃的勇气, 但是你依然走到了这里, 未来, 请继续带着这份勇敢和坚持往 前走, 我将始终与你相伴! 


\section{Curriculum Vitae}

彭练慈 (Lianci Peng) was born on $4^{\text {th }}$ December 1990 in Chongqing, China. After finishing high school, she started her bachelor studies in the College of Veterinary Medicine at Sichuan Agriculture University in September 2009. After three years she obtained a bachelor degree, then she did her master studies in the same college under the supervision of Prof. Zhongqiong Yin. She mainly focused on the antibacterial activities and mechanisms of action of Chinese Traditional Medicines. She obtained her Master degree in June 2015. In September 2015, she was awarded financial support by the China Scholarship Council (CSC) for doing her PhD in the Netherlands. In November 2016, she started her PhD project at Utrecht University under the supervision of Prof. Dr. Henk Haagsman and Dr. Edwin Veldhuizen. Her $\mathrm{PhD}$ project focused on chicken innate immunity and exploring chicken lung-associated cellular defense against microbial infection and the anti-infective role of chicken cathelicidins. During her $\mathrm{PhD}$ study, she was actively attending international conferences and finished the required PhD courses with success. In July 2020, she finished her PhD dissertation in the group of Molecular Host Defence resulting in this thesis. 


\section{List of publications}

Peng, Lianci., Matthijs, M. G. R., Haagsman, H. P., Veldhuizen, E. J. A. (2018). Avian pathogenic Escherichia coli-induced activation of chicken macrophage HD11 cells. Developmental and Comparative Immunology, 87: 75-83.

Peng, Lianci., Du, W., Balhuizen, M. D., Haagsman, H. P., de Haan, C. A. M., Veldhuizen, E. J. A. (2020). Antiviral activity of chicken cathelicidin B1 against influenza A virus. Frontiers in Microbiology, 11: 426.

Mol, ${ }^{1}{ }^{\text {., Peng, Lianci }}{ }^{1}$., Esnault, E., Quéré, P., Haagsman, H. P., Veldhuizen E. J. A. (2019). Avian pathogenic Escherichia coli infection of a chicken lung epithelial cell line. Veterinary Immunology and Immunopathology, 210: 55-59. ( ${ }^{1}$ Co-first author)

Peng, Lianci., van den Biggelaar, H.G.A., Jansen, C. A., Haagsman, H. P., Veldhuizen, E. J. A. A method to differentiate chicken monocytes into macrophages with proinflammatory properties. Manuscript submitted.

Peng, Lianci., Scheenstra, M. R., van Harten, R. M., Haagsman, H. P., Veldhuizen, E. J. A. The immunomodulatory effect of chicken cathelicidin-B1 on chicken macrophages. Manuscript submitted. 